DENILLE BRITO DE LIMA

VARIAÇÕES DO GRAFENO: UMA ABORDAGEM AB-INITIO DE NOVAS ESTRUTURAS BIDIMENSIONAIS 


\section{VARIAÇÕES DO GRAFENO: UMA ABORDAGEM AB-INITIO DE NOVAS ESTRUTURAS BIDIMENSIONAIS}

Tese apresentada à Escola Politécnica da Universidade de São Paulo para obtenção do título de Doutor em Ciências.

Área de Concentração:

Engenharia Elétrica

Orientador:

Prof. Dr. João Francisco Justo Filho 
Ex Este exemplar foi revisado e alterado em relação à versão original, sob responsabilidade única do autor e com a anuência de seu orientador.

São Paulo, 27 de janeiro de 2012.

Assinatura do autor

Assinatura do orientador

Lima, Denille Brito de

Variações do grafeno: uma abordagem Ab-initio de novas estruturas bidimensionais / D.B. de Lima. -- ed.rev. -- São Paulo, 2012.

$155 \mathrm{p}$.

Tese (Doutorado) - Escola Politécnica da Universidade de São Paulo. Departamento de Engenharia de Sistemas Eletrônicos.

1. Nanoeletrônica 2. Estado sólido 3. Grafeno I. Universidade de São Paulo. Escola Politécnica. Departamento de Engenharia de Sistemas Eletrônicos II. t. 


\section{AGRADECIMENTOS}

Agradeço primeiramente a Deus, O originador e doador da vida, e criador de todas as coisas, que nos deixou essa infinidade de maravilhas criadas neste mundo para que pudéssemos desvendar e contemplar!

Agradeço aos meus amados e queridos pais, que são meus exemplos de vida, pelo apoio, amor incondicional e conselhos dados. Muito obrigada!

Agradeço ao professor Justo, que sempre foi um ótimo orientador, por me abrir as portas do seu grupo de pesquisa e me ensinar a ser um pesquisador. Que algum dia eu possa ser competente como ele.

Ao meu noivo e futuro marido, Sérgio Colagrande, a pessoa que sempre me incentivou em todos os aspectos e sempre torceu pelo meu sucesso.

Ao meu amigo Joelson Cott, pelas horas de ajuda prestadas, sua ajuda foi essencial para o desenvolvimento deste trabalho. Muito Obrigada!

Ao meu amigo Rolando Larico, pela amizade, pelas dicas e conselhos dados desde que cheguei em São Paulo.

Ao prof. Maurício Perez, pela ajuda na implementação das máquinas nas quais foram desenvolvidos os resultados deste trabalho.

Ao meu amigo Rodrigo Amorim, pela amizade, pelas dicas e conselhos.

Aos meus amigos e colegas da Física, os quais sempre se mostraram muito amigos e me proporcionaram muitos momentos de descontração: Ney, Phillipe, Felipe, Járlesson e Jeconias.

Finalmente, agradeço ao $\mathrm{CNPq}$, pelo apoio financeiro recebido que possibilitou a execução deste trabalho. 


\section{RESUMO}

A eletrônica molecular vem sendo investigada intensivamente por mais de vinte anos. Nesse sentido, as pesquisas científicas estão sendo focadas na busca de estruturas que possam ser utilizadas na construção de dispositivos em escalas nanométricas, que possam substituir a tecnologia tradicional do silício.

O objetivo principal deste trabalho foi explorar as propriedades físicas de sistemas a base de grafano, um dos mais promissores materiais para serem usados como nanodispositivos. Para isso, foi realizada uma investigação teórica, baseada em cálculos de primeiros princípios, das propriedades estruturais e eletrônicas do grafeno numa forma pura ou com defeitos intrínsecos e extrinsecos. O primeiro grupo de estruturas investigadas foi o grafeno e grafano como nanofolhas constituídas por elementos do grupo IV da tabela periódica (C, SiC, Si, Ge e Sn). Também foram analisadas as mudanças nas propriedades eletrônicas do grafano do grupo IV com a substituição dos átomos de hidrogênio por flúor.

A segunda parte do trabalho explorou as propriedades de defeitos estruturais em grafeno, tais como a monovacância, divacância, trivacância e Stone-Wales, e também o grafeno com dopantes (boro e nitrogênio) em diversas configurações. Todos os cálculos foram feitos utilizando métodos $a b$ initio com base na teoria do funcional densidade. Foram estudadas algumas possíveis aplicações para os grupos de estruturas de grafeno investigados, através da análise de algumas de suas propriedades, tais como as densidades de estados próximas ao nível de Fermi e as estruturas de bandas eletrônicas para cada sistema.

Palavras-chave: nanodispositivos, grafeno, dispositivos bidimensionais. 


\begin{abstract}
The molecular electronics has been investigated for more than twenty years. In this sense, the scientific research has been focused on the search for structures that could be used in nanoelectronic devices that could replace the traditional silicon technology.

The major goal of this work is to explore the physical properties of systems based on graphene, one of the most promising materials to be used in nanoelectronics. For that, an ab initio investigation was carried on the structural and electronic properties of graphene in its pristine form and with intrinsic and extrinsic defects. The first investigation explored the properties of group IV nanosheets (of $\mathrm{C}, \mathrm{SiC}, \mathrm{Si}, \mathrm{Ge}$ e $\mathrm{Sn}$ ), and the modifications on their properties as result of hydrogenation or fluorination.

The second part of this work explored the physical properties of structural intrinsic defects in graphene, such as monovacancy, divacancy, trivacancy, and Stone-Wales ones. The work also explored the properties of boron and nitrogen dopants. All the calculations were performed using the ab initio methodology, based on the density functional theory.
\end{abstract}

Keywords: nanodevices, graphene, two-dimensional devices. 


\section{SUMÁRIO}

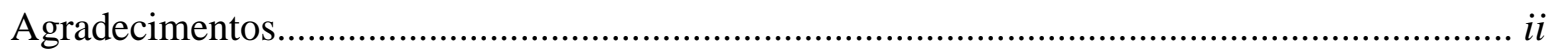

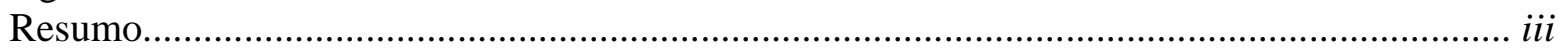

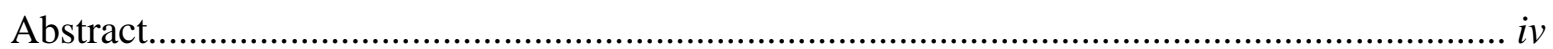

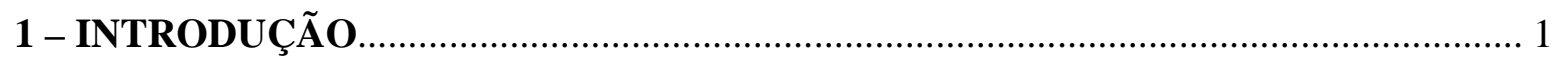

1.1 O Carbono e suas Formas Alotrópicas..................................................................... 1

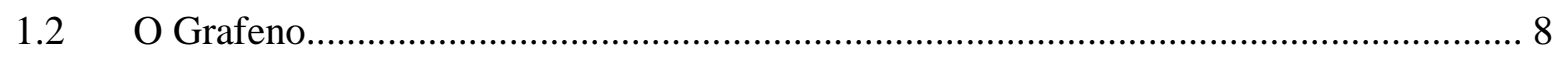

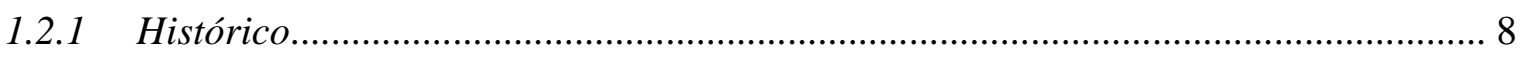

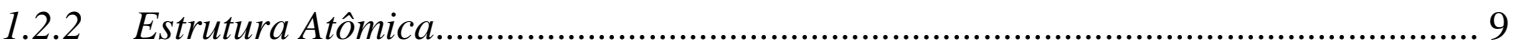

1.3 Nanossistemas, Nanoestruturas e Nanodispositivos................................................... 15

1.4 Organização e Descrição do Trabalho ......................................................................... 23

2 - O GRAFENO

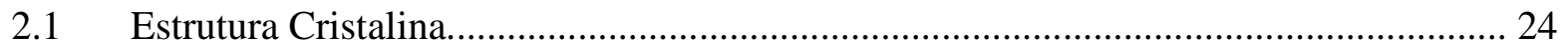

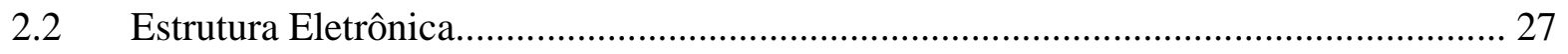

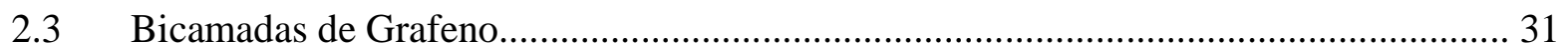

$2.4 \quad$ Propriedades de Transporte Eletrônico........................................................................ 35

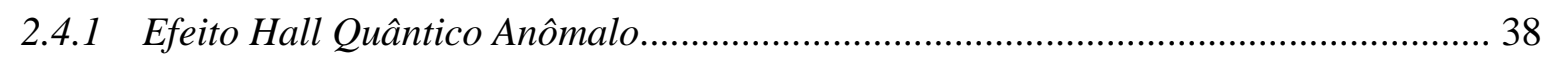

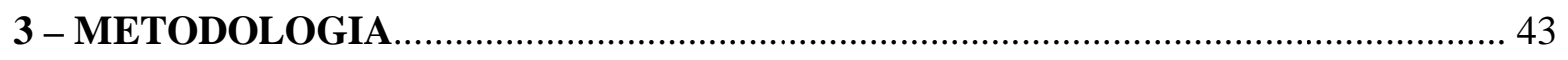

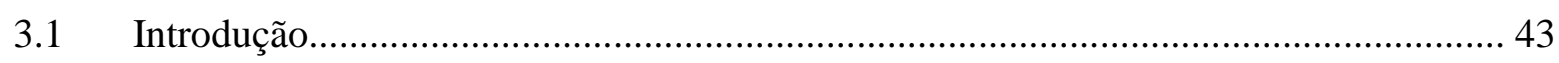

3.2 Aproximação de Born-Oppenheimer....................................................................... 45

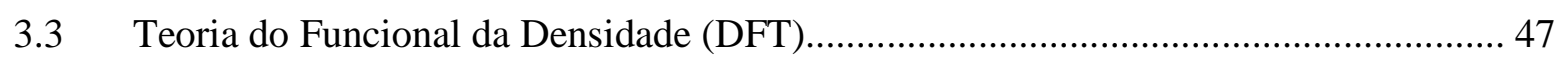

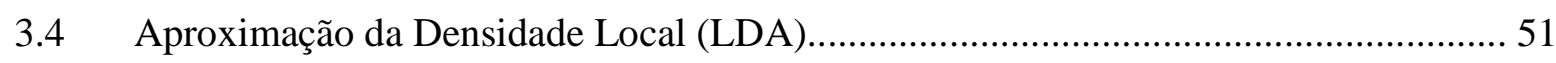

3.5 Aproximação do Gradiente Generalizado (GGA)................................................... 55

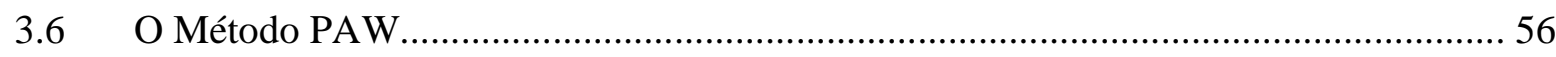

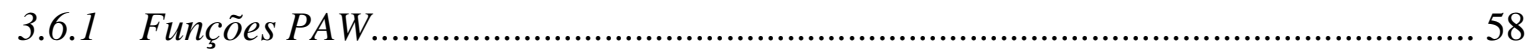

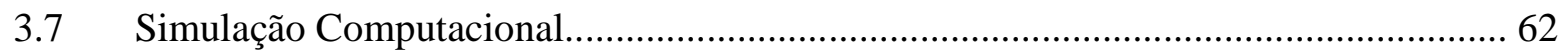

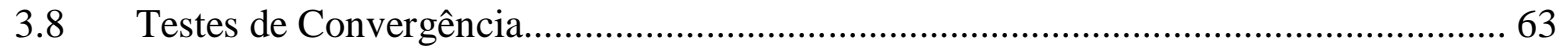

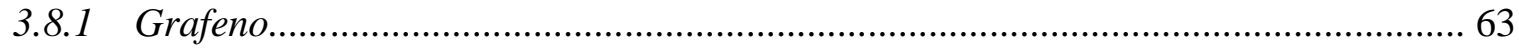




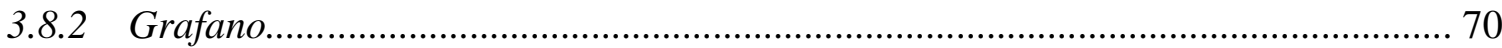

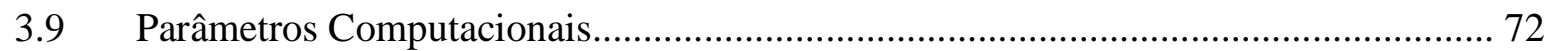

4 - FUNCIONALIZAÇÃO DO GRAFENO E NANOFITAS DE GRAFENO ................ 74

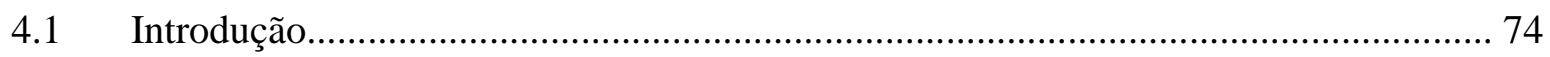

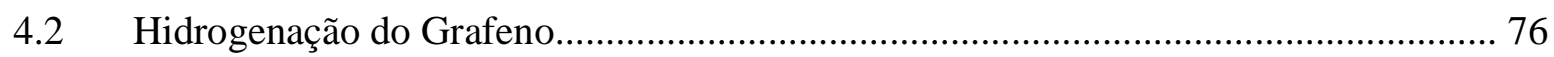

4.3 Funcionalização do Grafeno por Outras Espécies Químicas......................................... 84

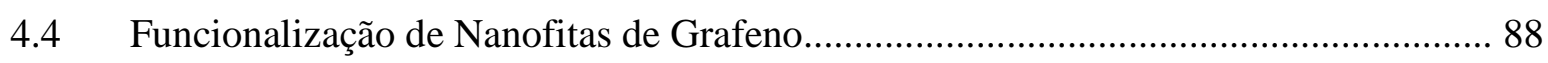

4.4.1 Defeitos em Nanofitas de Grafeno................................................................... 89

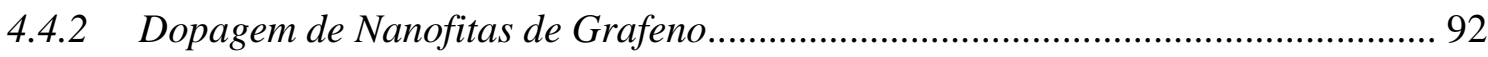

5 - GRAFENO E GRAFANO DA FAMÍLIA DO GRUPO IV ....................................... 94

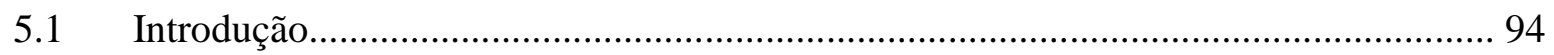

5.2 Propriedades Físicas de Folhas de Grafeno do Grupo IV e Grafano Hidrogenado e

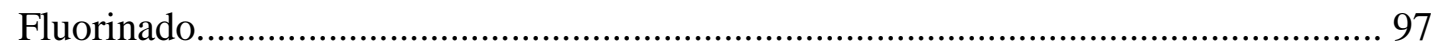

5.3 Propriedades Eletrônicas das Folhas de Grafeno do Grupo IV e Grafano Hidrogenado

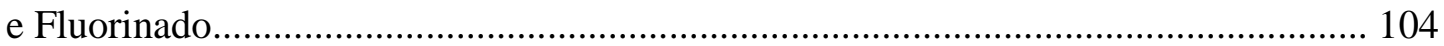

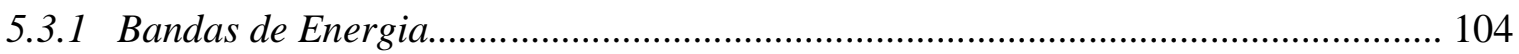

5.3.2 Densidade de Estados (DOS) ............................................................................... 108

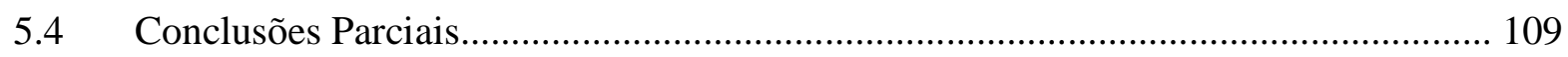

\section{6 - PROPRIEDADES FÍSICAS DE DEFEITOS ESTRUTURAIS E DOPAGEM COM}

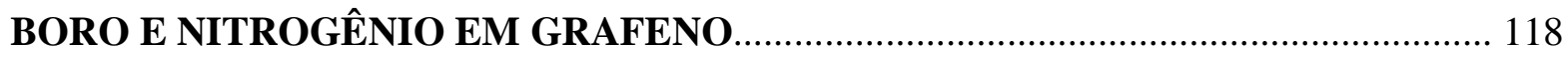

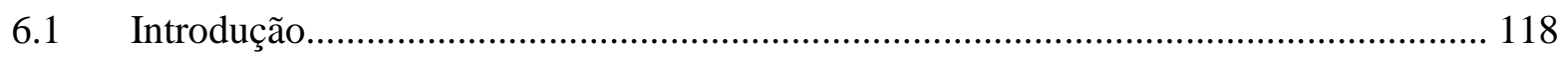

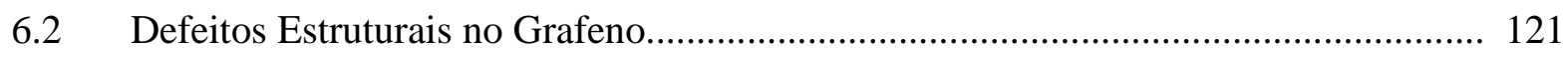

6.3 Propriedades Físicas do Grafeno com Defeitos Estruturais...................................... 123

6.3.1 Estabilidade e Distâncias Interatômicas....................................................................123

6.4 Propriedades Físicas do Grafeno com Defeitos Estruturais........................................ 128

6.4.1 Estrutura de Bandas e Densidade de Estados (DOS).............................................. 128 
6.5 Propriedades Físicas do Grafeno com Monovacância e Divacância 585 dopados com Boro e Nitrogênio

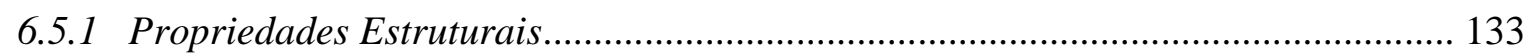

6.5.2 Estrutura de Bandas e Densidade de Estados (DOS)................................................ 135

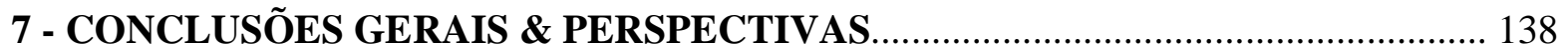

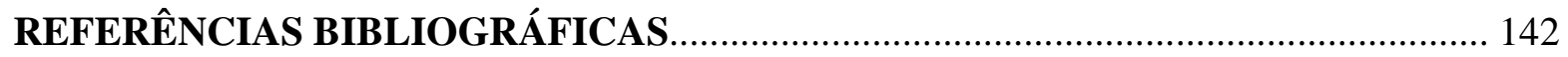

APÊNDICE A - PRODUÇÕES CIENTÍFICAS DURANTE O DOUTORADO................... 155

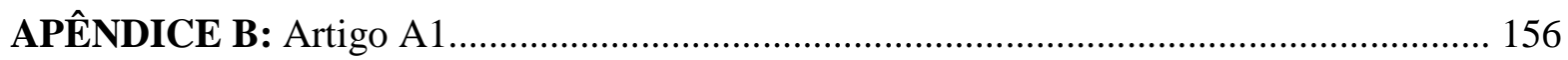




\section{Capítulo 1}

\section{INTRODUÇÃO}

\section{1 - O carbono e suas formas alotrópicas}

O carbono é o elemento químico fundamental na composição de todas as formas orgânicas existentes na natureza, o que o torna a matéria-prima para a vida neste planeta. Ele está presente na atmosfera, nos oceanos, no solo e rocha sedimentares, mesmo nas camadas mais profundas da Terra, nos combustíveis fósseis e faz parte da composição de todos os seres vivos. Combinado com átomos de oxigênio forma o dióxido de carbono $\left(\mathrm{CO}_{2}\right)$, que é essencial para os processos de fotossíntese nas plantas. Por outro lado, a combinação de átomos de carbono e hidrogênio leva à formação dos hidrocarbonetos, elementos básicos, por 
exemplo, do petróleo e gás natural, importantes fontes de energia. A combinação de átomos de carbono com oxigênio e hidrogênio resulta em uma grande variedade de compostos orgânicos, tais como ácidos graxos, ésteres, dentre outros. [1]

O carbono é um dos elementos químicos mais interessantes da tabela periódica, uma vez que exibe propriedades químicas singulares, permitindo uma gama de organizações moleculares e cristalinas. Isto é resultado das diversas possibilidades de hibridização para os elétrons associados às ligações químicas $\left(s p, s p^{2}\right.$ e $\left.s p^{3}\right)$ para os átomos de carbono, ou seja diversas configurações interatômicas são energeticamente favoráveis. Sendo assim, o carbono pode estar associado a diversas estruturas organizadas estáveis, chamadas de alotrópicas, como, por exemplo, o diamante, a grafite, os fulerenos, os nanotubos, os polímeros, o grafeno, nanofitas, dentre outras.

A estrutura cristalina do diamante, representada esquematicamente na figura 1.1, pode ser obtida em laboratório, colocando ligas de carbono, como a grafite, em condições de altas pressões e altas temperaturas. Embora o diamante possa ser obtido de forma artificial sob essas condições, o chamado diamante sintético, este também pode ser encontrado na natureza, chamado de diamante natural, mas que se formou por processos termodinâmicos equivalentes (de altas pressões e altas temperaturas em laboratório) nas camadas profundas do manto terrestre. Na estrutura do diamante, cada átomo de carbono está ligado a quatro átomos vizinhos de carbono, sendo que os quatro elétrons disponíveis (em cada átomo) para fazer as ligações químicas se arranjam espacialmente de tal forma a ficarem em configurações do tipo de orbitais $s p^{3}$. Esses orbitais formam uma estrutura tetraédrica com ângulos de $109,5^{\circ}$ entre si, considerando cada átomo de carbono na posição central desses orbitais. Sua estrutura cristalina é cúbica de face centrada (FCC), com uma base de dois átomos. O diamante, que é o mineral que apresenta maior dureza (maior módulo de compressibilidade) de ocorrência natural conhecido, normalmente é incolor e é um excelente isolante elétrico. Ele é muito utilizado em aplicações industriais como ferramentas de corte. Por outro lado, o diamante é comercializado na forma de jóias, sendo o mais valioso entre os minerais. Essa atração das pessoas pelo diamante remonta a milhares de anos, e é resultado de seu aspecto de grande transparência e estabilidade mecânica.

A pressão ambiente, a configuração cristalina mais estável para o carbono é a grafite, representada na figura 1.2. A grafite é um sólido escuro, bom condutor elétrico e razoavelmente maleável, em contraste ao diamante, que é transparente, isolante e extremamente rígido. 
(a)

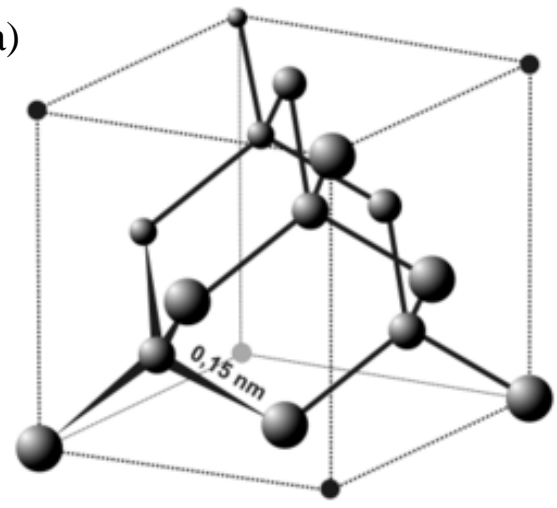

(b)

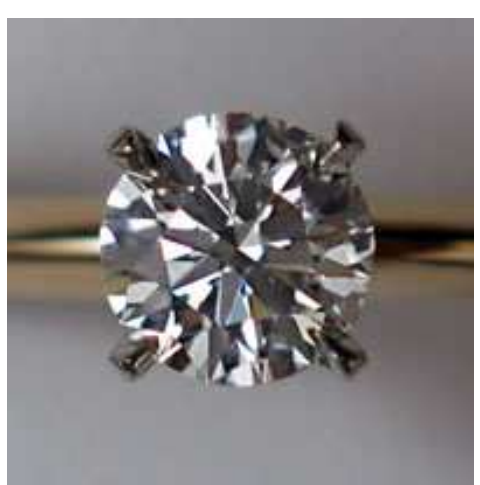

Figura 1.1 - (a) Estrutura cúbica de face centrada (FCC) dos átomos de carbono no diamante; (b) e configuração macroscópica de um cristal de diamante [2].

É surpreendente comparar as propriedades desses dois sólidos, que contém exatamente a mesma composição química, somente diferindo pelas suas organizações interatômicas. A grafite, que se tornou mais amplamente conhecida depois da invenção do lápis em 1644 [1], exibe uma configuração interatômica trigonal plana, ou seja, cada átomo de carbono tem três vizinhos em um mesmo plano. As nuvens eletrônicas da camada de valência formam um ângulo de $120^{\circ}$ entre si. Nesta configuração, três elétrons se encontram em orbitais híbridos $s p^{2}$ planares e um quarto elétron em um orbital $p$, perpendicular a esse plano. É um material frágil, constituído por diferentes camadas, separadas por átomos intercalados, os quais são ligados fracamente a partir de forças de Van der Waals, conforme figura 1.2.

(a)

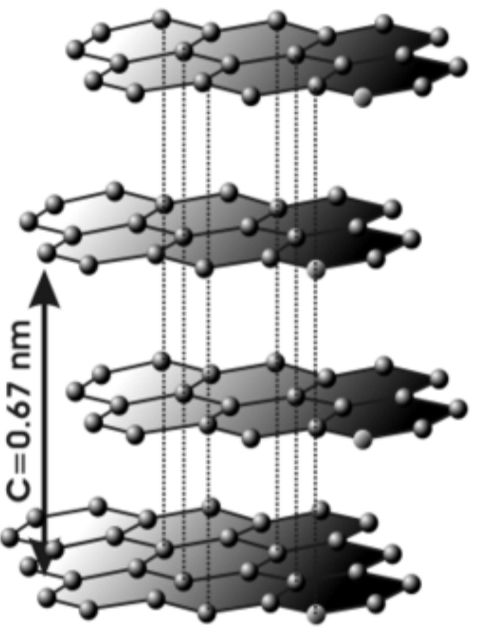

(b)

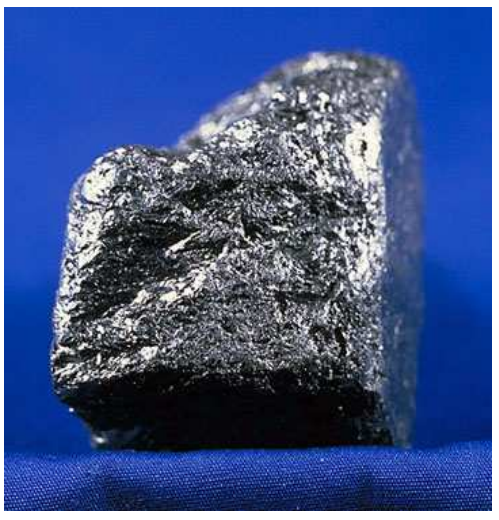

Figura 1.2 - (a) Arranjo interatômico, em configurações hexagonais, dos átomos de carbono na grafite (b) foto da estrutura macroscópica do material [5]. 
Em 1985, uma das mais importantes formas alotrópicas do carbono foi descoberta, chamada primeiramente de buckminsterfullerene ou buckball $\left(\mathrm{C}_{60}\right)$, representada na figura 1.3, e atualmente conhecida como pertencente à classe dos fulerenos. Essa descoberta, que pode ser definida como um dos mais importantes marcos da nanotecnologia, rendeu o prêmio Nobel de química em 1996 para o inglês Harold W. Kroto da Sussex University, na Inglaterra, e os americanos Robert F. Curl e Richard E. Smalley da Rice University, nos Estados Unidos. Os fulerenos são moléculas de carbono, onde os átomos estão arranjados em uma estrutura de superfície esférica, compostos por configurações atomísticas com pentágonos e hexágonos. Do ponto de vista físico e matemático, é uma estrutura com dimensão zero ${ }^{1}$ (0D) com estados de energia discretos, equivalentes a qualquer outra molécula isolada. Embora o $\mathrm{C}_{60}$, uma molécula com 60 átomos de carbono, tenha sido a primeira molécula de fulereno identificada e também sintetizada em laboratório, e ainda a mais conhecida, existem diversas outras formas moleculares, como o $\mathrm{C}_{70}$ e o $\mathrm{C}_{80}$, e hoje moléculas com mais de 100 átomos de carbono são facilmente obtidas em laboratório. Além disso, fulerenos foram identificados em estruturas multi-camadas, chamadas de estruturas tipo "cebola" (onion-like molecules) [3]. Os fulerenos podem ser formados, por exemplo, quando carbono vaporizado é condensado numa atmosfera de gás inerte (como o gás de hélio). Por outro lado, os fulerenos também podem ser formados com lasers de alta potência ou através de arcos voltaicos utilizando eletrodos de grafite [4].
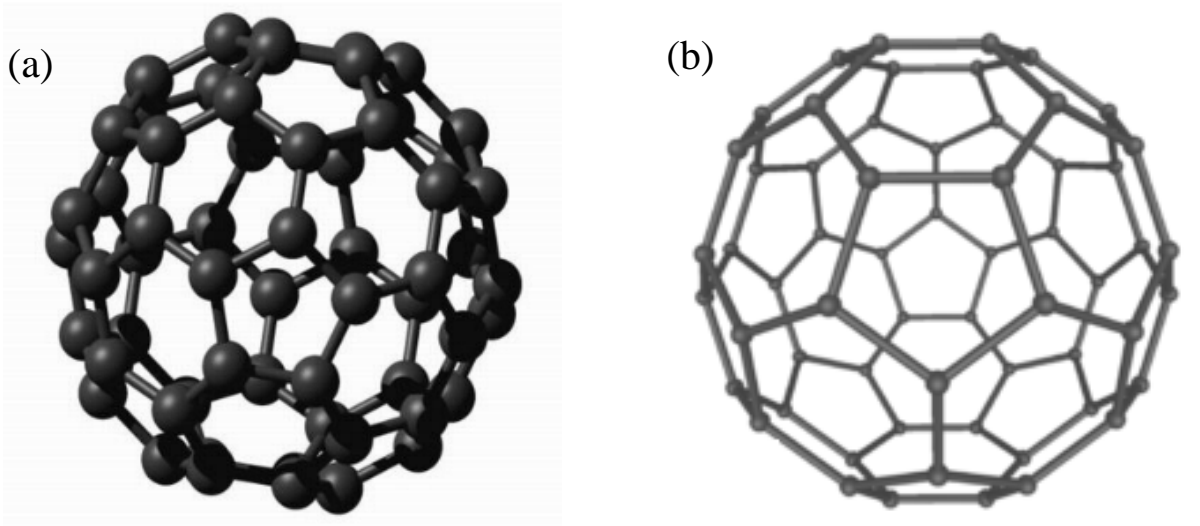

Figura 1.3 - Representação da molécula fulereno $\left(\mathrm{C}_{60}\right)$, destacando (a) os átomos e (b) as ligações interatômicas e estruturas tipo pentágono e hexágono [5].

\footnotetext{
${ }^{1}$ Dimensão zero é o termo utilizado para descrever a natureza das partículas que são representadas por um único ponto que se encontra dentro das dimensões conhecidas. Uma partícula de dimensão zero seria representada por apenas uma coordenada dentro de um gráfico dimensional.
} 
Posteriormente, com a intensificação das pesquisas sobre fulerenos, em 1991, no Laboratório de Pesquisas Básicas da NEC, no Japão, o especialista em ciência do carbono Sumio Ijima pesquisou a possibilidade da formação de outras moléculas de carbono a partir do mesmo método de síntese de fulerenos. Entretanto, Ijima fez uma pequena modificação no método; ao invés de deixar que os eletrodos de grafite entrassem em contato, deixou-os separados enquanto descargas elétricas faiscavam entre eles [2]. Desta forma, uma espécie de fuligem se formou sobre as paredes da câmara de síntese, e também se formou um depósito negro sobre o eletrodo negativo (catodo), que se verificou ser feita de carbono. Usando a técnica de microscopia eletrônica, ele detectou outras formas de carbono, os chamados nanotubos de carbono, estruturas alotrópicas unidimensionais do carbono (1D). Os nanotubos são estruturas moleculares na forma de tubos cilíndricos de diâmetros nanométricos com as extremidades fechadas por "semiesferas" (fulerenos), conforme mostrado na figura 1.4.

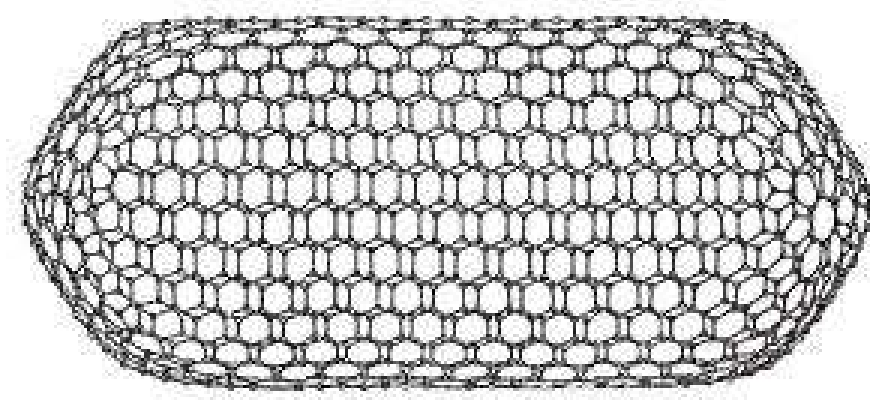

Figura 1.4 - Representação esquemática de um nanotubo de carbono com terminações do tipo fulereno. [5]

Em termos estruturais, existem três tipos de nanotubos de carbono, o de parede simples (chamado em inglês de single-walled nanotube, ou SWNT), de paredes duplas (double-walled nanotube, ou DWNT) e os de paredes múltiplas (multi-walled nanotube, ou MWNT) (conforme figura 1.5). Adicionalmente, os nanotubos podem ser classificados de acordo com sua quiralidade: zigzag, quiral e armchair. Esta classificação depende de como a(s) camada(s) da grafite é (são) 'enrolada(s)', e as propriedades eletrônicas e mecânicas resultantes variam consideravelmente com a quiralidade, podendo, por exemplo, ir de condutores a isolantes. Os nanotubos podem ser crescidos por diversos métodos, como o método de descarga por arco elétrico, descrito nos parágrafos anteriores, no qual ocorre a sublimação do carbono contido em um eletrodo negativo devido às altas temperaturas causadas pela descarga. Eles também podem ser crescidos pelo processo de ablação por laser 
(laser ablation), no qual um pulso de laser vaporiza a grafite em um reator a altas temperaturas com gás inerte lançado numa câmara. Como resultado, os nanotubos desenvolvem-se aderidos às superfícies resfriadas do reator, no momento em que ocorre a condensação do carbono vaporizado. Existe também a técnica chamada de deposição química a vapor (Chemical Vapor Deposition, ou CVD), na qual os nanotubos são crescidos sobre substratos que contém nanopartículas metálicas catalisadoras, como, por exemplo, partículas de níquel, cobalto, ferro e suas ligas. O diâmetro dessas nanopartículas acabam por determinar o diâmetro do nanotubo resultante [2].

SWNT

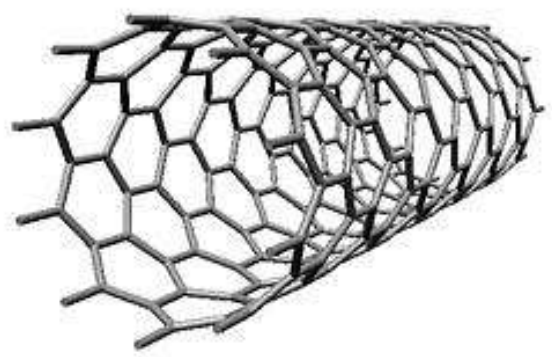

DWNT

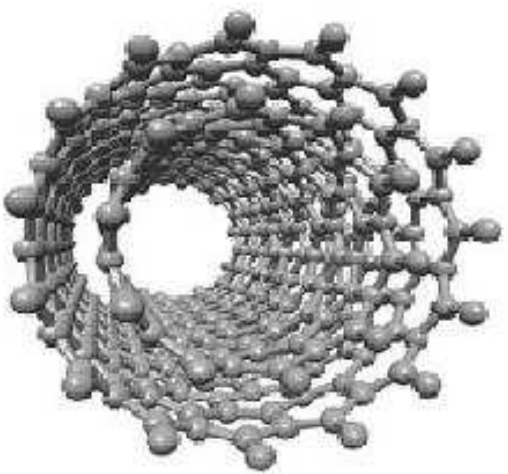

MWNT

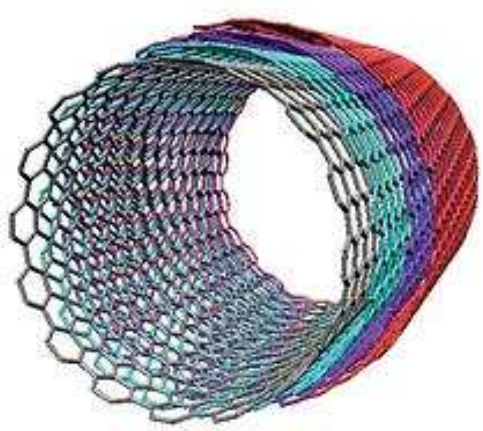

Figura 1.5 - Classificação dos nanotubos de carbono [5].

Em termos de estrutura, os nanotubos, fulerenos e a grafite têm algo em comum, pois todos são formados, ou derivados, a partir da estrutura do grafeno [4]. O grafeno é uma monocamada plana (ou folha simples) de átomos de carbono fortemente empacotados em uma rede bi-dimensional (2D). Ele é um bloco básico, ou a matriz, para a formação de materiais de grafite com todas as outras dimensionalidades. Pode ser "embrulhado" em fulerenos de dimensão nula (0D), "enrolados" em nanotubos unidimensionais (1D) ou "empilhados" em grafite, formando estruturas tri-dimensionais (3D). No grafeno, todos os átomos de carbono são tri-coordenados, ou seja, têm três átomos vizinhos, e portanto estão agrupados de acordo com uma hibridização $s p^{2}$. No caso da grafite, pode-se dizer que os átomos possuem primordialmente somente três ligações interatômicas (fortes) e intraplanares, sendo que a quarta ligação é essencialmente associada com ligações inter-planares, de natureza de Van der Waals. 

(a) Fulerenos
(b) Nanotubos
(c) Grafite

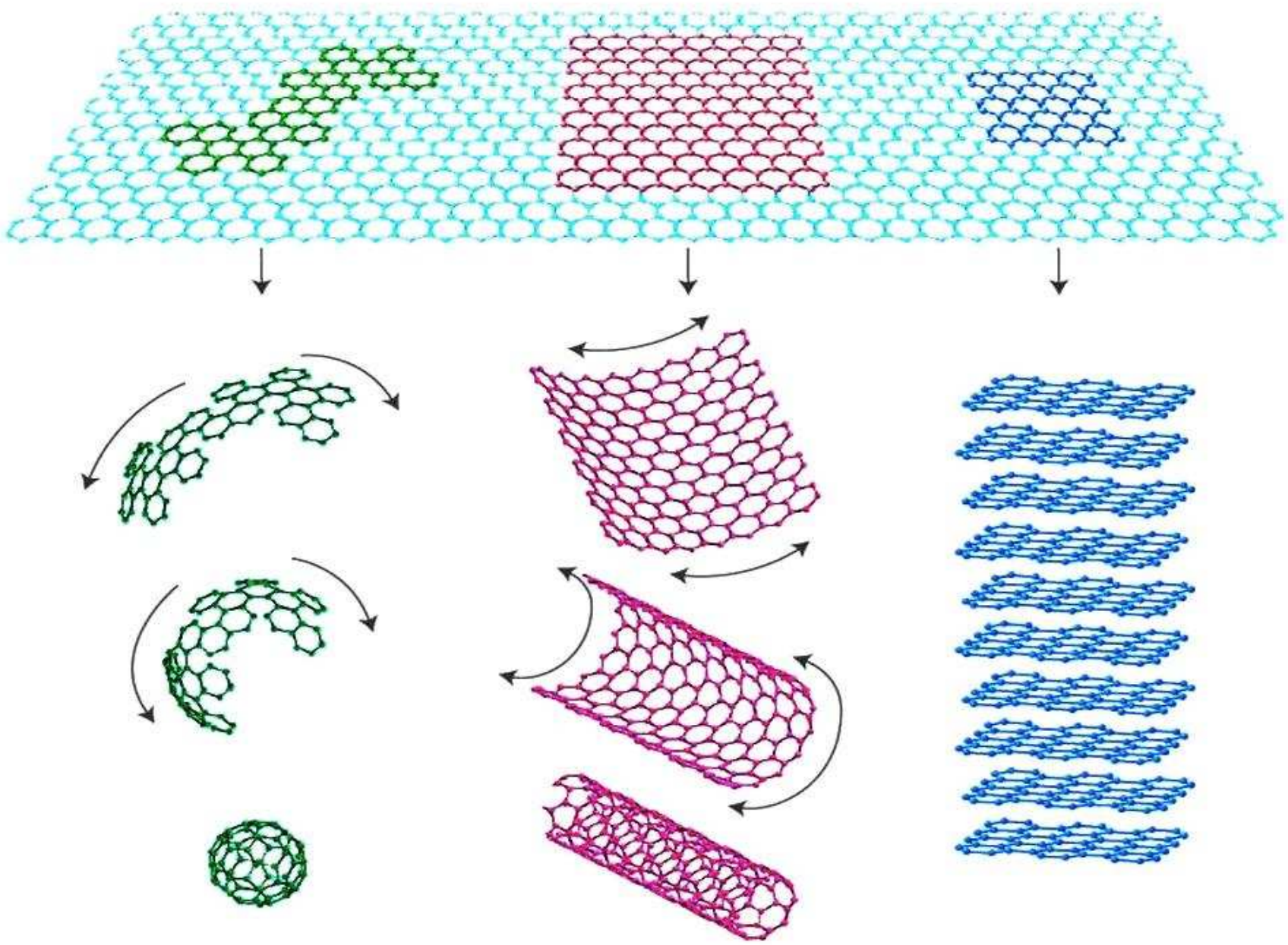

Figura 1.6 - Estruturas derivadas do grafeno, para formar um fulereno (a), um nanotubo (b) e a grafite (c). [6] 


\section{2 - O Grafeno}

\subsection{1 - Histórico}

O grafeno despertou grande interesse na comunidade cientifica mundial nos últimos anos por diversas razões. Primeiro, partindo da idéia de que vários materiais baseados em carbono tais como o fulereno, os nanotubos, a grafite, são derivados do grafeno, ele pode ser considerado como uma espécie de "bloco" fundamental para a construção de materiais grafíticos de todas as outras dimensionalidades. Adicionalmente, ele apresenta propriedades estruturais, eletrônicas e de transporte únicas na natureza, podendo ser considerado como o único sistema bidimensional realmente genuíno na natureza. Desta forma, o grafeno entrou no hall de materiais de grande potencial para o desenvolvimento de novas aplicações tecnológicas, principalmente como dispositivos eletrônicos.

A estrutura do grafeno foi concebida teoricamente há mais de 60 anos, desde o estudo da grafite por cristalografia de raio-X [7]. Entretanto, somente em 2004 que o grupo de cientistas liderado pelo professor Andre K. Geim da Manchester University, Inglaterra, desenvolveu um método para isolar planos de grafeno individuais sobre uma superfície de óxido de silício $\left(\mathrm{SiO}_{2}\right)$. Eles tiveram sucesso em isolar o grafeno através de um processo de esfoliação mecânica da grafite com uma espécie de fita adesiva, obtendo desta forma flocos de grafeno com propriedades eletrônicas de alta qualidade. O grafeno apresenta alta instabilidade mecânica, ou seja, ele é facilmente susceptível a deformações e pode perder a sua forma planar, indo para uma estrutura amorfa ou se enrolando e clusterizando. Nesse sentido, os cientistas inicialmente pensavam que não seria possível isolar uma camada de grafeno experimentalmente, mas com os avanços obtidos pelo grupo do Prof. Geim, intensivos estudos sobre o grafeno se seguiram.

A primeira revisão importante sobre técnicas de crescimento de grafeno foi publicada na literatura em 2007 pelo grupo da Manchester University [4]. Esses autores citam diversos outros artigos nos quais o grafeno em camada única ou múltiplas foi crescido epitaxialmente sobre diferentes materiais usados como substratos. Nessa revisão, os autores ainda fizeram referência a artigos anteriores à sua descoberta de 2004, nos quais compostos de grafite intercalados foram estudados utilizando microscopia eletrônica de transmissão (TEM), onde foi possível a observação de "flocos" de grafite extremamente finos, ou seja, com poucas camadas de grafeno e possivelmente até camadas isoladas [8]. Atualmente, sabe-se que pequenos fragmentos de folhas de grafeno são produzidos (juntamente com grandes 
concentrações de outros detritos) sempre que a grafite é esfoliada. Houve pouco interesse nestes resíduos grafiticos antes de $2004 \mathrm{e}$, portanto, a descoberta de um processo para isolar o grafeno a partir da grafite é freqüentemente atribuída a K. S. Novoselov e A. K. Geim.

O que diferencia as folhas de grafeno em relação a todos os materiais descobertos até o momento é que ele tanto pode ser considerado semicondutor como condutor, Pelo fato de que na sua estrutura de bandas eletrônicas, nos pontos de Dirac (K e K'), o grafeno apresenta gap nulo, ou seja, a banda de condução e a banda de valência se tocam e em outros pontos o gap varia linearmente dependendo do momento $k$ do elétron.

Além de todas as suas propriedades eletrônicas peculiares, descritas nos parágrafos anteriores, o grafeno apresenta outra propriedade única, que o faz ser interessante para estudos da área de física de partículas elementares. Nos planos de grafeno, os elétrons se movimentam a velocidades extremamente altas, próximas da velocidade da luz, e podem executar o movimento balístico ao longo de distâncias muito grandes, ou seja, os elétrons podem percorrer grandes distâncias no grafeno sem sofrerem nenhum evento de espalhamento com outros elétrons. A velocidade eletrônica é independente da energia, ou seja, os elétrons se movem como se fossem ondas de luz; de forma que eles se comportam como se fossem partículas com massa praticamente nula, sendo por este motivo chamados de férmions de Dirac sem massa. Essa propriedade de transporte dos elétrons foi comprovada através de experimentos de Efeito Hall Quântico realizados por Geim e Novoselov da Manchester University, Inglaterra [6], e por Philip Kim e Yuanbo Zhang, da Columbia University, EUA [9]. Adicionalmente, o grafeno apresenta uma grande condutividade térmica, superior até mesmo à do diamante [10] e a maior resistência mecânica entre os materiais [11].

\subsection{1 - Estrutura Atômica}

O grafeno é uma forma alotrópica do carbono totalmente bidimensional (2D) composto por anéis hexagonais de átomos de carbono (representado na figura 1.7), formando uma rede do tipo favo de mel (honeycomb lattice). O nome grafeno tem origem na grafite mais o grupo -ene; A grafite por si só consiste do empilhamento de muitas camadas de grafeno [1]. 


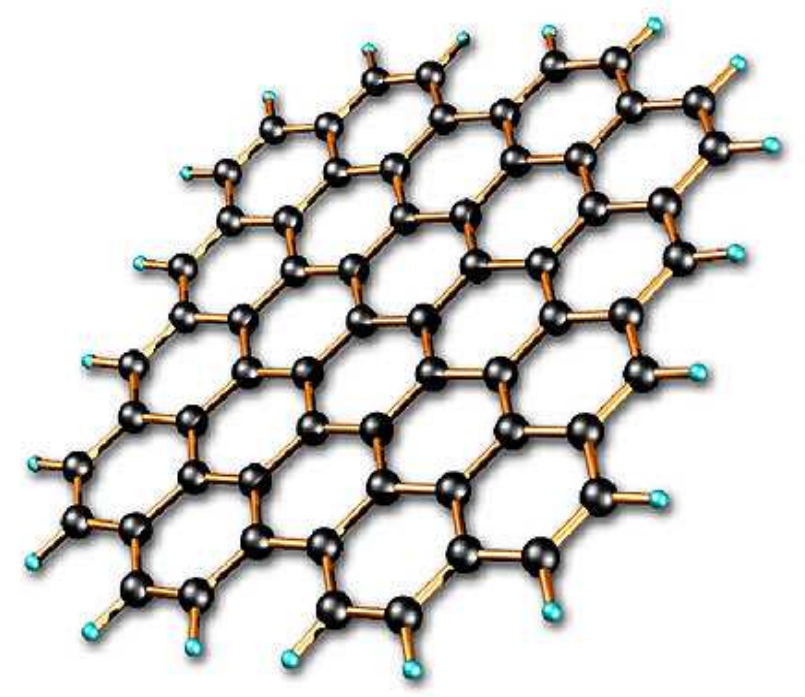

Figura 1.7 - Representação da estrutura hexagonal e planar do grafeno [5].

Para compreender a estrutura atômica do grafeno é importante entender qual o tipo de hibridização eletrônica existente nesse material. Para isso, é necessário saber qual a configuração eletrônica e os tipos de ligações realizadas entre os átomos de carbono. A configuração dos elétrons num átomo de carbono isolado, no seu estado fundamental, é $1 s^{2}$ $2 s^{2} 2 p^{2}$. Entretanto, quando o átomo de carbono está no seu estado excitado um elétron da camada $2 s^{2}$ absorve energia sendo promovido para um dos orbitais $p$ vazios, conforme representado na figura 1.8 .

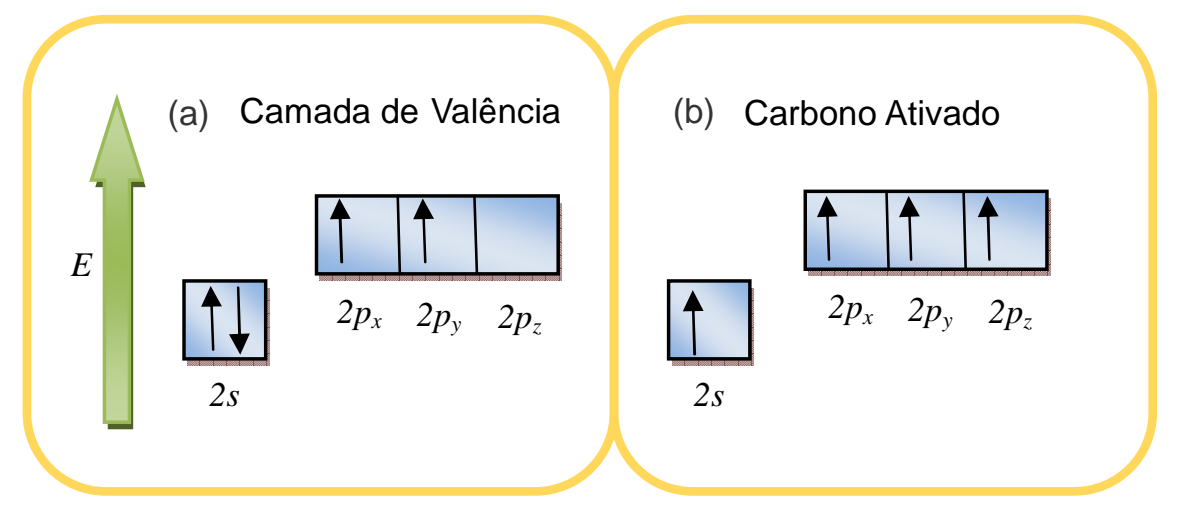

Figura 1.8 - (a) Configuração eletrônica da camada de valência de um átomo de carbono no seu estado fundamental; (b) Configuração desse carbono no seu primeiro estado excitado (ou ativado). 
De acordo com a teoria dos orbitais, as ligações químicas (ou ligações interatômicas) só são efetuadas através de orbitais atômicos semi-preenchidos ou incompletos, os quais se interpenetram com os orbitais dos átomos vizinhos, resultando em orbitais moleculares do tipo $\sigma$ (sigma) e $\pi$ (pi). Uma ligação química do tipo sigma é formada pela interpenetração frontal de orbitais (mesmo eixo), é uma ligação forte e difícil de ser rompida. Por outro lado, a ligação do tipo pi é formada através de uma aproximação lateral entre orbitais (eixos paralelos), é uma ligação mais fraca com maior facilidade de rompimento, só ocorre entre orbitais do tipo $p$.

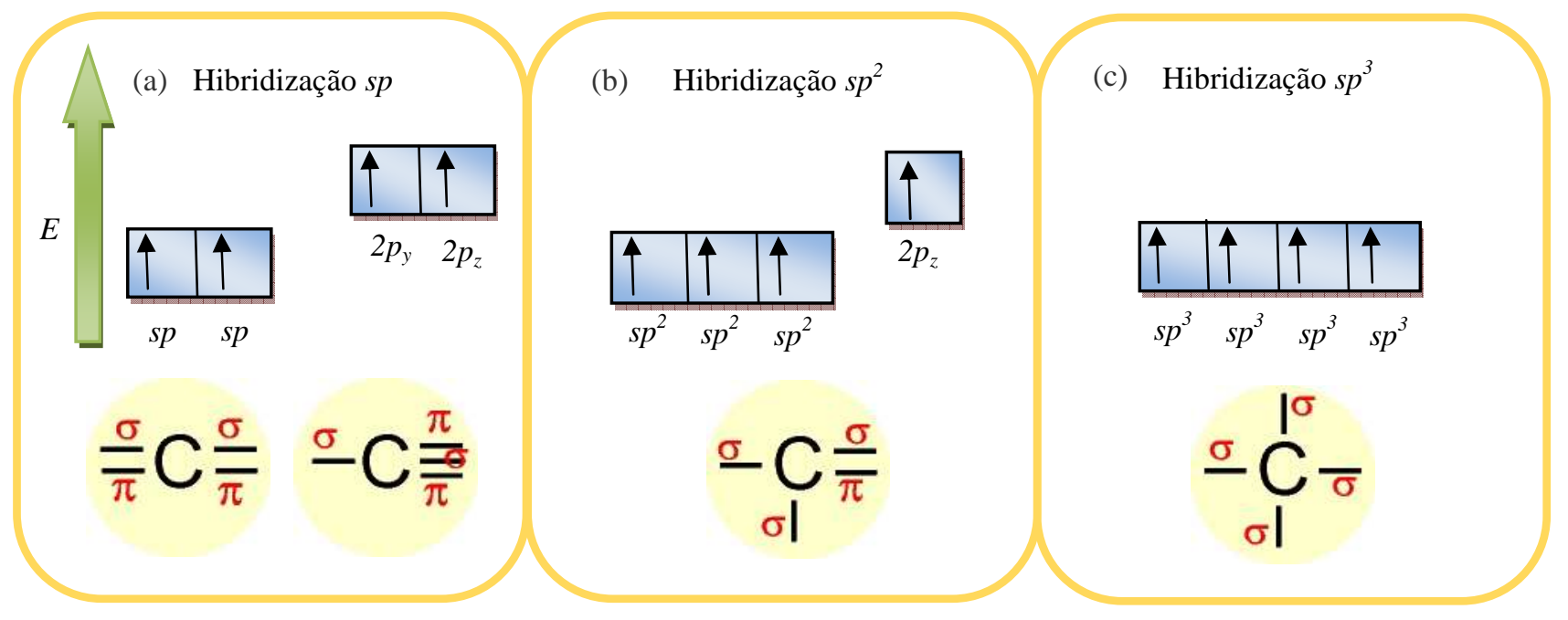

Figura 1.9 - Representação da configuração eletrônica da camada de valência do carbono e das suas possíveis ligações atômicas para hibridização do tipo: (a) $s p$; (b) $s p^{2}$; (c) $s p^{3}$.

A hibridização do tipo $s p$ no carbono ocorre quando o orbital $2 s$ se mistura com um orbital do tipo $2 p$, gerando dois orbitais híbridos do tipo $s p$, sobrando dois orbitais $2 p$ não hibridizados. Esta hibridização apresenta uma geometria linear plana. Os dois orbitais híbridos $s p$ se localizam no plano linear e os dois orbitais $2 p$ são perpendiculares entre si e ao plano linear. $\mathrm{O}$ ângulo entre os orbitais híbridos é de $180^{\circ}$. Um exemplo típico da ocorrência deste tipo de hibridização é a molécula de acetileno que apresenta uma ligação "tripla" entre dois átomos de carbono $(\mathrm{HC} \equiv \mathrm{CH})$, sendo que duas ligações são do tipo $\sigma$ e duas do tipo $\pi$. Pode também ocorrer com duas duplas ligações entre carbonos. Trata-se do carbono insaturado.

Por outro lado, a hibridização do tipo $s p^{2}$ no carbono é gerada através da interação entre o orbital $2 s$ com dois orbitais $2 p$, resultando em três orbitais híbridos do tipo $s p^{2}$ restando assim apenas o orbital $2 p_{z}$ não hibridizado, que é perpendicular ao plano que contém 
as outras três ligações. Esta configuração eletrônica permite a existência de três ligações covalentes planares com outros átomos, separadas por um ângulo de $120^{\circ}$, tendo um arranjo hexagonal, sendo por esse motivo chamada de geometria trigonal plana. Uma molécula de poliacetileno $\left(\mathrm{C}_{2} \mathrm{H}_{2}\right)_{n}$ é um exemplo típico da ocorrência deste tipo de hibridização, que é caracterizado por apresentar uma alternância entre ligações duplas e simples entre átomos de carbono em sua estrutura. Esta configuração apresenta três ligações do tipo $\sigma$ (sigma) e uma do tipo $\pi$ (pi).

Por último, na hibridização do tipo $s p^{3}$, o orbital $2 s$ interage com os três orbitais $2 p$, gerando, dessa forma, quatro orbitais híbridos do tipo $s p^{3}$. Essa configuração tem uma geometria tetraédrica, com ângulos de separação entre os orbitais de aproximadamente $109.3^{\circ}$ onde cada orbital híbrido pode formar ligações do tipo $\sigma$ (quatro ligações simples). Nesse caso, trata-se do carbono saturado, por exemplo, moléculas do gás metano $\left(\mathrm{CH}_{4}\right)$.

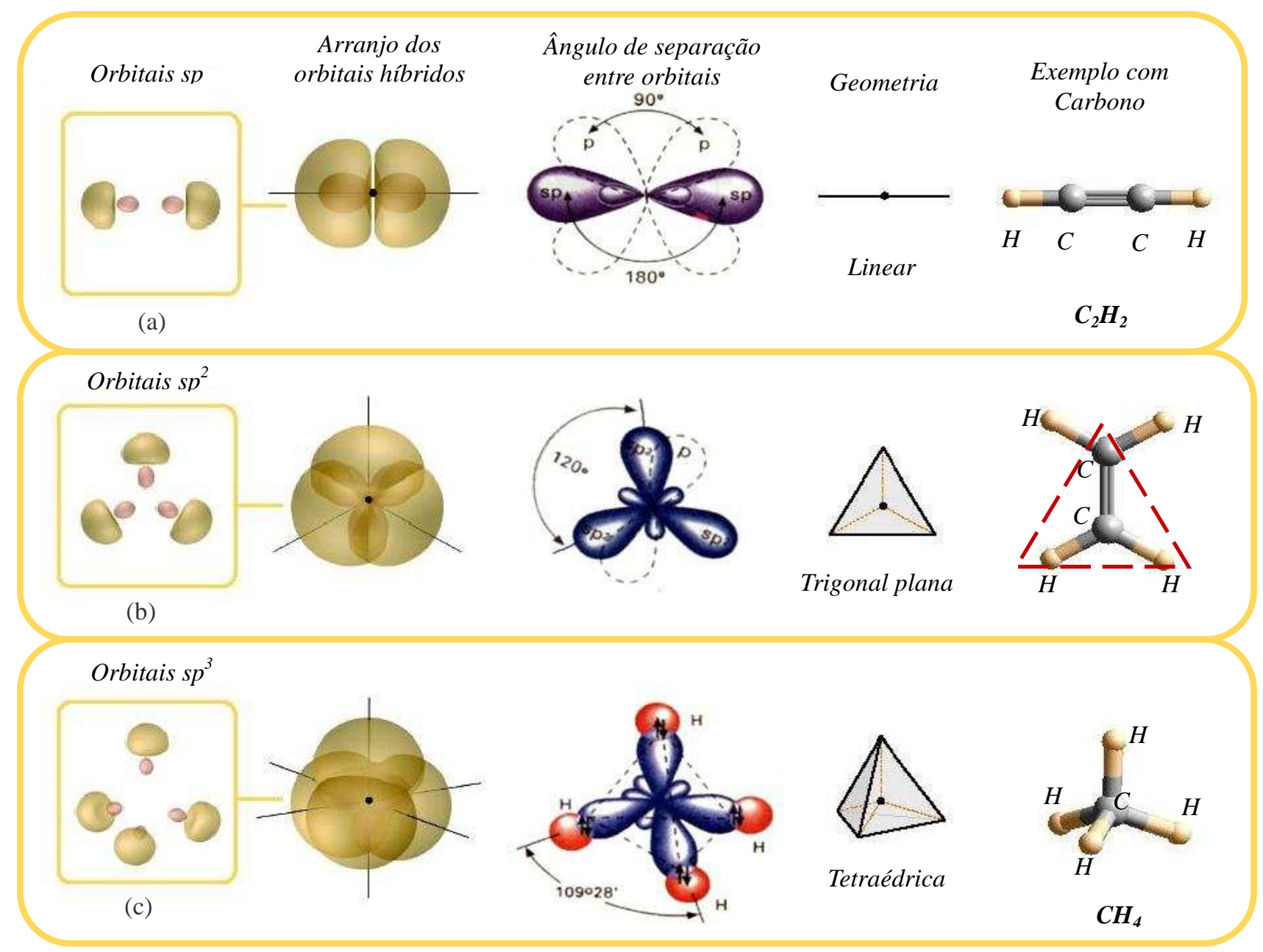

Figura 1.10 - Representação dos orbitais e seus respectivos ângulos de ligação e geometria para hibridização do tipo: (a) $s p$; (b) $s p^{2}$; (c) $s p^{3}$. 
No caso do grafeno, observa-se a hibridização do tipo $s p^{2}$, na qual ocorre a combinação de um orbital $2 s$ e dois orbitais $2 p$ formando três orbitais equivalentes, orbitais híbridos do tipo $s p^{2}$. Cada orbital $s p^{2}$ é representado por um lobo largo apontando para uma direção e outro menor apontando para a direção oposta, como mostrado na figura 1.11(a).

(a)

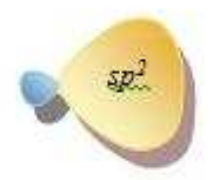

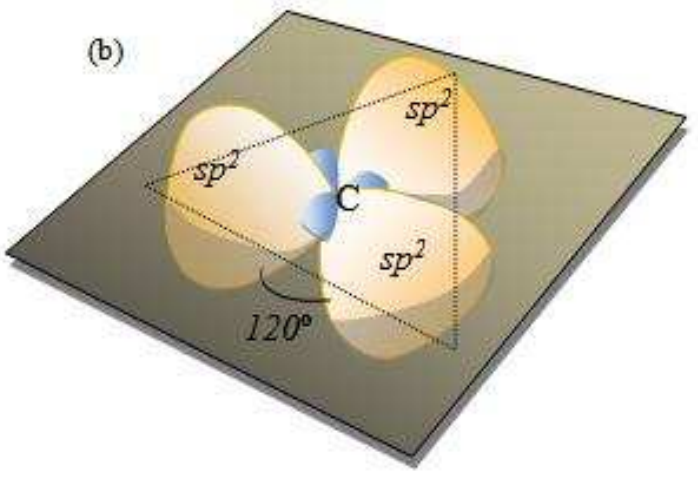

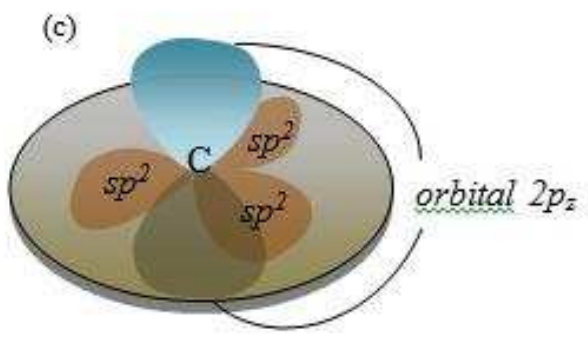

Figura 1.11 - (a) Representação do orbital $s p^{2}$ (lobo largo apontando uma direção e lobo menor apontando para direção oposta); (b) Três orbitais híbridos do tipo $s p^{2}$ de um átomo de carbono ligados entre si e separados por um ângulo de $120^{\circ}$; (c) Representação da localização dos orbitais $s p^{2}$ no plano e do orbital $2 p$ vazio perpendicular ao plano.

Os eixos dos três orbitais híbridos $s p^{2}$ estão sobre o mesmo plano e estão apontados em direção aos vértices de um triângulo eqüilátero, conforme mostrado na figura 1.11(b). O orbital atômico $2 p_{z}$ não se envolve na hibridização e consiste de dois lobos situados no plano perpendicular ao plano dos orbitais híbridos $s p^{2}$, conforme figura 1.11(c).

Conforme descrito anteriormente, uma ligação tipo sigma é formada pela sobreposição de dois orbitais híbridos $s p^{2}$ sobre um eixo comum, conforme mostrado na figura 1.12(a), que é o caso das três ligações simples que o carbono faz no mesmo plano, o que resulta em uma estrutura hexagonal, de forma que os orbitais estão dispostos em uma estrutura planar formando ângulos entre si de aproximadamente $120^{\circ}$, tendo um comprimento de ligação da ordem de 1.42 Á (no caso do grafeno), conforme descrito na figura 1.13.

Por outro lado, o orbital $2 p$, remanescente em cada um dos átomos de carbono no plano de grafeno, está paralelo aos orbitais $2 p$ remanescentes de todos os outros átomos de carbono. Todos esses orbitais se sobrepõem, formando uma ligação $\pi$, conforme mostrado na figura 1.12(b). Sendo assim, a superfície plana do grafeno apresenta uma espécie de "mar" de orbitais $\pi$ vazios, que interagem entre si. A figura 1.14 faz uma ilustração da formação desses orbitais $\pi$. 

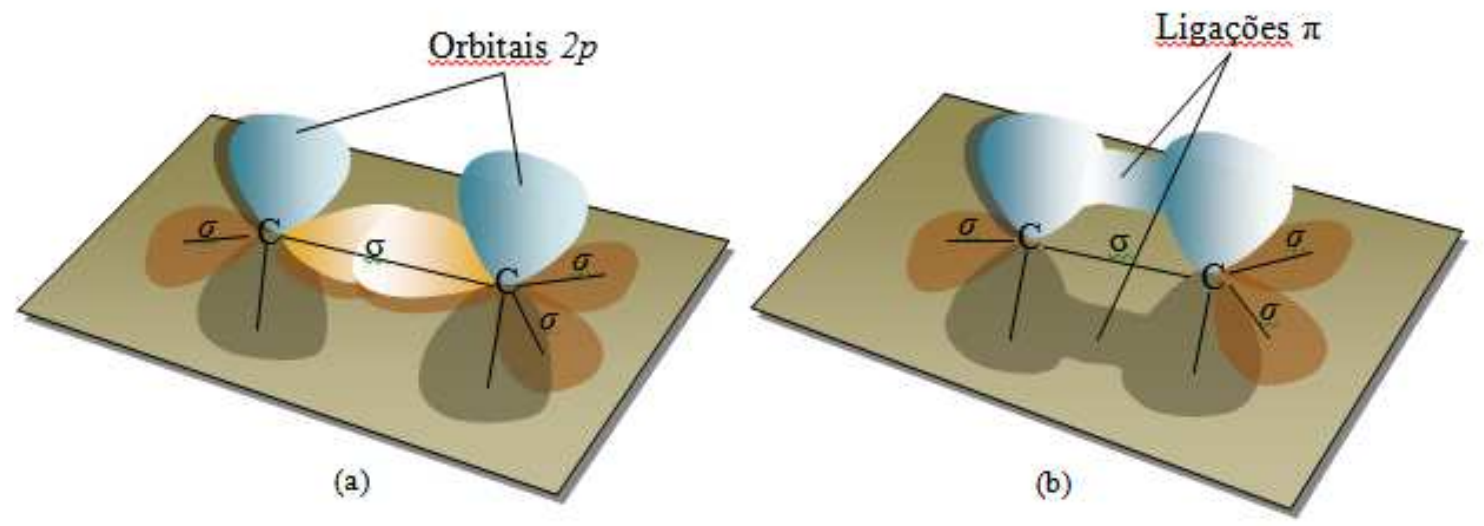

Figura 1.12 - (a) Representação da sobreposição de dois orbitais híbridos do tipo $s p^{2}$ de dois átomos de carbono formando uma ligação sigma; (b) Representação da sobreposição de dois orbitais $2 p$ de dois átomos de carbono perpendiculares ao plano formando uma ligação $\pi$.

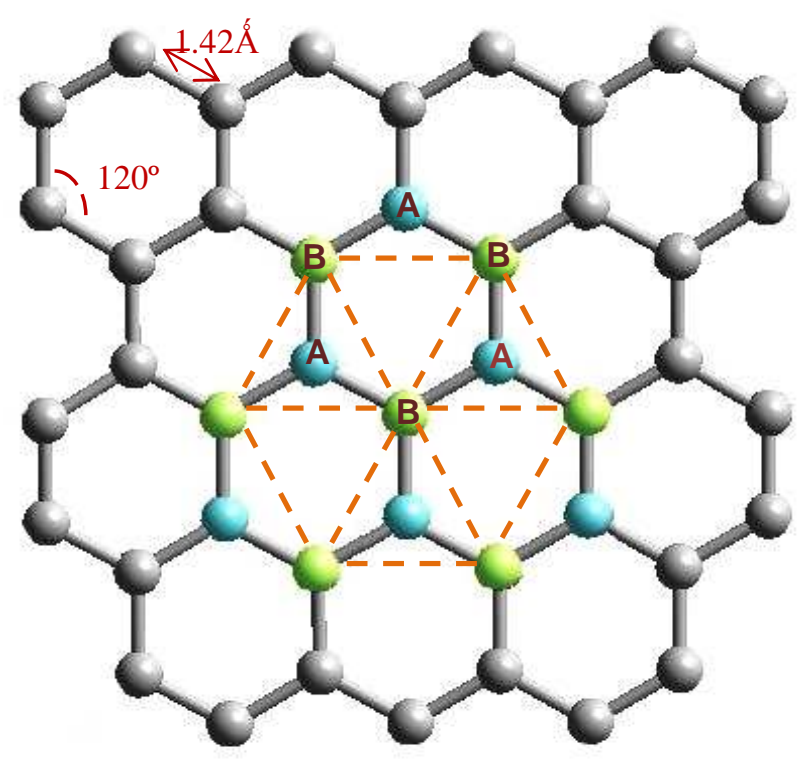

Figura 1.13 - Representação da estrutura hexagonal planar do grafeno.

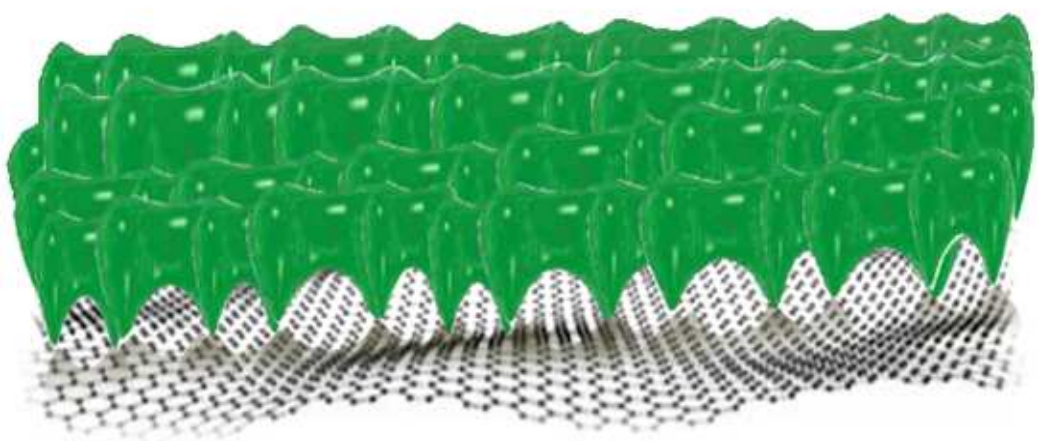

Figura 1.14 - Representação das ligações entre os orbitais $p_{z}$ não hibrizados vazios perpendiculares ao plano do grafeno. 


\section{3 - Nanossistemas, Nanoestruturas e Nanodispositivos}

Enquanto a nanociência está associada com a investigação das propriedades fundamentais de sistemas físicos em escalas nanométricas, a nanotecnologia está associada com os métodos artificiais de manipulação de sistemas a essas escalas, e em suas potenciais aplicações. Nesse sentido, pode-se dizer que essas duas abordagens do mundo nanométrico são totalmente complementares, o domínio desse mundo nanoscópico requer intensivas pesquisas usando essas duas abordagens. Desta forma, o sucesso da nanotecnologia está associado com a tecnologia que permite manipular átomos e moléculas individualmente, e organizá-las de forma a criar sistemas (ou nanomáquinas) que realizem tarefas de interesse. $\mathrm{O}$ conjunto de tarefas, que essas nanomáquinas executam ou podem ser programadas para executar, encontram potenciais aplicações em diversas áreas do conhecimento, como a medicina, computação, biologia, química, física, engenharia eletrônica, dentre outras áreas. $\mathrm{Na}$ medicina, nanomáquinas tem sido estudadas para diversas aplicações, por exemplo, para auxiliar no transporte de medicamentos dentro do corpo humano (chamado em inglês de drug delivery). Por outro lado, na engenharia eletrônica, a nanotecnologia, conhecida como nanoeletrônica, tem como principal objetivo desenvolver dispositivos eletrônicos, como diodos, transistores, sensores e atuadores, em escalas nanométricas, que possam executar operações lógicas a velocidades maiores que a atual geração de dispositivos eletrônicos à base de silício. Porém diversos outros problemas são enfrentados pela indústria de dispositivos eletrônicos, questões como empacotamento de dispositivos (ou seja, aumentar o número de componentes eletrônicos por unidade de volume), melhorias na dissipação de energia dos chips, dentre outros.

O transistor é o elemento principal de toda a eletrônica, e o grande desafio da indústria de microeletrônica é construí-lo cada vez mais compacto e que permita velocidades de processamento cada vez maiores. Os modernos chips, disponíveis no mercado, possuem transistores com tamanhos em torno de 40 nanômetros, e acredita-se ser inviável a fabricação dos atuais transistores em dimensões abaixo de $10 \mathrm{~nm}$, pois nessa escala existem problemas como oxidação, decomposição e migração de forma descontrolada sobre as superfícies em todos os elementos semicondutores, incluindo o silício [12]. 
Tendo em vista essas limitações da tecnologia tradicional dos circuitos integrados à base de silício, diversas soluções alternativas de dispositivos eletrônicos, mais compactos e mais rápidos que os dispositivos tradicionais, foram propostas nos últimos anos. Muitas dessas soluções se inserem em designs de dispositivos dentro do contexto da nanotecnologia, e algumas dessas soluções já tiveram sua viabilidade, ou prova de conceito de dispositivo, executada experimentalmente. Esses dispositivos ainda freqüentam um universo puramente acadêmico, sem a extensão ao universo corporativo, e, portanto, ainda sem comprovações de viabilidade econômica para produção em larga escala. Mesmo assim, a comprovação experimental da execução de operações lógicas e a compreensão dos fenômenos físicos envolvidos permitem vislumbrar um desenvolvimento em potencial desses dispositivos no meio industrial.

Em 2006, um transistor molecular foi desenvolvido por pesquisadores da University of Arizona, nos Estados Unidos, que o batizaram como QuIET (“Quantum Interference Effect Transistor") [13]. Esse dispositivo de aproximadamente 1nm, era composto por uma molécula de benzeno ligada a três eletrodos metálicos, os quais correspondiam à fonte, porta e dreno dentro dos conceitos de um transistor convencional. Diferentemente da fenomenologia da física clássica, onde as duas correntes que passam em cada braço do anel simplesmente se somam, no transistor proposto, as duas ondas eletrônicas interferem uma com a outra de forma destrutiva, de maneira que não passa nenhuma corrente. Este é o estado desligado do transistor. Por outro lado, o estado ligado ocorre quando o padrão de interferência das ondas é mudado ao alterar a fase das ondas, permitindo que a corrente flua. Desta forma, o dispositivo realiza a operação lógica como um chaveador. A figura 1.15 apresenta uma representação esquemática desse dispositivo molecular. Na figura, as esferas de cor verde, violeta e amarelo correspondem a átomos de carbono, hidrogênio e enxofre, respectivamente. As três estruturas contendo esferas douradas representam os contatos metálicos do transistor molecular. Uma voltagem aplicada no eletrodo à esquerda controla o fluxo de corrente entre os outros dois eletrodos [13], e funciona como o eletrodo chaveador, equivalente ao terminal chamado de base num transistor convencional. 


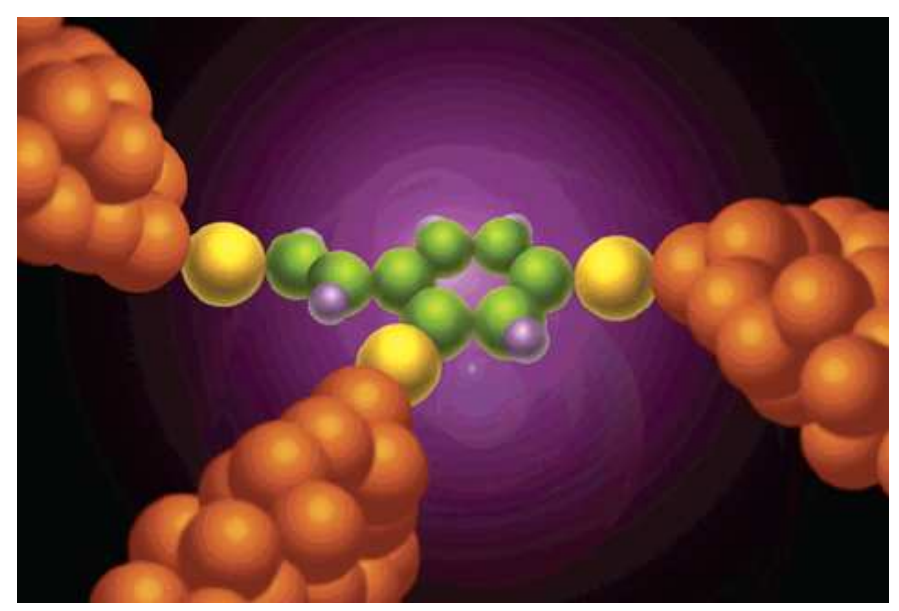

Figura 1.15 - Representação esquemática do transistor QuIEt [13].

Pesquisadores da Universidade de Delft na Holanda propuseram um transistor atômico em [14]. Esses pesquisadores tiveram sucesso em medir e manipular o comportamento quântico de um único átomo de elemento dopante (arsênio) no interior de um ambiente semicondutor realístico, um transistor MOSFET com uma estrutura de $35 \mathrm{~nm}$. Esses pesquisadores obtiveram sucesso em manipular um ou dois elétrons em uma camada específica daquele átomo [14]. Na prática, este experimento demonstrou a possibilidade de se manipular o estado eletrônico em átomos individuais inseridos em materiais semicondutores. Desta forma, ficou demonstrada a possibilidade de se construir o menor dispositivo a nível atômico.

Diversas outras propostas de nanodispositivos foram apresentadas nos últimos anos na literatura. Entre elas, temos o exemplo do transistor SET ("Single Electron Tunneling”), ou transistor de tunelamento de elétron único, proposto em 2006 por Akira Fujiwara, no Laboratório de Pesquisas Básicas da NTT no Japão [15]. Este transistor de silício consiste de um canal de nanofio de silício e finas portas para formar as barreiras eletrostáticas (LGS, LGC e LGD), conforme mostrado na figura 1.16. As três barreiras ajustáveis são controladas pela tensão da porta para as portas inferiores $\left(\mathrm{V}_{\mathrm{LGS}}, \mathrm{V}_{\mathrm{LGC}} \mathrm{e} \mathrm{V}_{\mathrm{LGD}}\right)$, as regiões existentes entre as barreiras agem como ilhas de carga, as quais são controladas principalmente pela tensão de porta superior $\mathrm{V}_{\mathrm{UG}}$. Barreiras ajustáveis possibilitam ter várias configurações para as ilhas de carga. Por exemplo, uma ilha longa é formada se duas barreiras são formadas em LGS e LGD, enquanto uma pequena ilha é formada se as barreiras são formadas por LGC e LGD. Este 
transistor de silício é capaz de funcionar com o movimento de apenas um elétron, o qual precisará atravessar as "ilhas de carga". Além do transistor SET, também foi proposto o transistor de nanotubo [16], os transistores à base de nitretos com velocidades de chaveamento da ordem de $100 \mathrm{GHz}$ [17].

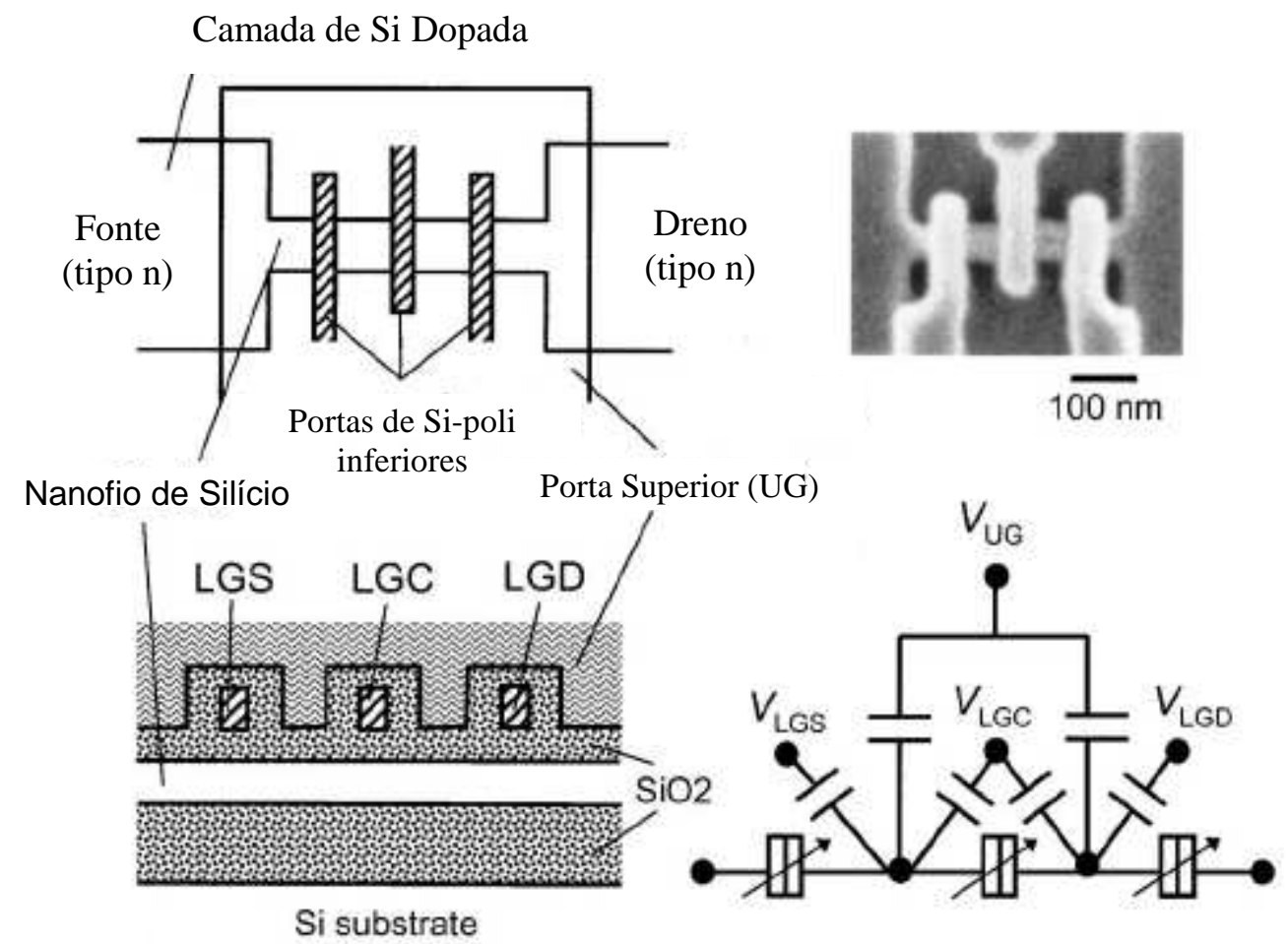

Figura 1.16 - Representação do transistor SET [15].

Os exemplos apresentados nos parágrafos anteriores mostraram que o conceito de dispositivos quânticos pode ser realizado experimentalmente usando diversas possibilidades, indo de soluções que envolvem moléculas a outras formas nanoestruturadas, como os nanotubos e fitas de DNA. Os grandes desafios são então em como incorporar essas soluções dentro do contexto da indústria de microeletrônica mundial. A tecnologia dos dispositivos à base de silício se desenvolveu de forma exponencial nos últimos cinqüenta anos, e se estabeleceu como um dos segmentos econômicos mais bem sucedidos. Entretanto, nos últimos anos, a tecnologia do silício vem enfrentando grandes desafios no desenvolvimento de novos dispositivos (menores e mais rápidos). As soluções propostas nos parágrafos anteriores, baseadas em dispositivos construídos por outros tipos de materiais, poderiam ser a solução para superar essas dificuldades da tecnologia do silício. Entretanto, elas representam 
um novo paradigma no design de dispositivos, e a simples substituição de uma tecnologia por outra, dentro do contexto industrial, ainda parece ser economicamente inviável por diversas razões, como os custos envolvidos na substituição da tecnologia e questões de escalabilidade na construção desses novos dispositivos. Desta forma, as soluções propostas nesses parágrafos ainda têm um longo caminho a percorrer antes de serem incorporados em alguma nova tecnologia de circuitos integrados.

Dispositivos a base de grafeno parecem ser, no momento, uma das soluções viáveis para a construção de uma nova geração de nanodispositivos eletrônicos. Isto se deve às surpreendentes propriedades elétricas e eletrônicas, descritas detalhadamente no capitulo II, entre as quais se destacam a sua alta capacidade de condução de corrente elétrica, a sua excelente condutividade térmica e baixa tensão de operação.

O grafeno, que é uma folha de carbono com apenas um átomo de espessura, com uma estrutura hexagonal, similar à dos favos de mel de uma colméia, foi utilizado na construção do transistor, mais rápido [18], menor [19] e também na construção do transistor mais fino do mundo [4], com comprimento de dez átomos de carbono (1nm), com espessura de apenas um único átomo de carbono. A figura 1.17 apresenta uma representação esquemática da organização atômica desse dispositivo.

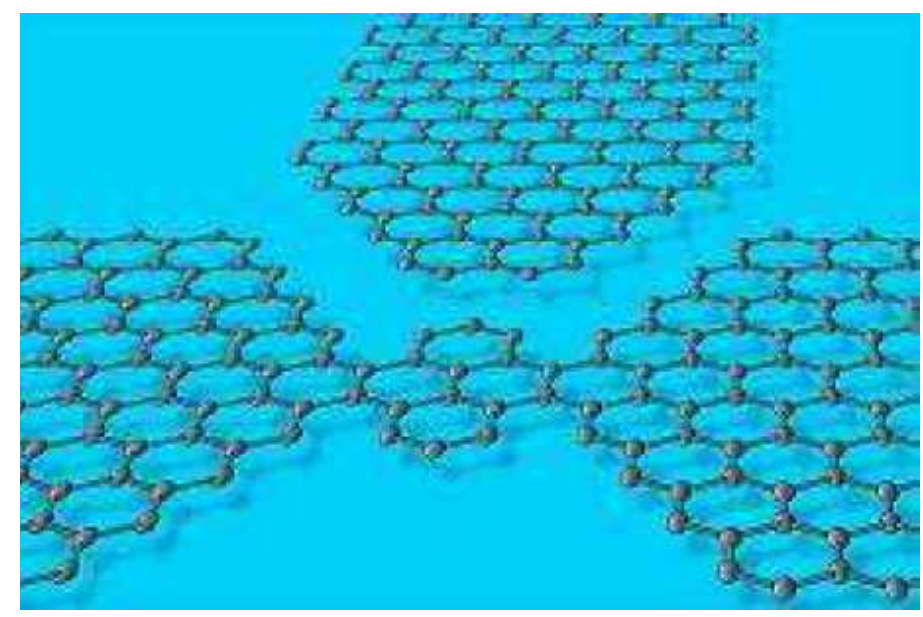

Figura 1.17 - Representação do transistor mais fino do mundo contruído a partir de uma folha de grafeno [4].

No ano de 2008, pesquisadores do Massachusetts Institute of Technology (MIT), nos Estados Unidos, também fabricaram um chip experimental de grafeno. Este chip de demonstração é um multiplicador de freqüências, que é um dispositivo capaz de receber um 
sinal elétrico de determinada freqüência, por exemplo, o sinal de clock que determina a velocidade de funcionamento dos processadores, e produzir um sinal de saída que tem uma freqüência que é um múltiplo daquela do sinal de entrada. É um dispositivo com potenciais aplicações em sistemas de comunicações de rádio e outras aplicações sem fio. O chip de grafeno, por sua vez, utiliza um único transistor e produz um sinal de saída limpo que dispensa os circuitos adicionais de filtragem, como ocorre com os atuais multiplicadores de freqüência que exigem diversos componentes eletrônicos, gerando sinais de saída com ruídos, que exigem filtros e consomem muita energia. Esses chips de grafeno poderão operar na região de terahertz $(\mathrm{THz})[20]$.

No mesmo ano, sob o comando do pesquisador Jeong-sun Moon, pesquisadores dos Laboratórios HRL (Hughes Research Laboratories), nos Estados Unidos, conseguiram fabricar pela primeira vez os transistores de efeito de campo (FET) de grafeno utilizando uma tecnologia padrão na fabricação de componentes eletrônicos, conhecida como crescimento epitaxial de filmes finos [21]. O objetivo dessa pesquisa é utilizar as propriedades únicas do grafeno para aplicações de comunicações de grande largura de banda, imagens e sistemas de radar. Os transistores de grafeno agora construídos no método "bottom-up", no qual as folhas de grafeno são depositadas a partir de um vapor de carbono, funcionam no domínio das radiofreqüências, tornando-os componentes para uso em telecomunicações com um rendimento e precisão sem precedentes. Isto significa que não falta muito para que os transistores de grafeno sejam produzidos em escala industrial e possam ser comercializados.

Outro exemplo de aplicação do grafeno é em dispositivos emissores de luz. O LED orgânico, mais conhecido como OLED, que já está sendo fabricado em escala comercial, é um dispositivo que consiste de uma camada contendo compostos emissores de luz (moléculas orgânicas ou polímeros), colocada entre dois eletrodos, um dos quais deve ser transparente, para que a luz não seja atenuada. Um design desse dispositivo é apresentado na figura 1.18. Este dispositivo é essencialmente um diodo emissor de luz cuja camada orgânica é composta por moléculas de carbono que emitem luz ao receberem uma carga elétrica. Esses dispositivos podem ser usados em aparelhos de televisão, câmeras digitais, monitores, celulares, dentre outros equipamentos. 


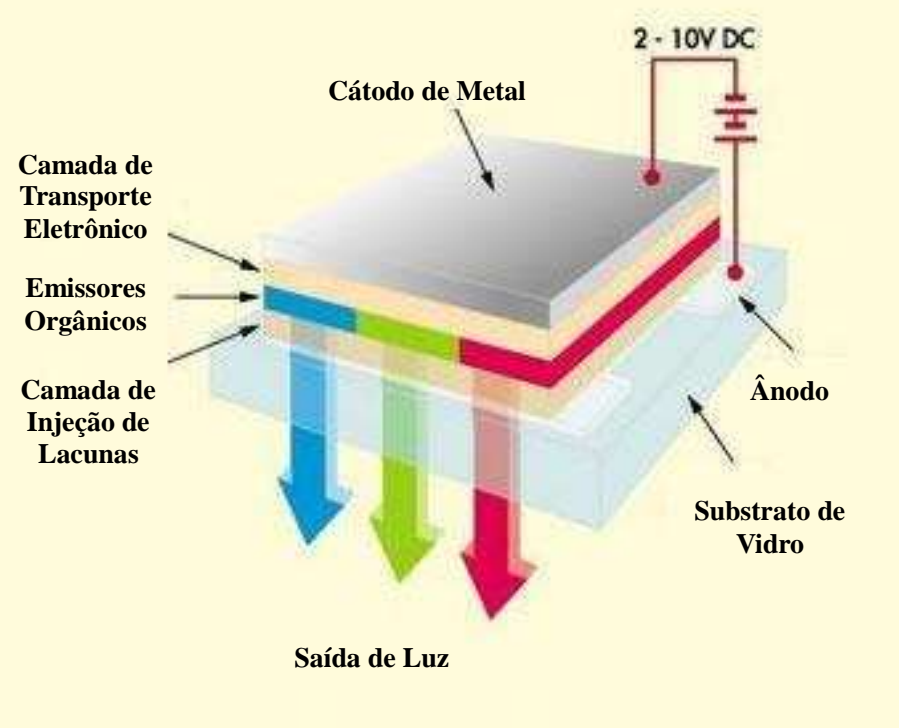

Figura 1.18 - Camadas que compõem o LED orgânico (OLED). [22]

Pesquisadores das universidades de Linköping e Umeå, na Suécia, e da State University of New Jersey, nos Estados Unidos, construíram uma alternativa aos OLEDs, chamada de LEC (Light-emitting Electrochemical Cell), que é um dispositivo emissor de luz orgânico com grafeno [22]. No LED comum, o eletrodo transparente ou substrato de vidro (conforme figura 1.18) é feito com a liga metálica de óxido de estanho-índio, que é um material raro e bastante caro. No LEC, a liga metálica de óxido de estanho-índio é substituída por grafeno, o que é uma grande vantagem na questão de custo, pois o índio é um material raro e caro, além de ser muito difícil sua reciclagem. Outra potencial aplicação do grafeno está na fabricação de aparelhos eletrônicos flexíveis, uma vez que o grafeno pode formar folhas resistentes e capazes de serem deformadas (ou dobradas) sem danos, por conta de seu arranjo atômico planar e em formato hexagonal [23].

Em geral, a pesquisa sugere que os circuitos eletrônicos do futuro possam ser criados a partir de uma única folha de grafeno. Esses circuitos poderiam incluir pontos quânticos, barreiras semitransparentes para controlar o movimento de elétrons individuais, interconexões e portas lógicas, tudo construído de grafeno, ou pelo menos à base de carbono. Isto significaria um novo paradigma para os dispositivos eletrônicos, substituindo a tecnologia do silício por uma tecnologia do carbono. 
Entretanto, as aplicações do grafeno ultrapassam as fronteiras da eletrônica, podendo ser útil também em diversas outras áreas, como por exemplo, no armazenamento de hidrogênio em pilhas de camadas de grafeno de forma segura para utilização em células a combustível, entre outras aplicações. No modelo mostrado na figura 1.19 [24], as folhas de grafeno são empilhadas umas sobre as outras, com moléculas entre elas que funcionam tanto como ligante como espaçadores, formando o chamado GOF (Graphene-Oxide-Framework), uma estrutura de óxido de grafeno capaz de acomodar grandes quantidades de hidrogênio, que foi inspirado nos MOFs (Metal-Oxide-Framework), que são estruturas metal-orgânicas muito pesquisada para armazenamento de hidrogênio e para a captura de $\mathrm{CO}_{2}$ da atmosfera. O GOF pode conter pelo menos cem vezes mais moléculas de hidrogênio do que o óxido de grafeno normal. A capacidade de armazenamento de hidrogênio de um GOF se deve às próprias moléculas de ligação, que nesse caso foram usados ácidos benzeno-borônicos, os quais interagem fortemente com o hidrogênio.

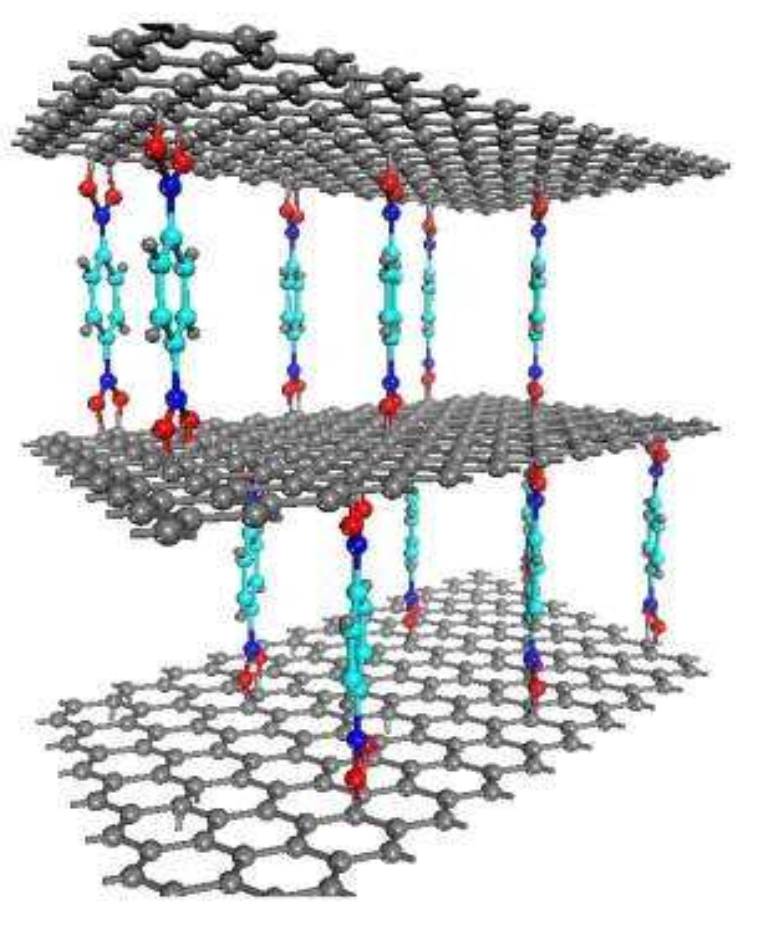

Figura 1.19 - Representação de pilhas de camadas de grafeno para armazenamento de hidrogênio [24]. 


\section{4 - Organização e Descrição do Trabalho}

Este primeiro capítulo apresentou as estruturas alotrópicas do carbono, o histórico da pesquisa sobre materiais derivados do carbono até a descoberta do grafeno como uma estrutura bidimensional estável. Também apresentou alguns dos nanodispositivos desenvolvidos até o momento e a grande possibilidade do grafeno ser o material substituto do silício nas novas tecnologias de dispositivos eletrônicos.

O capítulo 2 apresenta as propriedades eletrônicas e estruturais do grafeno a partir do modelo tight-binding, bem como o transporte eletrônico e o que vem a ser o Efeito Hall Quântico Anômalo. O capítulo 3 apresenta a metodologia utilizada para os cálculos que foram realizados neste trabalho. O capítulo 4 trata do grafeno e suas principais funcionalizações, além de descrever o efeito deste processo na estrutura do grafeno.

O capítulo 5 apresenta os resultados referentes às propriedades eletrônicas e estruturais do grafeno e grafano como nanofolhas constituídas por elementos do grupo IV da tabela periódica (C, SiC, Si, Ge e Sn). O capítulo, então, apresenta uma análise das mudanças nas propriedades do grafeno do grupo IV com a incorporação de átomos de hidrogênio e flúor. O capítulo 6 discute as propriedades eletrônicas de defeitos estruturais em grafeno, tais como a monovacância, divacância, trivacância e Stone-Wales, assim como dopantes (boro e nitrogênio) em diversas configurações usando cálculos quânticos baseados na teoria do funcional densidade (DFT). 


\section{Capítullo 2}

\section{O GRAFENO}

\section{1 - Estrutura Cristalina}

O grafeno, uma forma alotrópica do carbono, é uma folha constituída por átomos de carbono com hibridização do tipo $s p^{2}$ em uma estrutura hexagonal planar bidimensional (2D). Ele pode ser considerado como o bloco fundamental de construção de todos os outros materiais grafíticos (conforme discutido no capítulo 1). Os orbitais híbridos do tipo $s p^{2}$ formam as ligações $\sigma$ no plano da folha de grafeno, enquanto que os orbitais $2 p_{z}$ formam as ligações do tipo $\pi$ que são paralelas ao plano atômico do grafeno gerando sobre a superfície planar do grafeno um "mar" de orbitais $\pi$. 
Os elétrons que compõem a faixa de valência são originados dos orbitais híbridos $s p^{2}$ (ligações tipo $\sigma$ ) e dos orbitais $p_{z}$ (ligações tipo $\pi$ ). As ligações $\sigma$ são do tipo covalente, e portanto, consideravelmente fortes, e são responsáveis em grande parte pelas propriedades mecânicas e elásticas do grafeno. Por outro lado, os elétrons dos orbitais $2 p_{z}$, que correspondem às ligações do tipo $\pi$ estão mais fracamente ligados aos átomos e podem assim se locomover na rede cristalina, ou ainda serem excitados para níveis eletrônicos acessíveis mais energéticos, são os elétrons de maior importância para a determinação das propriedades ópticas e elétricas do grafeno.

A estrutura do grafeno pode ser descrita como uma rede de Bravais triangular bidimensional com uma base de dois átomos por unidade celular (um átomo de carbono no sítio A e outro no sítio B), conforme representação na figura 2.1 (a). Os vetores dos átomos de base, ou vetores de rede $\vec{a}_{1}$ e $\vec{a}_{2}$ podem ser escritos em coordenadas cartesianas como:

$$
\begin{aligned}
& \vec{a}_{1}=\frac{a}{2}(3, \sqrt{3}), \\
& \vec{a}_{2}=\frac{a}{2}(3,-\sqrt{3})
\end{aligned}
$$

onde $a \approx 1.42 \AA$ '́ a distância entre os átomos de carbono vizinhos e $\left|\vec{a}_{1}\right|=\left|\vec{a}_{2}\right|=2.46 \AA$ é o parâmetro de rede da folha do grafeno [25]. Sua respectiva zona de Brillouin é definida, então, pelos vetores da rede recíproca $\vec{b}_{1}$ e $\vec{b}_{2}$ dados por:

$$
\begin{aligned}
& \vec{b}_{1}=\frac{2 \pi}{3 a}(1, \sqrt{3}), \\
& \vec{b}_{2}=\frac{2 \pi}{3 a}(1,-\sqrt{3})
\end{aligned}
$$

Onde $\left|\vec{b}_{1}\right|=\left|\vec{b}_{2}\right|=4 \pi / 3 a$ é o parâmetro de rede da folha do grafeno no espaço recíproco. A primeira zona de Brillouin (BZ), ou zona de Brillouin irredutível, está representada na figura 2.1 (b), e possui diversos pontos especiais importantes, relacionados a certas simetrias intrínsecas do sistema. Os pontos $\mathrm{K}$ e K' nos cantos da zona de Brillouin (BZ) do grafeno são chamados de "pontos de Dirac". Suas posições no espaço dos momentos são dadas por: 


$$
\begin{aligned}
\mathbf{K} & =\left(\frac{2 \pi}{3 a}, \frac{2 \pi}{3 \sqrt{3} a}\right) \\
\mathbf{K}^{\prime} & =\left(\frac{2 \pi}{3 a},-\frac{2 \pi}{3 \sqrt{3} a}\right)
\end{aligned}
$$

Conforme a figura 2.1(a), os três vetores dos vizinhos mais próximos no espaço real são dados por:

$$
\boldsymbol{\delta}_{1}=\frac{a}{2}(1, \sqrt{3}) \quad \boldsymbol{\delta}_{2}=\frac{a}{2}(1,-\sqrt{3}) \quad \boldsymbol{\delta}_{3}=-a(1,0)
$$

A figura 2.1 mostra a estrutura da rede do grafeno, a localização dos vetores da rede do espaço real e recíproco, além dos vetores de primeiros vizinhos e também mostra o espaço recíproco do grafeno com a primeira zona de Brillouin (ZB) destacando os pontos de alta simetria $\Gamma, \mathrm{K}, \mathrm{K}$ ' e $\mathrm{M}$. Os pontos $\mathrm{K}$ e K' representam pontos não equivalentes da $\mathrm{ZB}$, e estão associados a propriedades interessantes do grafeno, que serão discutidas na próxima seção.
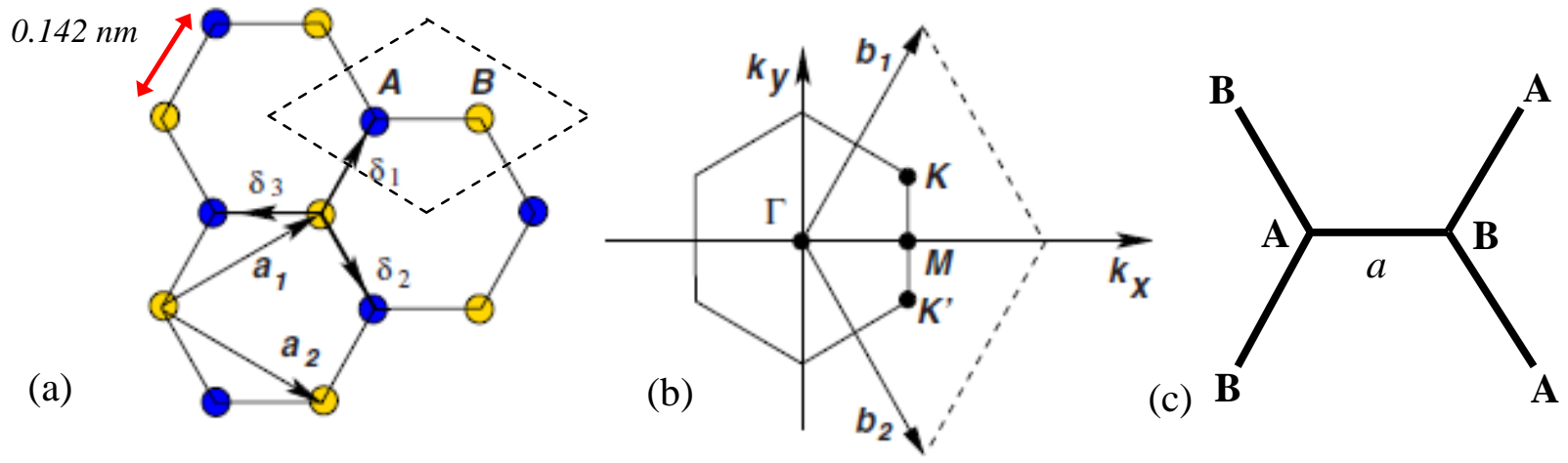

Figura 2.1 - (a) Estrutura de rede do grafeno, constituída de duas redes triangulares interpenetradas ( $\vec{a}_{1}$ e $\vec{a}_{2}$ são os vetores unitários da rede, e $\delta_{i}, i=1,2,3$ são os vetores vizinhos mais próximos); (b) Zona de Brillouin correspondente. Os cones de Dirac estão localizados nos pontos K e K'; (c) Três primeiros vizinhos dos átomos A e B [1]. 
Tabela 2.1 - Coordenadas cartesianas dos pontos especiais $\Gamma$, K e M da primeira zona de Brillouin do grafeno.

\begin{tabular}{|c|c|}
\hline Ponto & Coordenada \\
\hline$\Gamma$ & $(0,0)$ \\
\hline K & $\left(0, \frac{4 \pi}{3 \sqrt{3} a}\right)$ \\
\hline M & $\left(\frac{2 \pi}{3 a}, 0\right)$ \\
\hline
\end{tabular}

\section{2 - Estrutura Eletrônica}

A estrutura eletrônica do grafeno pode ser entendida usando um modelo teórico bastante simplificado, o modelo de Tight-Binding, considerando apenas os elétrons do tipo $\pi$. Desta forma, é possível descrever qualitativamente os estados eletrônicos próximos ao nível de Fermi, o nível ocupado de mais alta energia. O diagrama de bandas para os elétrons $\pi$ é composto pelas bandas de valência e de condução, $\pi$ e $\pi^{*}$, respectivamente. O modelo TightBinding descreve a dinâmica de elétrons livres no grafeno pelo seguinte Hamiltoniano:

$$
\mathrm{H}=-t \sum_{\langle i, j\rangle, \sigma}\left(a_{\sigma, i}^{\dagger}, b_{\sigma, i}+a_{\sigma, i}, b_{\sigma, i}^{\dagger} \cdot\right)-t \sum_{\langle\langle i, j\rangle\rangle, \sigma}\left(a_{\sigma, i}^{\dagger}, a_{\sigma, j}, b_{\sigma, i}^{\dagger}, b_{\sigma, j}+a_{\sigma, i}, a_{\sigma, j}^{\dagger}, b_{\sigma, i}, b_{\sigma, j}^{\dagger}\right),
$$

onde o operador $a_{i \sigma}\left(a_{i \sigma}^{\dagger}\right)$ aniquila (cria) um elétron com spin $\sigma(\sigma=\uparrow, \downarrow)$ na posição $\boldsymbol{R}_{\boldsymbol{i}}$ sobre a sub-rede A (uma definição equivalente é usada para a sub-rede B). A constante $t(\approx 2.8 \mathrm{eV})$ é a energia de hopping de vizinhos próximos, ou primeiros vizinhos (energia de hopping entre diferentes sub-redes), e $t$ ' é a energia de hopping de segundos vizinhos (energia de hopping na mesma sub-rede).

As bandas de energia, derivadas deste hamiltoniano dado na equação (2.8), são representadas pela seguinte relação de dispersão, obtida pelo método de ligações fortes (Tight-Binding) [25]: 


$$
\mathrm{E}_{ \pm}(k)= \pm t \sqrt{3+f(k)}-t^{\prime} f(k)
$$

onde o sinal positivo se aplica à banda superior $\left(\pi^{*}\right)$, ou banda de condução, e o sinal negativo à banda inferior $(\pi)$, ou banda de valência do grafeno. Nesse caso, $f(k)$ é dado por uma soma de exponenciais sobre os vetores da rede do grafeno:

$$
f(k)=2 \cos \left(\sqrt{3} k_{y} a\right)+4 \cos \left(\frac{\sqrt{3}}{2} k_{y} a\right) \cos \left(\frac{3}{2} k_{x} a\right)
$$

Através da equação (2.9) pode-se observar que o espectro de energia eletrônico é simétrico em torno da energia $\mathrm{E}(k)$ zero, se $t^{\prime}=0$. Por outro lado, para valores finitos de $t^{\prime}$, a simetria elétron-lacuna é quebrada e as bandas $\pi$ e $\pi^{*}$ tornam-se assimétricas. A figura 2.2 mostra a estrutura de bandas completa do grafeno para valores finitos de $t$ ' e os pontos de Dirac K e K' na zona de Brillouin (BZ) [25]. É possível observar nesta figura que a relação de dispersão do grafeno na região próxima ao nível de Fermi é linear em relação ao vetor de onda $\vec{k}$, uma característica observada apenas em sistemas relativísticos, que são sistemas que possuem partículas que se movem a uma velocidade relativística, ou seja, uma velocidade comparável à velocidade da luz. Estes sistemas por sua vez, consideram as equações de Dirac em vez da equação de Schrödinger, pois a equação de Dirac descreve com sucesso as partículas elementares de spin $1 / 2$, como o elétron.

Esta relação linear para a dispersão de energia próxima ao ponto de Dirac implica em alta mobilidade eletrônica, mesmo com baixa densidade de portadores com energias próximas ao nível de Fermi.

A figura 2.3 apresenta a estrutura de bandas do grafeno de uma perspectiva diferente, onde se evidencia que as bandas $\pi$ e $\pi^{*}$ (em azul) estão desacopladas das bandas $\sigma$ e $\sigma^{*}$ (em vermelho) por causa da inversão de simetria e estão mais próximas à energia de Fermi porque tem uma participação menor nas ligações. Próximos aos pontos K e K', a energia varia linearmente com a magnitude do momento medido nos cantos da Zona de Brillouin. Os outros quatro pontos especiais da zona de Brillouin se relacionam com os vetores da rede recíproca K e K' e não representam estados eletrônicos distintos. 


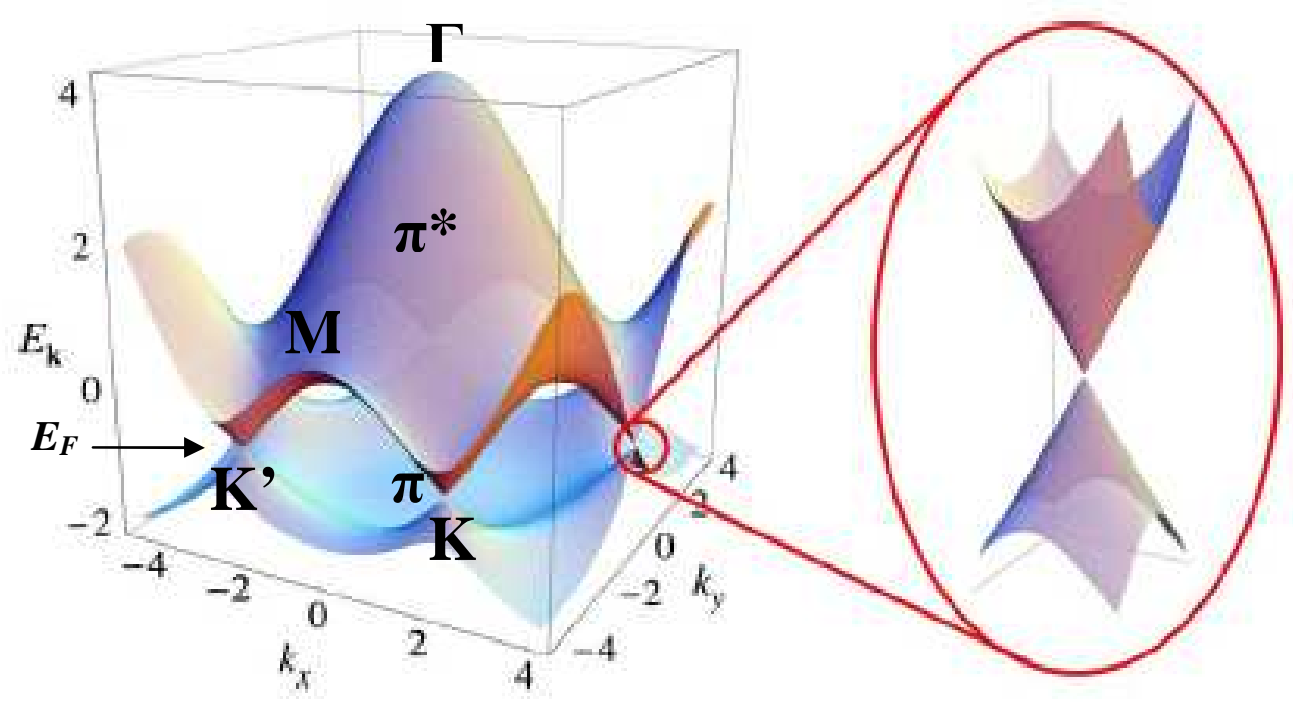

Figura 2.2 - Dispersão eletrônica na rede hexagonal favo de mel (honeycomb). Espectro de energia (em unidades de t) para valores finitos de $t$ e $t^{\prime}$, com $t=2.7 \mathrm{eV}$ e $t^{\prime}=-0.2 \mathrm{t}$ e Imagem ampliada das bandas de energia para os pontos de Dirac (K e K') ( retirado da Ref. [1]).

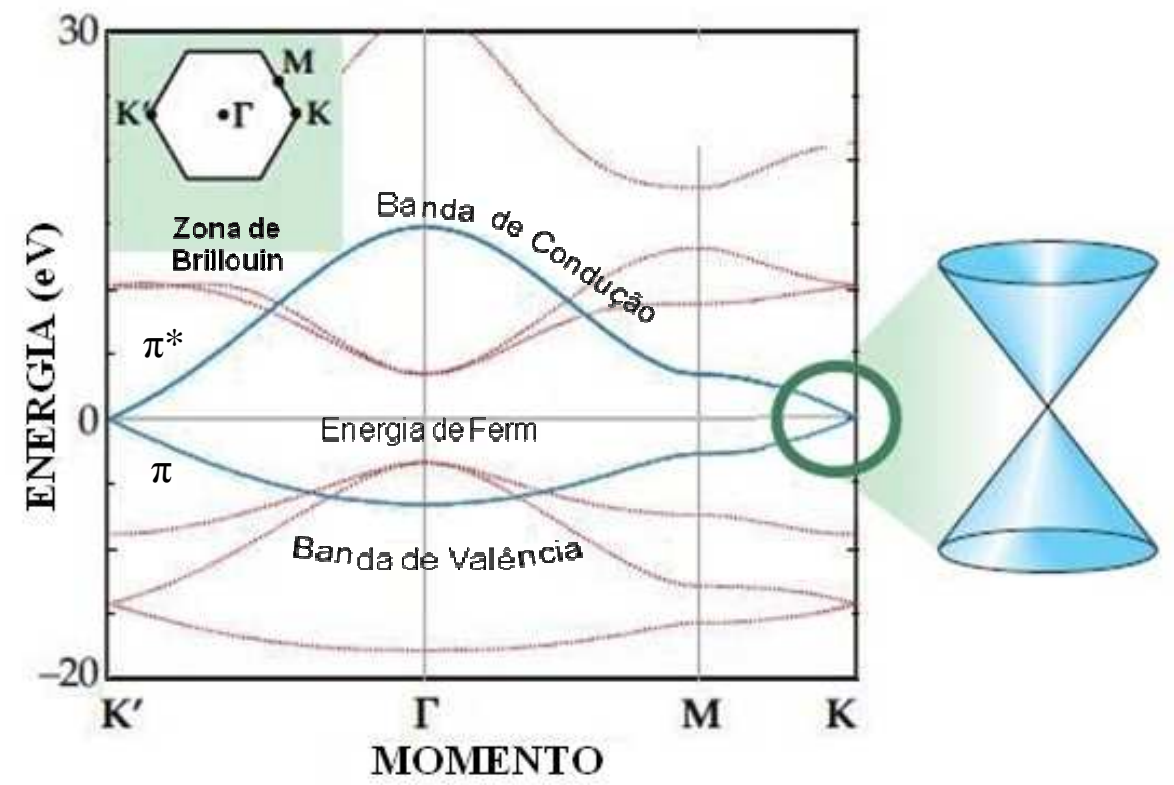

Figura 2.3 - Estrutura de Bandas do grafeno [7].

Uma vez que existem dois elétrons $\pi$ por célula unitária (um elétron $\pi$ do átomo da sub-rede A e outro do átomo da sub-rede $\mathrm{B}$, que são os átomos que compõem a célula unitária), eles ocupam completamente a banda de valência, deixando a banda de condução 
vazia. Cálculos de densidade de estados mostraram que a densidade de estados é nula no nível de Fermi $\left(\mathrm{E}=\mathrm{E}_{\mathrm{F}}\right)$, conforme mostrado na figura 2.4 [25]. Desta forma, o grafeno pode ser classificado como um semicondutor de gap nulo nos vértices da zona de Brillouin (pontos K e K'). Esta informação pode ser comprovada ao analisar as figuras 2.2 e 2.3, onde é possível observar que as bandas de valência e de condução se tocam exatamente nos pontos de Dirac (ou pontos de alta simetria K e K’), que é onde se localiza o nível de Fermi, o qual faz separação entre os estados ocupados e vazios.
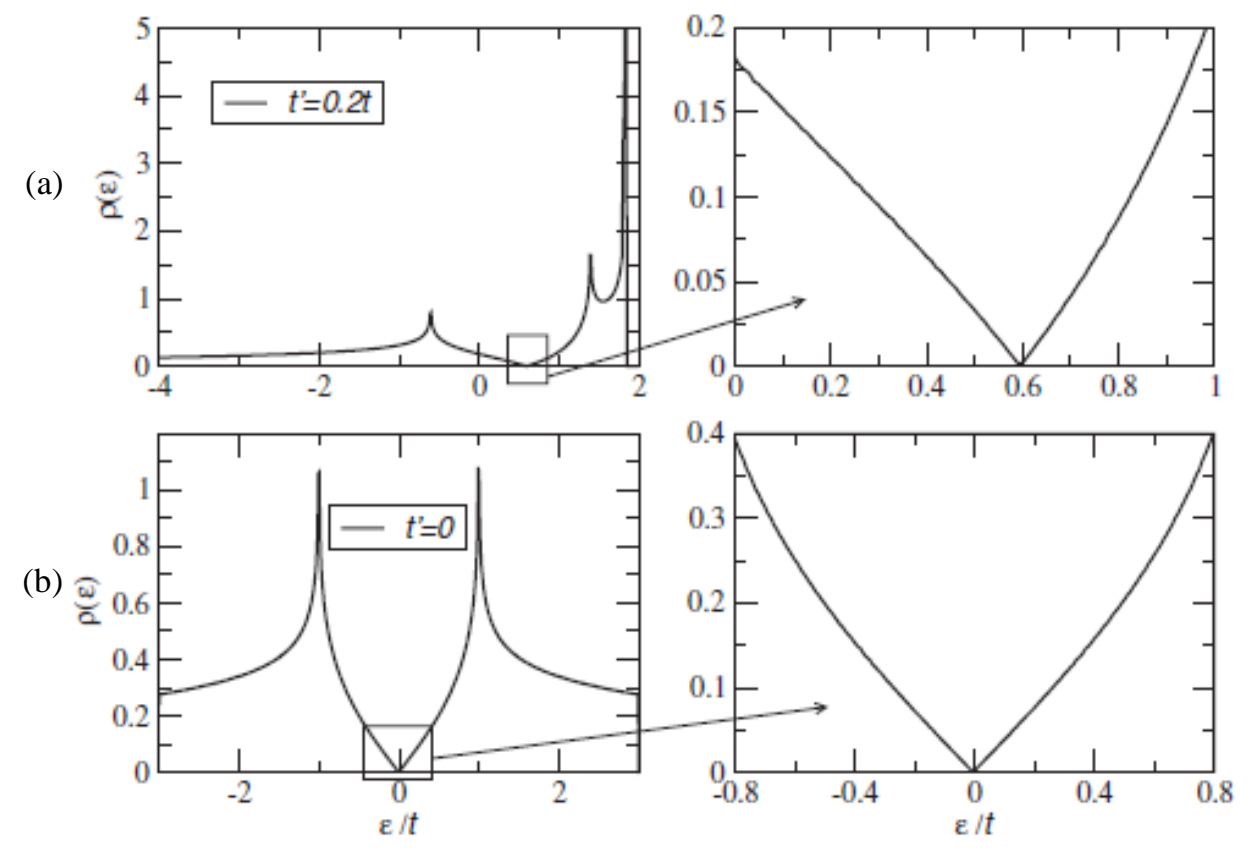

Figura 2.4 - Densidade de estados por unidade celular como função da energia (em unidades de t) calculada a partir da energia de dispersão, (a) t' $=0.2 \mathrm{t}$ e (b) t' $=0$. (retirado da Ref. [1]).

Muito cedo foi percebido que a relação entre E-k é linear para baixas energias próximo aos seis cantos da zona de Brillouin hexagonal bidimensional (2D), e que a estrutura eletrônica do grafeno apresenta gap nulo nos pontos de alta simetria, levando a uma massa efetiva nula para elétrons e lacunas. Desta forma, os elétrons podem se mover a altíssimas velocidades e perder pouca energia no nível de Fermi, ou seja, os elétrons movem-se como se fossem partículas praticamente sem massa, equivalentes a fótons, podendo ser assim descritos pela equação relativística de Dirac para partículas com spin 1/2. Então, elétrons e lacunas são chamados de "Férmions de Dirac", e os seis cantos da zona de Brillouin são chamados de "pontos de Dirac" [26, 27]. Experimentos de Efeito Hall quântico, apresentados na literatura em 2005, confirmaram essas propriedades [9, 28]. 
O grafeno promete ser um sistema com propriedades eletrônicas mais controláveis que os nanotubos de carbono, e muitos projetam que uma eletrônica baseada no carbono poderá ser implementada usando o grafeno.

\section{3 - Bicamadas de Grafeno}

O modelo Tight-Binding desenvolvido para a grafite pode ser extendido para pilhas com um número finito de camadas de grafeno. A generalização mais simples é uma bicamada de grafeno, que é interessante por apresentar anomalias no Efeito Hall Quântico Inteiro (IQHE - Integer Quantum Hall Effect), embora sejam diferentes daquelas observadas em uma monocamada de grafeno. E também pode abrir um gap entre a camada de condução e de valência.

É importante saber que da mesma forma como na monocamada, a bicamada de grafeno consiste de um material puramente bidimensional (2D), onde os portadores de carga são quirais [29]. Ela pode ser construída através da repetição periódica de sua célula unitária, que é composta por quatro átomos, $\mathrm{A}_{1}, \mathrm{~A}_{2}, \mathrm{~B}_{1}$ e $\mathrm{B}_{2}$. As dimensões e formas dos vetores primários e da célula unitária são iguais à da monocamada de grafeno, sendo assim, a representação da bicamada é feita no espaço recíproco como no grafeno, sendo a sua zona de Brillouin hexagonal com vértices $\mathrm{K}$ e K' equivalentes.

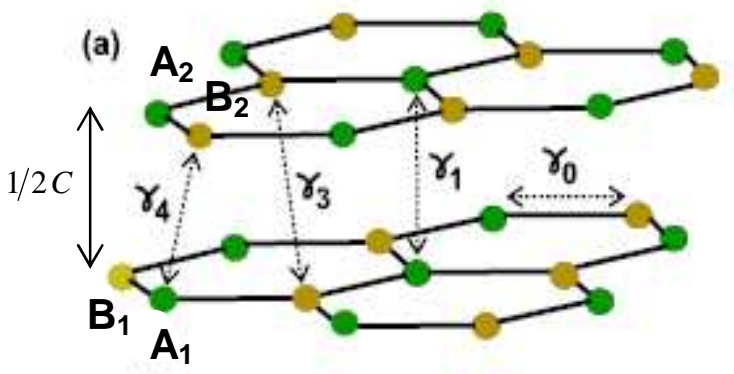

(b)

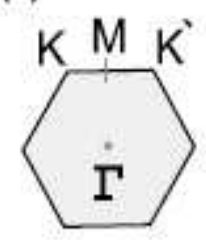

Figura 2.5 - (a) Estrutura de rede de uma bicamada de grafeno com os vários parâmetros de hopping de acordo com o modelo SWM (modelo padrão de Slonczewski-Weiss-McClure);

(b) Sua respectiva zona de Brillouin. (retirado da Ref. [1]).

A estrutura da figura 2.5 consiste em duas camadas de grafeno empilhadas, de forma que, o sítio $A_{1}$ da camada inferior se localiza exatamente abaixo do sítio $B_{2}$ da camada superior, a uma distância de $1 / 2 C=0.34 \mathrm{~nm}$ entre os planos [30]. Esta forma é conhecida 
como empilhamento $\mathrm{AB}$ e não é a única existente para as bicamadas de grafeno e para a grafite, entretanto é a forma mais comum encontrada na natureza [31].

O Hamiltoniano Tight-binding é construído considerando as interações entre diferentes tipos de átomos desta estrutura, de forma que:

$$
\begin{aligned}
\mathrm{H}_{t . b .}= & -\gamma_{0} \sum_{\langle i, j\rangle}\left(a_{m, i, \sigma}^{\dagger} b_{m, j, \sigma}+a_{m, i \sigma} b_{m, j, \sigma}^{\dagger} .\right) \\
& -\gamma_{1} \sum_{j, \sigma}\left(a_{1, j, \sigma}^{\dagger} a_{2, j, \sigma}+a_{1, i, \sigma} a_{2, j, \sigma}^{\dagger} \cdot\right), \\
& -\gamma_{4} \sum_{j, \sigma}\left(a_{1, j, \sigma}^{\dagger} b_{2, j, \sigma}+a_{2, j, \sigma}^{\dagger} b_{1, j, \sigma}+a_{1, j, \sigma} b_{2, j, \sigma}^{\dagger}+a_{2, j, \sigma} b_{1, j, \sigma}^{\dagger}\right) \\
& -\gamma_{3} \sum_{j, \sigma}\left(b_{1, j, \sigma}^{\dagger} b_{2, j, \sigma}+b_{1, i, \sigma} b_{2, j, \sigma}^{\dagger}\right),
\end{aligned}
$$

onde,

- $\gamma_{0}$ é a energia de hopping entre os átomos em uma mesma camada, ou seja, $\mathrm{A}_{1}$ e $\mathrm{B}_{1}$ ou $\mathrm{A}_{2} \mathrm{e}$ $\mathrm{B}_{2}$;

- $\gamma_{1}=t_{\perp} \approx 0.4 \mathrm{eV}$ (na grafite) é a energia de hopping entre os átomos $\mathrm{A}_{1} \mathrm{e} \mathrm{A}_{2}$;

- $\gamma_{4}=\left[\gamma_{4} \approx 0.04 \mathrm{eV}\right]$ (na grafite) é a energia de hopping entre os átomos $\mathrm{A}_{1} \mathrm{e} \mathrm{B}_{2} \mathrm{e}$ os átomos $\mathrm{A}_{2}$ e $\mathrm{B}_{1}$. E por último,

- $\gamma_{3}=\left[\gamma_{3} \approx 0.3 e V\right]$ é a energia de hopping que conecta os átomos $\mathrm{B}_{1} \mathrm{e} \mathrm{B}_{2}$.

As interações entre os demais vizinhos são muito fracas sendo, portanto, desconsideradas. No limite contínuo, expandindo o momento próximo ao ponto de $\mathrm{K}$ na zona de Brillouin, o Hamiltoniano é dado por:

$$
\mathrm{H}=\sum_{k} \Psi_{k}^{\dagger} \cdot H_{k} \cdot \Psi_{k}
$$

Onde $H_{k}$ é dado por (ignorando $\gamma_{4}$ por enquanto):

$$
H_{k} \equiv\left(\begin{array}{cccc}
-V & v_{F} k & 0 & 3 \gamma_{3} a k^{*} \\
v_{F} k^{*} & -V & \gamma_{1} & 0 \\
0 & \gamma_{1} & V & v_{F} k \\
3 \gamma_{3} a k & 0 & v_{F} k^{*} & V
\end{array}\right)
$$


Sendo $k=k_{x}+i k_{y}$ um número complexo. $V$ representa a metade do deslocamento do potencial eletroquímico entre as duas camadas (este termo aparece se uma polarização é aplicada entre as camadas), e $\Psi_{k}^{\dagger}$ é um spinor de quatro componentes dado por:

$$
\Psi_{k}^{\dagger}=\left(b_{1}^{\dagger}(k), a_{1}^{\dagger}(k), a_{2}^{\dagger}(k), b_{2}^{\dagger}(k)\right)
$$

Considerando $V=0$ e $\gamma_{3}, v_{F} k\left\langle\left\langle\gamma_{1}\right.\right.$, os estados de alta energia podem ser eliminados perturbativamente, ou seja, eliminados por aproximação. Desta forma, o Hamiltoniano efetivo pode ser escrito como:

$$
H_{k} \equiv\left(\begin{array}{cc}
0 & \frac{v_{F}^{2} k^{2}}{\gamma_{1}}+3 \gamma_{3} a k * \\
\frac{v_{F}^{2}(k *)^{2}}{\gamma_{1}}+3 \gamma_{3} a k & 0
\end{array}\right)
$$

A energia de hopping $\gamma_{4}$ leva a um acoplamento entre as sub-redes dependentes de $k$ ou a uma pequena renormalização de $\gamma_{1}$. A mesma regra é aplicada pela inequivalência entre sub-redes dentro de uma camada.

Para $\gamma_{3}=0$, a equação 2.15 resulta em duas bandas parabólicas, conforme mostrado na figura 2.6:

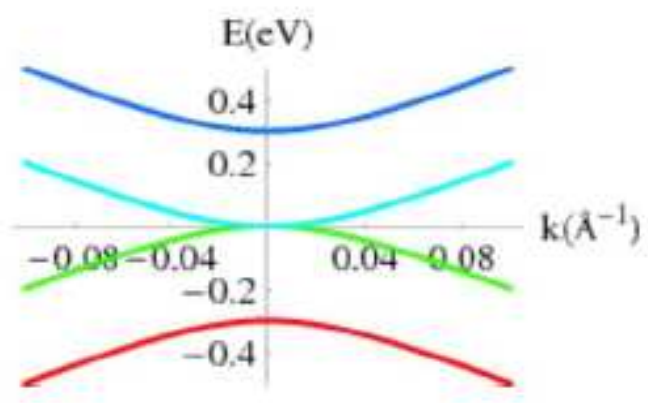

Figura 2.6 - Estrutura de bandas de uma bicamada de grafeno para $V=0$ e $\gamma_{3}=0$ (retirado da Ref. [1]).

A figura 2.6 mostra que $\varepsilon_{k, \pm} \approx \pm v_{F}^{2} k^{2} / t_{\perp}$, que toca em $\varepsilon=0$. Desta forma, o espectro elétron-lacuna é simétrico. Dentro desta aproximação, a bicamada apresenta comportamento metálico, com uma densidade de estados constante. 
O termo $V$ dado na equação 2.13 , quebra a equivalência das duas camadas, ou, a simetria de inversão. Neste caso, pode-se obter a seguinte relação de dispersão:

$$
\varepsilon_{ \pm, k}^{2}=V^{2}+v_{F}^{2} k^{2}+t_{\perp}^{2} / 2 \pm \sqrt{4 V^{2} v_{F}^{2} k^{2}+t^{2} v_{F}^{2} k^{2} t_{\perp}^{4} / 4}
$$

Resultando na dispersão mostrada na figura 2.7, e a abertura de um gap na região próxima ao ponto K. A bicamada apresenta um gap em $k^{2} \approx 2 V^{2} / v_{F}^{2}$. O gap no sistema de bicamadas polarizadas depende do valor da polarização aplicada, podendo ser medido experimentalmente [25]. A possibilidade de se controlar a abertura ou criação de um gap torna o grafeno interessante para aplicações tecnológicas.

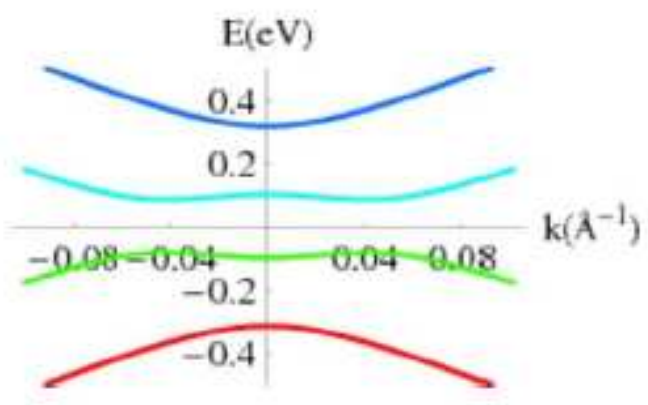

Figura 2.7 - Estrutura de Bandas de uma Bicamada de Grafeno para $V \neq 0$ e $\gamma_{3}=0$ (retirado da Ref. [1]).

Finalmente, a figura 2.8 mostra um gráfico de superfície da relação de dispersão para uma bicamada de grafeno, gerada a partir da equação 2.13 [25]. Ela apresenta duas bandas de condução e duas bandas de valência, sendo que a banda de condução de menor energia toca a banda de valência de maior energia, nos seis pontos $\mathrm{K}$ e $\mathrm{K}^{\prime}$ da primeira zona de Brillouin. Desta forma, pode-se dizer que uma bicamada de grafeno também é um semicondutor de gap nulo. Entretanto, o fundo dessas bandas não podem mais ser aproximadas por uma relação de dispersão linear, como no caso do grafeno, ou seja, os portadores de carga na bicamada não podem ser mais considerados como férmions de Dirac relativísticos e a massa desses portadores tem um valor finito, diferente de zero [29]. 


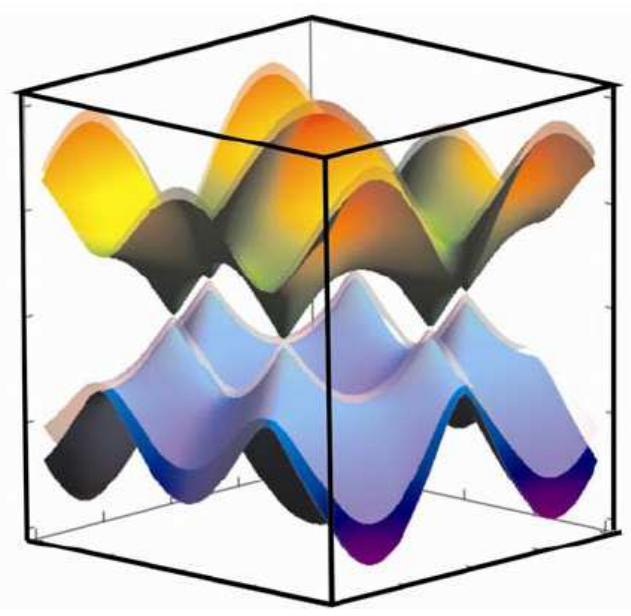

Figura 2.8 - Estrutura de bandas de uma bicamada de grafeno. (retirado da Ref. [7]).

\section{4 - Propriedades de Transporte Eletrônico no Grafeno}

O trabalho considerado como um marco inicial do crescente desenvolvimento da pesquisa sobre o grafeno foi a publicação de Novoselov et al sobre medidas de transporte e magnetotransporte realizadas em dispositivos construídos com base em filmes ultrafinos de grafite [32]. Apesar de não apresentarem resultados referentes aos dispositivos de monocamada e bicamada de grafeno, eles concluíram que dispositivos feitos a partir de materiais com poucas camadas de grafeno seriam semimetais, ôhmicos, e suportariam densidades de corrente elétrica de até $1 \mathrm{~mA} / \mu \mathrm{m}$.

No mesmo trabalho, medidas da condutividade em função da tensão da porta $V_{g}$, indicaram que esses materiais apresentam o mínimo de condutividade nos pontos de Dirac, ou ponto de neutralidade (NP), e com base em medidas de efeito Hall no regime clássico, concluíram que a densidade de portadores de carga e o tipo de portador que constitui esse gás (elétrons ou lacunas) sofrem variação em torno do NP. Através de medidas de efeito Hall quântico (EHQ) e de oscilações de Shubnikov-de Haas (OSdH), eles concluíram que esses materiais apresentam um gás de portadores de carga bidimensional, com a mobilidade variando de $\mu=3000 \mathrm{~cm}^{2} V^{-1} s^{1}$ a $\mu=10000 \mathrm{~cm}^{2} V^{-1} s^{1}$ dependendo do dispositivo, não sofrendo entretanto, variações significativas com a temperatura $T$, o que significa que o mecanismo de espalhamento dominante é o de espalhamento de defeitos (defect scattering) [33].

Posteriormente, o mesmo grupo desenvolveu um método de clivagem micromecânica 
[34], o que possibilitou a produção de amostras de monocamadas e bicamadas de grafeno grandes o suficiente para que pudessem ser construídos dispositivos do tipo ponte Hall com esses materiais. A partir dos resultados da caracterização em dispositivos com uma camada e bicamada de grafeno, esses pesquisadores concluíram que ambos os materiais são semimetais, ou seja, semicondutores de gap nulo nos pontos $\mathrm{K}$, constituídos por um gás de férmions quirais, quadruplamente degenerado (duplo vale e duplo spin). Essas características resultam em anomalias no efeito Hall quântico, que será explicado mais detalhadamente na seção 2.4.1.

Em outros trabalhos, foi certificado que o espalhamento por fônons acústicos nos limites intrínsecos do grafeno à temperatura ambiente tem mobilidade de $200.000 \mathrm{~cm}^{2} \mathrm{~V}^{-1} \mathrm{~s}^{-1}$ para uma densidade de portadores de $10^{12} \mathrm{~cm}^{-2}$, e a resistividade correspondente é de $10^{-6}$ $\Omega \cdot \mathrm{cm}$, menor que a resistividade da prata, o material com mais baixa resistividade conhecido à temperatura ambiente [35]. Entretanto, quando o grafeno é colocado sobre substratos de $\mathrm{SiO}_{2}$, o espalhamento de elétrons por fônons ópticos do substrato apresenta um efeito maior em temperatura ambiente que o espalhamento de fônons do próprio grafeno, e limita a mobilidade a $40.000 \mathrm{~cm}^{2} \mathrm{~V}^{-1} \mathrm{~s}^{-1}[35]$.

Entre outros fatores que exercem influencia sobre a mobilidade dos portadores no grafeno estão os dopantes químicos [36]. Chen et al. doparam o grafeno com potássio em ultra alto vácuo a baixa temperatura. Eles descobriram que íons de potássio podem reduzir a mobilidade de portadores no grafeno em vinte vezes [37], sendo esta redução da mobilidade reversível ao aquecer o grafeno para remover o potássio.

Por outro lado, as ondulações presentes na folha de grafeno ou impurezas ionizadas no substrato de $\mathrm{SiO}_{2}$ podem gerar poços locais (intervalleys) de portadores que permitem a condução, alterando a mobilidade no grafeno [37]. Apesar da densidade de portadores ser zero próximo aos pontos de Dirac, a maioria das medidas de condutividade são da ordem de $4 e^{2} / h$ ou maiores e dependem da concentração de impurezas [37]. Esse valor de condutividade mínima, bem como a mobilidade do grafeno, praticamente não sofre variação em função da temperatura.

Eliminando os espalhadores extrínsecos, o transporte em dispositivos de monocamada e bicamada de grafeno é balístico à temperatura ambiente e o livre caminho médio dos portadores de carga pode chegar a alguns micrometros, valores que excedem os valores de mobilidade intrínseca conhecidos de outros materiais. 
A resistividade do grafeno pode ser obtida experimentalmente em dispostivos fabricados na configuração de ponte Hall e em dispositivos do tipo van der Pauw [38]. O primeiro dispositivo consiste de amostras de grafeno depositadas sobre um substrato de $\mathrm{Si} / \mathrm{SiO}_{2}$ por clivagem micromecânica. A camada de óxido $\left(\mathrm{SiO}_{2}\right)$ do substrato isola a camada de silício ( $\mathrm{Si}$ ) dopado abaixo dela, possibilitando a aplicação de uma tensão de porta entre o silício e o grafeno, o que permitirá controlar a densidade de portadores de carga do dispositivo. As medidas de resistividade longitudinal $\left(\rho_{x x}\right)$ e transversal $\left(\rho_{x y}\right)$ são feitas simultaneamente, enquanto uma corrente $I$, passa através de outros dois terminais, o que evita os efeitos de resistência de contato e dos cabos.
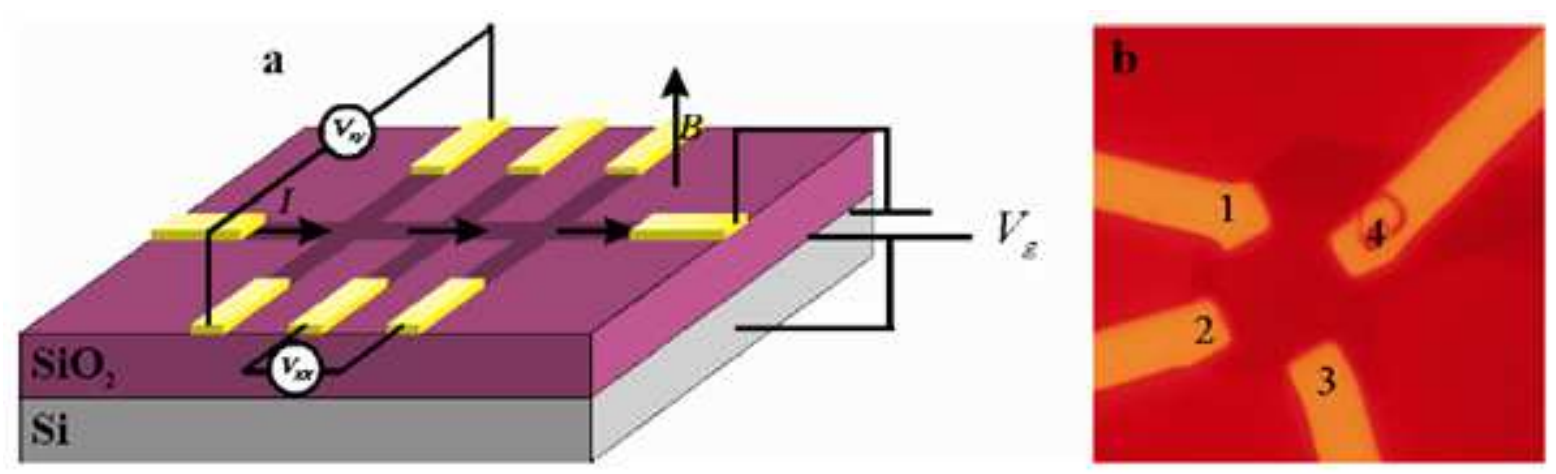

Figura 2.9 -. (a) Ilustração de um dispositivo de efeito de campo no formato de ponte Hall; (b) Imagem de um dispositivo do tipo van der Pauw, sobre um floco de uma bicamada de grafeno (retirado da Ref. [38]).

Por outro lado, o dispositivo tipo van der Pauw é composto por apenas quatro contatos dispostos sobre a amostra. Neste caso, as medidas de resistência longitudinal $\left(R_{x x}\right)$ são feitas aplicando a corrente através de contatos em lados opostos aos lados onde estão localizados os contatos de medidas de tensão. Na figura 2.9 (b), a corrente $I$ é aplicada através dos contatos 1 e 2 , e a tensão é medida pelos contatos 3 e 4 . E a resistência transversal $\left(R_{x y}\right)$ é obtida aplicando a corrente $I$ através dos contatos 1 e 3, e medindo a tensão através dos contatos 2 e 4. 


\subsection{1 - Efeito Hall Quântico Anômalo (EHQA)}

O efeito Hall Quântico é relevante para precisas normas de medição de quantidades elétricas, e em 1985 Klaus Von Klitzing recebeu o prêmio Nobel de física por esta descoberta [39]. O conceito referencia a dependência de uma condutividade transversa a um campo magnético, que é perpendicular a uma faixa de corrente. Geralmente o fenômeno, a quantização da condutividade Hall chamado $\sigma_{x y}$ em múltiplos inteiros da quantidade básica de $e^{2} / h$ (onde $e$ é a carga elétrica elementar e $h$ a constante de Planck), pode ser observado apenas em sólidos como Si ou GaAs com alto nível de limpeza, a temperaturas muito baixas (menores que $3 \mathrm{~K}$ ), e em campos magnéticos muito elevados.

Em contrapartida, o grafeno, além de sua alta mobilidade e condutividade mínima, e devido a certas peculiaridades pseudo-relativisticas, exibe um comportamento particularmente interessante com relação à quantização da condutividade na presença de um campo magnético: ele apresenta um efeito Hall quântico anômalo com a sequiência de passos desviados por $1 / 2$ em relação à seqüência padrão, e com um fator adicional de 4 . Sendo assim, no grafeno, a condutividade Hall é dada por:

$$
\sigma_{x y}=4 .(N+1 / 2) e^{2} / h
$$

Onde, $N$ é o índice do "nível de Landau" inteiro mencionado acima e o duplo vale e dupla degenerescência de spin dão o fator de 4 [4]. Sobretudo, no grafeno, estas notáveis anomalias podem ser medidas em temperatura ambiente [6]. Este comportamento anômalo é um resultado direto de elétrons de Dirac sem massa emergentes no grafeno, ou seja, devido à quiralidade dos elétrons e lacunas no grafeno [6].

Para analisar o efeito Hall no regime quântico, o grafeno deve ser submetido a intensos campos magnéticos enquanto as resistividades longitudinais e transversais são monitoradas de maneira que o espectro de energia dos portadores de carga se abre em níveis de Landau, espaçados por $\hbar \omega_{c}$, onde $\omega_{c}=q_{0} B / m_{c}$, sendo $m_{c}$ a massa de cíclotron. Em um gás bidimensional de portadores de carga, esses níveis de Landau originam o efeito Hall quântico $(\mathrm{EQH})$, que aparece na forma de platôs nas curvas de $\rho_{x y}(B)$ ou $\rho_{x y}\left(V_{g}\right)$, e às 
oscilações Shubnikov-de Haas (OSdH) que aparecem nas curvas de $\rho_{x x}(B)$ ou $\rho_{x x}\left(V_{g}\right)$, onde $\rho_{x x}$ e $\rho_{x y}$ é a resistividade longitudinal e transversal, respectivamente, medidas a $B \neq 0$ [39].

A figura 2.10 (a), publicada em [6], mostra as oscilações OSdH em amostras de monocamada de grafeno (MCG), obtidas através de medidas de $\rho_{x x}$ para diferentes valores de campo magnético $B$, com $n$ constante. Essas oscilações são periódicas em $1 / B$, e para encontrar o período delas, os valores correspondentes de $1 / B$ são plotados a cada mínimo em função de um índice $N$, inteiro. O valor da freqüência fundamental $\operatorname{OSdH}\left(B_{F}\right)$ é determinado a partir da regressão linear do gráfico da figura 2.10(b). Essa linearidade indica o caráter estritamente bidimensional do gás dos portadores de carga de uma monocamada de grafeno.

Na figura 2.10(c), é mostrado o gráfico da dependência resultante de $B_{F}$ sobre $n$ [6]. Ambos os portadores (elétrons e lacunas) exibem a mesma dependência linear, indicando que as bandas de valência e de condução são simétricas em torno do ponto de neutralidade (NP), ou seja:

$$
B_{F}=\beta n,
$$

Com $\beta \approx 1.04 \times 10^{-15} \mathrm{Tm}^{2}$. Teoricamente $\beta$ é definido apenas pela sua degenerescência $g$. De modo que $B_{F}$ é dado por:

$$
B_{F}=\frac{\Phi_{0} n}{g}
$$

Onde $\Phi_{0}$ é o quantum do fluxo magnético, dado por:

$$
\Phi_{0}=\frac{h}{q_{0}}=4,14 \times 10^{-15} \mathrm{Tm}^{2}
$$

Sendo assim, pode-se concluir que a degenerescência de uma monocamada de grafeno é $g=4$, o que pode ser atribuído às duplas degenerescências de spin e de vale nesse material $[6]$. 
(a)

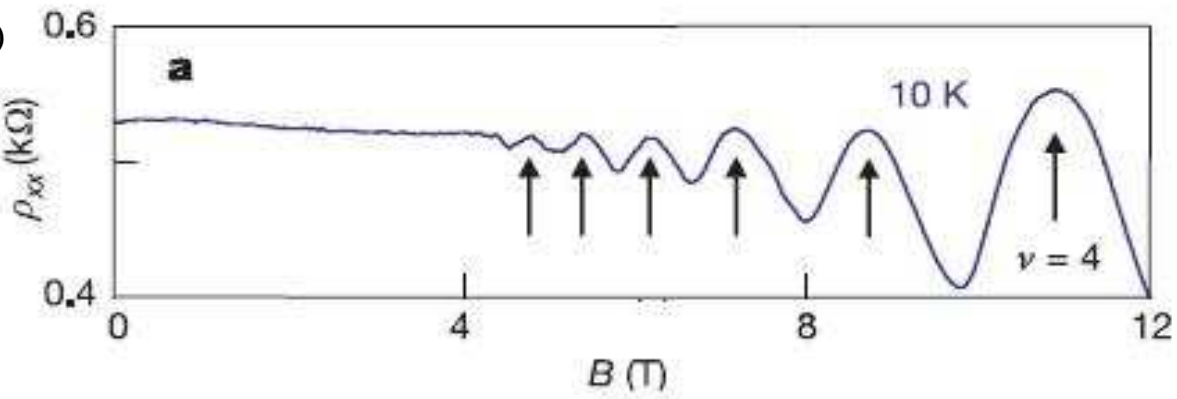

(b)

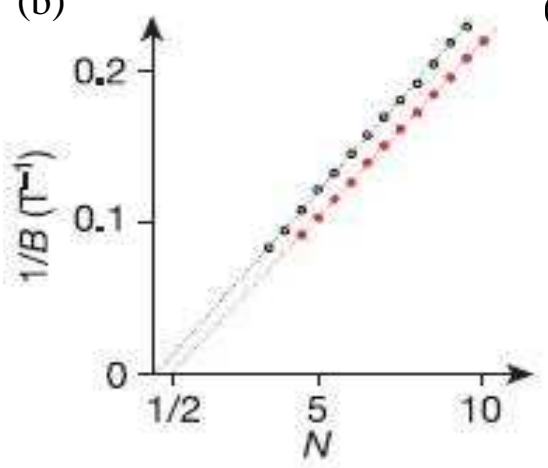

(c)

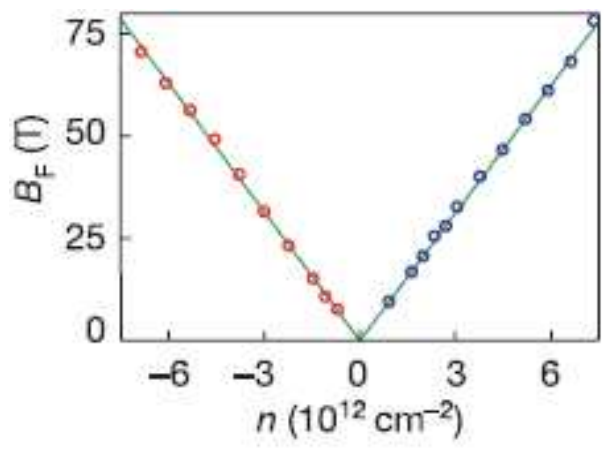

Figura 2.10 - (a) Oscilações Shubnikov-de Haas, onde $\rho_{x x}$ está em função de $B$, para $V_{g}=60$ e $T=10 K$; (b) Análise da periodicidade para uma monocamada de grafeno (vermelho) e para um filme ultrafino de grafite; (c) $B_{F}$ em função de $n$, para elétrons (azul) e lacunas (vermelho). Regressão linear (verde) (retirado da Ref. [6]).

A figura 2.11 mostra uma anomalia na periodicidade das oscilações OSdH. Ao contrário do que é observado em gases bidimensionais de portadores de carga tradicionais, as oscilações da $\mathrm{OSdH}$ do grafeno exibem uma fase de 1/2. A mesma diferença de periodicidade é mostrada no gráfico da figura 2.10(b), o qual compara a periodicidade de uma monocamada de grafeno com a de um filme ultrafino de grafite, cujo $B_{F}$ é semelhante. Podemos ver que para $1 / B=0, N$ também é zero para a grafite, enquanto que para o grafeno temos $N=1 / 2$, enfatizando o aparecimento dessa fase [6].

Ao contrário dos metais normais, a resistência longitudinal do grafeno apresenta máximos, em vez de valores mínimos para valores integrais do fator de preenchimento de Landau em medidas de oscilações Shubnikov-de Haas, o qual apresenta um deslocamento de fase de $\pi$, conhecidos como fase de Berry [37,6]. A fase de Berry surge devido à massa de portadores efetiva zero próximo aos pontos de Dirac [5]. 
A figura 2.11 mostra o efeito da anomalia nas medidas de condutividade Hall $\sigma_{x y}$, que tem a forma de platôs.

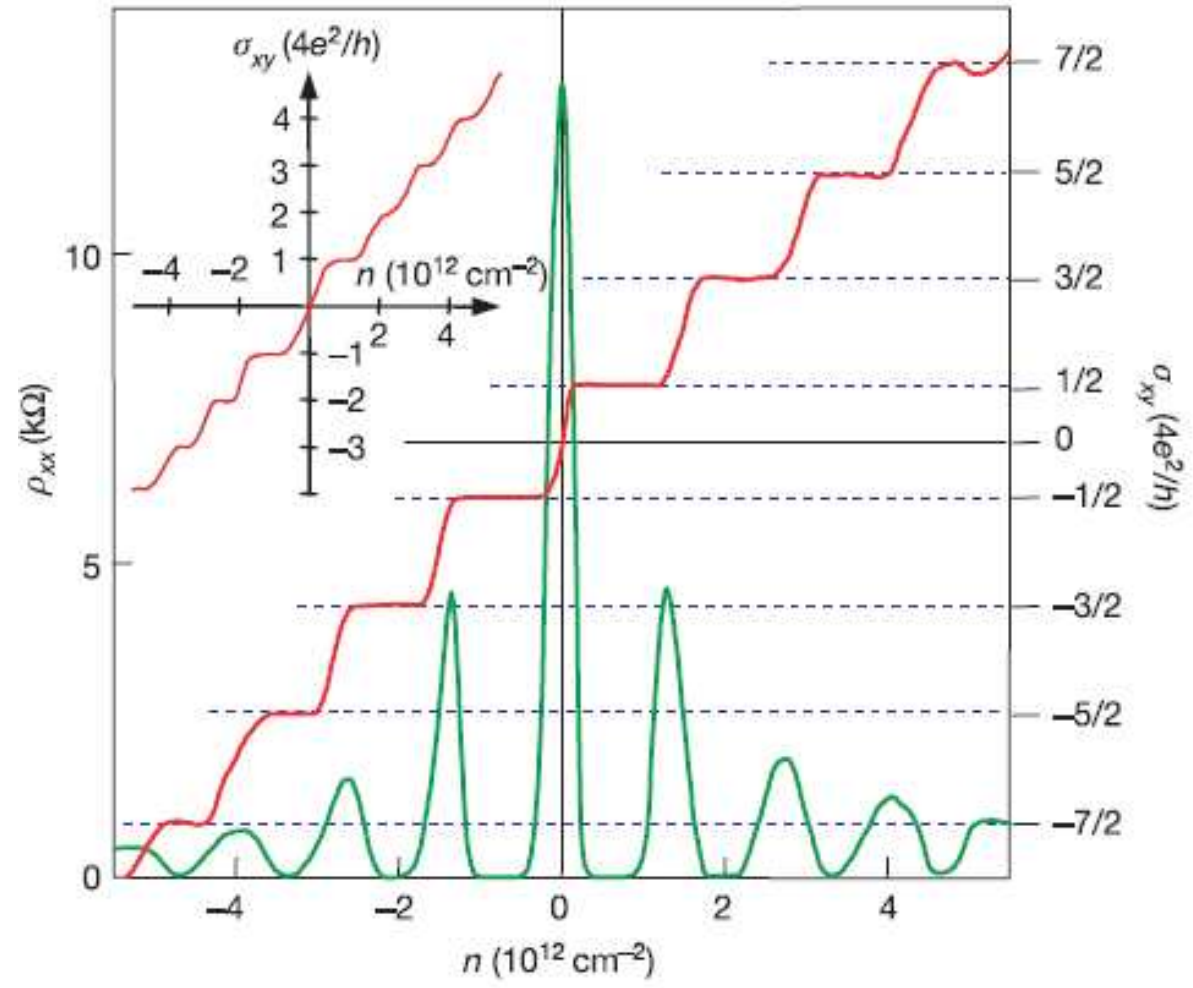

Figura 2.11 - Medidas de oscilações OSdH (verde) e efeito Hall quântico (vermelho) em função da densidade de portadores de carga $\left(n=\alpha V_{g}\right)$, obtidas a $4 K$ e $14 T$ para uma amostra de grafeno (retirado da Ref. [6]).

Os valores da condutividade Hall nesses platôs são dados por:

$$
\sigma_{x y}=\frac{v g q_{0}^{2}}{h}
$$

Em um gás de Férmions convencional o fator de preenchimento $v$ apresenta valores inteiros [6]. Entretanto, para o grafeno, $v$ apresenta valores semi-inteiros, além de apresentarem um nível de Landau com energia nula. As anomalias no efeito Hall quântico, mostradas nas figuras 2.10 e 2.11, podem ser explicadas por efeitos de quiralidade no gás de elétrons do grafeno. 
Com o objetivo de compreender melhor as propriedades físicas do grafeno e explorar a sua possibilidade de aplicação na nanoeletrônica, dentro das variadas linhas de investigação possíveis, neste trabalho será desenvolvido um estudo teórico sobre o grafeno puro e com defeitos estruturais (vacâncias, divacâncias, Stone-Wales, etc.), além de dopantes como nitrogênio e boro em diferentes configurações. Também serão investigadas as estruturas do grafeno e grafano compostos por elementos do grupo IV da tabela periódica ( $\mathrm{Si}, \mathrm{Ge}, \mathrm{Sn}$ e $\mathrm{SiC})$ através de métodos ab initio que serão descritos no próximo capítulo. 


\section{Capítulo 3}

\section{METODOLOGIA}

\section{1 - Introdução}

O desenvolvimento da teoria da mecânica quântica, que ocorreu na primeira metade do século XX, permitiu entender e descrever a fenomenologia de sistemas microscópicos com dimensões de escala atômica, como por exemplo, a estrutura eletrônica de átomos e moléculas. Posteriormente a mecânica quântica permitiu que se compreendesse como os átomos interagem entre si a nível microscópico para formar os sólidos, líquidos e outras estruturas organizadas [40]. A descrição desse mundo microscópico permitiu ainda a compreensão de diversos fenômenos a nível macroscópico, abrangendo um amplo espectro 
de áreas, indo da física e química até a biologia e medicina, evidenciando o impacto e amplitude que a mecânica quântica teve nas ciências naturais e até mesmo no pensamento do mundo moderno [41]. Um exemplo da conexão entre os fenômenos macroscópicos e microscópicos é o mecanismo chamado de "chave e fechadura" (lock and key) que ocorre em diversos sistemas biológicos, e é utilizado em aplicações farmacêuticas, mais especificamente no design de remédios a nível molecular (drug design). O mecanismo da "chave e fechadura" é controlado por interações quânticas, e acontece, por exemplo, nas enzimas, que contém uma espécie de "chave", que procura algum outro elemento microscópico (por exemplo, um vírus, bactéria, ou qualquer outro elemento estranho ao indivíduo) que ela se encaixe perfeitamente, funcionando como se fosse uma "fechadura". Embora a resolução das equações de Schrödinger ainda não tenha permitido, de forma direta, o design de remédios moleculares, esta aplicação particular da mecânica quântica não está tão distante, numa área emergente chamada de biologia e medicina molecular.

O exemplo apresentado no parágrafo anterior, assim como diversos outros problemas em áreas como a bioquímica, geofísica, astronomia, engenharias, dentre outras, indicam que uma modelagem teórica, baseada nos princípios da mecânica quântica, pode permitir um acesso direto às propriedades físicas de sistemas microscópicos, onde as medidas experimentais são inviáveis ou inacessíveis. Entretanto, este princípio não se limita somente a situações nas quais não é possível a realização dos experimentos. A execução de simulações computacionais pode permitir um controle mais acurado dos procedimentos experimentais, ou auxiliar na compreensão dos fenômenos físicos.

As simulações computacionais a nível atomístico tomaram outro rumo, que transcende o caráter de servirem somente para comprovar fenômenos a nível microscópicos. Simulações atomísticas, cada vez mais, passaram a auxiliar na investigação de propriedades em que as interações interatômicas são determinantes na fenomenologia do respectivo sistema. Por exemplo, a execução de experimentos virtuais, no computador, permite fazer uma exploração preliminar de um determinado fenômeno físico complexo, auxiliando assim na execução posterior de experimentos mais focados. Isto somente é possível, e útil, se o modelo teórico, que descreve as interações interatômicas, é confiável. Os desenvolvimentos de métodos quânticos, chamados de $a b$ initio ou de primeiros princípios, que ocorreram nos últimos cinqüenta anos, permitiram obter uma descrição consideravelmente precisa do mundo microscópico, como propriedades estruturais, eletrônicas, ópticas, magnéticas e de transporte. Um entendimento da estrutura eletrônica de um material representa um passo fundamental na 
compreensão de todas essas outras propriedades, e a mecânica quântica, com as aproximações apresentadas neste capitulo, propiciam uma descrição altamente precisa da respectiva estrutura eletrônica.

Isto representa uma considerável vantagem da modelagem quântica sobre as medidas experimentais. Comparando o custo decrescente de computadores com o custo do aparato experimental necessário para executar as mesmas funções, percebe-se que a rentabilidade de métodos de modelagem quântica sobre os experimentos físicos continuarão a aumentar com o passar do tempo. Mas esta vantagem de custo não significa que as simulações computacionais podem simplesmente substituir os experimentos, mas sim auxiliá-los.

\section{2 - A Aproximação de Born-Oppenheimer}

Para obter conhecimento acerca da estrutura eletrônica de um material e suas propriedades é necessário resolver as equações de Schrödinger acopladas, o que se torna extremamente complicado, mesmo a nível numérico e computacional, para sistemas que envolvem muitos elétrons e núcleos. Para superar essa limitação, e transformar a solução desse problema num objetivo factível, em 1927, Born e Oppenheimer fizeram uma aproximação para a solução da equação de Schrödinger, o que possibilitou a descrição do movimento relativo elétrons-núcleos.

A equação de Schrödinger é dada pela equação abaixo:

$$
H|\Phi\rangle=E|\Phi\rangle
$$

onde $H$ é o operador Hamiltoniano e $|\Phi\rangle$ a função de onda. Para sistemas com $\mathbf{N}$ elétrons e $\mathbf{M}$ núcleos, o Hamiltoniano é dado por:

$$
H=-\sum_{i=1}^{N} \frac{1}{2} \nabla_{i}^{2}-\sum_{A=1}^{M} \frac{1}{2 M_{A}} \nabla_{A}^{2}-\sum_{i=1}^{N} \sum_{A=1}^{M} \frac{Z_{A}}{r_{i A}}+\sum_{i=1}^{N} \sum_{j>1}^{N} \frac{1}{r_{i j}}+\sum_{A=1}^{M} \sum_{B>A}^{M} \frac{Z_{A} Z_{B}}{R_{A B}}
$$

onde, $r_{i A}$ é a distância entre um elétron $i$ e um núcleo $A, R_{A B}$ é a distância entre os núcleos $A$ e $B$, e por fim, $Z_{A}$ e $Z_{B}$ representam os números atômicos dos núcleos $A$ e $B$, respectivamente. Sendo assim, o primeiro termo da equação (3.2) é o operador referente à energia cinética dos elétrons, o segundo termo é o operador para energia cinética dos núcleos, 
o terceiro representa a interação Coulombiana elétron-núcleo, o quarto termo é interpretado como a energia de repulsão entre os elétrons e o último como a energia de repulsão entre os núcleos.

Para solução da equação de Schrödinger para sistemas de muitos corpos, a aproximação de Born-Oppenheimer leva em consideração que a massa de um núcleo atômico é muito maior que a massa de um elétron, desta forma, a velocidade do movimento nuclear é pelo menos mil vezes menor que velocidade eletrônica para uma mesma energia. Desta forma, pode-se executar a solução da equação de Schrödinger para sistemas de muitos corpos considerando um desacoplamento entre elétrons e núcleos. Essa aproximação pode ainda ser enunciada da seguinte forma: qualquer movimento nuclear tem uma resposta instantânea da distribuição dos elétrons do sistema. Dentro desta aproximação, o segundo termo (energia cinética nuclear) pode ser considerado nulo e o último termo que é referente à energia de repulsão entre núcleos, pode ser considerado constante, conforme a equação (3.2). Sendo assim, pode-se escrever a equação de Schrödinger levando em conta somente o movimento eletrônico.

$$
H_{\text {elétrons }} \Phi_{\text {elétrons }}=E_{\text {elétrons }} \Phi_{\text {elétrons }}
$$

onde $H_{\text {elétrons }}$ é o Hamiltoniano eletrônico, $E_{\text {elétrons }}$ é a energia eletrônica e $\Phi_{\text {elétrons }}$ é a função de onda eletrônica (que depende somente das coordenadas relacionadas aos elétrons). Considerando os termos negligenciados pela aproximação, o Hamiltoniano eletrônico $H_{\text {elétrons }}$ e energia total do sistema $E_{\text {total }}$ (considerando núcleos fixos) podem ser escritas pelas equações (3.4) e (3.5):

$$
\begin{gathered}
H_{\text {elétrons }}=-\sum_{i=1}^{N} \frac{1}{2} \nabla_{i}^{2}-\sum_{i=1}^{N} \sum_{A=1}^{M} \frac{Z_{A}}{r_{i A}}+\sum_{i-1}^{N} \sum_{j>1}^{N} \frac{1}{r_{i j}}, \\
E_{\text {total }}=E_{\text {elétrons }}+\sum_{A=1}^{M} \sum_{B>A}^{M} \frac{Z_{A} Z_{B}}{R_{A B}},
\end{gathered}
$$

Neste caso, a equação (3.5) que representa a energia total do sistema para núcleos fixos deve incluir a constante de repulsão nuclear. Além do movimento eletrônico, a aproxi- 
mação de Born-Oppenheimer permite a resolução da equação de Schrödinger para o movimento nuclear, considerando a influência eletrônica como um potencial dependente das posições dos núcleos [42]. Neste trabalho, os movimentos nucleares das moléculas serão tratados dentro de uma teoria de mecânica Newtoniana.

\section{3 - Teoria do Funcional da Densidade (DFT)}

Para encontrar as soluções das equações eletrônicas acopladas para todos os elétrons do sistema, diversas aproximações devem ser feitas. A primeira delas é a aproximação de Born-Oppenheimer, já descrita na seção 3.2, a qual permite o desacoplamento dos movimentos de núcleos e elétrons. Entretanto, mesmo com esta aproximação, a solução exata do problema do sistema eletrônico ainda é intratável, sendo necessário, portanto, fazer novas aproximações, como por exemplo, a aproximação de Hartree-Fock (HF), na qual os elétrons são tratados como se fossem independentes, e como resultado o termo de correlação eletrônico não é incluído, o que transforma o problema de uma equação acoplada de $\mathrm{N}$ elétrons em $\mathrm{N}$ equações desacopladas de um elétron. Entretanto, o termo de correlação intereletrônico é geralmente de grande importância na solução do problema, sendo importante nos cálculos para se obter resultados precisos.

Com o objetivo de descrever a interação inter-eletrônica, foi proposta, em 1964 por Hohenberg e Kohn, a Teoria do Funcional da Densidade (DFT), e posteriormente em 1965, por Kohn e Sham [43], uma implementação factível da DFT. Pelo impacto que essa teoria teve tanto na física como na química, W. Kohn recebeu o prêmio Nobel de química em 1998. Essa teoria é um dos métodos de cálculo de estrutura eletrônica para sistemas moleculares com maior sucesso atualmente, a qual usa a densidade eletrônica como variável fundamental para descrever a energia de um sistema eletrônico no seu estado fundamental, em contraste com a teoria HF, onde as funções de onda são escritas na forma de um determinante de Slater.

De acordo com a DFT, se a densidade eletrônica $(\rho)$ em cada posição do espaço for conhecida (densidade eletrônica conforme definida a seguir), a energia total desse sistema eletrônico em seu estado fundamental, assim como as demais propriedades estruturais desse sistema, pode ser determinada univocamente. 
Diferente da função de onda eletrônica, que, para os $\mathrm{N}$ elétrons do sistema, é uma função de $4 \mathrm{~N}$ coordenadas ( $3 \mathrm{~N}$ de espaço e $\mathrm{N}$ de spin), a densidade eletrônica $\rho(r)$ é igual a probabilidade de encontrar um elétron em um elemento de volume $d r(d x, d y, d z)$, sendo portanto, uma função das três coordenadas de espaço somente, podendo ser representada por:

$$
\rho(r)=\sum_{i=1}^{M}\left|\psi_{i}(r)\right|^{2},
$$

Pode-se ainda definir a densidade eletrônica com polarização de spin, assim existem duas densidades, $\rho_{\uparrow}(r)$ e $\rho_{\downarrow}(r)$, para elétrons com spin up e down, respectivamente.

A DFT baseia-se nos seguintes teoremas [43]:

Teorema 1 - "O potencial externo $v(r)$ sentido pelos elétrons é um funcional único da densidade eletrônica."

Teorema 2 - "A energia total do estado fundamental $E_{0}[\rho]$ é mínima para a densidade $\rho(r)$ exata."

Desta forma, o problema de $\mathrm{N}$ elétrons pode ser então resolvido a partir de um sistema de equações monoeletrônicas autoconsistentes denominadas equações de Kohn-Sham, que são da forma:

$$
f^{K S} \varphi_{i}=\varepsilon_{i} \varphi_{i}
$$

onde $f^{K S}$ é o operador Kohn-Sham, análogo ao operador Fock, dado por:

$$
f^{K S}=-\frac{\hbar^{2}}{2 m} \nabla_{i}^{2}+V^{K S}(r)
$$

na qual o primeiro termo é a energia cinética $\boldsymbol{T}$ e $V^{K S}$ o "potencial de Kohn-Sham" que assume a seguinte forma: 


$$
V^{K S}|\rho(r)|=V_{\text {ext }}(r)+V_{\text {Hartree }}|\rho(r)|+V_{X C}|\rho(r)|,
$$

onde $V_{e x t}$ é o potencial de atração elétron-núcleo (potencial externo), $V_{\text {Hartree }}$ é um termo funcional de $\rho$ relativo à aproximação de Hartree (campo médio sentido pelo elétron) e $V_{X C}$ é o termo de troca-correlação que contém as contribuições de troca $V_{X}$ e correlação $V_{C} \cdot V_{\text {ext }}, V_{\text {Hartree }}$ e $V_{X C}$ são dados respectivamente por:

$$
\begin{gathered}
V_{e x t}(r)=\sum_{A} \frac{Z_{A}}{\left|r-R_{A}\right|}, \\
V_{\text {Hartree }}=\int \frac{\rho\left(r^{\prime}\right)}{\left|r-r^{\prime}\right|} d \tau, \\
V_{X C}=\frac{\delta E_{X C}}{\delta \rho},
\end{gathered}
$$

Substituindo (3.8) em (3.7), temos as equações de Kohn-Sham:

$$
\left(-\frac{\hbar^{2}}{2 m} \nabla_{i}^{2}+V^{K S}(r)\right) \varphi_{i}=\varepsilon_{i} \varphi_{i}
$$

O processo autoconsistente para resolver as equações de Kohn-Sham consiste primeiramente em fazer uma escolha criteriosa da densidade, tentativa do primeiro passo do processo, $\rho_{0}(r)$, a partir da qual se calcula $V^{K S}$. Este potencial é então introduzido nas equações de Kohn-Sham, obtendo-se desta maneira os orbitais e as energias. A partir dos orbitais obtidos é calculada uma nova densidade $\rho(r)$, com a qual se calcula novamente $V^{K S}$ e desta maneira o processo se repete até se obter convergência. $\mathrm{O}$ ciclo iterativo termina quando algum critério de convergência pré-determinado é alcançado. Os dois critérios mais usados são baseados nas diferenças das densidades $\rho^{(i)}$ ou energias totais $E^{(i)}$ entre duas iterações sucessivas. A representação do ciclo autoconsistente descrito acima é mostrada na figura 3.1 . 


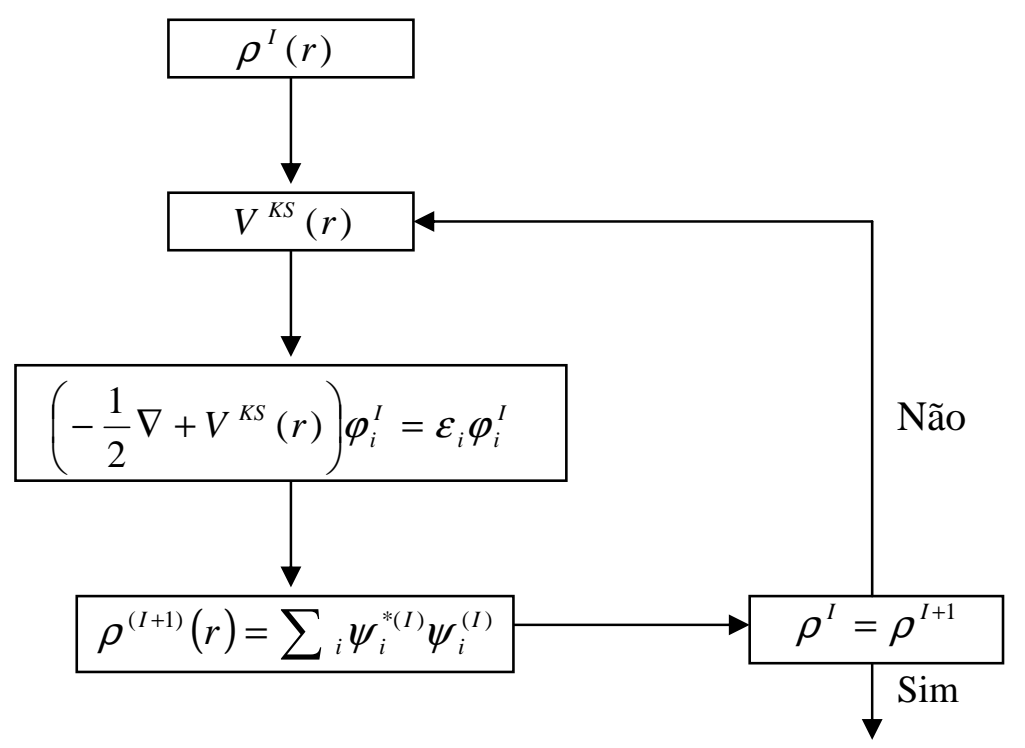

Observáveis Físicas

Figura 3.1 - Representação esquemática do ciclo de autoconsistência para a obtenção da solução da equação de Kohn-Sham.

Com a utilização de uma base para os orbitais de Kohn-Sham torna-se necessário diagonalizar a matriz $F^{K S}$ da mesma maneira como é preciso diagonalizar a matrtiz $F$ no método de Hartree-Fock. A minimização da energia é feita também pelos multiplicadores de Lagrange baseada no princípio variacional, com a diferença que o fator de normalização é dado por:

$$
\int \rho(r) d \tau=N
$$

A expressão de energia total (equação 3.15) é análoga a da teoria HF, diferindo apenas no operador de Kohn-Sham e por usar a densidade eletrônica como variável fundamental.

$$
E[\rho]=\int v(r) \rho(r) d^{3} r+\frac{1}{2} \iint \frac{\rho(r) \rho\left(r^{\prime}\right)}{\left|r-r^{\prime}\right|} d^{3} r d^{3} r^{\prime}+G[\rho]
$$

onde,

$$
G[\rho]=T_{0}[\rho]+E_{x c}[\rho]
$$


substituindo (3.16) em (3.15), chega-se a:

$$
E[\rho]=\int v(r) \rho(r) d^{3} r+\frac{1}{2} \iint \frac{\rho(r) \rho\left(r^{\prime}\right)}{\left|r-r^{\prime}\right|} d^{3} r d^{3} r^{\prime}+\int \rho(r) E_{x c}(\rho(r)) d^{3} r
$$

ou em outra notação,

$$
\mathrm{E}[\rho]=T_{R}+V_{e x t}+E_{H}+E_{X C}
$$

O último termo da equação (3.18) se refere à interação de troca e de correlação. Os orbitais de Kohn-Sham servem como ferramenta para calcular a densidade eletrônica, levando em consideração os efeitos de correlação, o que não ocorre na metodologia HF.

\section{4 - Aproximação da Densidade Local (LDA)}

A estratégia para resolver o problema de muitos corpos na teoria DFT consiste em dividir a energia total de um sistema eletrônico em um número de diferentes contribuições, cada uma das quais pode ser tratada separadamente.

$$
\mathrm{E}[\rho]=T_{R}+V_{e x t}+E_{H}+E_{X}+E_{C},
$$

onde, $T_{R}$ é o funcional energia cinética não interagente com a densidade eletrônica $\rho(r) . V_{e x t}$ é a interação dos elétrons com campos externos, em particular dos núcleos atômicos, $E_{H}$ é o termo de Hartree ou interação elétron-elétron clássica, $E_{X}$ é a energia de troca e $E_{C}$ o termo de correlação, como discutido na seção 3.3. Os termos $V_{e x t}$ e $E_{H}$ são conhecidos como funcionais explícitos da densidade eletrônica. Os termos $T_{R}$ e $E_{X}$ são conhecidos como funcionais de orbitais não interagentes que por sua vez são funcionais (desconhecidos) da densidade. O termo de energia de correlação $E_{C}$, é o grande desconhecido, por isso certas aproximações devem ser usadas para calcular as contribuições do termo de troca-correlação. 
Atualmente, a aproximação da densidade local LDA (Local Density Approximation) tem sido a aproximação mais amplamente utilizada para a energia de troca-correlação. Foi proposta em 1965 por Kohn e Sham [44], mas a filosofia já estava presente na teoria de Thomas-Fermi-Dirac, desenvolvida muito antes em 1927. A idéia principal é considerar um sistema eletrônico não-homogêneo como localmente homogêneo, em outras palavras, o sistema não-homogêneo é dividido em pequenos volumes, que podem ser chamadas de células, e dentro destas células a densidade de energia é calculada considerando um gás de elétrons homogêneo.

Desta maneira, pode-se obter uma aproximação para o termo de troca-correlação ao calcular os valores que a densidade eletrônica assume em cada ponto $\mathbf{r}$ no volume e depois integrar sobre o volume do sistema a densidade de energia correspondente, como representado na figura 3.2:

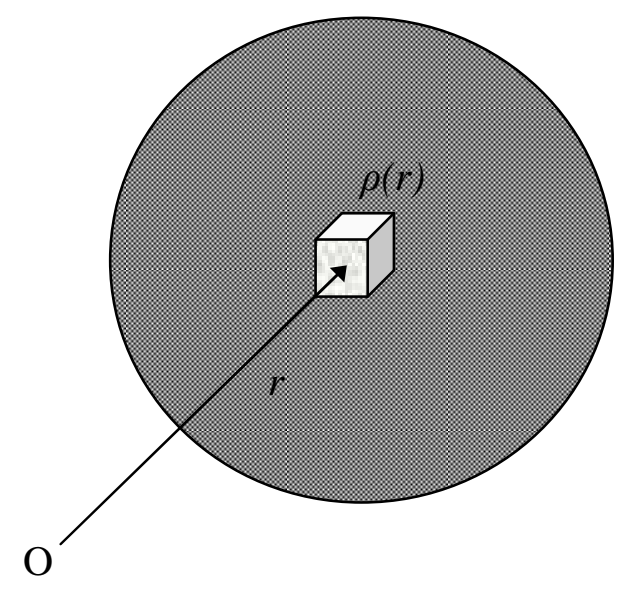

Figura 3.2 - Os termos da equação são obtidos através da integração da densidade de energia calculada com os valores assumidos pela densidade eletrônica $\rho(r)$ [45].

Sendo assim, o funcional da energia de troca-correlação pode ser escrito por:

$$
E_{X C}^{L D A}[\rho]=\int \rho(r) \varepsilon_{X C}^{L D A}[\rho(r)] d r
$$

onde o termo $\varepsilon_{X C}^{L D A}[\rho]$ corresponde à energia de correlação por partícula, de um gás de elétrons homogêneo, em um ponto $\mathbf{r}$, considerando que a densidade local $\rho(r)$ é igual à densidade local do sistema não-homogêneo. 
A energia de correlação, utilizando a aproximação LDA, é calculada através da equação (3.20) decompondo o termo $\varepsilon_{X C}^{L D A}[\rho]$ da seguinte maneira:

$$
\varepsilon_{X C}^{L D A}[\rho]=\varepsilon_{X}^{L D A}[\rho]+\varepsilon_{C}^{L D A}[\rho]
$$

onde $\varepsilon_{X}^{L D A}[\rho]$ é a densidade de energia de troca e $\varepsilon_{C}^{L D A}[\rho]$ é a densidade de energia de correlação. Considerando a decomposição da densidade de energia de troca e correlação, a equação (3.20) pode ser escrita da seguinte maneira:

$$
\begin{gathered}
E_{X C}^{L D A}[\rho]=E_{X}^{L D A}[\rho]+E_{C}^{L D A}[\rho] \\
E_{X C}^{L D A}[\rho]=\int\left[(\rho(r)) \varepsilon_{X}^{L D A}+(\rho(r)) \varepsilon_{C}^{L D A}\right] \rho(r) d r
\end{gathered}
$$

O primeiro a estimar a parte de correlação para um gás de elétrons homogêneo foi Wigner [8]. Entretanto, Cerpeley e Alder conseguiram realizar cálculos quânticos de alta precisão para o mesmo sistema utilizando o método de Monte Carlo [177]. Com base nestes cálculos, Perdew e Zunger [46] fizeram uma parametrização, através do raio de Wigner $r_{s}=(3 / 4 \pi)^{1 / 3}$, que é muito utilizada para o cálculo da energia de correlação. Nesta aproximação $E_{X}^{L D A}[\rho]$ é dada por:

$$
\begin{aligned}
& E_{X}^{L D A}[\rho]=\int \rho(r) \varepsilon_{X}^{L D A}[\rho(r)] d r \\
& E_{X}^{L D A}[\rho]=-\frac{0.4582}{r_{s}}
\end{aligned}
$$

Por outro lado, a densidade de energia de correlação $E_{C}^{L D A}[\rho]$ obedece às seguintes condições:

$$
\mathrm{E}_{C}^{L D A}[\rho]= \begin{cases}\frac{-0.1423}{\left(1+1.9529 \sqrt{r_{s}}+0.3334 r_{s}\right)} & r_{s}>1 \\ \left(-0.0480+0.0311 \ln r_{s}-0.0116 r_{s}+0.0020 r_{s} \ln r_{s}\right) & r_{s}<1\end{cases}
$$


Uma vez que a aproximação LDA é baseada na aproximação de um gás de elétrons homogêneo, é esperado que funcione melhor para sistemas homogêneos, como por exemplo, os metais, nos quais a densidade eletrônica varia espacialmente muito lentamente. Entretanto, apesar de haver grande variação espacial da densidade eletrônica para sistemas atômicos, moleculares e cristalinos, é possível descrevê-los satisfatoriamente através da LDA, uma vez que a região de interesse nos cálculos não é a região nuclear, a qual é "suavizada" nos cálculos com LDA.

Cerpeley e Alder [177] desenvolveram também uma amostragem estocástica da solução exata da equação de Schrödinger para um gás de elétrons, chamada de parametrização LDA-CA, que tem se mostrado eficiente em cálculos de energia de correlação. Existe ainda a LSDA (Local Spin Density Approximation), que é uma aproximação que inclui a dependência da densidade com o spin, geralmente usada em sistemas que considera a polarização de spin, onde a energia total do sistema se torna um funcional das duas densidades de spin [47]. Sendo a equação (3.20) reescrita da seguinte forma:

$$
E_{X C}^{L D A}\left[\rho_{\uparrow}(r), \rho_{\downarrow}(r)\right]=\int\left[\rho_{\uparrow}(r)+\rho_{\downarrow}(r)\right] \varepsilon_{X C}^{h}\left[\rho_{\uparrow}(r), \rho_{\downarrow}(r)\right] d r
$$

Onde, por convenção $\rho_{\uparrow}$ corresponde à densidade eletrônica para spin $u p$ e $\rho_{\downarrow}$ à densidade eletrônica para spin down. 


\section{5 - Aproximação do Gradiente Generalizado (GGA)}

Mesmo que a aproximação LDA consiga descrever satisfatoriamente sistemas que tenham a densidade eletrônica com grandes variações espaciais na densidade eletrônica, é necessário que seja feita uma descrição melhorada, que forneça resultados mais precisos para o termo de troca-correlação. Nesse sentido, Perdew, Burke e Ernzehof [48] propuseram uma aproximação que incluía alguma informação sobre a taxa de variação da densidade $\rho(r)$ em relação à posição r, chamada de aproximação de Gradiente Generalizada - GGA (Generalized Gradient Approximation), que propõe o termo de troca-correlação de forma generalizada pela equação (3.26):

$$
E_{X C}^{G G A}\left[\rho, \nabla_{\rho}\right]=\int \rho(r) \varepsilon_{X C}^{G G A}\left[\rho(r),|\nabla \rho(r)|, \nabla^{2} \rho(r), \ldots\right] d r
$$

Nesta aproximação, a equação LDA é substituída por uma função que não dependa só da densidade $\rho(r)$, mas também do gradiente da densidade. Na equação (3.26), o termo $\varepsilon_{X C}^{G G A}$ depende da densidade no ponto $\mathbf{r}$ e também da densidade de sua vizinhança infinitesimal, através do gradiente, fazendo com que o funcional $E_{X C}^{G G A}$ seja expresso em termos do gradiente da densidade de carga total.

A escolha dessa função define os diferentes tipos de GGA, as quais são chamadas de funcionais. Estes funcionais melhoram a descrição de parâmetros tais como a energia atômica, energia de ligação e coesão, comprimentos e ângulos de ligação, as constantes de rede de metais alcalinos e de transição, dentre outras propriedades [46]. Atualmente, o funcional GGA mais conhecido na comunidade científica é o PBE, proposto em 1996 por Perdew, Burke e Ernzerhof [48].

Ao comparar as aproximações LDA e GGA, não é possível estabelecer univocamente qual delas propicia uma melhor descrição das propriedades dos materiais, uma vez que cada uma apresenta particularidades que terão melhores aplicações dependendo do sistema a ser estudado. Por exemplo, a LDA se mostra melhor na descrição de sistemas cristalinos ou sistemas que tem a variação da densidade mais uniforme, enquanto que o GGA se mostra mais eficiente na descrição de sistemas moleculares, onde podem ocorrer grandes variações espaciais da densidade eletrônica. 
Os funcionais GGA têm dificuldade em descrever interações do tipo Van Der Waals e outros tipos de forças dispersivas. Por outro lado, a LDA subestima a energia total de superfícies metálicas quando comparada com os valores experimentais. Além disso, as energias de troca da aproximação LDA são subestimadas em 15\% a $20 \%$ e as energias de correlação são superestimadas em até $100 \%$. Nestes casos, o GGA se mostra mais eficiente. Enquanto o funcional LDA subestima as distâncias atômicas, ocorre a superestimação pela aproximação GGA. A LDA também subestima o valor da constante de rede em sólidos entre 1 a 3\%, os módulos de compressibilidade (bulk modulus) entre 8 a $18 \%$ e o valor da faixa proibida de energia (gap) nos semicondutores e isolantes em média 30\%.

\section{6 - O Método PAW}

Nas últimas décadas, os cálculos de estrutura eletrônica têm oferecido significantes contribuições para o entendimento das propriedades de estado sólido. A maioria desses cálculos é baseada na aproximação da densidade local (LDA) da teoria do funcional da densidade. Essa teoria mapeia o estado fundamental de um gás de elétrons interagente para o estado fundamental de elétrons não-interagentes, os quais experimentam um potencial efetivo.

Entretanto, existem algumas dificuldades apresentadas pelas equações de Kohn-Sham para descrever a região de ligação com um alto grau de precisão levando em consideração as grandes variações no centro do átomo, uma vez que as funções de onda na região próxima ao núcleo sofrem rápidas oscilações espaciais devido à energia cinética (ou potencial de atração nuclear) ser muito grande nesta região. Por outro lado, nas regiões intersticiais entre os átomos, onde ocorrem as ligações químicas, a energia cinética dos elétrons é pequena, resultando em pequenas variações espaciais na função de onda. Por isso, para descrever este tipo de ambiente de forma satisfatória é necessário um grande conjunto de combinações lineares de orbitais atômicos.

Devido a essas dificuldades, numerosos métodos de estrutura eletrônica têm sido desenvolvidos para resolver a equação de Schrödinger de uma partícula. Entre estes métodos está o proposto por Peter E. Blöchl, chamado PAW (Projector Augmented-Wave method), que é um método ab initio “all- electron" (AE), ou seja, que leva em conta todos os elétrons para 
cálculo da estrutura eletrônica. O PAW é essencialmente uma combinação de idéias dos métodos de pseudopotencial [49] e LAPW (Linear Augmented Plane Wave method) [50].

No método de pseudopotencial, a pseudo-função de onda é suavizada nas proximidades do núcleo (dentro de um raio $r_{c}$, chamando de raio de corte), onde a função de onda deveria oscilar rapidamente. Neste caso, somente os elétrons de valência, aqueles quimicamente ativos, são tratados de forma explícita utilizando as ondas planas para descrição do seu comportamento eletrônico, enquanto os elétrons do núcleo são "congelados" sendo considerado junto com os núcleos como rígidos e não polarizáveis. Este método apresenta a desvantagem da perda de toda informação a respeito da densidade de carga e a função de onda nas regiões próximas do núcleo, e diversas propriedades não podem ser estudadas, como os parâmetros hiperfinos de centros eletronicamente ativos.

Por outro lado, no método "Augmented Wave” (Ondas Expandidas) são formadas funções de onda tipo orbitais atômicos na região do núcleo e uma base de ondas planas, chamadas de funções envelope para representar a região intersticial dos átomos (regiões onde ocorrem as ligações químicas). Este tipo de tratamento gera soluções parciais, que são separadas de acordo com esferas centradas nos átomos, definindo a região atômica e a região intersticial. Após obter as soluções parciais das diferentes regiões é necessário formar uma interface entre ambas, garantindo a continuidade e a linearidade das funções de onda.

Conforme descrito anteriormente, o método PAW (Projector Augmented Wave) é uma extensão dos métodos de ondas expandidas e a aproximação dos pseudopotenciais, combinando partes de ambas aproximações em um método para tratamento da estrutura eletrônica unificado. A estratégia desta metodologia é dividir a função de onda em partes: uma expansão de ondas parciais dentro de uma esfera centrada nos átomos e funções envelopes fora dessas esferas. A função envelope é expandida em ondas planas ou algum outro conjunto de bases conveniente [51].

Através de um conjunto de ondas planas é possível descrever de maneira conveniente a região que contém a "cauda" das funções de onda atômicas, ou seja, a região em que existem interações entre os átomos (geralmente relacionada com os elétrons de valência) [47]. Por outro lado, para descrever a região próxima ao núcleo atômico onde pode haver grandes oscilações da função de onda, seria necessário utilizar um número muito grande de ondas planas. Por isso, para otimizar o problema, utiliza-se a expansão em orbitais atômicos para descrever corretamente a estrutura nodal da função de onda nesta região, mas faltarão graus de liberdade variacionais para descrever as regiões de ligação e de "cauda" [47]. 
No método PAW, os coeficientes dos orbitais atômicos não são determinados variacionalmente, ou seja, não são realizados cálculos variacionais para determinar a estrutura eletrônica na região que abrange o núcleo e os elétrons de caroço. Em vez disso, os coeficientes são tratados como funções dos coeficientes das ondas planas, o que evita o esforço duplo de realizar dois cálculos de estrutura eletrônica (para ondas planas e orbitais atômicos) [47].

Através do método PAW é possível recuperar a energia total DFT com grande precisão, pois as expansões em orbitais atômicos e ondas planas formam uma base completa [47]. Obtendo esta base completa é possível diminuir sistematicamente os erros criados pela escolha do conjunto de base. Ao escolher uma supercélula suficientemente grande, tornando possível o desacoplamento das interações de longo alcance, as limitações do conjunto de base em ondas planas são superadas. Desta forma, o método PAW se constitui numa poderosa ferramenta para a investigação de estruturas complexas, incluindo moléculas, superfícies e sólidos.

\subsection{1 - Funções PAW (Projector Augmented Wave method)}

A idéia básica do método PAW é transformar a função de onda $|\Psi\rangle$, relativa a todos os elétrons em uma função de onda suave e numericamente conveniente chamada de função de onda auxiliar $|\tilde{\Psi}\rangle$, o que não é uma tarefa fácil devido às fortes oscilações na região próxima ao núcleo atômico. Para transformar a função de onda real em uma função de onda auxiliar consideramos o operador $T$, que irá transformar a função de onda real em uma função de onda computacionalmente adequada.

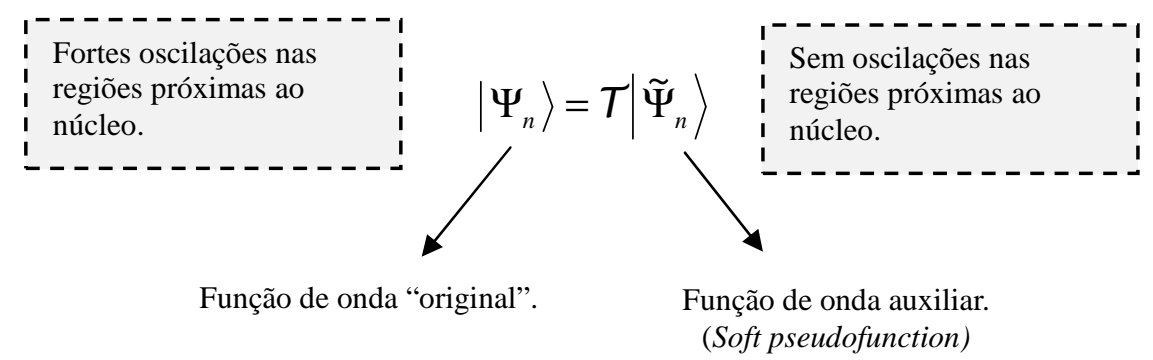

Figura 3.3 - Representação da transformação do operador $T$ na função de onda $|\Psi\rangle$ na metodologia PAW. 
$\mathrm{Na}$ equação (3.27), o índice $n$ contém as informações referentes às funções de onda, tais como o ponto-k, índice de banda, índice de spin, dentre outros. Através desta transformação pode-se recuperar as oscilações da função real $|\Psi\rangle$ nas regiões próximas ao núcleo atômico. As regiões que apresentam essas oscilações estão inseridas em um conjunto de esferas de raio $r_{c}$, centradas em cada átomo.

Desta forma, é possível expandir estas funções de onda auxiliares em uma base de ondas planas e avaliar todas as propriedades físicas após reconstruir as funções de onda originais $\Psi$. Substituindo a equação (3.27) na equação de Schrödinger, pode-se encontrar:

$$
T^{\dagger} H T\left|\tilde{\Psi}_{n}\right\rangle=\varepsilon_{n} T^{\dagger} T\left|\tilde{\Psi}_{n}\right\rangle
$$

Neste caso, o operador Hamiltoniano assume a forma $\tilde{H}=T^{\dagger} H T$ e um operador superposição é representado por $\tilde{\mathcal{O}}=T^{\dagger} T$. Através deste formalismo, o valor esperado para um operador $\tilde{A}$, no espaço de Hilbert das funções de onda relativas ao potencial real, pode ser obtido através das funções auxiliares mais suaves [47]. Define-se desta forma dois espaços de Hilbert, um para as funções de onda all electron (AE) e outro para as pseudofunções (PS). O passo seguinte é mapear as funções de onda de valência AE sobre as funções de onda PS [47], onde cada função de onda $|\tilde{\Psi}\rangle$ (pseudo) deverá ser expandida em ondas parciais $\left|\tilde{\phi}_{i}\right\rangle$ (pseudo).

$$
|\tilde{\Psi}\rangle=\sum_{i \in R}\left|\tilde{\phi}_{i}\right\rangle c_{i}, \quad \text { para } \quad|\vec{r}-\vec{R}|<r_{c}
$$

O índice $i$, na equação (3.29), representa a posição $R$ e os índices $(l, m)$ representam o momento angular. A função all electron correspondente é obtida a partir da função de onda auxiliar através da transformação $T$, conforme equação (3.27).

O operador $T$ pode ser definido como a soma do operador identidade com o operador das contribuições atômicas $S_{R}$, o qual modifica a função de onda auxiliar em cada região atômica, resultando em uma função de onda que expressa corretamente a estrutura nodal. 


$$
T=1+\sum_{R} S_{R}
$$

onde o índice $R$ especifica o sítio atômico. Para todos os átomos presentes no sistema, $S_{R}$ adiciona as diferenças entre a função de onda verdadeira e auxiliar. Pelo fato das funções de caroço não se espalharem até os átomos vizinhos, pode-se tratá-las separadamente [47].

Para cada função parcial $\left|\phi_{i}\right\rangle$ (ver equação 3.29), uma função de onda parcial auxiliar $\left|\tilde{\phi}_{i}\right\rangle$ deverá ser definida, de forma que:

$$
\left|\phi_{i}\right\rangle=\left(1+S_{R}\right)\left|\tilde{\phi}_{i}\right\rangle \quad \text { para } \quad i \in R
$$

Sendo assim, pode-se obter:

$$
\begin{aligned}
& \left|\phi_{i}\right\rangle=\left|\tilde{\phi}_{i}\right\rangle+\left|\tilde{\phi}_{i}\right\rangle S_{R} \\
& \left|\tilde{\phi}_{i}\right\rangle S_{R}=\left|\phi_{i}\right\rangle-\left|\tilde{\phi}_{i}\right\rangle
\end{aligned}
$$

que definirá a contribuição local de $S_{R}$ no operador transformação. A função de onda parcial $\left|\phi_{i}\right\rangle$ e a função de onda parcial auxiliar $\left|\tilde{\phi}_{i}\right\rangle$ correspondente devem ser idênticas, além de um determinado raio de corte $r_{c}$, uma vez que o termo $\left(1+S_{R}\right)$ modifica a função de onda auxiliar apenas localmente, ou seja,

$$
\phi_{i}(r) \equiv \tilde{\phi}_{i}(r) \quad \text { se } \quad i \in R \quad \text { e } \quad|\vec{r}-\vec{R}|>r_{c, R}
$$

E as funções projetoras são escolhidas de maneira que,

$$
|\tilde{\Psi}(\vec{r})\rangle=\sum_{i}\left|\tilde{\phi}_{i}(\vec{r})\right\rangle\left\langle\tilde{p}_{i} \mid \tilde{\Psi}(\vec{r})\right\rangle \quad \text { para } \quad|\vec{r}-\vec{R}|<r_{c, R}
$$


Considerando que as funções projetoras são ortogonais aos pseudo-orbitais

$$
\sum_{i}\left|\tilde{\phi}_{i}\right\rangle\left\langle\tilde{p}_{i}\right|=1 \quad \text { e } \quad\left\langle\tilde{p}_{i} \mid \tilde{\phi}_{i}\right\rangle=\delta_{i j}
$$

e utilizando as equações (3.30), (3.32) e (3.34), o operador transformação assume a seguinte forma:

$$
T=1+\sum_{i}\left(\left|\phi_{i}\right\rangle-\left|\tilde{\phi}_{i}\right\rangle\left\langle\tilde{p}_{i}\right|\right.
$$

Substituindo a equação (3.36) na equação (3.27), a função de onda total do elétron de valência $|\Psi\rangle$ é obtida por:

$$
|\Psi\rangle=|\tilde{\Psi}\rangle+\sum_{i}\left\langle\mid \phi_{i}\right\rangle-\left|\tilde{\phi}_{i}\right\rangle\left\langle\tilde{p}_{i} \mid \tilde{\Psi}\right\rangle
$$

Para facilitar a visualização, será usado o exemplo do orbital $p-\sigma$.da molécula $\mathrm{Cl}_{2}$ obtido pelo método PAW [51], o qual representa o comportamento dos três termos $|\tilde{\Psi}\rangle,\left|\Psi^{1}\right\rangle$ e $\left|\tilde{\Psi}^{1}\right\rangle$ da função de onda total all electron $|\Psi\rangle$.

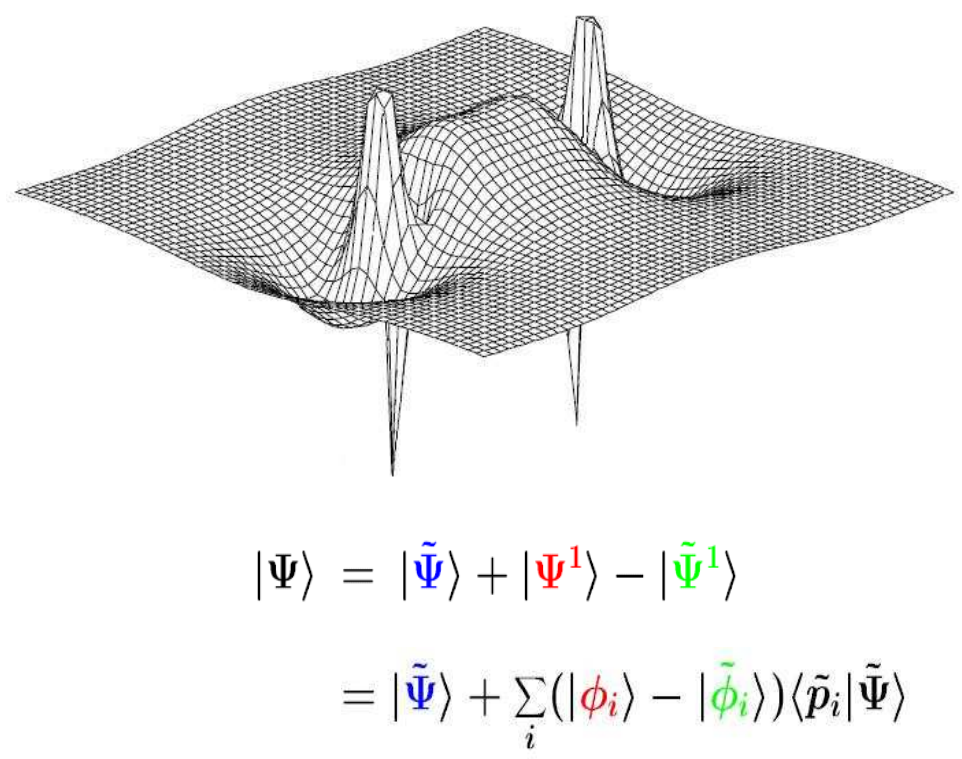



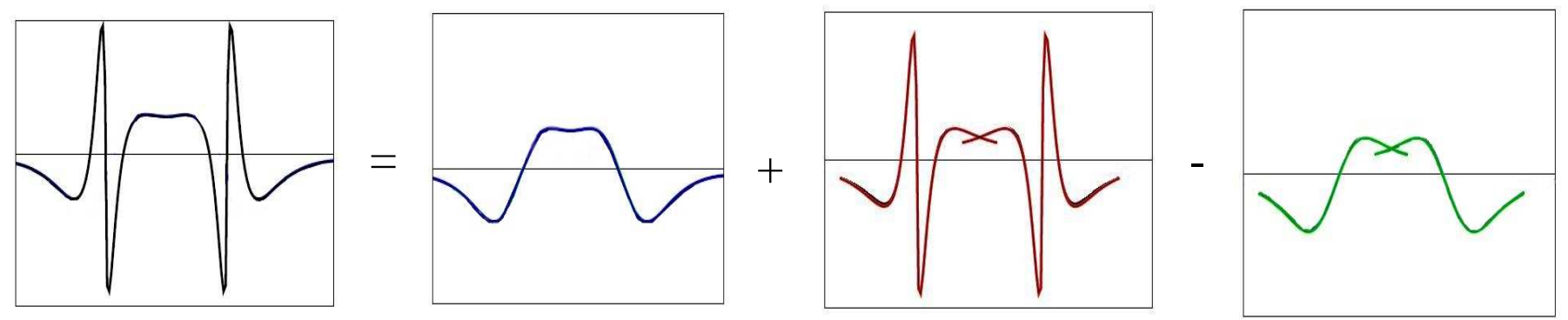

Figura 3.5 - Representação esquemática dos termos da função de onda total all electron $|\Psi\rangle$ para uma molécula de $\mathrm{Cl}_{2}$ através da metodologia PAW [47].

Em resumo, a idéia principal do método PAW é escrever a função de onda total de valência $|\Psi\rangle$ em termos de três componentes.

\section{7 - Simulação Computacional (VASP)}

Todos os cálculos apresentados nesta investigação foram feitos utilizando o código VASP (Vienna Ab-initio Simulation Package). O VASP é um programa que realiza cálculos de estrutura eletrônica e dinâmica molecular baseados na teoria do funcional da densidade (DFT), onde a resolução da equação de Kohn-Sham é feita no espaço recíproco, tomando uma base de ondas planas (no caso, o método PAW - Projector Augmented-Wave, descrito na seção 3.6), para expandir as funções de onda, pseudopotenciais para tratar os elétrons de caroço e condições periódicas de contorno. Os núcleos são tratados classicamente, através da aproximação de Born-Oppenheimer.

Os testes de convergência realizados para a escolha dos parâmetros computacionais dos cálculos apresentados nesta investigação serão descritos nas próximas seções. Foram realizados testes de convergência com os funcionais LDA [44], GGA-PW91 [48] e o GGAPBE [48]. O funcional escolhido como padrão para os cálculos realizados para todos os sistemas investigados foi o funcional densidade do gradiente generalizado (GGA) no formalismo de Perdew-Burke-Ernzerhof (PBE). 
O programa VASP foi escolhido por ser altamente confiável e pelo uso de ondas planas como base. Este último fato elimina problemas com erros de superposição de base ao se calcular energias de formação, embora, por outro lado, eleve o custo computacional para descrever regiões do vácuo.

\section{8 - Testes de Convergência}

\subsection{1 - Grafeno}

Para a escolha do conjunto de aproximações metodológicas que permitisse fazer uma modelagem satisfatória das propriedades físicas para os sistemas de grafeno e grafano compostos por elementos do grupo IV da tabela periódica (C, SiC, Si, Ge e Sn) (ver capítulo 5) e para as estruturas de grafeno com defeitos e dopagens (ver capítulo 6), foi necessário primeiramente executar testes de convergência para a escolha do funcional de trocacorrelação padrão. A estrutura utilizada nos testes foi o grafeno puro, que é constituído somente por átomos de carbono, e possui uma base de dois átomos. Além de definir o funcional de troca-correlação, foi definida também a energia de corte $E_{C U T}$ e a amostragem de pontos $\vec{k}$ padrão que seria utilizada em todos os cálculos posteriores.

O parâmetro que definiu a escolha do funcional de troca-correlação foi a constante de rede $a$. Neste sentido, foi escolhido o funcional que apresentou resultados mais aproximados dos resultados experimentais disponíveis na literatura. Para calcular o parâmetro de rede, é necessário estabelecer os valores de alguns parâmetros de entrada no pacote VASP, tais como, a energia de corte das ondas planas $E_{C U T}$, a célula unitária, o tamanho da supercélula utilizada e a quantidade de pontos $\vec{k}$ tomados para a integração na primeira zona de Brillouin (ZB). Os testes foram executados comparando os resultados dos funcionais LDA [44], GGAPW91 [47] e GGA-PBE [48]. As curvas apresentadas nas figuras 3.7, 3.8 e 3.9, são referentes aos testes realizados com os três funcionais, LDA, GGA-PW91 e GGA-PBE, respectivamente. 
Para a escolha da energia de corte $E_{C U T}$, ou seja, a determinação do número de ondas planas necessárias para expandir as funções de onda eletrônicas, o teste realizado foi a variação da energia total do sistema $\left(E_{T O T}\right)$ em função da energia de corte $\left(E_{C U T}\right)$.

É importante ressaltar que para obter a energia de corte, foi necessário estabelecer um valor inicial para o parâmetro de rede do sistema, sendo este o valor do parâmetro de rede experimental do grafeno, com o valor de 2.46 Á e uma base de dois átomos (ver cap. 2) [25].

Além disso, foi necessário definir a amostragem de pontos $\vec{k}$, para a integração da Zona de Brillouin (BZ). Encontramos convergência na energia total para uma amostragem de $15 x 1 x 15$, representando as direções $x, y$ e $z$ da rede recíproca, respectivamente, que totaliza 225 pontos na ZB. Para os cálculos realizados neste trabalho, os eixos $x, y$ e $z$ foram "rotacionados", de maneira que a "imagem" do grafeno se repete no eixo $y$, conforme representado na figura 3.6. A distância entre as "imagens" adotada foi de 10 Á para evitar a interação entre a estrutura e sua imagem, como representado na figura a seguir.

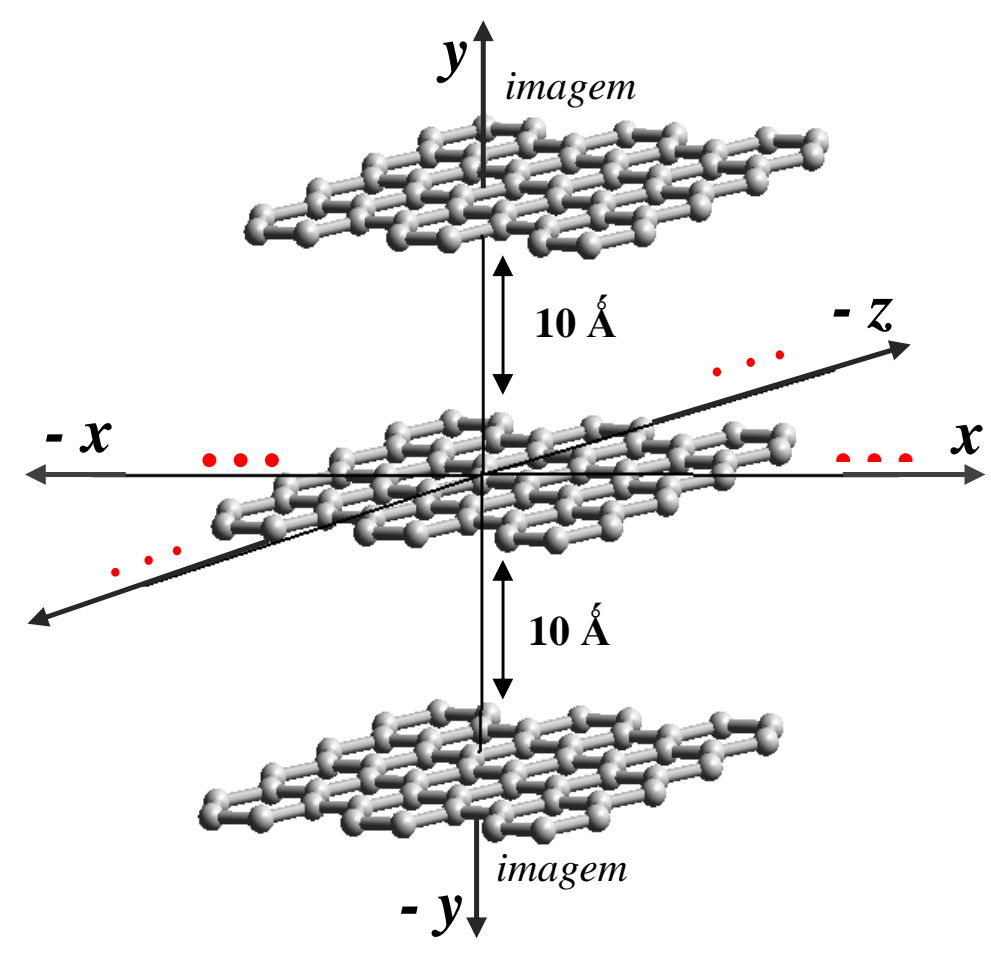

Figura 3.6 - Ilustração da configuração (plano na célula principal e suas imagens) dos eixos da estrutura do grafeno nos cálculos realizados no VASP. 
Com todos estes parâmetros definidos, foram obtidas as curvas $E_{\text {TOTAL }} \times E_{\text {CUT }}$ apresentadas nas figuras 3.7, 3.8 e 3.9 para o grafeno, utilizando os funcionais LDA, GGA-PW91 e GGA-PBE, respectivamente.
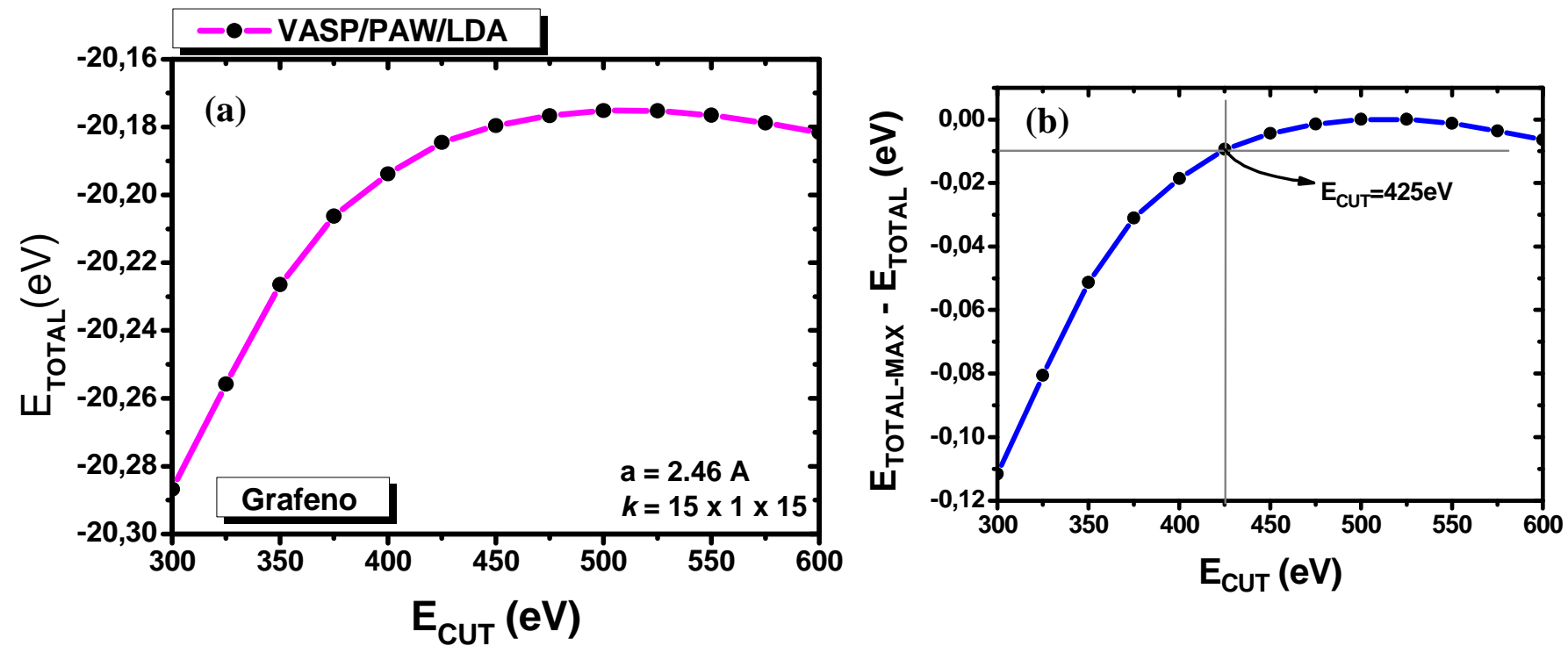

Figura 3.7 - (a) Curva $E_{\text {TOTAL }}$ x $E_{C U T}$ utilizando o funcional LDA para o grafeno; (b) Curva da diferença entre o valor de $E_{\text {TOTAL-MAX }}$ do sistema e os valores de $E_{\text {TOTAL }}$ correspondente a cada energia de corte $\left(E_{C U T}\right)$ versus $E_{C U T}$ utilizando o funcional LDA.
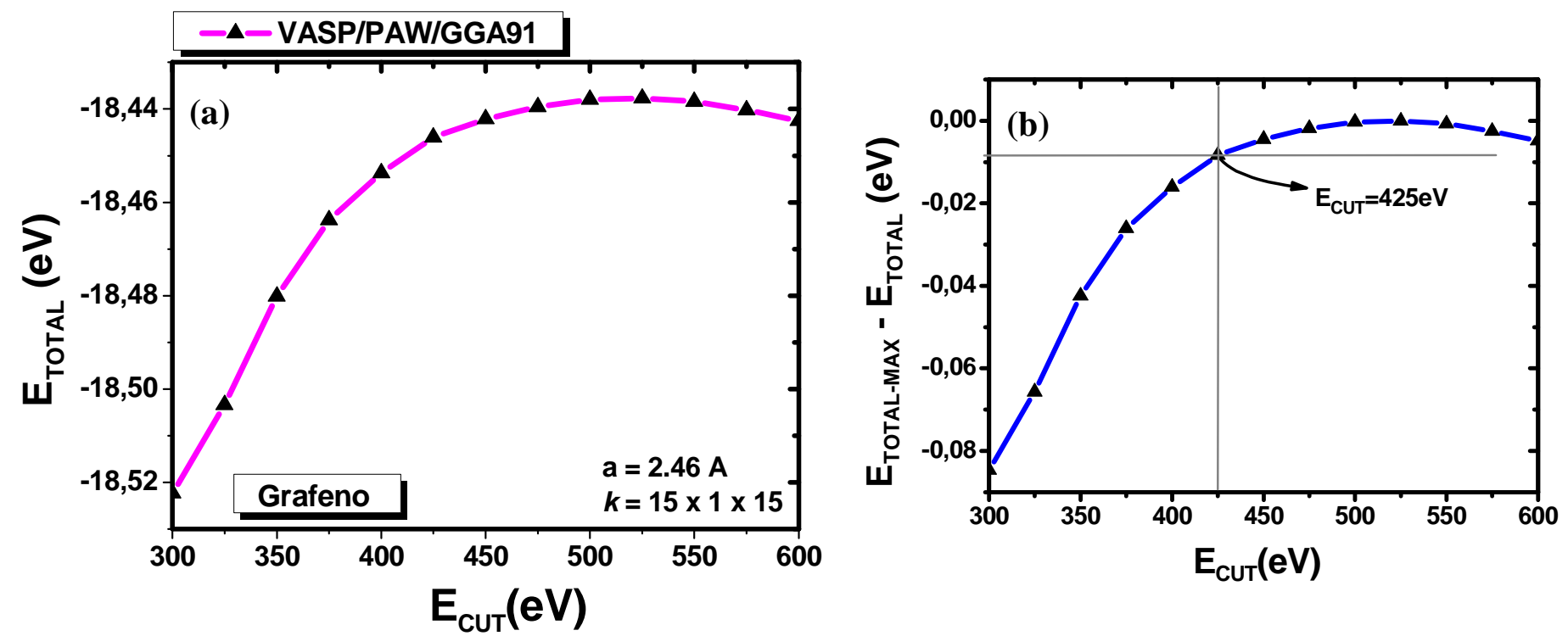

Figura 3.8 - (a) Curva $E_{\text {TOTAL }}$ x $E_{C U T}$ utilizando o funcional GGA-PW91 para o grafeno; (b) Curva da diferença entre o valor de $E_{\text {TOTAL-MAX }}$ do sistema e os valores de $E_{\text {TOTAL }}$ correspondente a cada energia de corte ( $E_{C U T}$ ) versus $E_{C U T}$ utilizando o funcional GGA-PW91. 


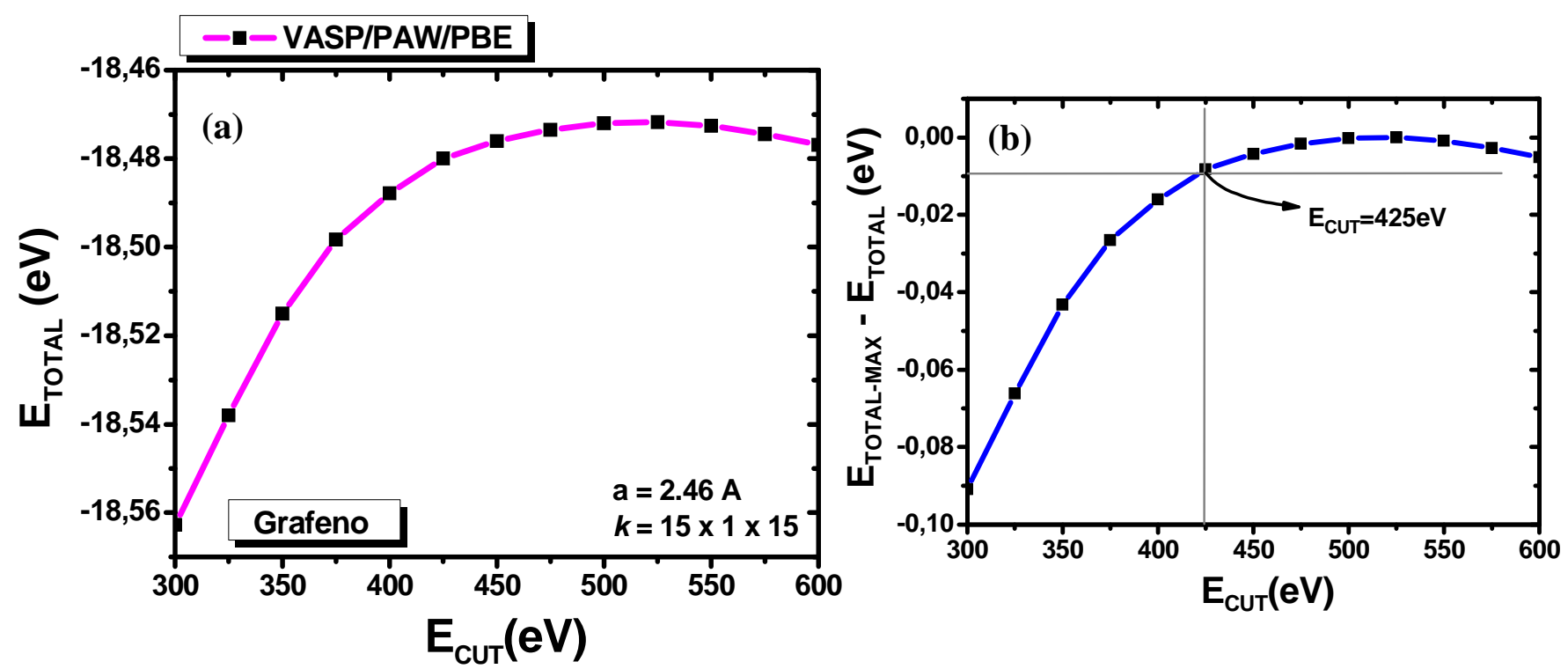

Figura 3.9 - (a) Curva $E_{\text {TOTAL }}$ x $E_{C U T}$ utilizando o funcional GGA-PBE para o grafeno; (b) Curva da diferença entre o valor de $E_{\text {TOTAL-MAX }}$ do sistema e os valores de $E_{\text {TOTAL }}$ correspondente a cada energia de corte $\left(E_{C U T}\right)$ versus $E_{C U T}$ utilizando o funcional GGA-PBE.

Através dos gráficos das figuras 3.4(b), 3.5(b) e 3.6(b), observou-se que para $\left(E_{C U T}\right)$ na faixa de 425 a $600 \mathrm{eV}$, a energia total $\left(E_{T O T}\right)$ sofreu variações da ordem de apenas $10 \mathrm{meV}$, isto significa que pode ser escolhido um valor para $\left(E_{C U T}\right)$ nesta faixa de energia sem comprometer a precisão dos resultados. Desta forma, a energia de corte padrão escolhida para os três funcionais foi de $550 \mathrm{eV}$, uma vez que este valor é suficiente para obter resultados precisos utilizando um tempo computacional satisfatório.

Com a energia de corte $\left(E_{C U T}\right)$ definida como $550 \mathrm{eV}$, e a amostragem de pontos $\vec{k}$ sendo $15 \times 1 \times 15$, foram obtidas as curvas apresentadas nos gráficos 3.10, 3.11 e 3.12, com os parâmetros de rede para os três funcionais LDA, GGA-PW91 e GGA-PBE, respectivamente. 


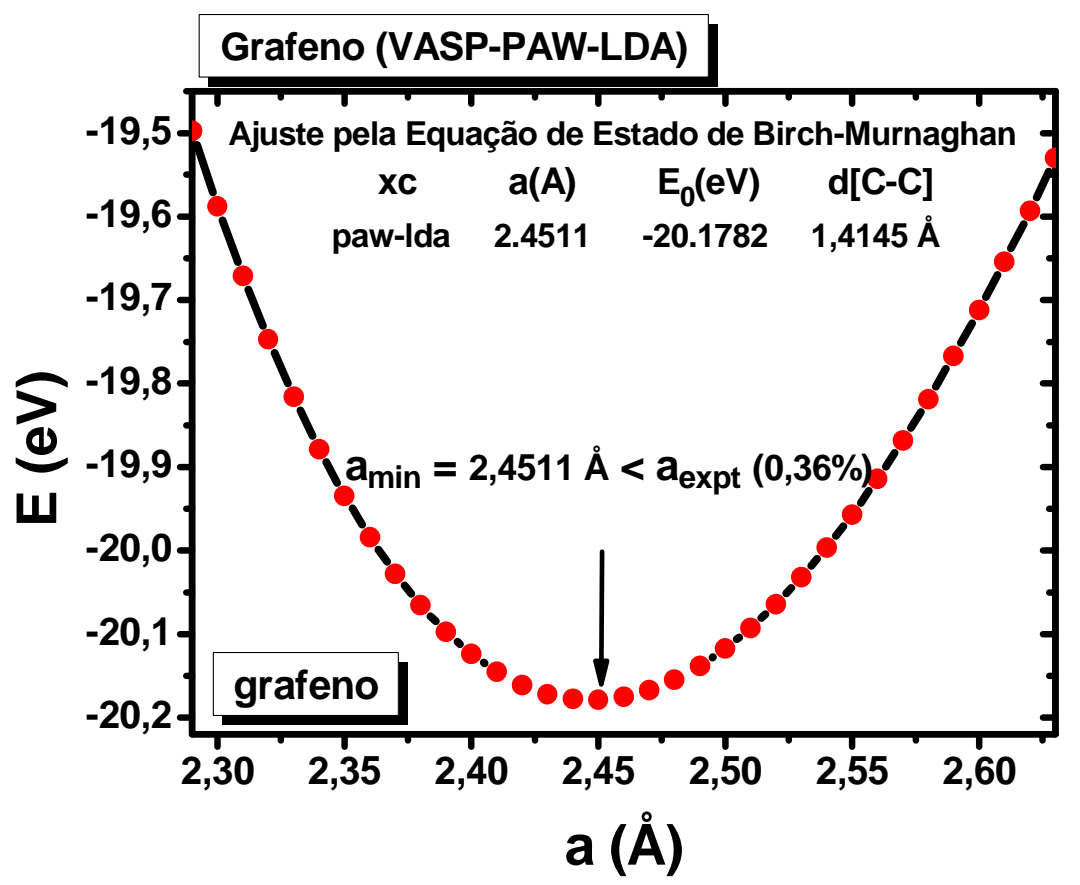

Figura 3.10 - Curva energia total, $E(e V)$, versus parâmetro de rede, $a(\AA)$ para o grafeno. Com essa curva, foi possível definir o valor do parâmetro de rede ótimo utilizando o funcional LDA.

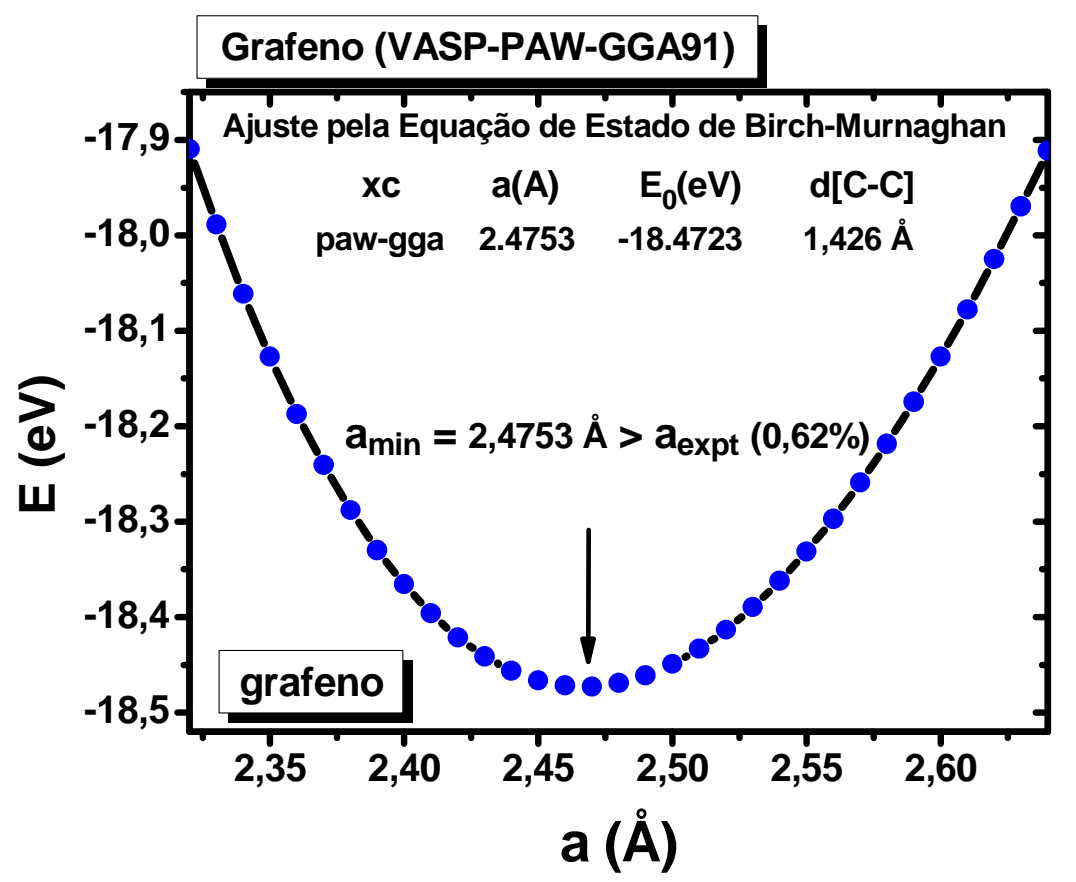

Figura 3.11 - Curva energia total, $E(e V)$, versus parâmetro de rede, $a(\AA)$ para o grafeno. Com essa curva, foi possível definir o valor do parâmetro de rede ótimo utilizando o funcional GGA-PW91. 


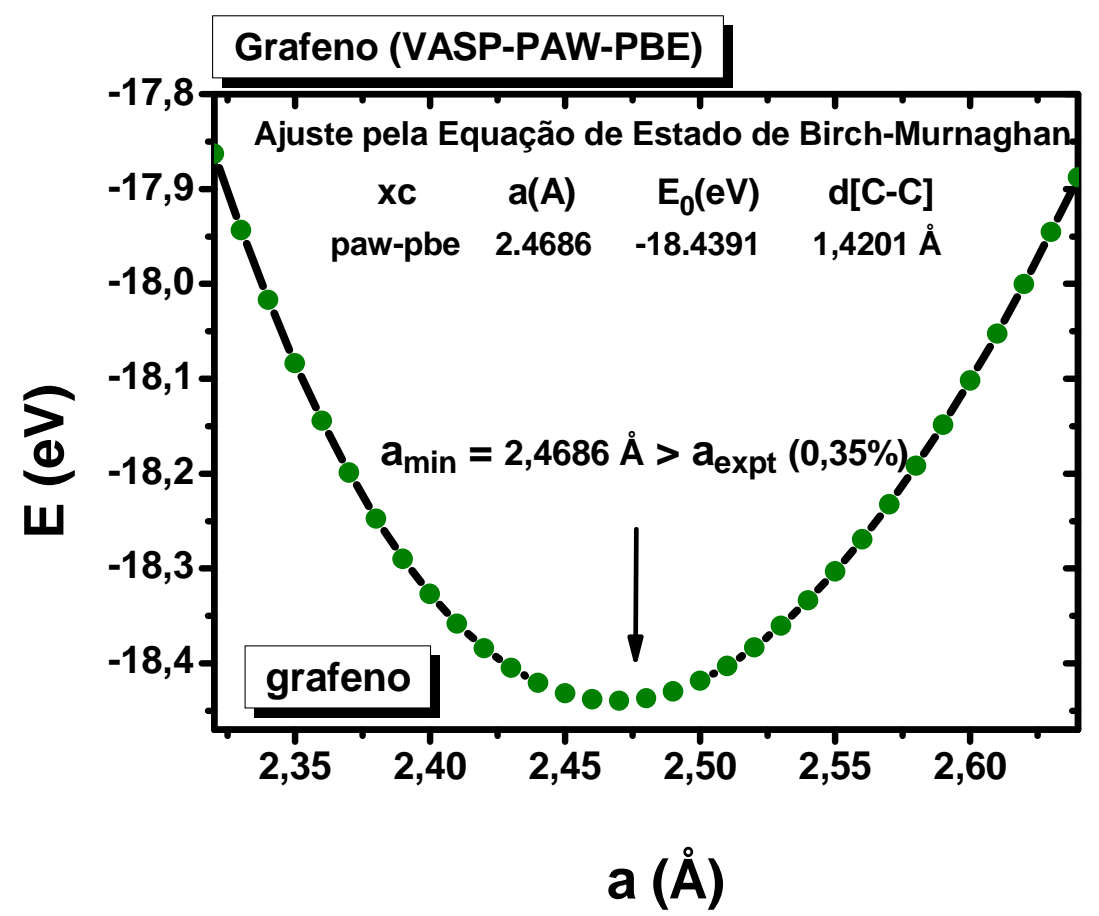

Figura 3.12 - Curva energia total, $E(e V)$, versus parâmetro de rede, $a(\AA)$ para o grafeno. Com essa curva, foi possível definir o valor do parâmetro de rede ótimo utilizando o funcional GGAPBE.).

Para a rede do grafeno, enquanto o funcional LDA subestimou o valor do parâmetro de rede em 0,36\%, o funcional GGA-PW91 superestimou o valor do parâmetro de rede em $0,62 \%$. O funcional que apresentou o parâmetro de rede mais aproximado do experimental foi o GGA-PBE, sendo o valor apenas $0,35 \%$ maior que o valor experimental de 2,46 ̊́. Portanto, o funcional que apresentou resultados mais aproximados do experimental para o grafeno foi o GGA-PBE.

Finalmente, as figuras 3.13 e 3.14 apresentam a estrutura de bandas e a densidade de estados do grafeno, respectivamente, obtidas a partir do funcional padrão escolhido (GGAPBE). Pode-se observar que semelhantemente à estrutura de bandas experimental do grafeno, a banda de condução e a banda de valência se tocam nos pontos de Dirac (ou pontos de alta simetria $\mathrm{K}$ e $\mathrm{K}^{\prime}$ ), que é onde se localiza o nível de Fermi, o qual faz separação entre os estados ocupados e vazios. Além disso, existe uma relação linear para a dispersão de energia próxima a esse ponto, o que implica em alta mobilidade eletrônica, mesmo com baixa densidade de portadores com energias próximas ao nível de Fermi. 


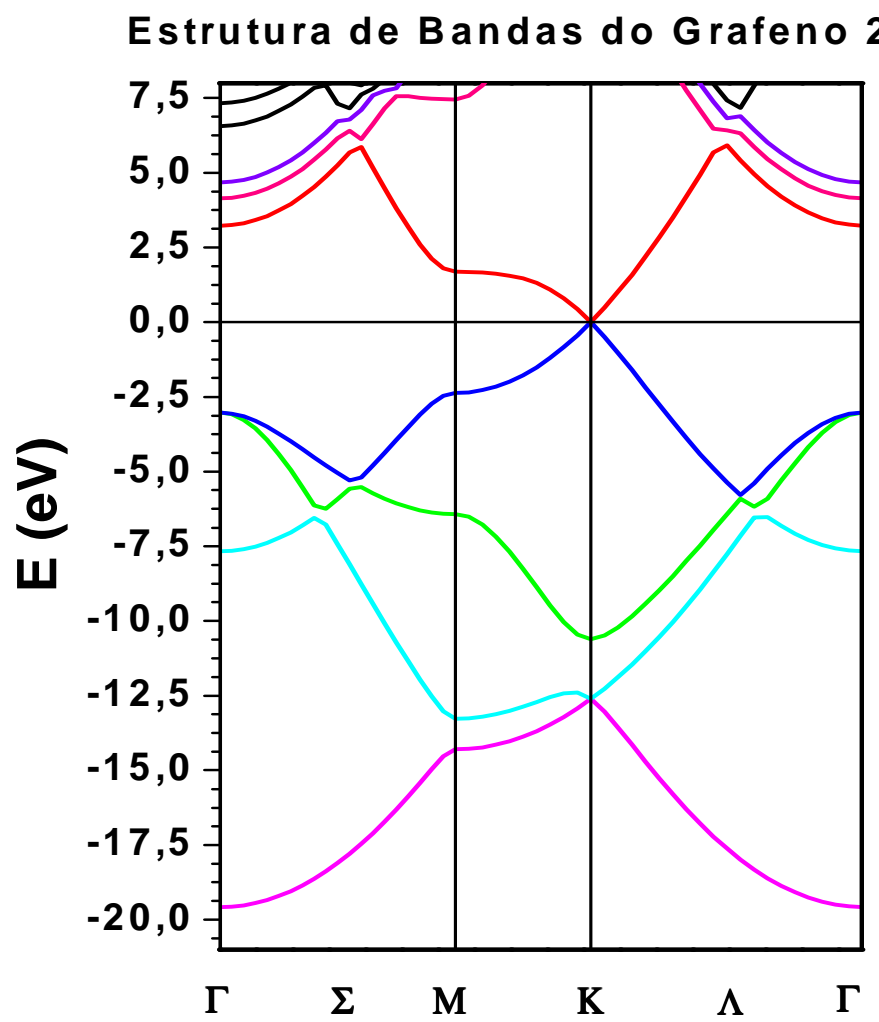

Figura 3.13 - Estrutura de bandas do grafeno utilizando o funcional GGA-PBE.

Os cálculos de densidade de estados também mostraram que a densidade de estados é nula no nível de Fermi $\left(\mathrm{E}=\mathrm{E}_{\mathrm{F}}\right)$, conforme mostrado na figura 3.11 [52]. Desta forma, o grafeno pode ser classificado como um semicondutor de gap nulo nos vértices da zona de Brillouin (pontos K e K’) (conforme discutido no capítulo 2).

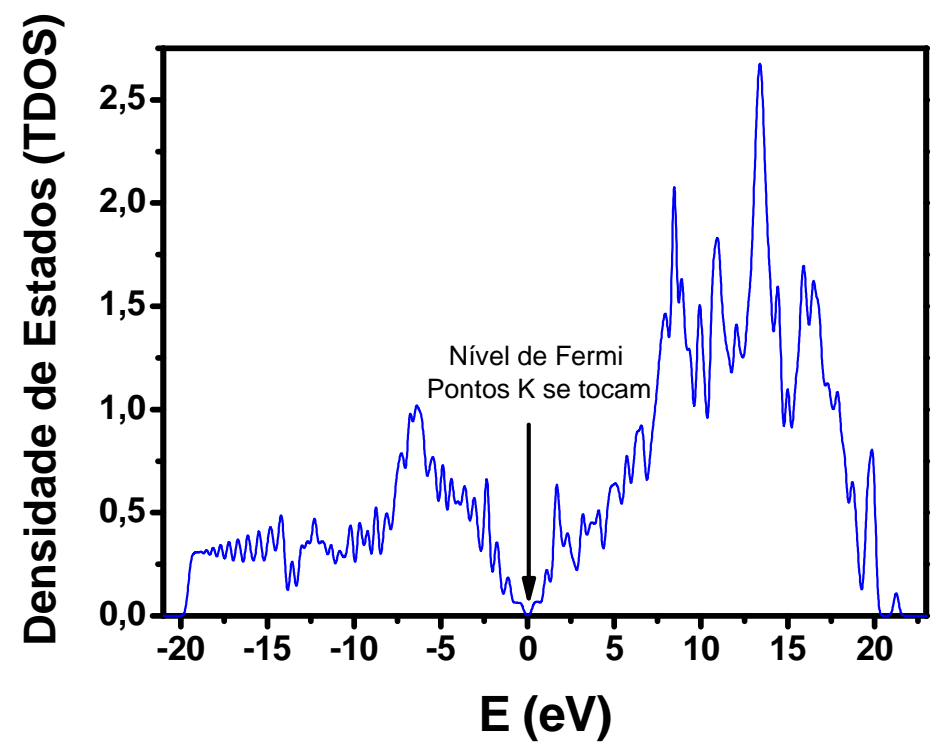

Figura 3.14 - Densidade de estados do grafeno utilizando o funcional GGA-PBE. 


\subsection{2 - Grafano}

Da mesma forma que para o grafeno, obtivemos o parâmetro de rede do grafano para a conformação "em cadeira" (chair-like), que é a conformação mais estável para o grafano, utilizando o funcional GGA-PBE. A energia de corte $E_{C U T}$ utilizada foi de $550 \mathrm{eV}$, e a amostragem de pontos $\vec{k}$ utilizada foi a mesma usada para o grafeno, de $15 \times 1 \times 15$. O valor do parâmetro de rede obtido através do funcional GGA-PBE foi muito próximo ao valor experimental [53, 54] (figura 3.15) e os valores das ligações C-C e C-H são semelhantes aos valores experimentais (conforme descrito no capítulo 4).

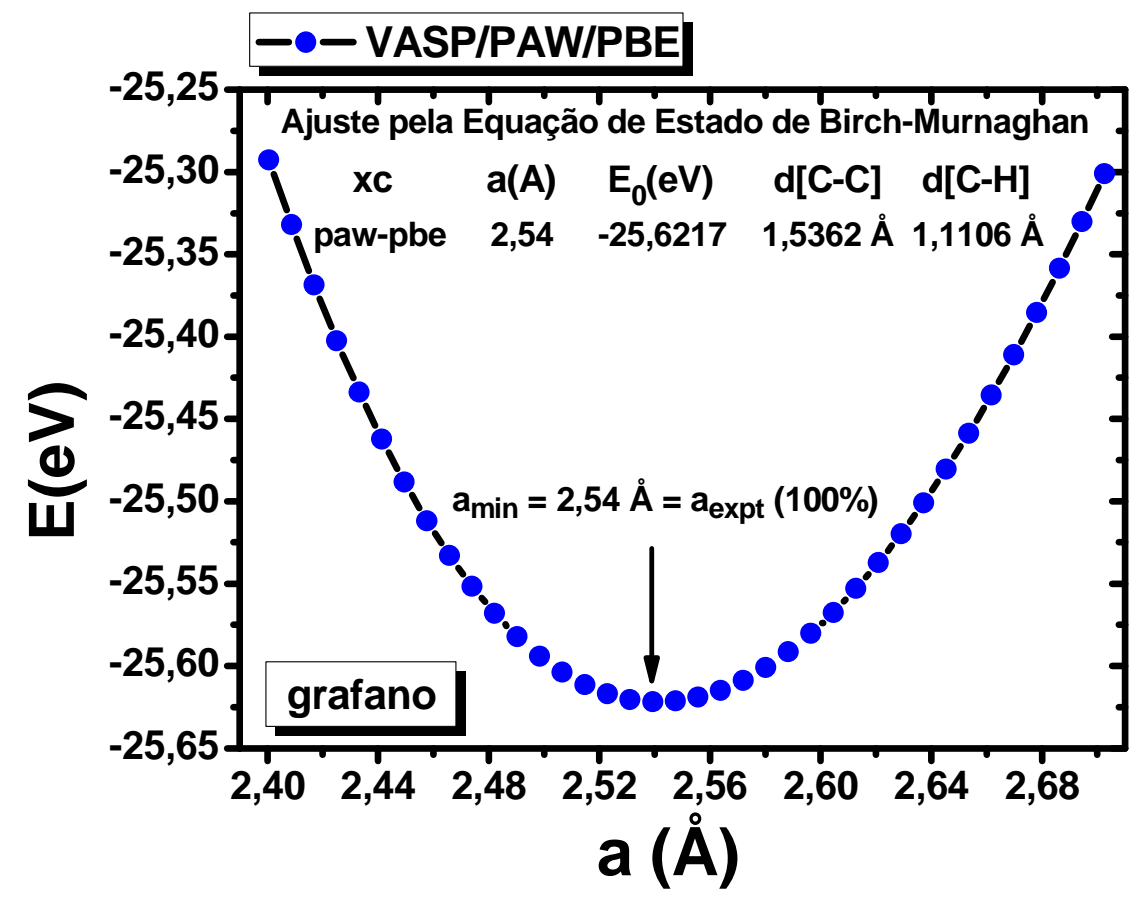

Figura 3.15 - Curva $E(e V)$ versus $a(\AA)$ para o grafano. Definição do valor do parâmetro de rede ótimo utilizando o funcional GGA-PBE.

A estrutura de bandas do grafano, obtida utilizando o funcional GGA-PBE, é apresentada na figura 3.16. A presença de átomos de hidrogênio resulta na abertura de um gap de 4,15 eV no ponto $\Gamma$, em relação ao grafano. Esse valor é muito próximo aos disponíveis na literatura [53,55]. Devido à hibridização $s p^{3}$ nos átomos de carbono (conforme descrito no capítulo 4), o grafano 2D é considerado um semicondutor com gap direto em $\Gamma$.

De acordo com [56], os estados duplamente degenerados no ponto $\Gamma$ no topo da banda de valência são derivados dos orbitais $2 p_{x}$ e $2 p_{y}$ dos átomos de carbono. Por outro lado, a parte inferior da banda de condução é composta principalmente por orbitais $p_{z}$ dos átomos de carbono. 
Os resultados obtidos, até então, foram gerados com o objetivo de comparar com resultados já existentes na literatura. A consistência entre os resultados permite confirmar uma confiabilidade da metodologia proposta neste trabalho. Além disso, serve como referência na comparação com os resultados que serão produzidos posteriormente.

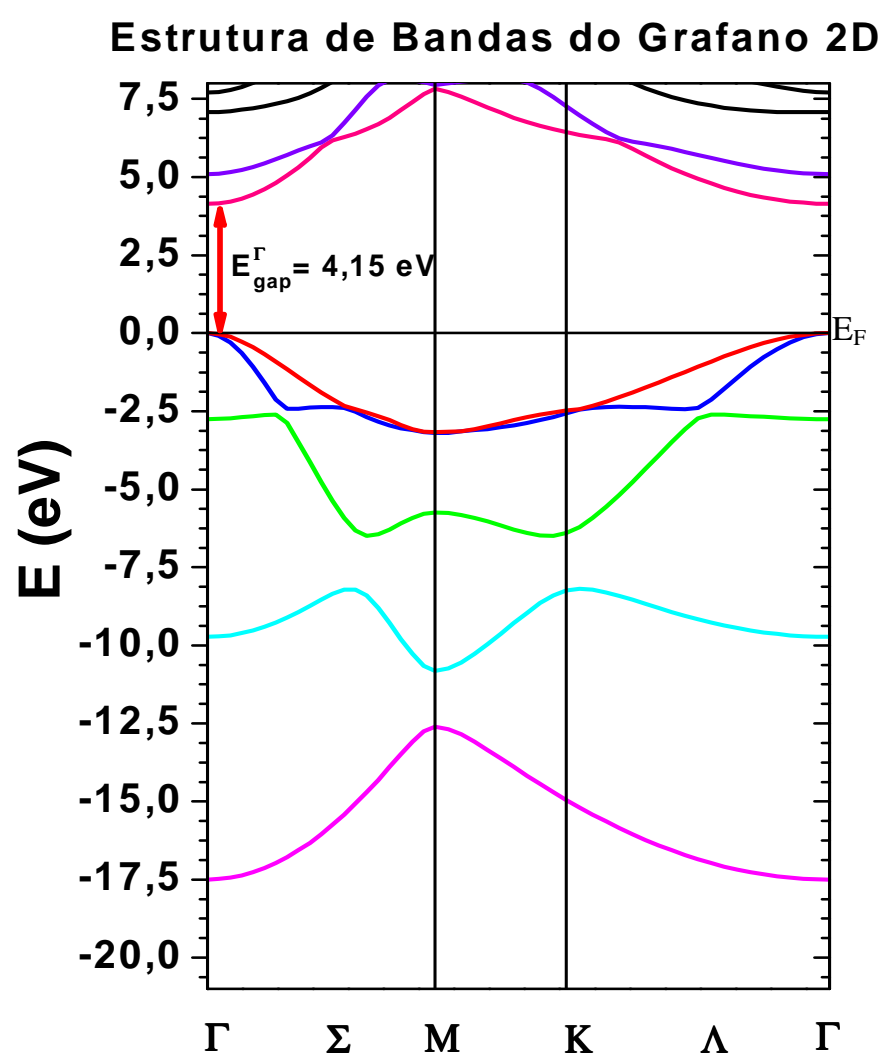

Figura 3.16 - Estrutura de bandas do grafano utilizando o funcional GGA-PBE.

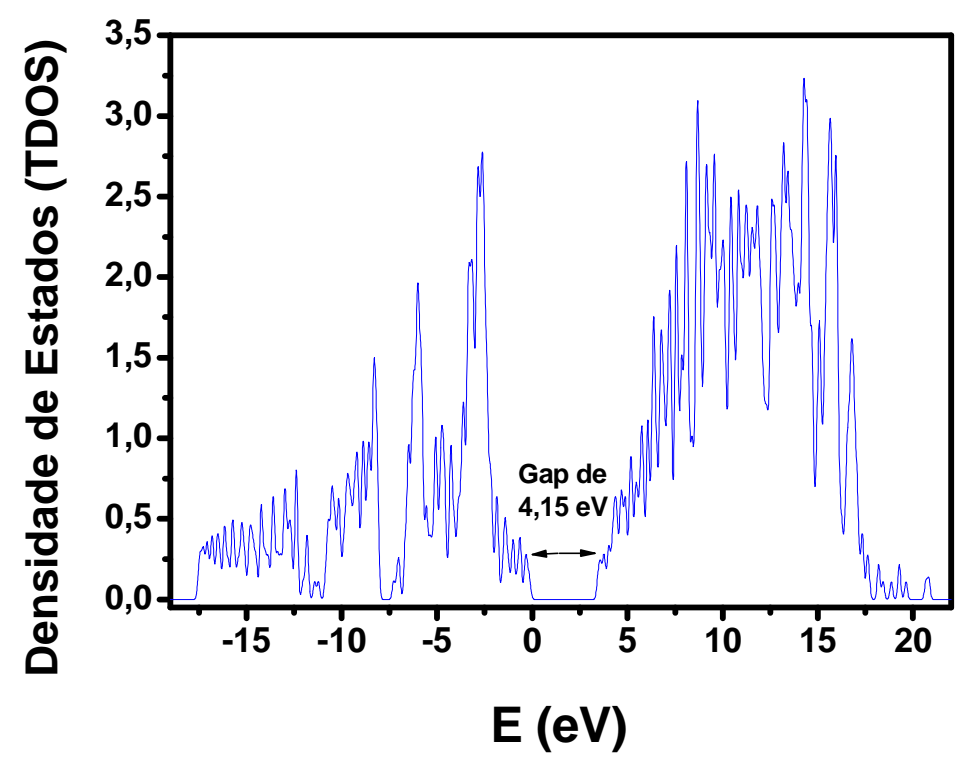

Figura 3.17 - Densidade de estados do grafano utilizando o funcional GGA-PBE. 


\section{9 - Parâmetros Computacionais}

Todos os resultados desta investigação foram obtidos através da teoria do funcional da densidade (DFT) e implementados no pacote de simulação computacional VASP [52]. O potencial de troca-correlação foi descrito dentro da teoria do funcional da densidade e da aproximação de gradiente generalizado (DFT-GGA) na parametrização de Perdew-BurkeErnzerhof (PBE) para todos os sistemas propostos [50]. As funções de onda eletrônicas foram descritas pelo método PAW (Projector Augmented Wave) [52], tendo um conjunto de bases de ondas planas com uma energia de corte $\left(E_{C U T}\right)$ de $550 \mathrm{eV}$ para os sistemas apresentados no capítulo 5 e uma energia de corte $\left(E_{C U T}\right)$ de $400 \mathrm{eV}$ para os sistemas apresentados no capítulo 6. A otimização configuracional foi realizada considerando a relaxação em todos os átomos, sem vínculo de simetria, até que as forças fossem menores que 3meV/Á em qualquer átomo.

A zona de Brillouin foi mapeada por uma amostragem de $15 \times 1 \times 15$ pontos $\vec{k}$ (Monkhorst-Pack) para os sistemas de grafeno compostos por elementos do grupo IV da tabela periódica (capítulo 5). Por outro lado, foi utilizada uma amostragem de $2 \times 1 \times 2$ pontos $\vec{k}$ (Monkhorst-Pack) para as estruturas de grafeno com uma supercélula hexagonal $8 x 8$, ou seja, 128 átomos, com defeitos e dopagens, estruturas apresentadas no capítulo 6. As estruturas planares foram construídas usando condições de contorno periódicas com uma célula de simulação hexagonal. Na direção $(y)$, perpendicular às folhas, foi usado um parâmetro de rede de $20 \AA$ para os sistemas do capítulo 5 devido à torção (distância de "buckling") apresentada por estes sistemas. Por outro lado, para o grafeno com defeitos e dopagens investigados no capítulo 6, foi utilizada a distância de 10 Á entre o plano atômico e suas imagens (na direção y), por serem sistemas planos. Os valores escolhidos foram suficientes para evitar a interação entre os átomos na célula principal e suas imagens. A tabela 3.1 apresenta o resumo dos parâmetros utilizados nos cálculos.

As energias de formação $\left(E_{F}\right)$ e de ligação $\left(E_{B}\right)$ para todos os sistemas foram calculadas seguindo o mesmo procedimento apresentado em investigações anteriores [55]. A energia de ligação $\left(E_{B}\right)$ das estruturas foi calculada como a diferença entre a energia total da estrutura estável e as energias totais dos respectivos átomos isolados nos seus estados de carga neutra, para o grafano, por exemplo, a energia de ligação pode ser calculada através da seguinte expressão: 
$E_{B}($ Grafano $) /$ átomo $=\frac{E_{\text {TOTAL }}(\text { Grafano })}{4}-\frac{\left[E_{\text {TOTAL }}(\text { átomo } C)+E_{\text {TOTAL }}(\text { átomoH })\right]}{2}$

Por outro lado, o calor de formação $\left(E_{F}\right)$ da folha de grafano hidrogenada (ou fluorinada) foi calculada como a diferença entre a energia de ligação do grafano e as energias de ligação das respectivas estruturas do grafeno (estável) e as energias das moléculas diatômicas $\mathrm{H}_{2}$ (ou $\left.\mathrm{F}_{2}\right)$, ou seja:

$$
E_{F}(\text { Grafano })=E_{F}(\text { Grafano })-E_{F}(\text { Grafeno })-E_{\text {TотаL }}\left(H_{2}\right)+2 E_{A T}(H)
$$

As energias totais dos átomos isolados e moléculas diatômicas foram obtidas considerando uma grande célula de simulação e as mesmas aproximações metodológicas de todos os outros cálculos descritos nos parágrafos anteriores.

Outro parâmetro de grande importância calculado foi a velocidade dos portadores, que é definida como a variação da energia em função do espaço de momentos $k$, a qual é dada pela seguinte expressão:

$$
v=\frac{1}{\hbar} \frac{d E}{d k}
$$

Para os sistemas considerados no capítulo 5, a velocidade de Fermi foi calculada nos seus respectivos pontos de Dirac $K$, na direção $K \rightarrow \Gamma$.

Tabela 3.1 - Parâmetros Computacionais utilizados nos cálculos.

\begin{tabular}{|l|c|c|}
\hline \multicolumn{1}{|c|}{ Parâmetros } & Capítulo 5 & Capítulo 6 \\
\hline Funcional de Troca-Correlação & GGA-PBE & GGA-PBE \\
\hline Método & PAW & PAW \\
\hline Amostragem de pontos $\vec{k}$ & $15 x 1 x 15$ & $2 x 1 x 2$ \\
\hline $\mathbf{D}_{\text {plano atômico- imagem }(\AA)}(\mathbf{A})$ & 20 & 400 \\
\hline$\left(E_{C U T}\right)(\mathbf{e V})$ & 550 & $3 \mathrm{meV} / \AA$ \\
\hline Critério de Convergência & $3 \mathrm{meV} / \AA$ & \\
\hline
\end{tabular}




\section{Capítulo 4}

\section{FUNCIONALIZAÇÃO DO GRAFENO E NANOFITAS DE GRAFENO}

\section{1 - Introdução}

A funcionalização química é um dos principais procedimentos de manipulação das propriedades físicas e químicas de nano-elementos para a obtenção de determinados comportamentos. A funcionalização permite ainda estudar os mecanismos de interação desses nano-elementos com outros nanosistemas. Inicialmente, o grafeno foi usado por teóricos como um modelo simplificado para descrever as propriedades de nanotubos $[4,57,58]$. Depois da descoberta do grafeno e de suas propriedades eletrônicas extraordinárias, a funcionalização química do grafeno se tornou foco de grande interesse para a físico-química contemporânea [59]. 
Os principais motivos para o desenvolvimento de pesquisas nesta área são:

- A possibilidade de modificar as propriedades eletrônicas através da abertura de um gap de energia de uma monocamada ou bicamada de grafeno [53, 60, 61].

- O potencial uso para armazenamento de hidrogênio [53, 60];

- O potencial uso em spintrônica através do magnetismo de nanofitas de grafeno [60, $62]$

- A pesquisa de métodos de produção de grafeno a baixo custo por redução química de óxido de grafite e manipulação das suas propriedades eletrônicas e mecânicas [63, 64];

- A funcionalização das "bordas" de nanofitas de grafeno [65-67];

- A oxidação e "quebra" de ligações no grafeno como ferramenta para criar nanoestruturas de grafeno com determinadas formas [68, 69];

Em termos gerais, a funcionalização ocorre ao inserir, ou substituir, átomos e/ou moléculas específicas na superfície de determinada estrutura, de modo que possam executar alguma função física ou química bem definida. Um exemplo bem conhecido da funcionalização do grafeno é a adição átomos de hidrogênio à sua superfície (hidrogenação) [53, 60], além de impurezas como o boro e nitrogênio [70], defeitos [62] ou vacâncias (neste último caso, a funcionalização ocorre com a subtração de átomos) [71]. O grafeno funcionalizado pode apresentar propriedades eletrônicas e mecânicas substancialmente diferentes daqueles não funcionalizados. Sendo assim, é de extrema importância o entendimento teórico das propriedades físicas e químicas do grafeno resultante das funcionalizações.

Existem dois tipos principais de funcionalização: uma chamada de covalente, com a formação de ligações fortes de natureza covalente, e a outra não-covalente, onde forças de Van der Waals estão associadas. A maioria das investigações teóricas foca-se na funcionalização covalente, uma vez que muitos dos códigos usados atualmente, baseados na DFT, não permitem tratar as interações de Van der Waals de forma apropriada [72, 73]. A funcionalização química do grafeno pode ainda estar relacionada às ligações químicas iônicas. Existem os casos de camadas de grafeno em compostos de grafite intercalados [74, 75] e camadas de grafeno em superfícies de metal. Este tipo de funcionalização é importante no estudo da possibilidade da supercondutividade no grafeno, pela analogia com o supercondutor intercalado cristalino formado por $\mathrm{CaC}_{6}$ e $\mathrm{YbC}_{6}[76]$. 
Este capítulo descreve resultados de primeiros princípios existentes na literatura que abordam os processos de funcionalização do grafeno e nanofitas de grafeno. A seção 4.2 descreve o processo de hidrogenação do grafeno e as suas propriedades resultantes. A seção 4.3 discute a dopagem do grafeno por outras espécies químicas. Finalmente, a seção 4.4 trata do processo de funcionalização de nanofitas de grafeno e os seus efeitos.

\section{2 - Hidrogenação do Grafeno}

A hidrogenação de nano-elementos de carbono, como os fulerenos, é um tema de grande interesse na comunidade científica internacional, especialmente devido às potencialidades no desenvolvimento de células de combustível baseadas no armazenamento de hidrogênio. Logo em seqüência à síntese do primeiro fulereno, apareceram na literatura diversos trabalhos teóricos e experimentais sobre o menor fulereno hidrogenado $\mathrm{C}_{60} \mathrm{H}_{2}$ [7780]. Posteriormente, novas investigações resultaram na descoberta de numerosos sistemas com maiores concentrações de hidrogênio, até um limite $C_{60} H_{36}$. Observou-se, por exemplo, que os compostos $C_{60} H_{x}$ só seriam estáveis quando apresentassem números pares de hidrogênio [80,81]. Maiores concentrações de hidrogênio nos fulerenos tornam-se impossíveis, devido às suas estruturas geométricas específicas.

Outro tema que vem atraindo grande interesse científico é o magnetismo em fulerenos hidrogenados, causado por elétrons desemparelhados. Isto pode ser alcançado somente com números ímpares de átomos de hidrogênio em moléculas de buckball. Infelizmente, estes fulerenos hidrogenados são instáveis e observados somente como produtos intermediários de algumas reações químicas. Deve ser destacado que os fulerenos hidrogenados são estáveis quimicamente e dificilmente perdem átomos de hidrogênio, mesmo sob a ação de altas pressões, o que torna a reversibilidade da hidrogenação de um fulereno muito difícil. Por outro lado, pesquisas tiveram sucesso na hidrogenação reversível de nanotubos de carbono de parede única, revelando que os nanotubos são bons candidatos para o armazenamento de hidrogênio em células de energia [57]. 
Recentemente, os efeitos da hidrogenação sobre a curvatura de nanotubos foram estudados detalhadamente, onde se observou propriedades distintas para a hidrogenação em duas direções, ao longo e em torno dos nanotubos. Além disso, foi discutido também que o raio de curvatura de nanotubos típicos $(1.0-1.5 \mathrm{~nm})$ é comparável ao raio de distorções geométricas induzidas pelo hidrogênio em uma folha de grafeno [60]. Desta forma, para simplificar a simulação da funcionalização química dos nanotubos, usa-se frequentemente o grafeno.

Entretanto, o grafeno tornou-se o foco principal das pesquisas de nano-elementos de carbono para armazenamento de hidrogênio, devido às suas propriedades físicas peculiares (conforme discutido no capítulo 2). Desde a descoberta do grafeno, diversos trabalhos têm sido realizados sobre a sua hidrogenação, para modificar as suas propriedades físicas. Foram feitos estudos sobre barreiras de potencial para os casos de adsorção de um único átomo de hidrogênio sobre o grafeno, bem como uma formação de cadeias de hidrogênio sobre o mesmo [58].

As modificações na estrutura eletrônica do grafeno perfeito e do grafeno com defeito do tipo de "Stone-Wales", provocados pela adsorção de um único átomo de hidrogênio, foram discutidos recentemente em [4]. Adicionalmente, foi investigada a relação do magnetismo com a quimissorção de hidrogênio para o grafeno perfeito e para dois tipos de defeitos: monovacância e átomos de carbono entre as camadas do grafite em [57]. Sluiter e Kawazoe usaram o "algoritmo de expansão de grupo" para achar a configuração mais estável para completa cobertura do grafeno por hidrogênio, para modelar a hidrogenação de nanotubos [82]. Esta configuração corresponde ao chamado grafano o qual tem sido estudado por cálculos DFT $[53,83]$. O grafeno foi também estudado para modelar a hidrogenação da grafite [84-87].

Recente estudo [88] endereçou a questão da quimissorção de um único átomo de hidrogênio em grafeno, bem como as interações dos momentos magnéticos decorrentes, devido aos elétrons não-emparelhados, na hidrogenação de átomos de carbono pertencentes à mesma sub-rede. Os resultados mostraram que neste caso a interação acaba sendo ferromagnética. Adicionalmente, descobriu-se que a combinação de três átomos de hidrogênio (dois deles pertencentes à sub-rede A e o terceiro pertencente à sub-rede B) permanece magnética, fato que pode ser importante no contexto de discussões sobre o potencial magnetismo dos sistemas de carbono. 
Sofo e co-autores [53] consideraram teoricamente o grafano, que é um hidrocarboneto totalmente saturado, derivado de uma única folha de grafeno com a fórmula $\mathrm{CH}$, onde todos os átomos de carbono na hibridização $\mathrm{sp}^{3}$ formam uma rede hexagonal e os átomos de hidrogênio são ligados a átomos de carbono em ambos os lados da folha do grafeno de forma alternada (conforme figura 4.1). Esta estrutura corresponde a camadas semelhantes às de diamantes fracamente acopladas, com hibridização $\mathrm{sp}^{3}$, em vez de $\mathrm{sp}^{2}$ como na grafite e grafeno. Esta mudança de hibridização resulta em um abertura de gap da ordem de $3 \mathrm{eV}$ no espectro de energia eletrônico, devido a uma transformação de orbitais $\pi$ e $\pi^{*}$ para orbitais $\sigma$ e $\sigma^{*}$. A energia de coesão é relativamente pequena (da ordem de $0.4 \mathrm{eV}$ por átomo de hidrogênio), o que permite fazer o processo de hidrogenação reversível [60].

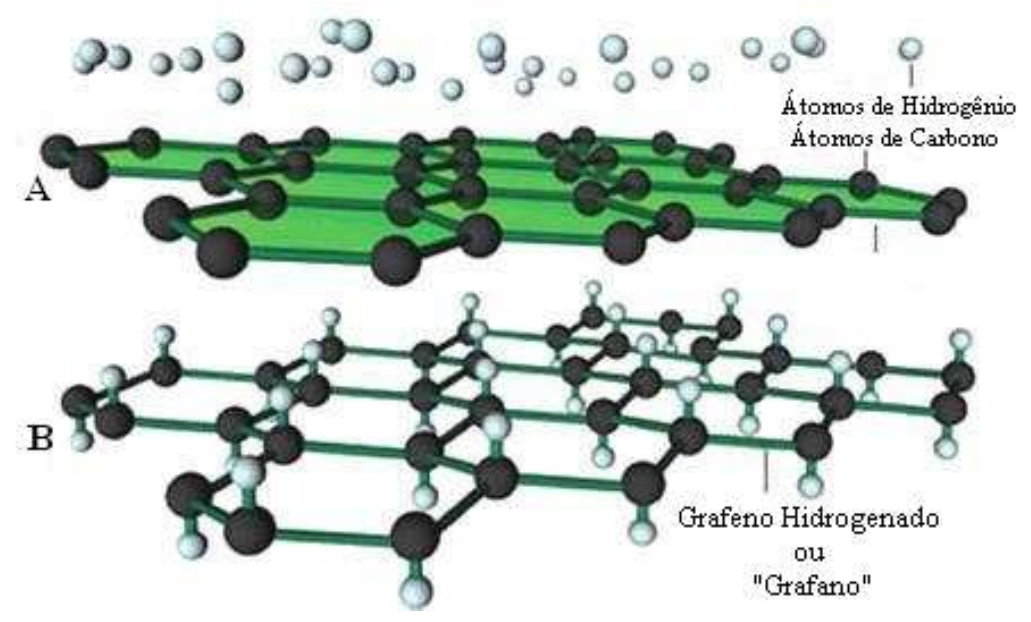

Figura 4.1 - Ilustração da estrutura do grafeno hidrogenado ou "grafano" [155].

Existem duas conformações mais estáveis para o grafano: a conformação "em cadeira" (chair-like) e a "em barco" (boat-like) [53, 54]. Na conformação "em cadeira”, os átomos de hidrogênio alternam sobre ambos os lados do plano da folha, enquanto que na conformação "em barco" os átomos de hidrogênio alternam em pares sobre ambos os lados do plano (conforme figura 4.2). O comprimento de ligação entre os átomos de carbono na primeira conformação é de $1.52 \AA$, valor similar ao comprimento de ligação teórico para átomos de carbono com hibridização $s p^{3}$ que é de $1.53 \AA$, como ocorre na estrutura do diamante, e é muito maior que $1.42 \AA$, característica da hibridização $s p^{2}$ do carbono no grafeno. 


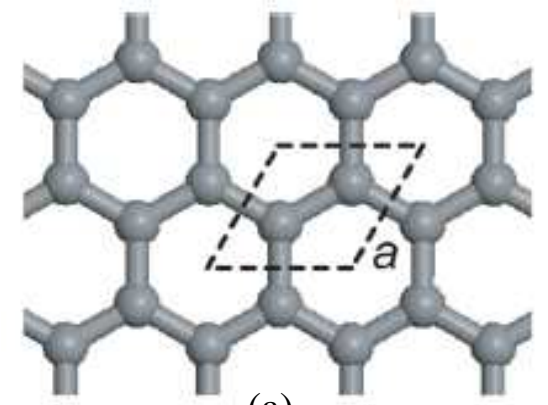

(a)

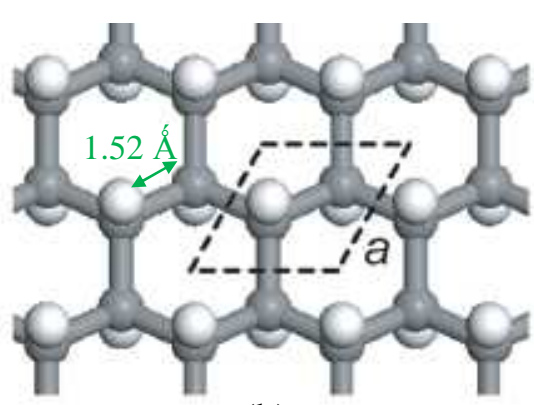

(b)

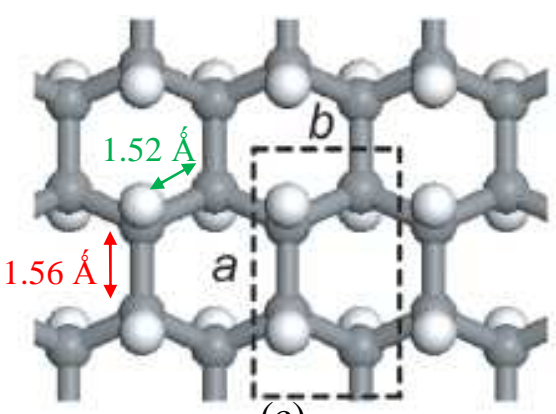

(c)

Figura 4.2 - (a) Estrutura do grafeno, com dois átomos por unidade celular; (b) Grafano chairlike, com quatro átomos (dois $\mathrm{C}$ e dois $\mathrm{H}$ ) por unidade celular e (c) Grafano boat-like com quatro átomos de carbono e quatro átomos de hidrogênio por unidade celular. [53]

Por outro lado, a conformação "em barco" apresenta dois comprimentos de ligação entre átomos de carbono $\left(\mathrm{d}_{\mathrm{C}-\mathrm{C}}\right)$. Os átomos de carbono ligados a átomos de hidrogênio em lados opostos do plano da folha de grafeno apresentam comprimento de ligação igual a $1.52 \AA$ Á, enquanto que os átomos de carbono ligados aos átomos de hidrogênio no mesmo lado do plano da folha apresentam comprimento de ligação de 1.56 Á, valor um pouco maior que o primeiro devido à repulsão entre os átomos de hidrogênio $(\mathrm{H}-\mathrm{H})$. $\mathrm{O}$ comprimento de ligação C-H de 1.1 Á é similar nas duas conformações e é o valor típico de compostos de hidrocarbonetos [53].

A conformação “em cadeira”, descrito na figura 4.2 (b), é mais estável que a "em barco”, na figura 4.2 (c), devido ao fato desta última apresentar duas distâncias carbonocarbono e devido à existência de dois diferentes alinhamentos entre os átomos de carbono e hidrogênio $(\mathrm{C}-\mathrm{H})$. Embora o comprimento de ligação $\mathrm{C}-\mathrm{C}$ no grafano seja muito maior que do grafeno, o parâmetro de rede é apenas um pouco maior, devido a sua topologia out-ofplane. Diferentemente do grafeno, o grafano "em cadeira" tem uma base atômica composta por quatro átomos (dois átomos de carbono e dois átomos de hidrogênio) e o parâmetro de rede igual a $2.54 \AA$, por outro lado, o grafano "em barco" tem a sua base atômica composta por oito átomos (quatro átomos de carbono e quatro átomos de hidrogênio) e dois parâmetros de rede diferentes, 4.35 Á e $2.51 \AA$ Á, conforme apresentado na tabela 4.1 . 
Tabela 4.1 - Comparação dos parâmetros de rede e comprimento de ligação C-C do grafeno, grafano chair-like e grafano boat-like. [53, 54].

\begin{tabular}{|c|c|c|c|}
\hline Parâmetros de rede & Grafeno & Grafano chair-like & Grafano boat-like \\
\hline$a(\dot{A})$ & 2.46 & 2.54 & 4.35 \\
\hline$b(\dot{A})$ & 2.46 & 2.54 & 2.51 \\
\hline Comp. de Ligação C-C $(\dot{A})$ & 1.42 & 1.52 & 1,52 e 1,56 \\
\hline
\end{tabular}

Com relação à estabilidade da estrutura do grafeno hidrogenado, Roman e co-autores [56,89] realizaram cálculos DFT considerando diferentes configurações de hidrogênio sobre o grafeno e concluíram que as configurações onde os átomos de hidrogênio são ligados a diferentes sub-redes são as mais estáveis, similar ao descrito na figura 4.3 (c), concordando com as informações apresentadas anteriormente. Além disso, alguns princípios gerais de hidrogenação do grafeno foram formulados baseados em cálculos DFT, utilizando ondas planas e pseudopotenciais ultra-suaves, e o funcional de troca-correlação GGA para várias configurações em uma ampla faixa de cobertura do grafeno em [60].

(a)

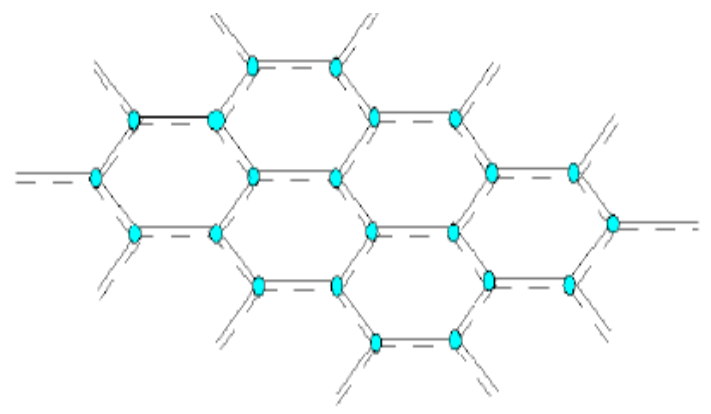

(b)

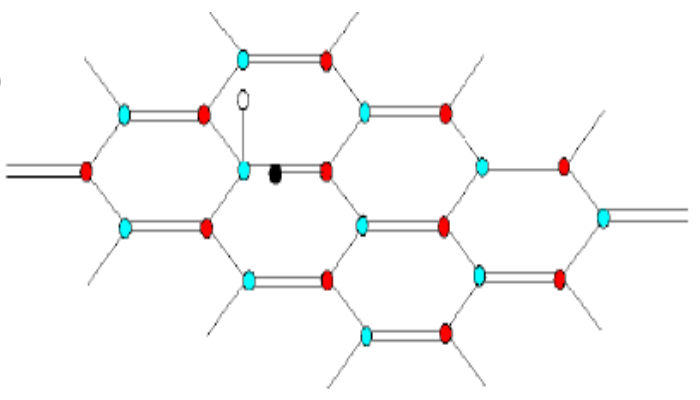

(c)

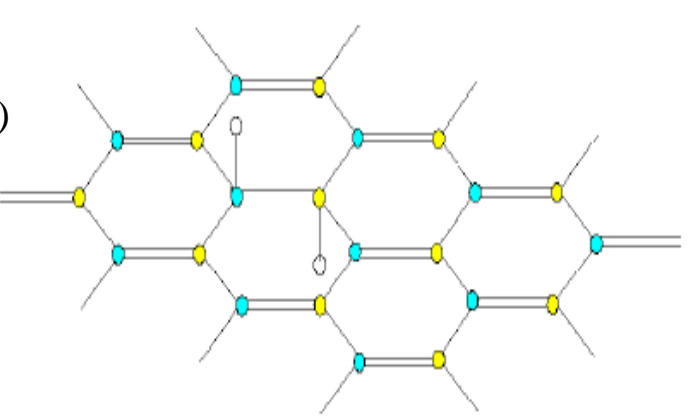

Figura 4.3 - Ilustração das ligações químicas em: (a) grafeno puro (a linha pontilhada corresponde às bandas duplas deslocalizadas); (b) grafeno com um único átomo de hidrogênio quimissorvido (o círculo branco representa o átomo de hidrogênio e o preto corresponde aos elétrons não emparelhados na ligação quebrada, (distribuído na rede em vermelho, subredes não equivalentes são mostradas em diferentes cores); (c) o grafeno com um par de átomos de hidrogênio quimissorvidos. [59] 
Os átomos de carbono no grafeno estão em um estado de hibridização $\mathrm{sp}^{2}$, no qual cada átomo de carbono tem três orbitais $\sigma$ e um do tipo $\pi$. A quimissorção de átomos de hidrogênio significa a quebra de uma das ligações $\pi$ e a transformação da hibridização $\mathrm{sp}^{2}$ para $\mathrm{sp}^{3}$. Com a quebra de uma das ligações $\pi$, os elétrons não-emparelhados permanecem nos átomos de carbono vizinhos, representado pelo círculo preto na figura 4.3 (b), formando um momento magnético. Entretanto, a quimissorção do próximo átomo de hidrogênio no átomo de carbono vizinho liga este elétron não emparelhado e faz com que o momento magnético desapareça, conforme figura 4.3 (c) [60].

Em [59], foram propostos dois princípios para a funcionalização química do grafeno. O primeiro princípio é a ausência de elétrons não-emparelhados, em outras palavras, bandas pendentes (dangling bands). Como uma conseqüência deste princípio, a quimissorção de grupos funcionais em diferentes sub-redes é mais energeticamente favorável que em uma mesma rede. O próximo princípio é a minimização de frustrações geométricas (geometric frustrations), ou seja, a quebra da alternância (up e down) das ligações dos átomos de hidrogênio ao plano da folha do grafeno. Uma pode ser vista na figura 4.3 (b), onde a quimissorção de um único átomo de hidrogênio resulta em deslocamentos atômicos essenciais dentro de um círculo de raio de $5 \AA$ Á (dois períodos da rede cristalina do grafeno) e em menor, mas ainda perceptível com distorções com um raio característico de $10 \AA \AA$, conforme figura 4.4. A quimissorção de um único átomo de hidrogênio leva a um grande deslocamento para cima do carbono ligado com o hidrogênio e um deslocamento para baixo para os dois átomos vizinhos.

Entretanto, se forem corrigidas as posições de todos os átomos de carbono, exceto os átomos de primeiros e segundos vizinhos do átomo central [90], os deslocamentos atômicos sofrem uma mudança. Tal procedimento deve ser razoável para simular a funcionalização química para sistemas tais como o grafeno sobre a grafite [91], Ru [92-94], Ir [93-95] e Pt $[93,94]$ onde parte da rede do grafeno é fortemente acoplada com o substrato.

A quimissorção do próximo hidrogênio é mais favorável quando resulta em mínimas distorções adicionais. Isto significa que a configuração energética mais estável surge se dois átomos de hidrogênio forem quimissorvidos por átomos de carbono vizinhos em diferentes lados com respeito à folha do grafeno, conforme descrito na figura 4.3 (c). Se somente um lado está disponível para a quimissorção, a configuração mais favorável de dois átomos de hidrogênio é a ligação com átomos de carbono nas bordas opostas do hexágono na rede favo de mel [96]. 


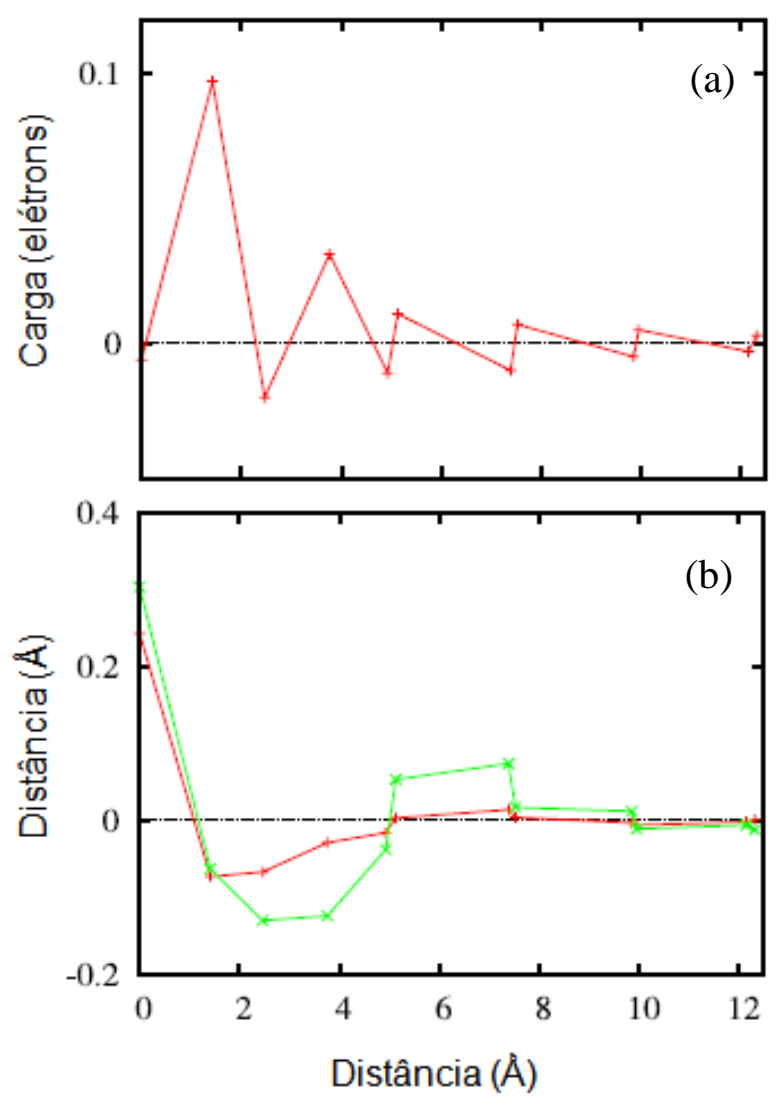

Figura 4.4 - (a) Distribuição de carga para elétrons não emparelhados em função da distância do átomo de carbono central, onde o hidrogênio é quimissorvido e (b) os desvios de átomos de carbono da configuração plana para os casos de átomos de hidrogênio isolados (linha vermelha (preta)) e dois átomos quimissorvidos em sítios vizinhos dos diferentes lados da folha de grafeno (linha verde) [25].

Para o caso de mais dois átomos de hidrogênio distantes, eles deveriam migrar para esta posição otimizada superando algumas barreiras de potencial [97], o que foi observado experimentalmente para ambos materiais, grafite [84] e grafeno [98].

Através destes dois princípios de funcionalização química defini-se que, na configuração mais estável para um par de átomos de hidrogênio sobre os átomos de carbono no grafeno, os átomos de hidrogênio estarão localizados em átomos de carbono vizinhos em lados opostos em relação à folha de grafeno. Devido às distorções geométricas, uma região de raio de $5 \AA$ Á ao redor do par é mais quimicamente ativa que o grafeno puro, similar ao caso do grafeno com defeitos $[57,62,70,97,98]$ e, assim, os próximos átomos de hidrogênio serão quimissorvidos perto do par. No caso do grafeno com defeitos, este processo envolve 
algumas barreiras de potencial enquanto que, para o grafeno infinito ideal procederá sem quaisquer obstáculos, até completar a hidrogenação e formação do grafano.

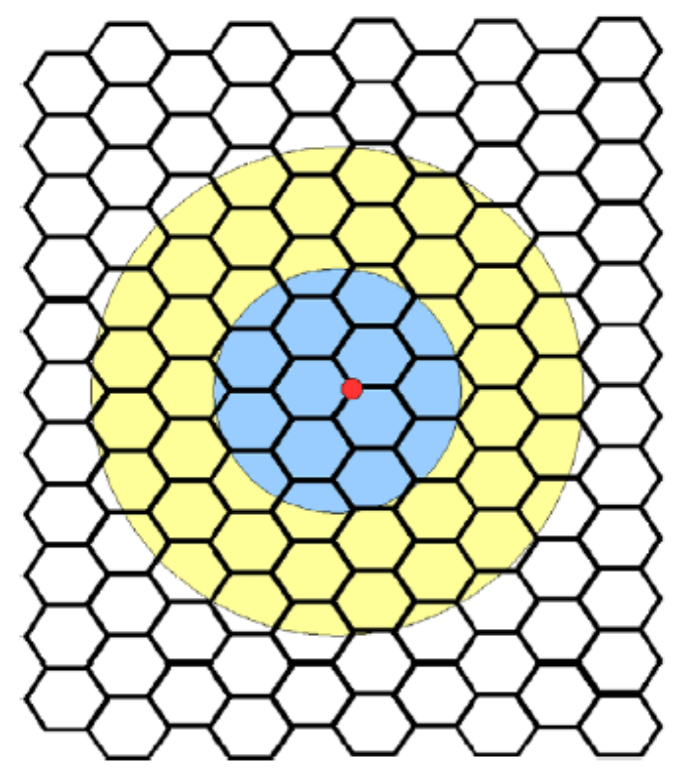

Figura 4.5 - Regiões de fortes (círculo azul) e fracas (círculo amarelo) distorções da rede de grafeno na quimissorção de um único átomo de hidrogênio (círculo vermelho) [25]. 


\section{3 - Funcionalização do Grafeno por Outras Espécies Químicas}

Conforme discutido na seção anterior, o grafano não é uma estrutura tão estável quanto o grafeno, o que é realmente muito conveniente sob o ponto de vista de armazenamento de hidrogênio, uma vez que permite hidrogenar e "desidrogenar" o grafeno a temperatura ambiente [77]. Ao mesmo tempo, para o uso potencial do grafano em eletrônica isto pode ser considerado como uma deficiência. Portanto, é interessante considerar outros grupos funcionais na busca de um composto com uma estrutura eletrônica similar ao do grafano, mas com maior energia de coesão.

Baseados em resultados computacionais presentes em [59], os grupos funcionais da tabela 4.2 podem ser divididos em duas classes:

1 - Com o gap de energia eletrônico $(\Delta E)$ da ordem de $3 \mathrm{eV}$ e com energia de coesão grande o suficiente para mantê-los estáveis e,

2 - Com ligação mais fraca e com gap de energia eletrônico $(\Delta E)$ muito menor ou nulo.

Tabela 4.2 - Dependência do comprimento de ligação carbono - carbono $(d)$, em $(\AA)$, e o gap de energia eletrônico $(\Delta E)$, em eV, das espécies químicas para o caso da cobertura de $100 \%$ dos dois lados do plano do grafeno. (Tabela retirada de [59])

\begin{tabular}{|c|c|c|}
\hline Espécies Químicas & $\boldsymbol{d}$ & $\Delta \boldsymbol{E}$ \\
\hline $\mathrm{NO}$ & 1,622 & Nenhuma \\
\hline $\mathrm{NH}_{2}$ & 1,711 & 2,76 \\
\hline $\mathrm{CN}$ & 1,661 & 2,11 \\
\hline $\mathrm{CCH}$ & 1,722 & 0,83 \\
\hline $\mathrm{CH} 3$ & 1,789 & 0,84 \\
\hline $\mathrm{OH}$ & 1,620 & 1,25 \\
\hline $\mathrm{H}$ & 1,526 & 3,82 \\
\hline $\mathrm{F}$ & 1,559 & 4,17 \\
\hline $\mathrm{H} \mathrm{e} \mathrm{F}$ & 1,538 & 5,29 \\
\hline $\mathrm{F} \mathrm{e} \mathrm{Cl}$ & 1,544 & 4,62 \\
\hline
\end{tabular}


Esta diferença pode estar relacionada com o comprimento da ligação química entre os átomos de carbono (distância carbono-carbono) (conforme tabela 4.2). Para os grupos funcionais da primeira classe, essa distância é quase igual a do diamante, 1.54 Á, enquanto que para os grupos funcionais da segunda classe a distância é maior. Isto significa que para o último caso, devido à repulsão mútua dos grupos funcionais, o grafeno é desestabilizado o que diminui a sua energia de coesão. Esta situação é observada experimentalmente em óxido de grafite o qual não pode ser completamente funcionalizado devido à interação entre grupos de hidroxila [63].

Diversas espécies químicas podem prover, similar ao hidrogênio, uma completa cobertura do grafeno [59]: $\mathrm{F}_{2}, \mathrm{HF}$ e $\mathrm{HCl}$. O flúor parece ser muito promissor para a funcionalização do grafeno uma vez que deve produzir uma estrutura muito homogênea, com uma completa cobertura por átomos do mesmo tipo. Portanto, isto deve ser um modo de criar um cristal bi-dimensional com um gap de energia bastante grande, mas ainda com boa mobilidade eletrônica, devido ao pequeno grau de desordem. Entretanto, o flúor é muito tóxico e muito agressivo, o que deve ser um problema para uso industrial. O flúor é também utilizado na "abertura" de nanotubos $[99,100]$ o que significa que, potencialmente, as bordas e defeitos da rede de grafeno interagindo com o flúor pode causar a sua destruição.

Por outro lado, de acordo com cálculos DFT realizados em [59], utilizando ondas planas e pseudopotenciais ultra-suaves, e funcional de troca-correlação GGA (Generalized Gradient Approximaion), o processo de funcionalização do grafeno por ácido fluorídrico (HF) começa com a quimissorção de flúor e átomos de hidrogênio nos sítios vizinhos do carbono, no mesmo lado da folha de grafeno. Em contraste com o flúor molecular onde a energia de quimissorção é negativa, ou seja, existe ganho de energia com a adsorção do átomo, para o caso do ácido fluorídrico (HF) a energia deste passo vem a ser positiva, +1.46 eV, principalmente devido às fortes distorções do plano do grafeno na funcionalização de somente um lado da folha, conforme descrito na figura 4.6 (a).

A figura 4.6 (b) apresenta a quimissorção de mais um par de HF, no lado oposto da folha do grafeno. Similar à quimissorção do segundo átomo de hidrogênio, este passo é energeticamente favorável, com a energia de formação de $-1.85 \mathrm{eV}$. A reconstrução da estrutura é mostrada na figura 4.6 (c), onde a energia total diminui de $0.33 \mathrm{eV}$. 
A energia de quimissorção de uma terceira molécula HF torna-se muito menor que a primeira, mas ainda positiva, $+0.27 \mathrm{eV}$ (figura 4.6 (d)). A partir da quarta molécula em diante, as energias de quimissorção são mais negativas na medida em que a reação for mais exotérmica. Como resultado, a cobertura completa do grafeno por ácido fluorídrico é energeticamente favorável, mas requer energia alta o suficiente para o primeiro passo. Isto significa que, provavelmente, a superfície do grafeno sem defeitos será estável o suficiente com relação às reações com HF, pelo menos à temperatura ambiente. Isto é um importante resultado, pois o ácido fluorídrico só é usado praticamente para dissolver um substrato de $\mathrm{SiO}_{2}$, no preparo de membranas de grafeno livremente suspensas [91, 93].

(a)

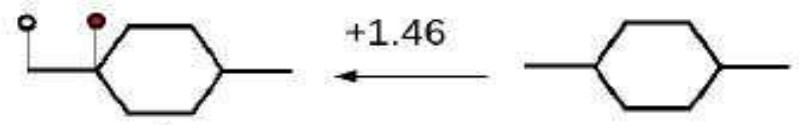

(c)

$$
-1.85
$$

(b)

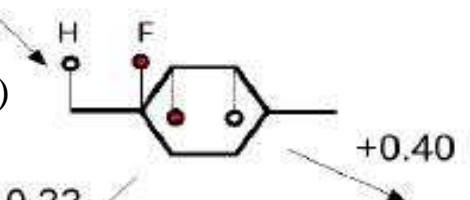

(f)

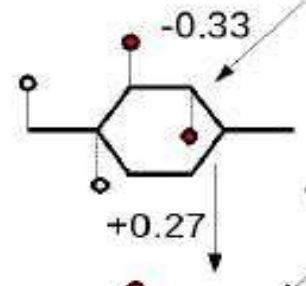

(d)

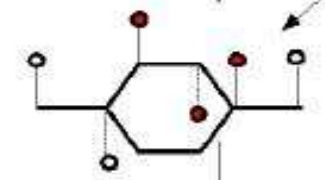

(e)

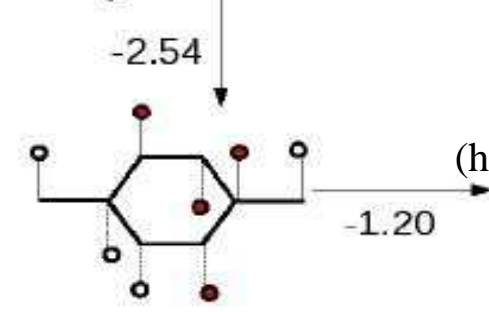

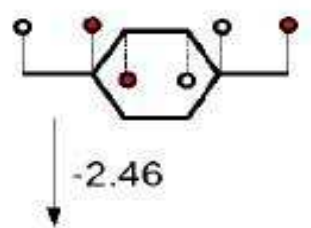

(g)

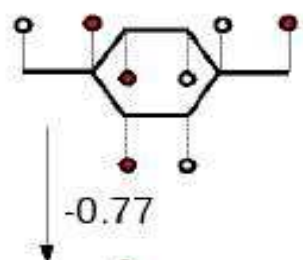

(h)

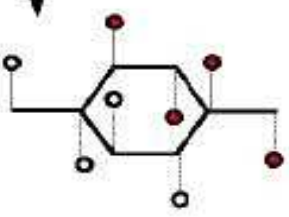

Figura 4.6 - Ilustração dos processos e energética de diferentes reações com ácido fluorídrico (HF), onde os círculos em vermelho representam os átomos de flúor e os círculos em branco representam os átomos de hidrogênio. [59] 
Para a funcionalização do grafeno por ácido clorídrico $(\mathrm{HCl})$, a energia do primeiro passo é essencialmente diferente da funcionalização com ácido fluorídrico (HF), devido à grande distância interatômica (1.27 ̊́ para o par de $\mathrm{HCl}$, em vez de $0.97 \AA$ Á para HF), o qual é próximo à distância carbono-carbono no grafeno (1.42 Á). Como resultado, não existe quebra de ligações entre hidrogênio e cloro, em vez disso, a molécula de $\mathrm{HCl}$ paira sobre a camada de grafeno, ligando-se a ela somente por uma fraca ligação de van der Waals, não existindo uma reação química. Então, o ácido clorídrico pode ser seguramente usado para limpar a superfície do grafeno. Regiões próximas às bordas ou defeitos em grafeno podem em princípio ser funcionalizadas por $\mathrm{HCl}$, similar ao caso do hidrogênio considerado em [62].

Além das funcionalizações com $\mathrm{F}_{2}, \mathrm{HF}$ e $\mathrm{HCl}$, existem pesquisas sobre reações do grafeno com outras espécies químicas. Em [63], a redução química do grafeno por óxido de grafite (GO) foi simulada através de cálculos DFT, utilizando ondas planas e pseudopotenciais ultra-suaves, e funcional de troca-correlação GGA (Generalized Gradient Approximaion). Além disso, foram feitos estudos sobre a funcionalização do grafeno por oxigênio $\left(\mathrm{O}_{2}\right)$ [68, 101-104]. Enfim, a investigação sobre a funcionalização química do grafeno é extensa, e o estudo das propriedades físicas produzidas a partir destas reações só tende a aumentar, com o objetivo de obter mais aplicações para o grafeno. 


\section{4 - Funcionalização de Nanofitas de Grafeno}

As nanofitas de grafeno (Graphene Nano-Ribbons - GNR) são formadas através do corte de uma folha de grafeno. Diferentes tipos de bordas podem ser obtidos dependendo da direção em que é feito o corte. Os dois tipos básicos de bordas são zig-zag e armchair. As GNRs com as bordas tipo zig-zag são semelhantes a nanotubos armchair abertos, conforme figura 4.7 (a). De forma semelhante, as GNRs com as bordas do tipo armchair podem ser vistas como nanotubos zig-zag abertos, conforme figura 4.7 (b). É possível também combinar os dois tipos de bordas em uma mesma nanofita.

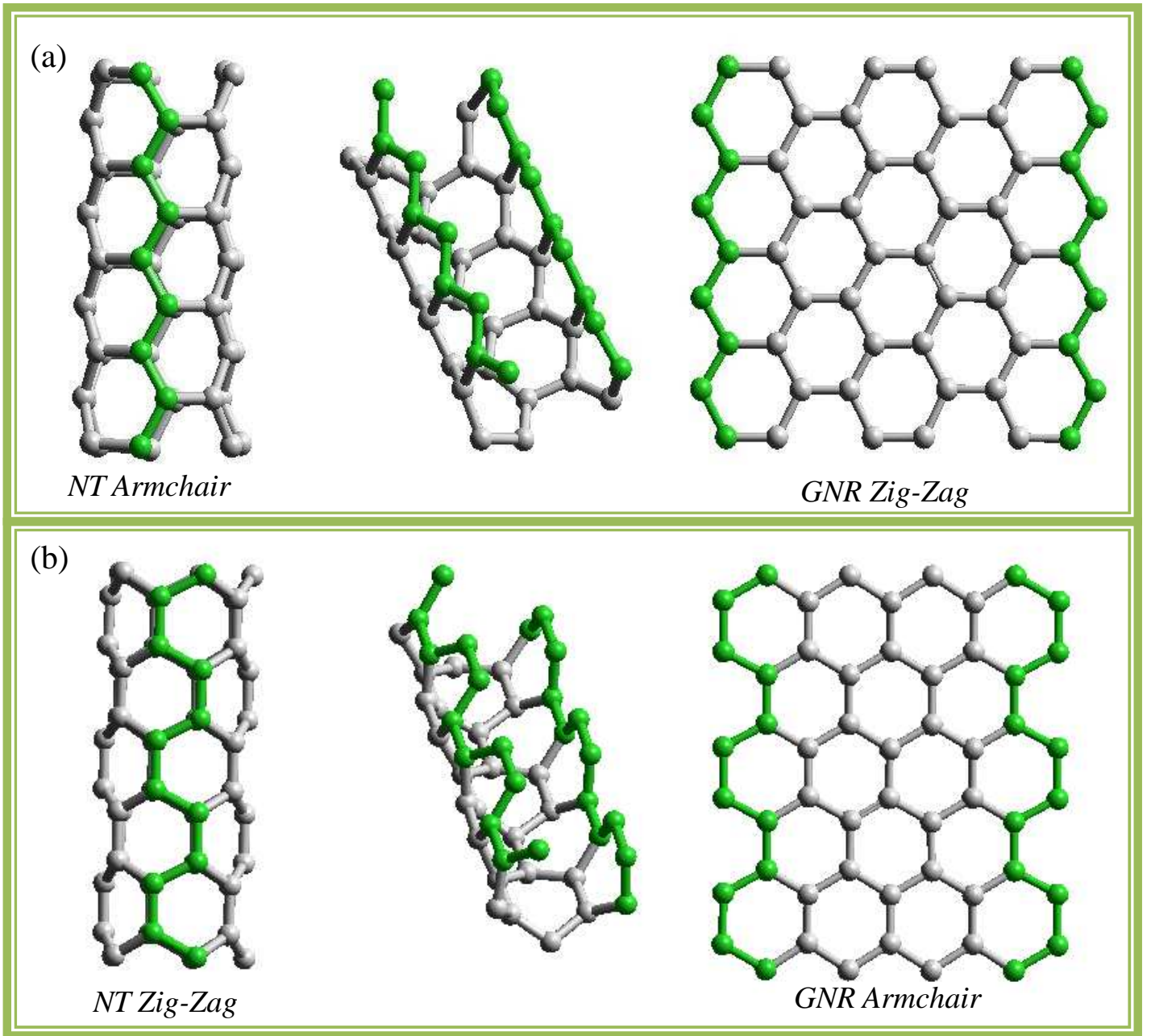

Figura 4.7 - (a) Ilustração da abertura de um nanotubo armchair formando uma nanofita do tipo zig-zag. (b) Ilustração da abertura de um nanotubo zig-zag formando uma nanofita do tipo armchair. 
O tipo de borda é um fator determinante das propriedades eletrônicas das nanofitas. Ao contrário do que ocorre com os nanotubos correspondentes, as nanofitas armchair são sempre semicondutoras [105], enquanto que as nanofitas zig-zag podem se comportar como semicondutor ou condutor $[65,105,106]$. O que definirá o tipo de comportamento das nanofitas do tipo zig-zag é a orientação dos momentos magnéticos das bordas (propriedade que depende da funcionalização das bordas da nanofita), magnetismo tal que é apresentado pelos estados mais estáveis das GNRs zig-zag.

\subsection{1 - Defeitos em Nanofitas de Grafeno}

A funcionalização química de nanofitas de grafeno (GNRs) é atualmente um dos assuntos mais populares na ciência do grafeno. Diversos trabalhos sobre a funcionalização de nanofitas de grafeno do tipo zig-zag tem sido realizados com o objetivo de definir as alterações produzidas nas propriedades eletrônicas e magnéticas destas estruturas, uma vez que esta pode apresentar variações de comportamento (semicondutor ou condutor) $[65,68$, 105, 106]. Entre estas funcionalizações, estão os defeitos do tipo monovacância, divacância e Stone Wales em nanofitas de grafeno.

Uma monovacância é formada com a retirada de um átomo de carbono de uma folha de grafeno. Ao se "reconstruir", dois dos átomos centrais do defeito se aproximam tentando fechar um pentágono, enquanto os átomos restantes sofrem uma re-hibridização, adquirindo ligeiro caráter $\mathrm{sp}^{3}$ e formando uma ligação pendente (dangling Bond), a qual é altamente reativa (conforme figura 4.8). Logo, se a monovacância estiver exposta a qualquer atmosfera, a probabilidade de adsorção de qualquer molécula próxima é grande, o que é muito favorável para a construção de nanosensores $[107,108]$. Este defeito também cria uma magnetização local [88, 109] (o grafeno puro não apresenta magnetismo). De acordo com [110, 111], a energia de formação de uma monovacância em uma nanofita de grafeno é $\approx 7,61 \mathrm{eV}$. 


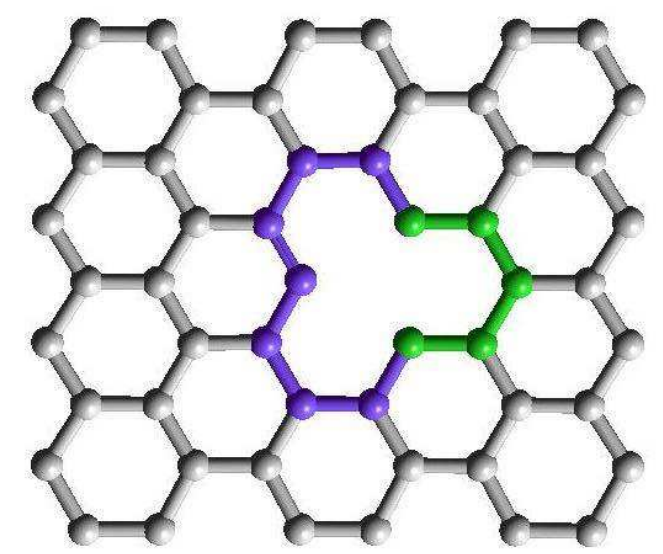

Figura 4.8 - Ilustração de uma monovacância em uma nanofita de grafeno zig-zag.

Por outro lado, a divacância é um defeito formado ao retirar dois átomos de carbono de uma folha de grafeno. Existem dois tipos de reconstrução, a 585 e a $555777 . \mathrm{Na}$ reconstrução 585, formam-se dois pentágonos e um octágono, conforme a figura 4.9 (a). As ligações dos pentágonos, destacadas em vermelho na figura, são chamadas de ligações "quase quebradas", uma vez que apresentam comprimento de ligação da ordem de 1.73 Á, enquanto o comprimento de equilíbrio no grafeno é de $1.42 \AA$ (conforme discutido no capítulo 2), a energia de formação deste defeito é de $7.5 \mathrm{eV}$ [112].

$\mathrm{Na}$ reconstrução 555777, formam-se três pentágonos e três heptágonos, apresentando energia de formação de $6,92 \mathrm{eV}$ [113], sendo mais estável que a 585 por uma diferença de 0,62 eV. Os átomos dos três pentágonos ligados ao átomo central (ligações destacadas em azul) são as ligações mais fracas do defeito, apresentando comprimento de $1.52 \AA$.

(a)

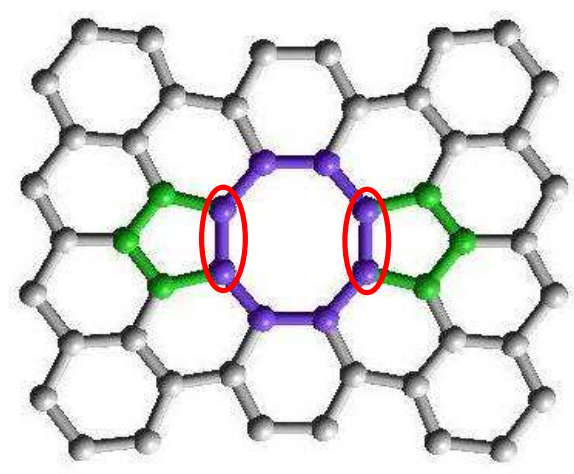

(b)

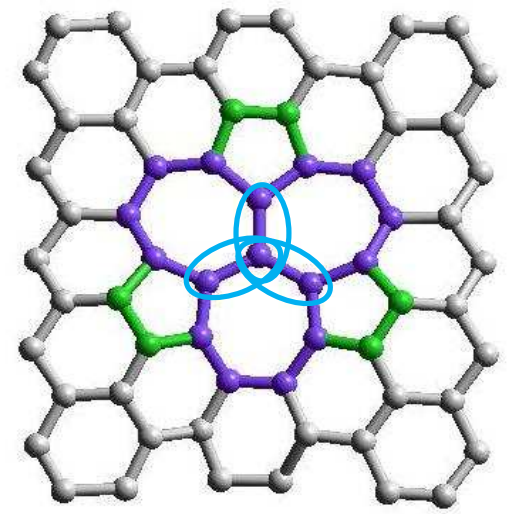

Figura 4.9 - Ilustração de uma divacância com: (a) reconstrução tipo 585; (b) reconstrução tipo 555777; em nanofita de grafeno zig-zag. 
Algo interessante a ser notado é que foi constatado que é mais fácil (mais barato) energeticamente, criar uma divacância do que uma monovacância [110].

Por fim, o defeito do tipo Stone-Wales (SW), ilustrado na figura 4.10, surge a partir da rotação de uma ligação (um par de átomos) em 90 graus, diferente dos dois primeiros que surgem com a retirada de átomos de carbono do grafeno. Na sua reconstrução, formam-se dois pentágonos e dois heptágonos, e a sua energia de formação é de 5,03 eV [110], menor que a dos outros defeitos, sendo por isso o defeito mais estável entre os três citados.

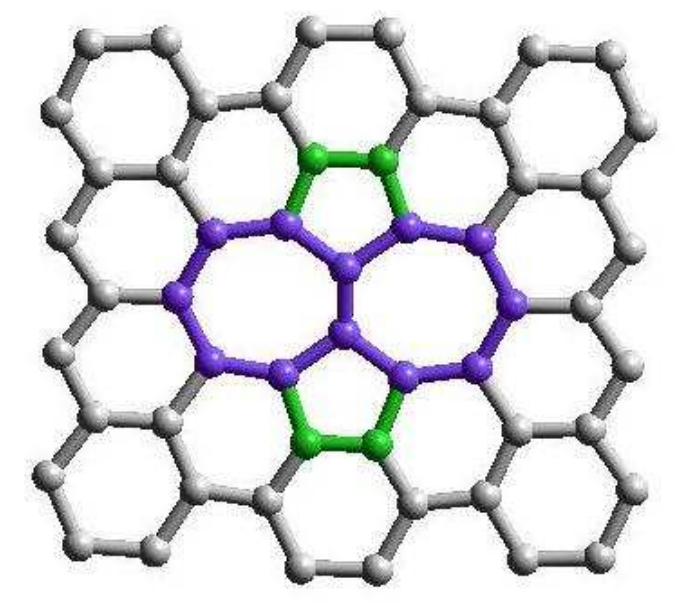

Figura 4.10 - Ilustração do defeito tipo "Stone Wales" em uma nanofita de grafeno zig-zag.

Embora as amostras de grafeno produzidas em laboratório geralmente apresentem boa qualidade cristalina [4], Hashimoto et al. [114] e Meyer et al. [115] mostraram a existência de defeitos em grafeno através de imagens obtidas por STM (scanning tunelling microscopy). Além disso, os defeitos podem ser criados por bombardeamento de elétrons ou íons [114116]. Portanto, é muito importante para a engenharia de dispositivos saber que tipos de defeitos podem surgir no grafeno e em nanofitas de grafeno, quais são os mais estáveis, e como eles podem alterar as propriedades eletrônicas do grafeno e das nanofitas de grafeno.

Da mesma forma que nos nanotubos de carbono, os defeitos mais estáveis (e mais estudados) no grafeno são: monovacância [88, 109, 110], divacâncias [110, 117-119] e StoneWales [110, 117, 120]. Considerando a semelhança entre esses sistemas e as nanofitas de grafeno, não é surpresa que tais tipos de defeitos também sejam os mais estáveis em nanofitas de grafeno. 


\subsection{2 - Dopagem de Nanofitas de Grafeno}

A influência da quimissorção de diferentes espécies químicas ( $\mathrm{N}$ e B) sobre a estrutura eletrônica de uma GNR foi investigada em [121] através de cálculos DFT utilizando ondas planas e pseudo-potencial ultra-suave, e funcional de troca-correlação PBE (Perdew-BurkeErnzerhof). Observou-se que a modificação química de nanofitas de grafeno zig-zag pode quebrar a degenerescência de spin. Isto promove o início de uma transição semicondutormetal, ou de um estado "meio-semicondutor", com os dois canais de spin tendo um band gap diferente, ou de um estado "meio-semicondutor" com polarização de spin, onde os spins nas bandas de valência e de condução são opostamente polarizados.

Por outro lado, a funcionalização de nanofitas do tipo armchair resulta em estados eletrônicos a poucos eV's distantes do nível de Fermi e não afeta significativamente seu band gap. Átomos de nitrogênio e boro produzem diferentes efeitos, dependendo do local de substituição. Em particular, as substituições na borda não alteram significativamente o band gap, enquanto que a substituição ao longo da superfície da nanofita promove o início da transição semicondutor-metal. Por outro lado, um defeito do tipo piridina (pyridinelike), ou mais conhecido como $3 \mathrm{NV}$, que consiste na substituição de quatro átomos de carbono por três átomos de nitrogênio e uma vacância, induz a uma transição semicondutor-metal.

A quimissorção de oxigênio molecular sobre nanofitas de grafeno, e os conseqüentes efeitos produzidos sobre o seu magnetismo, também vem sendo estudados [122]. Várias configurações de GNR hidrogenada [123] e GNR auto-passivada [124] foram estudadas; em ambos os casos os estados não-magnéticos da GNR foram os mais estáveis.

Nos cálculos envolvendo nanofitas de grafeno, geralmente assume-se que as bordas das nanofitas são passivadas por átomos de hidrogênio [66, 125-130], mas algumas vezes bordas puras são também consideradas [126, 127]. A estrutura real de algumas nanofitas de grafeno foi discutida em [133]. O estado das bordas de nanofitas de grafeno real não é bem compreendido ainda e este é um problema muito importante que precisa ser investigado.

Em [134], foram realizados cálculos DFT utilizando ondas planas e pseudo-potencial ultra-suave, com funcional de troca-correlação LSDA (Local Spin Density Approximation), e os resultados comparados com dados experimentais, considerando a funcionalização das bordas de uma nanofita de grafeno, onde cada átomo de carbono é ligado a um único átomo de hidrogênio em uma das bordas e a dois átomos de hidrogênio na borda oposta. 
Os resultados sugerem o aparecimento de uma banda plana (flat band) com spin polarizado na energia de Fermi, produzindo diferentes números de carbonos "monohidrogenado" e carbonos "bi-hidrogenados" que podem criar momentos magnéticos no nanografite. Além disso, Fujita e co-autores sugeriram que os elétrons $\pi$ sobre uma borda de uma nanofita de grafeno zig-zag "mono-hidrogenada" pode criar uma estrutura de spin ferromagnético sobre as bordas [54].

Foi mostrado também através de cálculos DFT [62], usando hidrogênio como um exemplo, que as bordas de GNR são centros de atividade química e a funcionalização deles pode ser apenas o primeiro passo para a funcionalização inteira das nanofitas.

Por outro lado, em $[62,135]$ foi mostrada a perda de magnetismo nas bordas zig-zag por oxidação, bem como a perda de magnetismo por fluoração [136]. Uma vez que a oxidação é um processo natural na produção de GNR [137-139] algumas medidas especiais para proteger o magnetismo quimicamente são provavelmente necessárias.

Em [125, 140], Hod et al. consideraram os efeitos das formas das nanofitas de grafeno semicondutoras sobre a sua estabilidade e estrutura eletrônica. Cálculos similares de estrutura eletrônica e magnetismo têm sido apresentados também em [130]. Além disso, são discutidos em [126, 141] os efeitos da geometria de nanofolhas de grafeno sobre a sua estrutura eletrônica e o reforço da "meia metalicidade" devido à oxidação parcial das bordas zig-zag.

Em [59], é considerada a reação de nanofitas de grafeno de $2.2 \mathrm{~nm}$ e $6.6 \mathrm{~nm}$ de largura, com ácido fluorídrico (HF). É mostrada a dependência da energia como uma função da cobertura. Em contraste com o caso do grafeno ideal infinito, para a nanofita de $2.2 \mathrm{~nm}$, existem apenas dois passos com energia de quimissorção positiva, de maneira a concluir que o custo de energia é tão pequeno que o processo de fluoração para a nanofita de $2.2 \mathrm{~nm}$ pode ocorrer mesmo à temperatura ambiente. Situação essencialmente diferente para a nanofita de largura de $6.6 \mathrm{~nm}$, para o qual os passos com energia de quimissorção positiva apenas desaparecem, devido à maior distância entre as regiões da reação. Desta forma, a fluoração de uma GNR grande o suficiente é fácil e completa.

Baseada na discussão feita neste capítulo será possível analisar os resultados obtidos nesta investigação sobre as estruturas de grafeno e grafano compostos por elementos do grupo IV da tabela periódica, além do grafeno com defeitos e dopantes, os quais serão apresentados nos próximos capítulos. 


\section{Capítulo 5}

\section{Grafeno e Grafano da Família do Grupo IV}

\section{1 - Introdução}

Este capítulo apresenta os resultados das propriedades eletrônicas e estruturais do grafeno e grafano como nanofolhas constituídas por elementos do grupo IV da tabela periódica (C, SiC, Si, Ge e Sn), usando cálculos quânticos baseados na teoria do funcional densidade (DFT). O capítulo também apresenta uma análise das mudanças nas propriedades do grafano do grupo IV com a substituição dos átomos de hidrogênio por flúor. 
Um dos principais focos das pesquisas na área de nanoeletrônica é o desenvolvimento de materiais adequados para a construção de nanodispositivos que possam operar com eficiência superior aos dispositivos da microeletrônica tradicional. Um material que seria considerado ideal para a realização dessa nanoeletrônica seria aquele que pudesse exercer diferentes funções, como eletrônicas, óticas e magnéticas. O silício é o material base da microeletrônica atual, embora ele tenha limitações intrínsecas para o seu uso em dispositivos óticos.

Os capítulos anteriores mostraram as propriedades únicas do grafeno, que permitem contemplar um vasto número de potenciais aplicações, tais como sensores químicos, dispositivos nanoeletrônicos ou sistemas de armazenamento de hidrogênio [142-148], tais propriedades se devem principalmente a sua estrutura bidimensional. Desta forma, inúmeras investigações têm sido realizadas sobre o grafeno e estruturas derivadas do grafeno. Por exemplo, foram realizados estudos teóricos, usando métodos de primeiros princípios, de planos de silício e germânio em uma configuração bidimensional [142, 144, 149, 150], ou seja, dispostos como folhas planas, semelhantes ao grafeno, estruturas que são conhecidas na literatura como siliceno e germaneno, respectivamente. Estes estudos demonstraram que estas estruturas se comportam de forma semelhante ao grafeno no que se refere a sua estrutura eletrônica de bandas, uma vez que a dispersão de energia também é linear em torno do ponto $\mathrm{K}$, equivalente ao que ocorre no grafeno. Além do silício e germânio, recentemente foram também realizadas investigações de folhas bidimensionais de carbeto de silício (SiC) [146], que mostraram que a monocamada de carbeto de silício $(\mathrm{SiC})$ favorece as ligações do tipo $s p^{2}$, diferindo do grafeno somente pelo fato de que na sua estrutura de bandas existe a abertura de um gap nos pontos de Dirac.

Também tem sido investigado o grafano de silício e germânio, ou seja, folhas funcionalizadas com hidrogênio, que são conhecidas como silicano e germanano, respectivamente $[143,151]$, estruturas que apresentaram da mesma maneira que o grafano, uma abertura de gap em suas estruturas de bandas, uma característica importante para seu possível uso em dispositivos nanoeletrônicos.

Além do grafano de silício e germânio, também ocorreram investigações sobre nanofitas de grafano de nitreto de boro [148], as quais apresentaram energias de formação $\left(E_{F}\right)$ favoráveis para a síntese, e um comportamento dependente do comprimento da fita e do tipo de borda, para bordas armchair apresentou comportamento de metal ferromagnético para diversas larguras de fita e para bordas zigzag comportou-se como semicondutor não- 
magnético, com o gap decrescente com o aumento da largura da fita. E por fim, também tem sido investigado o grafano convencional com os átomos de hidrogênio substituídos por átomos de flúor, o qual é chamado de grafano fluorinado [147, 152].

$\mathrm{Na}$ linha experimental, além da síntese das folhas de grafeno, tiras de siliceno tem sido crescidas epitaxialmente sobre substratos de prata, Ag (110) e Ag (100) [150, 153, 154]. Entretanto, o germaneno ainda permanece como um material hipotético. Os estudos apontam o siliceno e o germaneno como materiais promissores para aplicação em nanoeletrônica [142, 144, 149, 150]. Existindo a possibilidade de produzi-los experimentalmente, a integração dos mesmos na nanoeletrônica seria provavelmente mais favorável que o próprio grafeno.

Embora, nas últimas duas décadas, a comunidade científica internacional venha investindo intensivamente em pesquisas de materiais alternativos para nanodispositivos, o silício ainda permanece no centro dos desenvolvimentos da microeletrônica. Por isso, é importante explorar ao máximo as possibilidades do silício, uma vez que todo o aparato tecnológico instalado não é compatível com uma tecnologia de fabricação usando outros materiais. Isto cria dificuldades para uma transição da tecnologia baseada em silício para uma tecnologia baseada em outro elemento, principalmente em termos dos custos industriais. Partindo desse contexto mundial, o principal objetivo desta investigação é explorar as possíveis aplicações para a construção de nanotransistores baseados em folhas bidimensionais de silício. Se essas estruturas de silício se mostrarem robustas, elas poderiam ser facilmente incorporadas em circuitos integrados à base de silício, o que poderia permitir estender a vida útil dessa tecnologia. Nesse contexto, o capítulo discute as propriedades físicas do grafeno e grafano como nanofolhas constituídas por átomos de silício e também por outros elementos do grupo IV da tabela periódica (C, Ge, Sn e SiC). O capítulo também aborda as mudanças nas propriedades do grafano do grupo IV com a substituição dos átomos de hidrogênio por flúor.

Os elementos do grupo IV da tabela periódica apresentam quatro elétrons em seus orbitais de valência, o que resulta, em suas fases cristalinas tridimensionais na formação de quatro ligações covalentes. Apesar destes materiais possuírem a mesma estrutura de valência, eles apresentam diferenças entre si que podem ser vantajosas dependendo de sua aplicação. Por exemplo, o carbeto de silício ( $\mathrm{SiC}$ ) por ser um material muito rígido e apresentar uma alta condutividade térmica, torna-se adequado para a construção de dispositivos eletrônicos que operam em condições extremas, tais como em alta-potência, alta-frequência e em ambientes de alta temperatura. Desta forma, a pesquisa sobre materiais de grafeno de $\mathrm{SiC}$ para 
aplicações em eletrônica e opto-eletrônica passa a ser de grande interesse existindo a possibilidade de "transferir" as características deste material para dispositivos em dimensões nanométricas.

O silício e o germânio, na forma de folhas, ou seja, uma rede bidimensional (2D), exibem propriedades como a emissão balística de elétrons, condutividade térmica muito menor e atividades químicas mais altas comparadas ao silício e o germânio nas suas respectivas forma "bulk", são chamados de semicondutores de gap zero (gapless), propriedades muito semelhantes às do grafeno. Estas propriedades específicas têm potencial significativo para aplicações em células voltaicas, memórias não-voláteis, geradores ultrassônicos e biosensores [142].

Por fim, o estanho é geralmente utilizado na construção de ligas metálicas para recobrir outros metais para protegê-los da corrosão, uma vez que é um material que não se oxida facilmente e é muito resistente à corrosão, também se torna um elemento de interesse para ser estudado na sua forma bidimensional. Este capítulo também aborda as propriedades estruturais e físicas das estruturas de grafeno e grafano do estanho.

\section{2 - Propriedades Físicas de Folhas de Grafeno do Grupo IV e Grafano Hidrogenado e Fluorinado}

As figuras 5.1 (a) e (b) apresentam uma configuração esquemática das estruturas do grafeno com configuração plana $(\alpha)$ e "buckled" $(\beta)$, respectivamente. Suas formas de grafano hidrogenado e fluorinado são apresentadas nas figuras 5.1 (c) e (d), respectivamente. A tabela 5.1 apresenta as propriedades estruturais das folhas de grafeno do grupo IV e suas respectivas energias de ligação $\left(E_{B}\right)$ (calculada conforme descrito no capítulo 3, seção 3.9). De acordo com a tabela, a configuração mais estável para todas as estruturas investigadas foi a do tipo "buckled", uma vez que apresentam menor energia de ligação. A única exceção foi o grafeno puro, que sempre relaxa em direção à forma plana, ou seja, sua estrutura na forma "buckled" é energeticamente instável. Foi também possível constatar que as estruturas de grafeno de Si (siliceno), Ge (germaneno) e Sn em configuração plana são meta-estáveis, significando que existe um custo de energia maior para que estes sistemas possam ficar nesta configuração quando comparados com aquela na forma "buckled". 
Esses resultados refletem um fato já conhecido [143], de que os elementos do grupo IV, exceto o carbono, tem um alto custo energético para formar estruturas com ligações do tipo $s p^{2}$, concordando com os resultados de outras investigações para Si e Ge [143, 144].

(a)

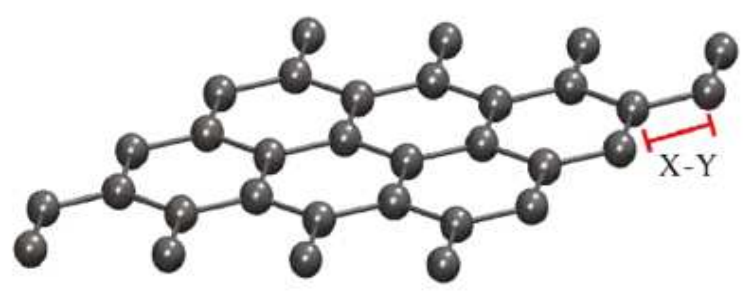

(c)

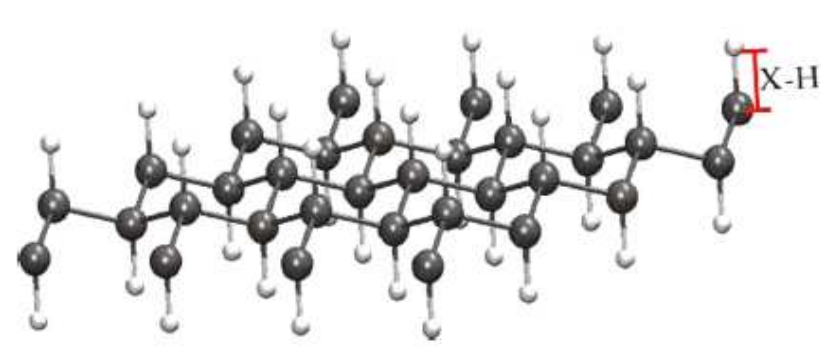

(b)

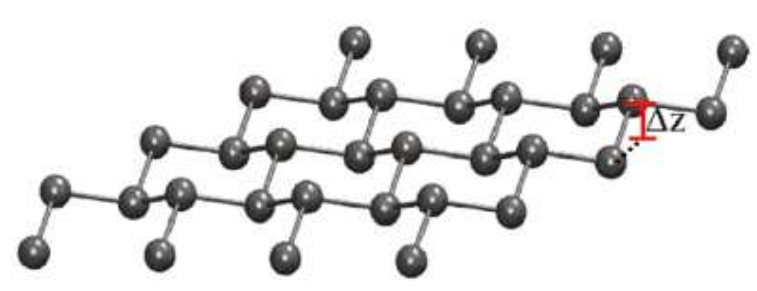

(d)

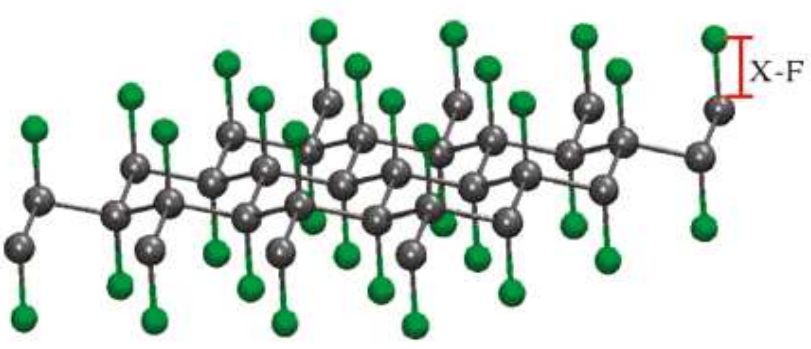

Figura 5.1 - Representação esquemática de materiais bi-dimensionais do grupo IV: (a) configuração plana do grafeno, (b) grafeno na configuração buckled, (c) grafano e (d) estrutura do tipo grafano fluorinado. A figura também indica as distâncias interatômicas, consistentes com as contidas na tabela 5.1.

Os gráficos da figura 5.2 apresentam as distâncias interatômicas teóricas e as energias de ligação $\left(E_{B}\right)$ de todas as estruturas de grafeno e grafano do grupo-IV em função de suas respectivas propriedades nas fases sólido cristalino (diamante cúbico ou estrutura cúbica do sulfeto de zinco - zinc-blende), onde todos os átomos do grupo-IV apresentam hibridização do tipo $s p^{3}[145]$. 


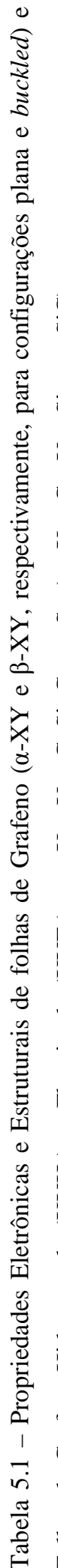

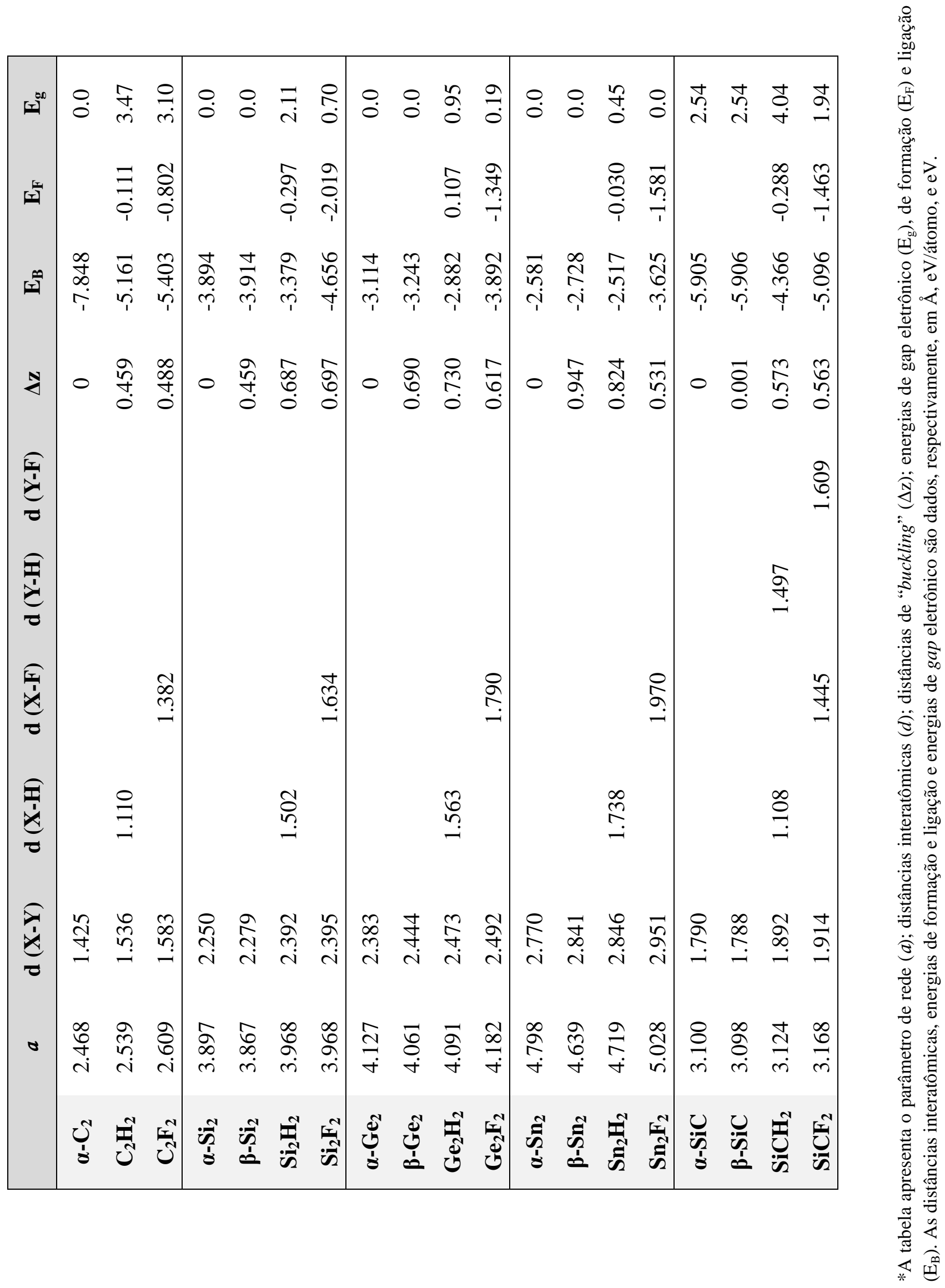


(a)

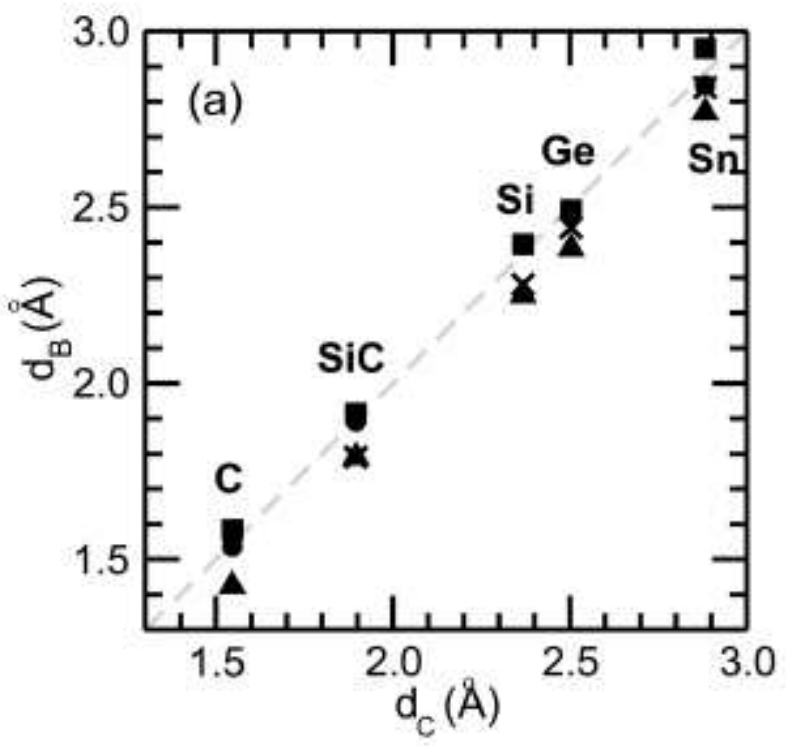

(b)

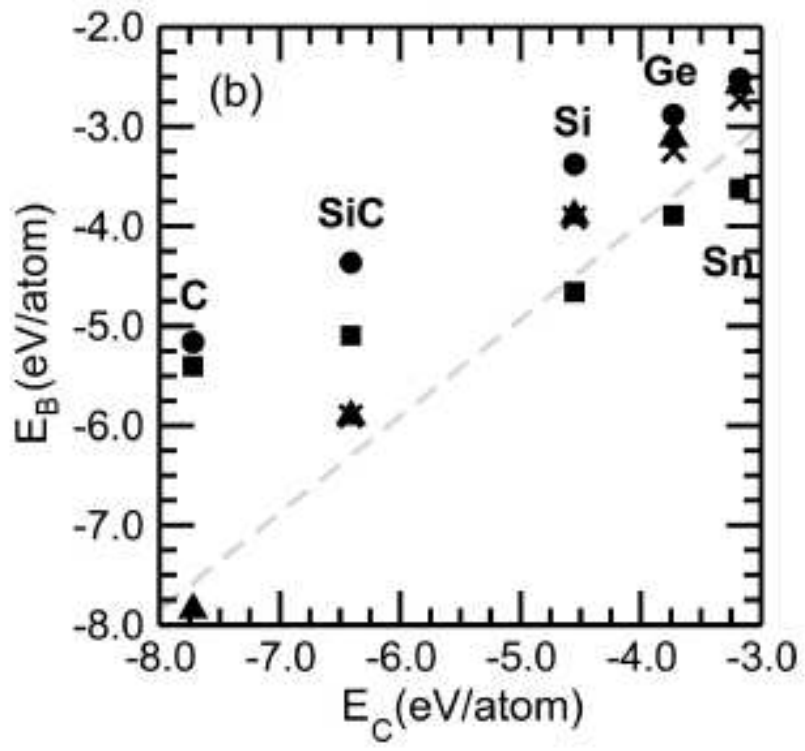

Figura 5.2 - Propriedades do grafeno do grupo IV (C, SiC, Si, Ge e Sn) (em configurações planas e na forma buckled e as estruturas de grafano, com cobertura completa por átomos de hidrogênio $(\mathrm{H})$ ou flúor (F). A figura mostra: (a) distâncias interatômicas $\left(\mathrm{d}_{\mathrm{B}}\right)$ em função das respectivas distâncias no cristal $\left(\mathrm{d}_{\mathrm{C}}\right)$; (b) energias de ligação $\left(\mathrm{E}_{\mathrm{B}}\right)$ das estruturas em função das energias de ligação $\left(\mathrm{E}_{\mathrm{C}}\right)$ nas estruturas cristalinas de diamante cúbico (ou zinc-blende). Os símbolos $\boldsymbol{\Lambda}, \times, \bullet$ e $\mathbf{m}$, representam respectivamente as estruturas do grafeno plano, do grafeno na configuração "buckled", do grafano e da estrutura tipo grafano fluorinado. As linhas pontilhadas são apenas um guia, representando as propriedades $d_{B}=d_{C} e m(a) e E_{B}=E_{C} e m(b)$.

De acordo com a figura 5.2 (a), as distâncias interatômicas $\left(d_{B}\right)$ entre os átomos do grupo-IV em estruturas de grafeno são em média $5 \%$ menores que as distâncias $\left(d_{C}\right)$ nas suas respectivas fases sólidas. Estes resultados mostram que todos os átomos do grupo-IV, em um ambiente $s p^{2}$, comportam-se essencialmente do mesmo modo que os átomos de carbono.

A figura 5.2 (b) mostra que as energias de ligação $\left(E_{B}\right)$ de muitas estruturas de grafeno do grupo-IV em suas configurações planas ou "buckled", exceto para o carbono, são menores que as respectivas energias em suas fases sólidas estáveis. A estabilidade pode ser medida através dos valores de energia de ligação $\left(E_{B}\right)$, pois quanto maior for o módulo da energia de ligação, mais estável será a estrutura, uma vez que será mais difícil a quebra de uma ligação. Isto indica que as estruturas de grafeno, que possuem os átomos com hibridização $s p^{2}$, não são muito estáveis quando comparados às suas respectivas fases sólidas, na qual os átomos estão na hibridização $s p^{3}$. Esses resultados são consistentes com a grande 
diferença de energia comum entre as duas hibridizações em muitos materiais covalentes, sendo pequena somente para o carbono. Adicionalmente, a energia de ligação $\left(E_{B}\right)$ das configurações "buckled" é maior que a energia de ligação $\left(E_{B}\right)$ das configurações planas, exceto para o carbono.

No caso do carbono, os cálculos indicaram que a configuração "buckled" é instável, relaxando em direção à forma plana. Um caso interessante é o SiC, no qual a diferença da energia de ligação $\left(E_{B}\right)$ entre as configurações "buckled" e plana é de apenas $1 \mathrm{meV} / a ́$ tomo e o "buckling" também é muito pequeno.

Para os outros elementos, ou seja, para o silício (Si), germânio (Ge) e estanho ( $\mathrm{Sn})$, diferentemente das estruturas com carbono, os valores de $\left(E_{B}\right)$ foram maiores para o grafeno na configuração "buckled". Isto significa que entre todas as configurações estudadas, estes três elementos são mais estáveis na configuração "buckled", o que mostra que estes elementos não tem tendência de formar ligações do tipo $s p^{2}$ como acontece com o grafeno convencional.

A Figura 5.2 (b) mostra ainda as tendências nas energias de ligação $\left(E_{B}\right)$ (por átomo) para estruturas de grafano hidrogenado e fluorinado. As estruturas fluorinadas são energeticamente mais estáveis que as hidrogenadas, e vem a ser consideravelmente mais favoráveis para os materiais $\mathrm{Si}, \mathrm{Ge}$ e $\mathrm{Sn}$. Estes resultados são consistentes com resultados experimentais disponíveis para estruturas do grafano e grafano fluorinado [147, 155]. Portanto, os resultados teóricos sugerem que o grafano fluorinado deveria ser facilmente sintetizado em laboratório.

Os resultados sugerem que a hidrogenação ou fluorinação favorecem estruturas bidimensionais que poderiam ser facilmente incorporadas à superfície de suas respectivas contrapartes cristalinas tridimensionais. Portanto, enquanto a integração de estruturas de grafeno em dispositivos tridimensionais ainda é difícil, devido à grande incompatibilidade de redes, isso poderia ser mais fácil para estruturas de grafano hidrogenado ou fluorinado. Isto porque os parâmetros de rede do grafano hidrogenado ou fluorinado tem valores mais aproximados aos dos respectivos sólidos.

Em termos das propriedades estruturais, a tabela 5.1 apresenta as distâncias interatômicas $(d)$ e de "buckling" $(\Delta z)$. Para o grafeno na configuração plana $\left(\alpha-C_{2}\right)$, as distâncias C-C, Si-Si, Ge-Ge, Sn-Sn e Si-C, foram de 1.425, 2.250, 2.383, 2.770, 1.790 Á, respectivamente. Por outro lado, as mesmas distâncias na configuração "buckled", exceto 


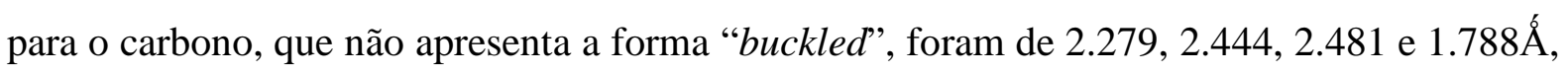
respectivamente, concordando com os resultados teóricos apresentados em outras investigações [143, 145]. Através destes resultados, é possível perceber que para as configurações "buckled", as distâncias interatômicas são sempre maiores que as respectivas distâncias nas configurações planas (exceto para o grafeno de carbeto de silício, onde as distâncias são praticamente iguais), fato que pode ser explicado pela deformação sofrida pela estrutura na configuração "buckled", gerando a chamada "distância de buckling" $\Delta \mathrm{z}$, como mostrado na figura 5.3.

(a)

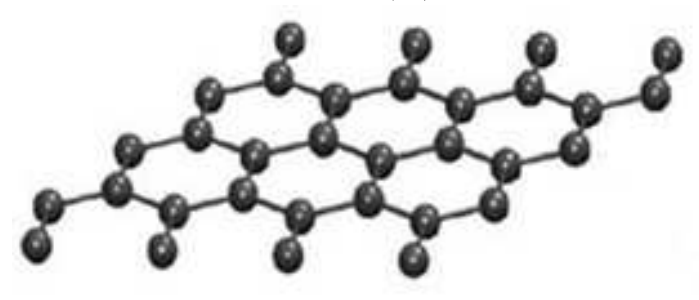

(b)

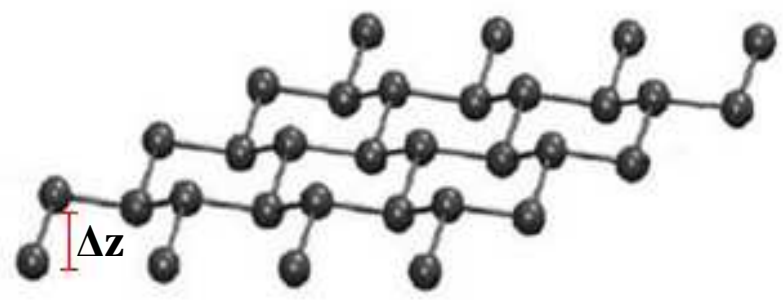

Figure 5.3 - Representação esquemática do grafeno nas configurações (a) plana e (b) buckled, onde aparece a distância de buckling $(\Delta \mathrm{z})$, gerada a partir da deformação sofrida pela estrutura inicialmente plana.

A tabela 5.1 também apresenta os parâmetros estruturais para as estruturas do grafano hidrogenado e fluorinado e suas respectivas energias de ligação $\left(E_{B}\right)$ e formação $\left(E_{F}\right)$, conforme discutido no capítulo 3, nas equações 3.39 e 3.40. Neste caso, foram considerados somente os sistemas associados com a conformação "em cadeira" (chair-like), e foram negligenciadas as configurações isoméricas na conformação "em barco" (boat-like). Esta escolha é justificada pelas recentes investigações teóricas para o grafano [55, 146] e grafano fluorinado [147], indicando que a conformação "em cadeira" (chair-like) é energeticamente mais favorável que a conformação "em barco" (boat-like), o que significa que os sistemas "chair-like" oferecem maior facilidade de síntese.

Conforme descrito nas figuras 5.1 (c) ou 5.1 (d), a conformação "em cadeira" (chairlike) apresenta átomos de hidrogênio (flúor) alternando acima e abaixo do plano contendo os átomos do grupo IV. A incorporação de átomos de hidrogênio (ou flúor) resulta em estruturas muito estáveis, com energias de ligação $\left(E_{B}\right)$ (por átomo) para estruturas de grafano maiores que as do grafeno, como mostrado na figura 5.2 (b). Adicionalmente, as estruturas do grafano têm energias de formação $\left(E_{F}\right)$ maiores, em muitos casos, consistentes com outras investigações teóricas para incorporação de hidrogênio no grafeno [55] e em estruturas de 
nanofitas de grafeno de nitreto de boro [148]. É importante notar que a estabilidade com respeito a outros compostos é mostrada pela energia de formação $\left(E_{F}\right)$. Quanto menor for o módulo da energia de formação, mais estável é a estrutura.

Para as estruturas de grafano hidrogenado e fluorinado, os resultados indicam que as distâncias interatômicas e as energias de ligação são semelhantes às de seu ambiente cristalino. Além disso, que os átomos do grupo IV são tetracoordenados e possuem uma configuração aproximadamente tetraédrica, como mostrado na figura 5.4, onde a geometria do grafano hidrogenado ou fluorinado é comparada com a geometria tetracoordenada de uma molécula de metano $\left(\mathrm{CH}_{4}\right)$. É possível observar que o ângulo de separação entre as ligações do grafano é maior que $109.5^{\circ}$ o que indica que as estruturas desviaram-se um pouco de uma configuração tetraédrica, o que pode ser evidenciado também pela distância de "buckling" $(\Delta \mathrm{z})$, devido a algumas ligações entre os átomos do grupo IV e os átomos de hidrogênio (ou flúor) apresentarem caráter parcialmente iônico.

(a)

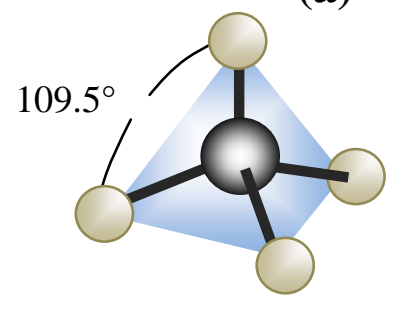

(b)

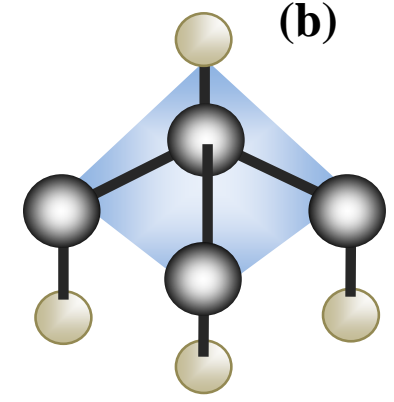

Figure 5.4 - Representação esquemática da(o): (a) geometria tetraédrica da molécula do metano $\left(\mathrm{CH}_{4}\right)$;

(b) desvio da geometria tetraédrica para a estrutura do grafano hidrogenado ou fluorinado.

As distâncias interatômicas $(d)$ entre os átomos do grupo IV e átomos de hidrogênio (ou flúor) também estão em excelente concordância com as respectivas distâncias em moléculas orgânicas típicas. Por exemplo, no grafano $\left(\mathrm{C}_{2} \mathrm{H}_{2}\right)$, as distâncias C-C, C-H, e de "buckling" ( $\Delta \mathrm{z})$ são de $1.536,1.110$ e $0.459 \AA$, concordando muito bem com resultados teóricos recentes de 1.520, 1.084 e $0.45 \AA$, respectivamente [143]. Para estruturas de grafano fluorinado $\left(\mathrm{C}_{2} \mathrm{~F}_{2}\right)$, as distâncias C-C e C-F são de 1.583 e $1.382 \AA$, também estão em boa concordância com recentes resultados teóricos de 1.579 e 1.371 Å, respectivamente [146]. De acordo com a figura 5.2 (a), ao longo da série, as distâncias interatômicas entre os átomos do grupo IV, tanto na forma hidrogenada como fluorinada, estão muito próximas de suas respectivas distâncias na forma cristalina. 
Analisando os valores das distâncias interatômicas também foi possível perceber que existe um aumento progressivo destas distâncias à medida que o elemento do grupo IV da tabela periódica que compõe a estrutura do grafeno ou grafano possui maior número atômico e massa atômica, que seria de forma crescente os elementos: C, Si, Ge e Sn. Além disso, as distâncias interatômicas também aumentam se forem comparadas todas as estruturas com configurações diferentes, compostos pelo mesmo elemento do grupo IV. Por exemplo, as estruturas: $\alpha-\mathrm{Si}, \beta-\mathrm{Si}, \mathrm{Si}_{2} \mathrm{H}_{2}$ e $\mathrm{Si}_{2} \mathrm{~F}_{2}$, apresentam distâncias interatômicas crescentes, o mesmo padrão é seguido para as estruturas de todos os outros elementos. As maiores distâncias interatômicas apresentadas foram para as estruturas fluorinadas.

\section{3 - Propriedades Eletrônicas das Folhas de Grafeno do Grupo IV e Grafano Hidrogenado e Fluorinado}

\subsection{1 - Bandas de Energia}

As propriedades eletrônicas de redes cristalinas são tratadas baseando-se no modelo de estrutura de bandas. Para estruturas em escalas nanométricas, o orbital de maior energia ocupado por elétrons é normalmente chamado de HOMO (Highest Occupied Molecular Orbital), e o orbital vazio de menor energia é denominado LUMO (Lowest Unoccupied Molecular Orbital), análogos, respectivamente, ao topo da banda de valência e fundo banda de condução em redes cristalinas, termos utilizados com frequência na microeletrônica.

Desta forma, a diferença de energia entre o orbital ocupado de maior energia (HOMO) e o orbital desocupado de menor energia (LUMO) é chamada de "band gap" (ou "banda proibida"). A condutividade eletrônica de um sólido é função da possibilidade de ocorrer transferência de elétrons dos orbitais mais altos ocupados os orbitais mais baixos desocupados, onde estes elétrons poderão movimentar-se livremente. Esta transferência requer energia suficiente para que os elétrons passem pelo "band gap". Conforme a magnitude deste, pode-se definir quatro tipos de sólidos:

1) Condutores ou metais, onde não há "band gap" (a banda de valência e a banda de condução estão sobrepostas) e a condutividade eletrônica aumenta com a diminuição da temperatura; 
2) Os semicondutores, cuja banda de valência está totalmente ocupada e a banda de condução vazia, com um valor de "band gap" variando entre 0 e $3 \mathrm{eV}$, onde a condutividade elétrica aumenta com o aumento da temperatura. Neste tipo de material, pequenos valores de energia (térmica ou luminosa) possibilitam a transferência de elétrons para a banda de condução, fazendo com que estes materiais apresentem condutividade elétrica [156].

3) Os semi-metais, com banda de valência ocupada e banda de condução vazia e um valor de "band gap" próximo de zero (como a grafite, por exemplo) e,

4) Os isolantes, também com a banda de valência totalmente preenchida e banda de condução vazia, mas com um valor de "band gap" bastante grande (maior que $5 \mathrm{eV}$ ).

Através da análise das estruturas eletrônicas de bandas, apresentadas nas figuras 5.5 a 5.9, foi possível observar que todas as estruturas de grafeno, em qualquer configuração, plana ou "buckled", apresentaram um gap eletrônico nulo, indicando comportamento metálico para estas estruturas [144, 149, 150], exceto para o SiC, que apresentou um gap da ordem de $2.54 \mathrm{eV}$, para as duas configurações, indicando comportamento semicondutor para estas estruturas. Este valor está em excelente conformidade com o valor de $2.53 \mathrm{eV}$ obtido em uma recente investigação teórica onde os cálculos foram realizados utilizando a metodologia DFT, o potencial PAW e o funcional de troca-correlação GGA-PW91 [150].

As estruturas de bandas eletrônica do grafeno do grupo-IV (de C, Si, Ge e Sn) na configuração plana (das figuras. 5.5 a 5.8 (a), respectivamente) foram similares, com uma banda atravessando os pontos de Dirac (K) no nível de Fermi. Para todos esses materiais, existe uma dispersão linear em torno do ponto de Dirac, uma propriedade resultante da estrutura "favo-de-mel” (honeycomb). Na configuração "buckled" (das figuras. 5.6 a 5.8 (b), respectivamente), a dispersão linear em torno dos pontos de Dirac (K e K') é mantida. Este resultado tem como consequiência que as bandas exibem um caráter ambipolar e os portadores de carga se comportam como férmions de Dirac sem massa, em uma pequena taxa de energia em torno do nível de Fermi $\left(\mathrm{E}_{\mathrm{F}}\right)$.

As estruturas de bandas eletrônicas do grafeno plano diferem entre si somente pelo fato de que para as estruturas de grafeno de C e $\mathrm{Si}$, o sistema é semi-metálico, sendo por outro lado, metálico para o grafeno de Ge e Sn. Tal diferença poderia ser entendida pelo fato de que para as estruturas planas do grafeno de $\mathrm{C}$ e $\mathrm{Si}$, existe uma banda de energia específica 
localizada sobre o nível de Fermi em toda a zona de Brillouin, Entretanto, para estruturas de grafeno planas de Ge e Sn, a mesma banda atravessa o nível de Fermi na direção de simetria $\Gamma \rightarrow \mathrm{M}$, sendo, portanto, estes sistemas metálicos com uma baixa densidade de estados próximo ao nível de Fermi. A estrutura de bandas eletrônica das configurações plana e "buckled" diferem pelo fato de que a última não apresenta a banda atravessando os pontos de Dirac (K) no nível de Fermi como descrito nesse parágrafo.

Uma vez que a estrutura eletrônica de bandas do grafeno de materiais do grupo-IV, em configuração plana, é equivalente à do carbono, seria interessante analisar como a velocidade dos portadores se comportariam ao redor dos pontos de Dirac em todos esses materiais. Usando as estruturas de banda apresentadas nas figuras 5.5 a 5.9 (a), as velocidades de portadores foram calculadas nestes pontos, sendo $0.91,0.58,0.59$ e $0.52 \times 10^{6} \mathrm{~m} / \mathrm{s}$ para o grafeno plano de $\mathrm{C}, \mathrm{Si}, \mathrm{Ge}$ e $\mathrm{Sn}$, respectivamente. As velocidades de portadores nos pontos de Dirac para o grafeno "buckled" de Si, Ge e Sn, são $0.46,0.69$ e $0.95 \times 10^{6} \mathrm{~m} / \mathrm{s}$, respectivamente. A metodologia usada no cálculo dessas velocidades está descrita no capítulo 3, seção 3.9. Esses resultados indicam que as velocidades de portadores em torno dos pontos de Dirac são muito maiores para as configurações "buckled" de Ge e Sn. Os resultados para o grafeno estão em boa concordância com os valores experimentais da literatura de $1.1 \times 10^{6} \mathrm{~m} / \mathrm{s}$ $[6,9]$ e com o resultado teórico de $0.63 \times 10^{6} \mathrm{~m} / \mathrm{s}$ [143].

Para o grafano do grupo IV, a hidrogenação produziu a abertura de um gap em todas as estruturas, devido à transição da hibridização $s p^{2}$ para $s p^{3}$. As energias de gap para o grafano $\left(\mathrm{C}_{2} \mathrm{H}_{2}\right.$ ), grafano de silício (ou silicano - $\mathrm{Si}_{2} \mathrm{H}_{2}$ ), de germânio (ou germanano - $\mathrm{Ge}_{2} \mathrm{H}_{2}$ ), de estanho $\left(\mathrm{Sn}_{2} \mathrm{H}_{2}\right)$ e de carbeto de silício $\left(\mathrm{SiCH}_{2}\right)$, foram de 3.47, 2.11, 0.95, 0.45 e $2.54 \mathrm{eV}$, respectivamente, consistentes com diversos resultados teóricos apresentados na literatura [143-146]. Desta forma, eles podem ser considerados materiais semicondutores. Todas as estruturas hidrogenadas apresentaram gap direto no ponto $\Gamma$, exceto o grafano de silício, que apresentou um gap indireto para a conformação "em cadeira" (chair-like), que foi o tipo de conformação investigada neste trabalho, por ser mais estável que a conformação "em barco" (boat-like).

De acordo com a figura 5.5 (b) e (c) e as figuras 5.6 a 5.9 (c) e (d), todas as estruturas de grafano hidrogenado e fluorinado, respectivamente, apresentaram a abertura de um gap eletrônico nas suas respectivas estruturas de banda. Em todos os casos, o gap eletrônico é maior nas configurações hidrogenadas do que nas fluorinadas. Para o grafano e o grafano fluorinado as energias de gap eletrônico foram em torno de $3 \mathrm{eV}$, enquanto que para o grafano 
de silício e grafano de silício fluorinado as energias de gap eletrônico foram 2.11 e $0.70 \mathrm{eV}$, respectivamente. Para o grafano de germânio e grafano de germânio fluorinado as energias de gap eletrônico diminuíram para 0.95 e 0.19 eV, respectivamente. Para o grafano de estanho a energia de gap eletrônico foi de $0.45 \mathrm{eV}$. Um caso interessante é o do grafano de estanho fluorinado $\left(\mathrm{Sn}_{2} \mathrm{~F}_{2}\right)$, no qual, embora os átomos de estanho sejam tetracoordenados, o material tem um gap nulo. Este resultado indica que as velocidades dos portadores deveriam ser muito maiores neste sistema, mesmo que todos os átomos de estanho tenham todos os elétrons de valência pareados com os de átomos vizinhos. Por fim, as energias de gap para o grafano de $\mathrm{SiC}$ e grafano de $\mathrm{SiC}$ fluorinado foram de 4.09 e $1.94 \mathrm{eV}$, respectivamente, energias de gap eletrônico maiores que os outros três elementos ( $\mathrm{Si}, \mathrm{Ge}$ e $\mathrm{Sn}$ ).

De acordo com os resultados, é possível concluir que da mesma forma que o grafeno, o grafeno de silício (ou siliceno), é um semicondutor de gap zero com férmions de Dirac sem massa tanto na configuração plana quanto na configuração buckled, uma vez que semelhantemente ao grafeno as bandas se tocam nos pontos de Dirac (K e K'). Por outro lado, os resultados indicam que o grafano de silício e germânio são semicondutores com energias de gap relativamente grande, em torno de $3 \mathrm{eV}$. Entretanto, esses valores são inferiores aos valores experimentais apresentados por estes materiais, uma vez que o cálculo DFT geralmente subestima o gap [146]. 


\subsection{2 - Densidade de Estados (DOS)}

A análise da estrutura eletrônica de bandas pode ser simplificada se considerarmos a densidade de estados (DOS), a qual é dada por:

$$
D(E)=\frac{2}{N} \sum_{\mu=1}^{N} \frac{\int \frac{1}{d E_{\mu}(k)}}{d k} \delta\left(E_{\mu}(k)-E\right) d k
$$

O estudo da densidade de estados (DOS) permite entender a relação entre as propriedades estruturais e eletrônicas das estruturas investigadas. As densidades de estados foram construídas a partir das estruturas de bandas das diversas estruturas, apresentadas nas figuras 5.10 a 5.14. Nestas figuras, é possível observar que para todas as estruturas de grafeno plano $(\alpha)$ e "buckled" $(\beta)$, exceto para o carbeto de silício (SiC), existem estados ressonantes no nível de Fermi $\left(\mathrm{E}_{\mathrm{F}}\right)$, o que explica o valor de gap nulo para essas estruturas. Por outro lado, quando as estruturas são hidrogenadas, ocorre uma abertura de um gap de energia da ordem de 3 a 4 eV para o carbono, silício e carbeto de silício e energias de gap menores que $1 \mathrm{eV}$ para o germânio e estanho.

Para todas as estruturas de grafano fluorinado as energias de gap decresceram comparadas às energias de gap do grafano hidrogenado, confirmando os valores da tabela 5.1 e das figuras 5.5 (b) e (c) e 5.6 a 5.9 (c) e (d). 


\section{4 - Conclusões Parciais}

Em resumo, este capítulo apresentou uma investigação sistemática das tendências das propriedades estruturais e eletrônicas dos sistemas de grafeno e grafano do grupo IV (C, SiC, $\mathrm{Si}$, Ge e Sn), nas configurações "buckled" e plana, através de cálculos de energia total de primeiros princípios.

Os resultados indicam que enquanto estruturas de grafeno (de $\mathrm{Si}, \mathrm{Ge}, \mathrm{Sn}$ e $\mathrm{SiC}$ ) apresentam pouca estabilidade, as respectivas estruturas de grafano hidrogenado e fluorinado são muito estáveis, ou seja, são energeticamente muito acessíveis, o que deve facilitar sua síntese em laboratório.

Além disso, verificou-se que as estruturas de grafano hidrogenado e fluorinado apresentaram os átomos do grupo-IV em uma configuração tetracoordenada e em uma configuração aproximadamente tetraédrica. As distâncias interatômicas nessas configurações foram próximas às suas respectivas distâncias nas fases sólidas [149, 157], uma propriedade que poderia facilitar a integração destas estruturas bidimensionais dentro de nanodispositivos tridimensionais.

No próximo capítulo serão apresentados os resultados referente a investigação sobre defeitos em grafeno, tais como vacância, divacância, Stone-Wales, dentre outros, além de dopagens com nitrogênio e boro e as mudanças que estas modificações químicas produzem nas propriedades estruturais e eletrônicas do grafeno. 

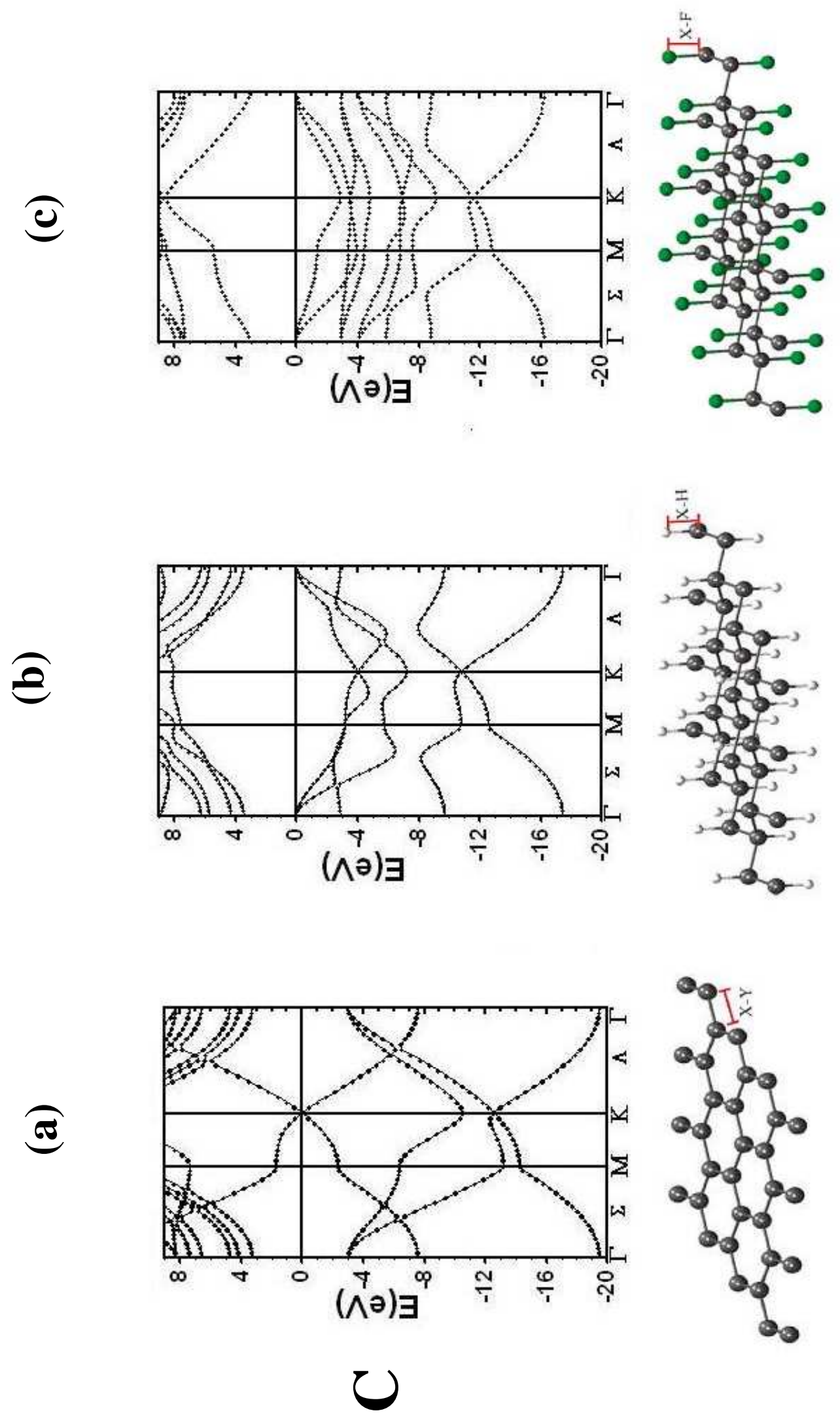

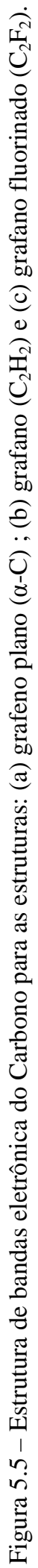



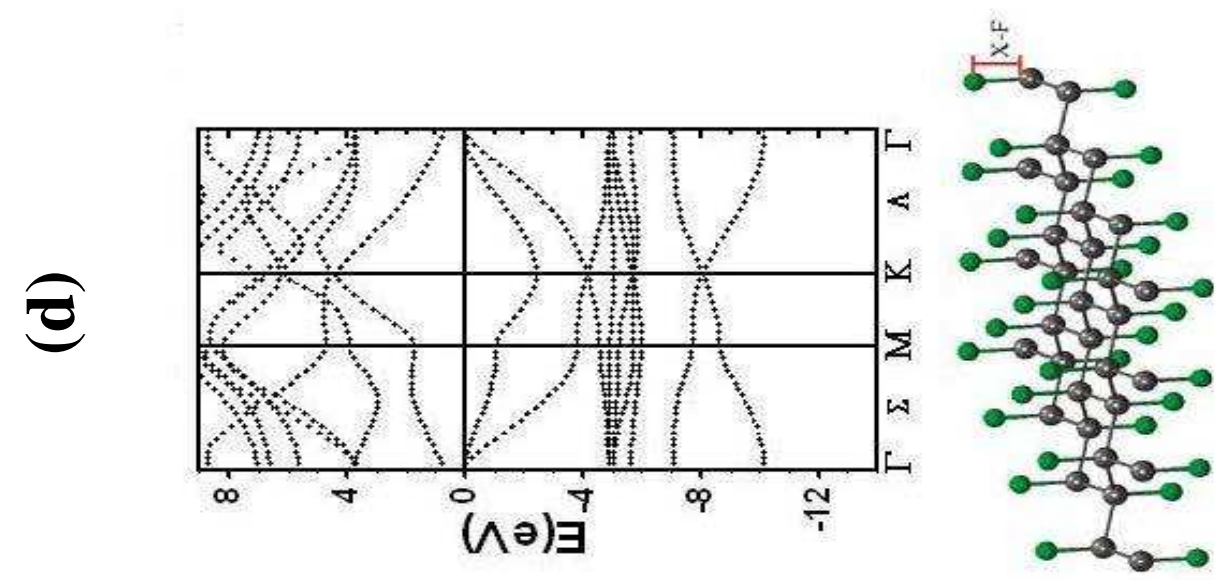

e
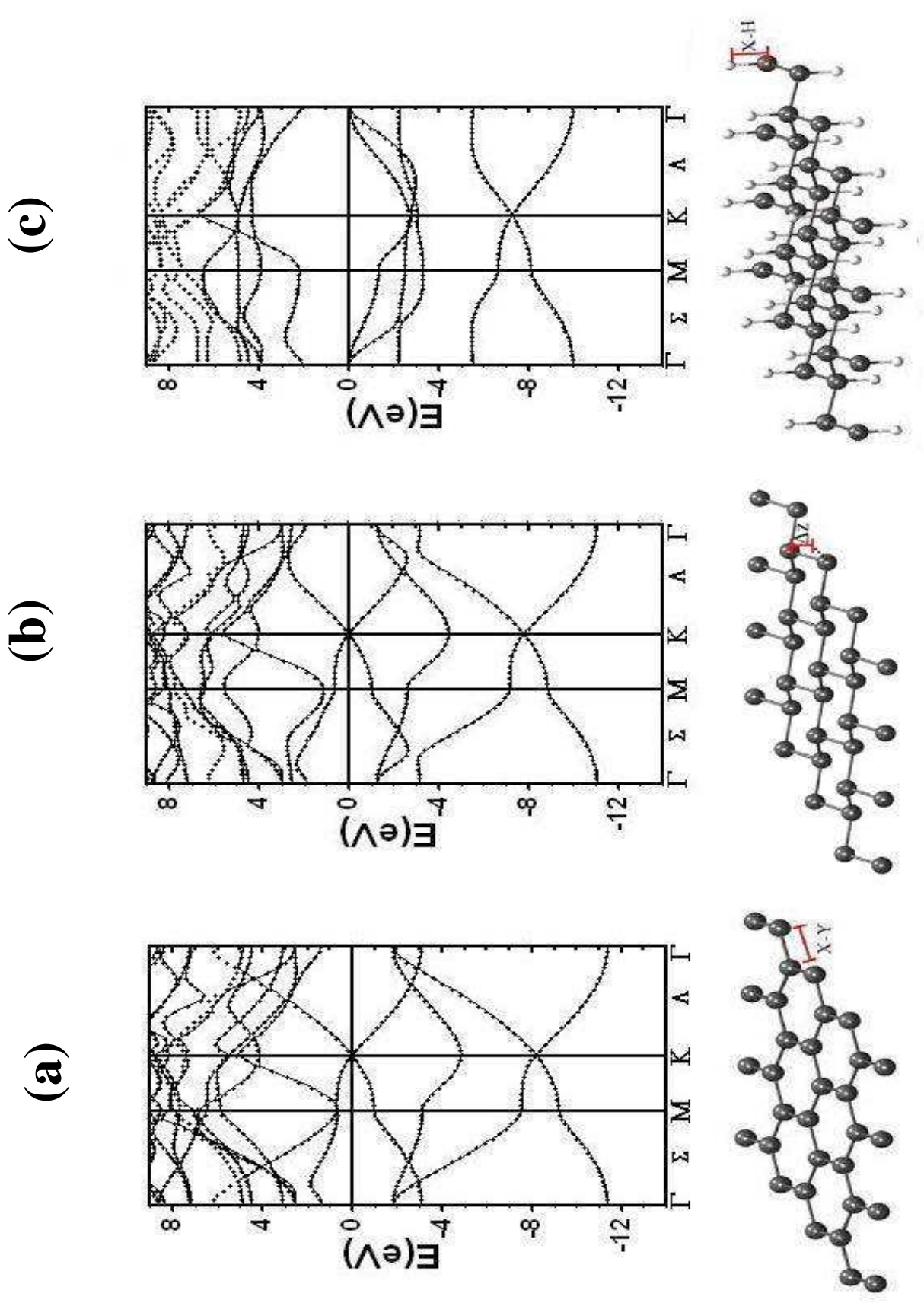

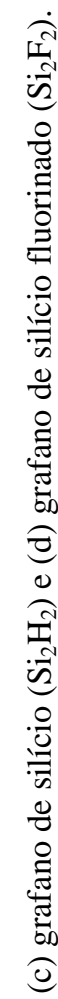

is 

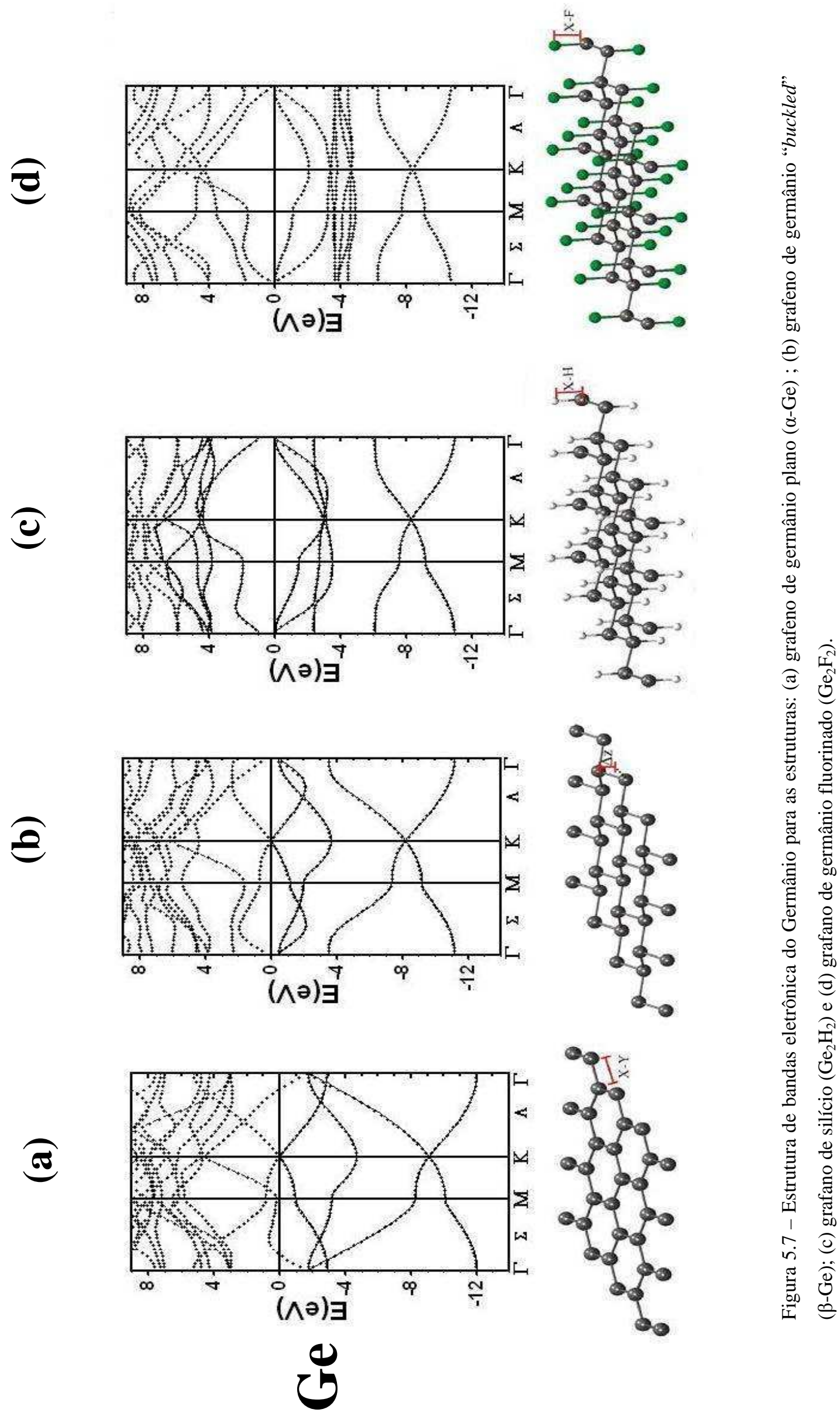

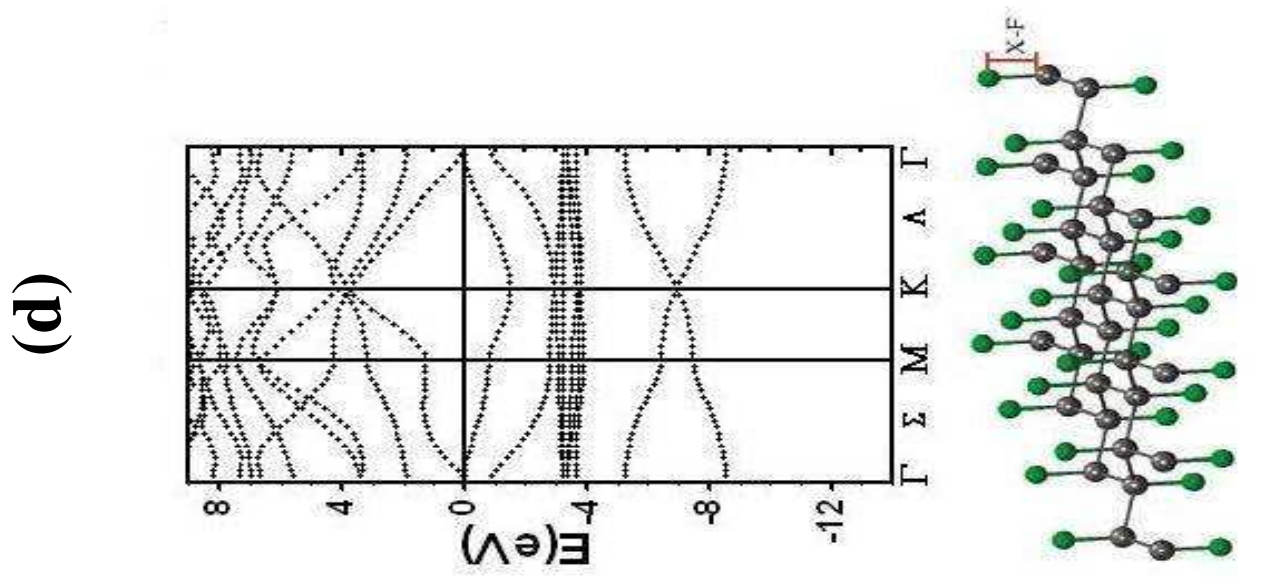

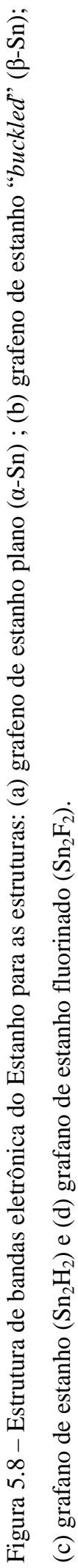
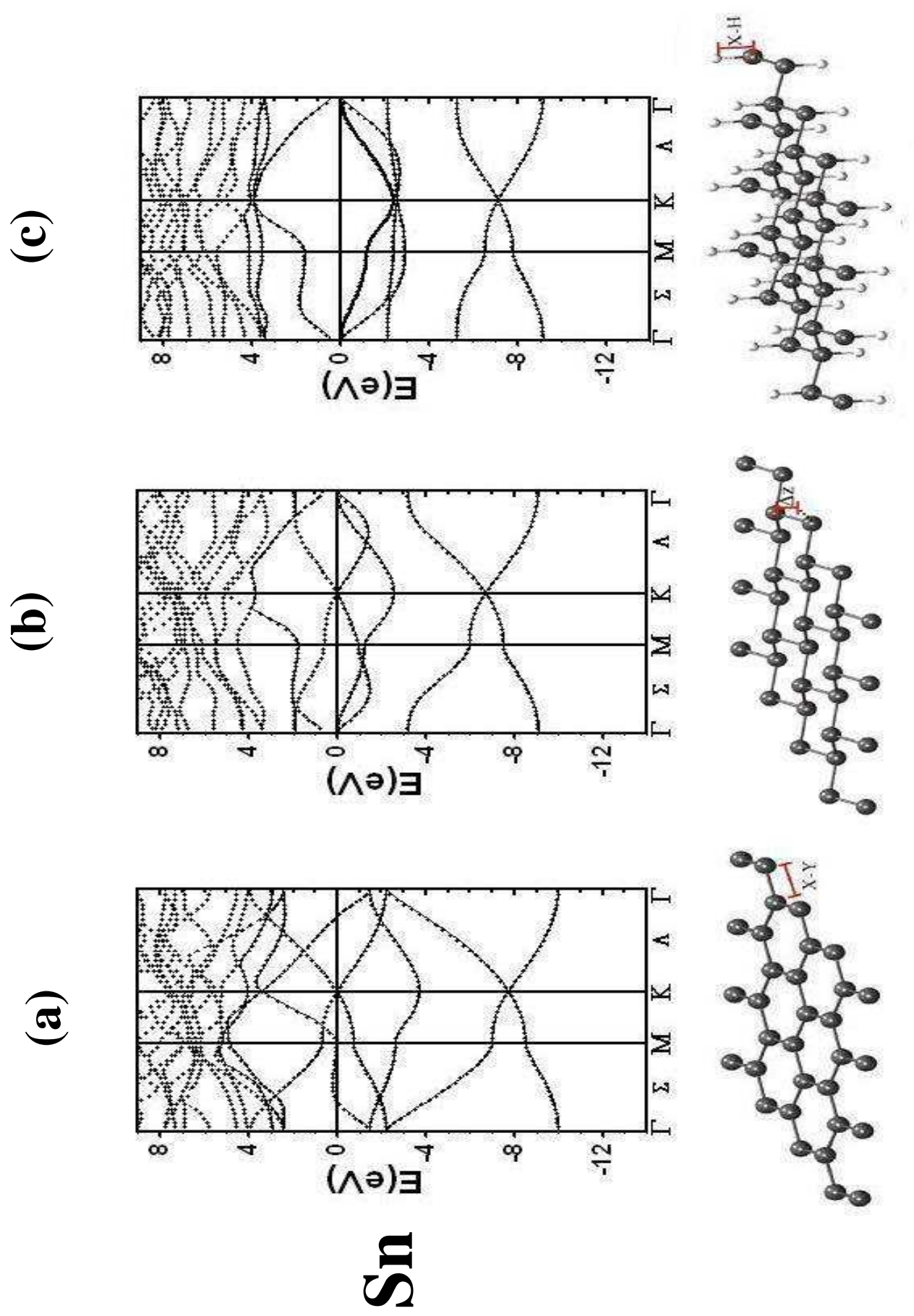

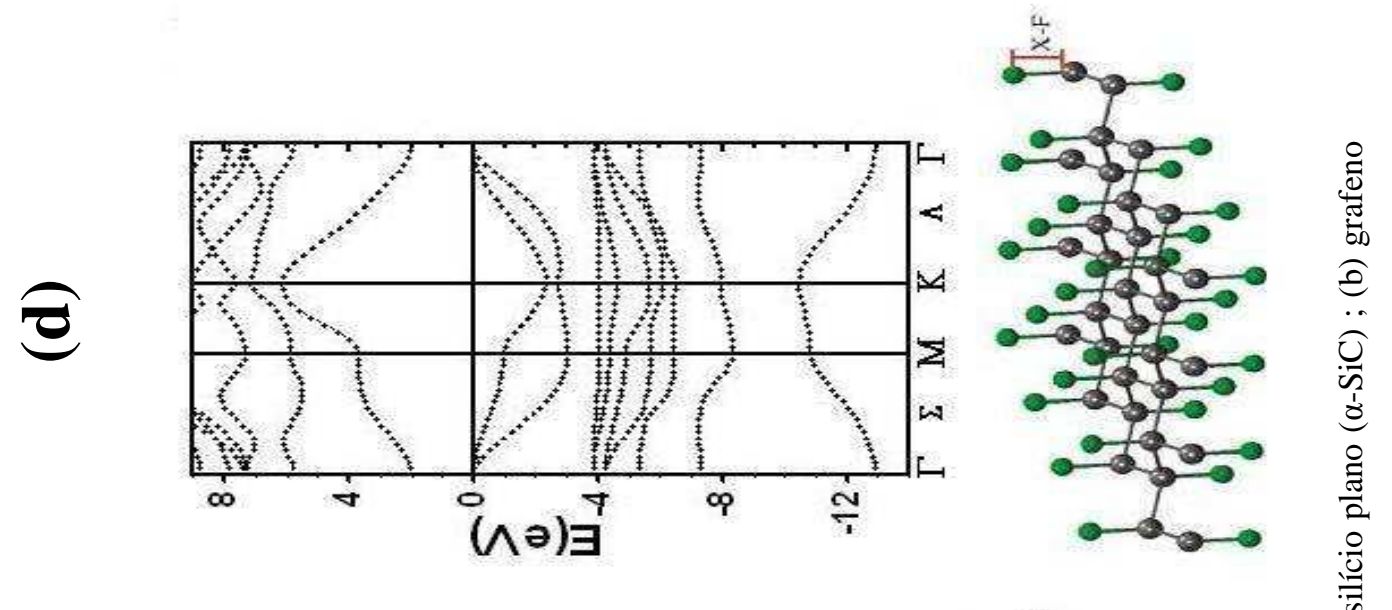

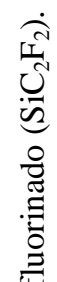
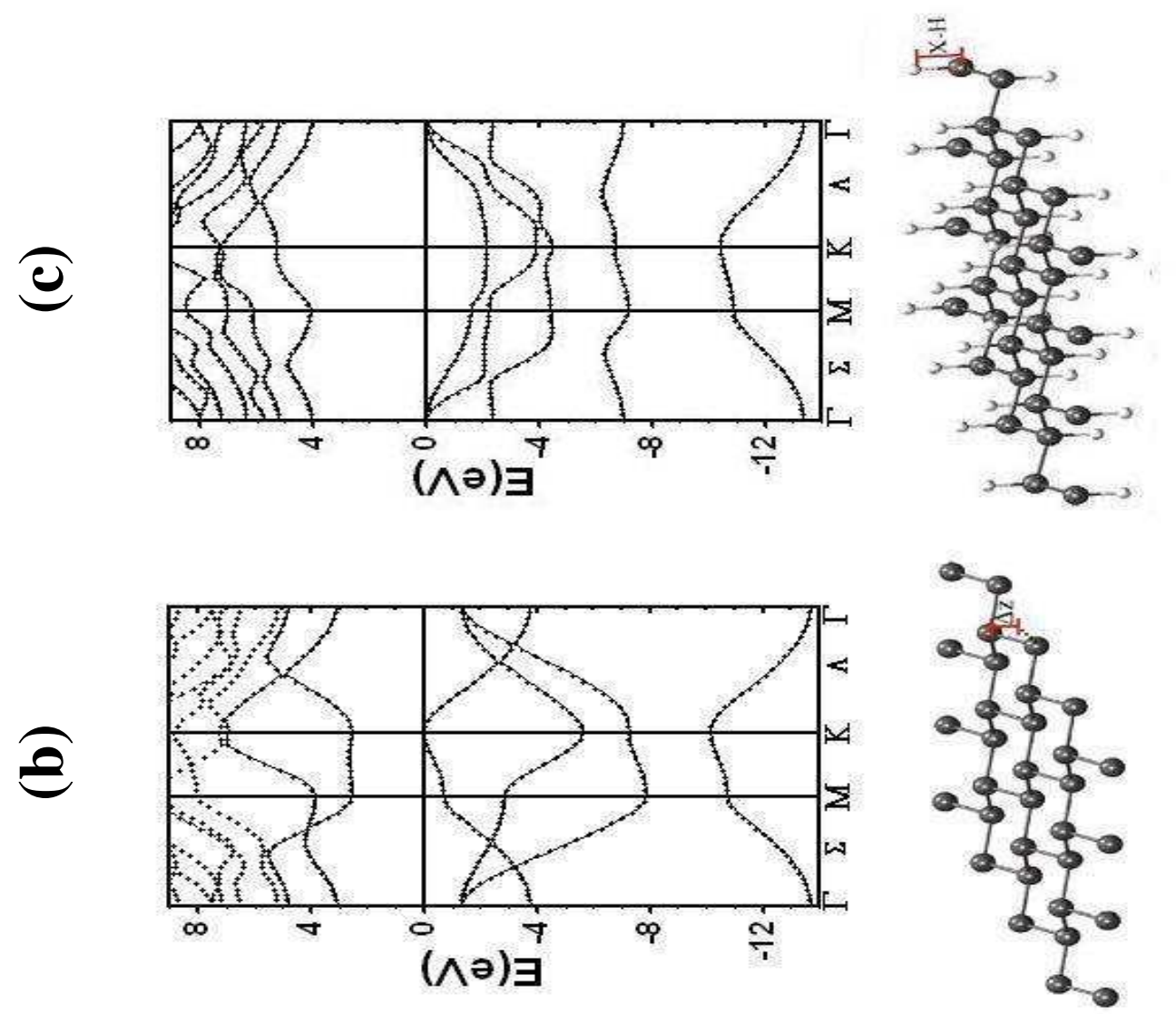

(⿹弋

$\stackrel{\circ}{\stackrel{0}{*}}$
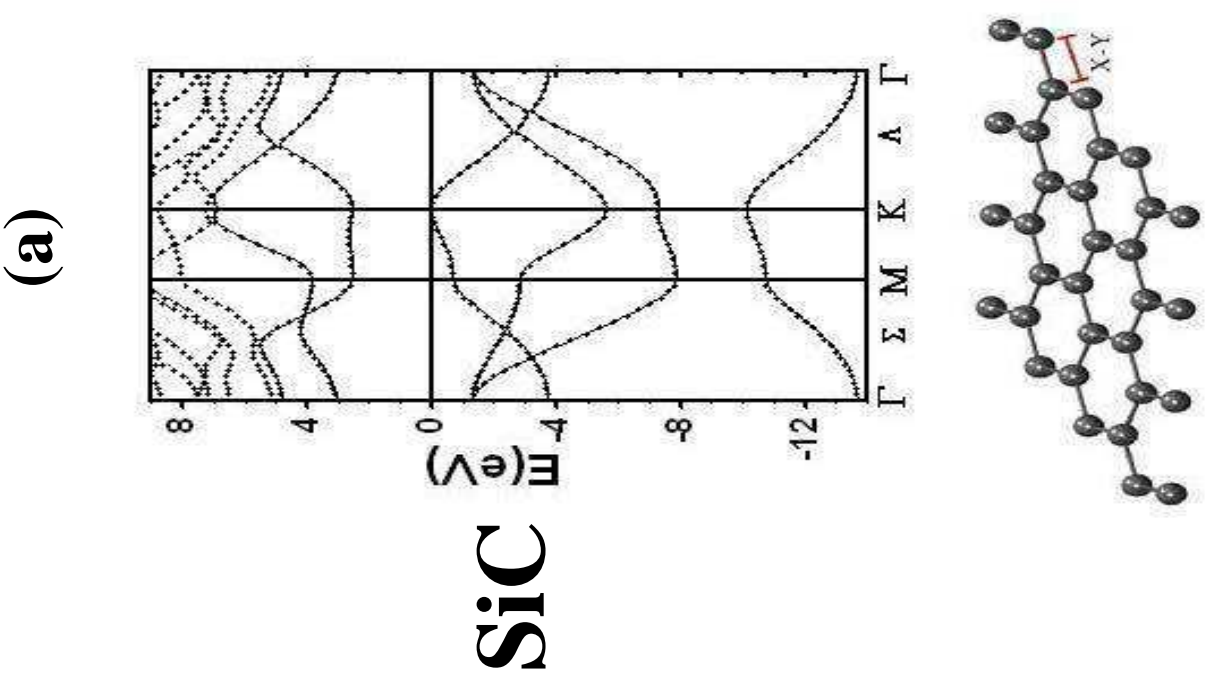


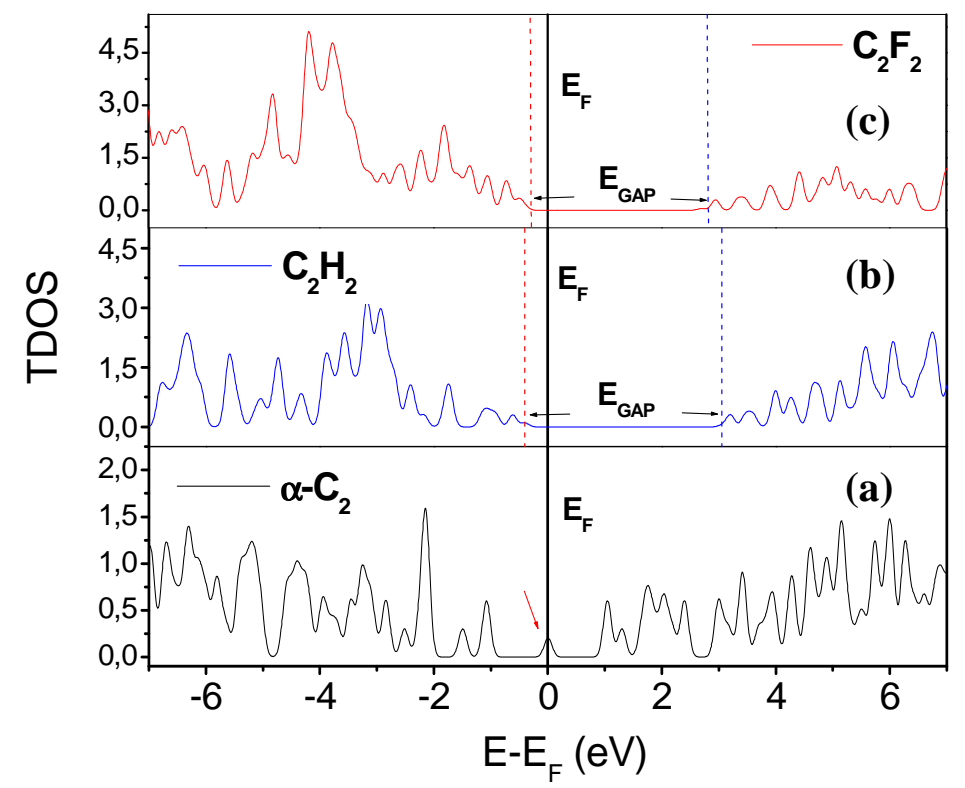

Figura 5.10 - Densidade de Estados (DOS) do Carbono para as estruturas: (a) grafeno plano ( $\alpha$-C); (b) grafano $\left(\mathrm{C}_{2} \mathrm{H}_{2}\right)$ e (c) grafano fluorinado $\left(\mathrm{C}_{2} \mathrm{~F}_{2}\right)$. As linhas pontilhadas em vermelho e azul representam a localizacão do orbital mais alto ocupado (HOMO) e do desocupado mais baixo (LUMO), respectivamente.

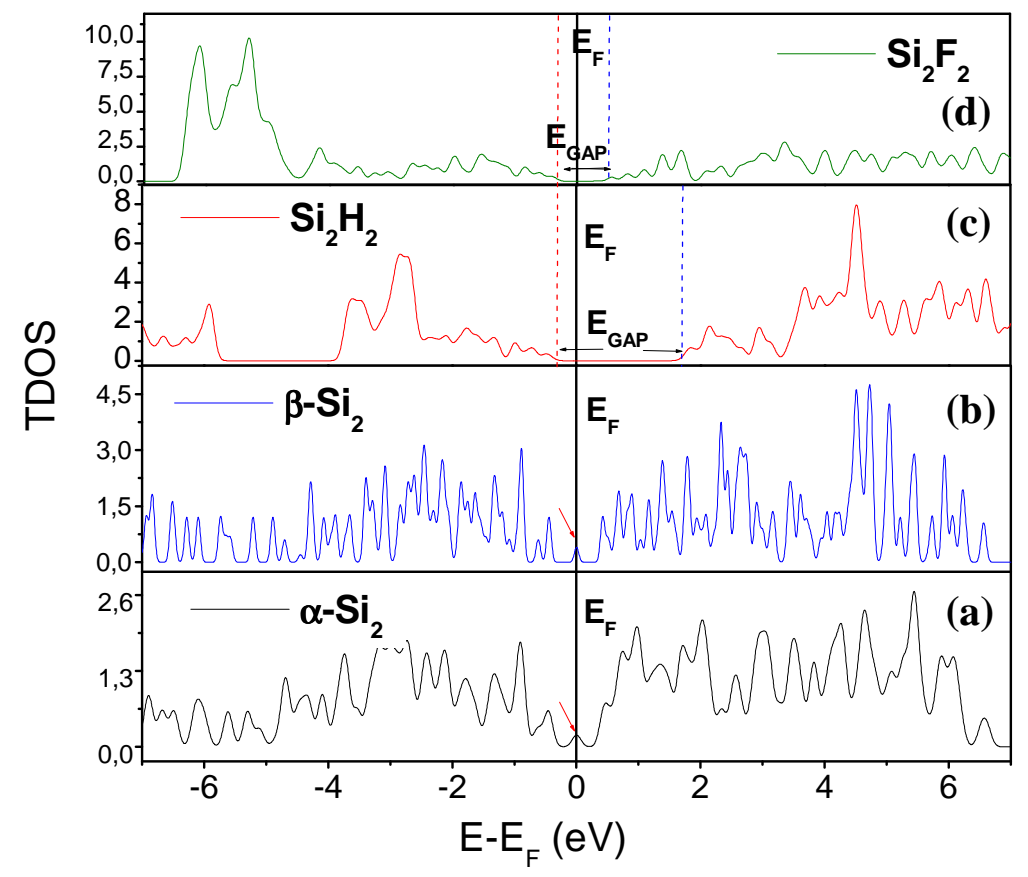

Figura 5.11 - Densidades de Estados (DOS) do Silício para as estruturas: (a) grafeno de silício plano $(\alpha-\mathrm{Si})$; (b) grafeno de silício "buckled" ( $\beta$-Si); (c) grafano de silício $\left(\mathrm{Si}_{2} \mathrm{H}_{2}\right)$ e (d) grafano de silício fluorinado $\left(\mathrm{Si}_{2} \mathrm{~F}_{2}\right)$. As linhas pontilhadas em vermelho e azul representam a localização do orbital mais alto ocupado (HOMO) e do desocupado mais baixo (LUMO), respectivamente. 


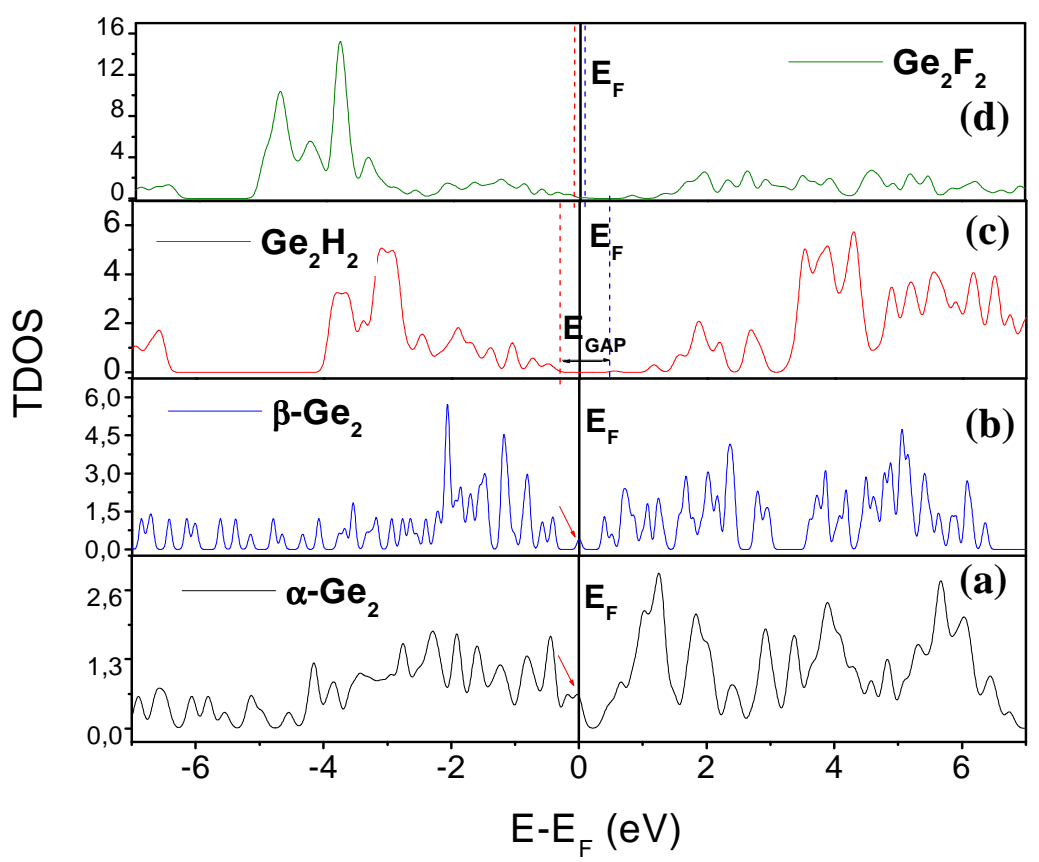

Figura 5.12 - Densidades de Estados (DOS) do germânio para as estruturas: (a) grafeno de germânio plano ( $\alpha-\mathrm{Ge})$; (b) grafeno de germânio "buckled" ( $\beta$-Ge); (c) grafano de germânio $\left(\mathrm{Ge}_{2} \mathrm{H}_{2}\right)$ e (d) grafano de germânio fluorinado $\left(\mathrm{Ge}_{2} \mathrm{~F}_{2}\right)$. As linhas pontilhadas em vermelho e azul representam a localização do orbital mais alto ocupado (HOMO) e do orbital desocupado mais baixo (LUMO),.respectivamente.

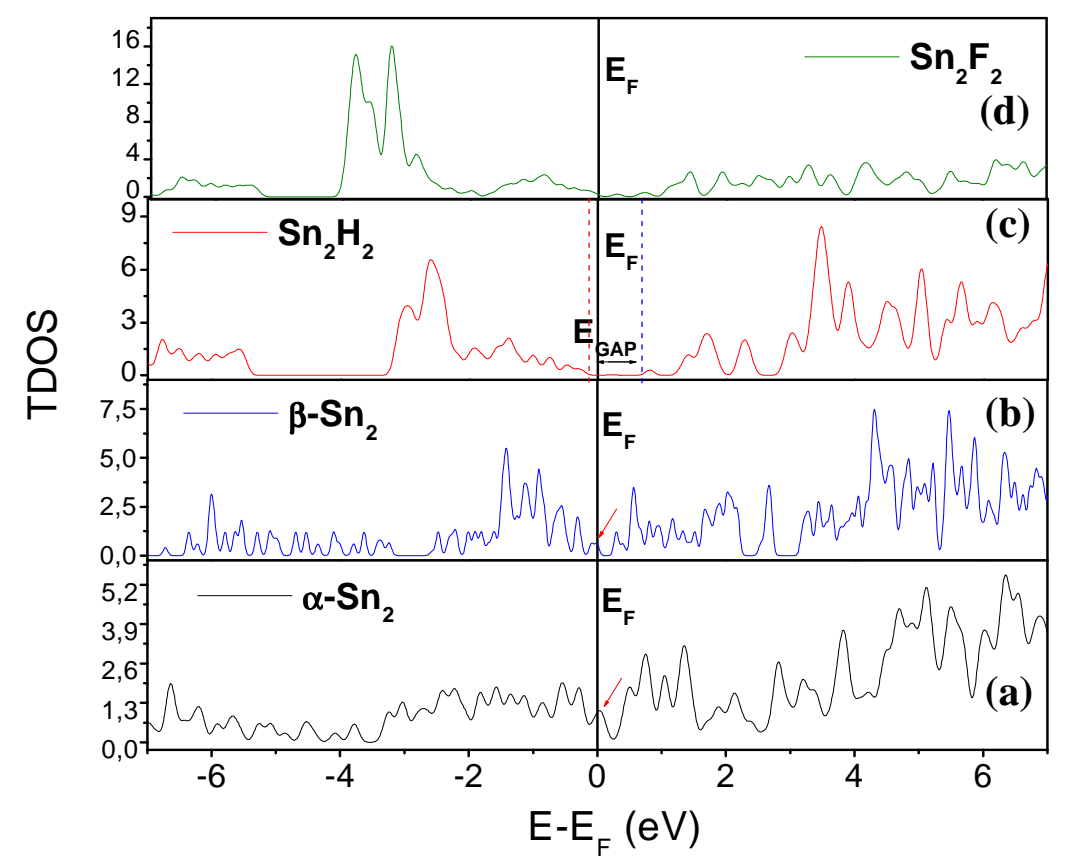

Figura 5.13 - Densidades de Estados (DOS) do Estanho para as estruturas: (a) grafeno de estanho plano ( $\alpha$-Sn) ; (b) grafeno de estanho "buckled" ( $\beta$-Sn); (c) grafano de estanho $\left(\mathrm{Sn}_{2} \mathrm{H}_{2}\right)$ e (d) grafano de estanho fluorinado $\left(\mathrm{Sn}_{2} \mathrm{~F}_{2}\right)$. As linhas pontilhadas em vermelho e azul representam a localização do orbital mais alto ocupado (HOMO) e do orbital desocupado mais baixo (LUMO), respectivamente. 


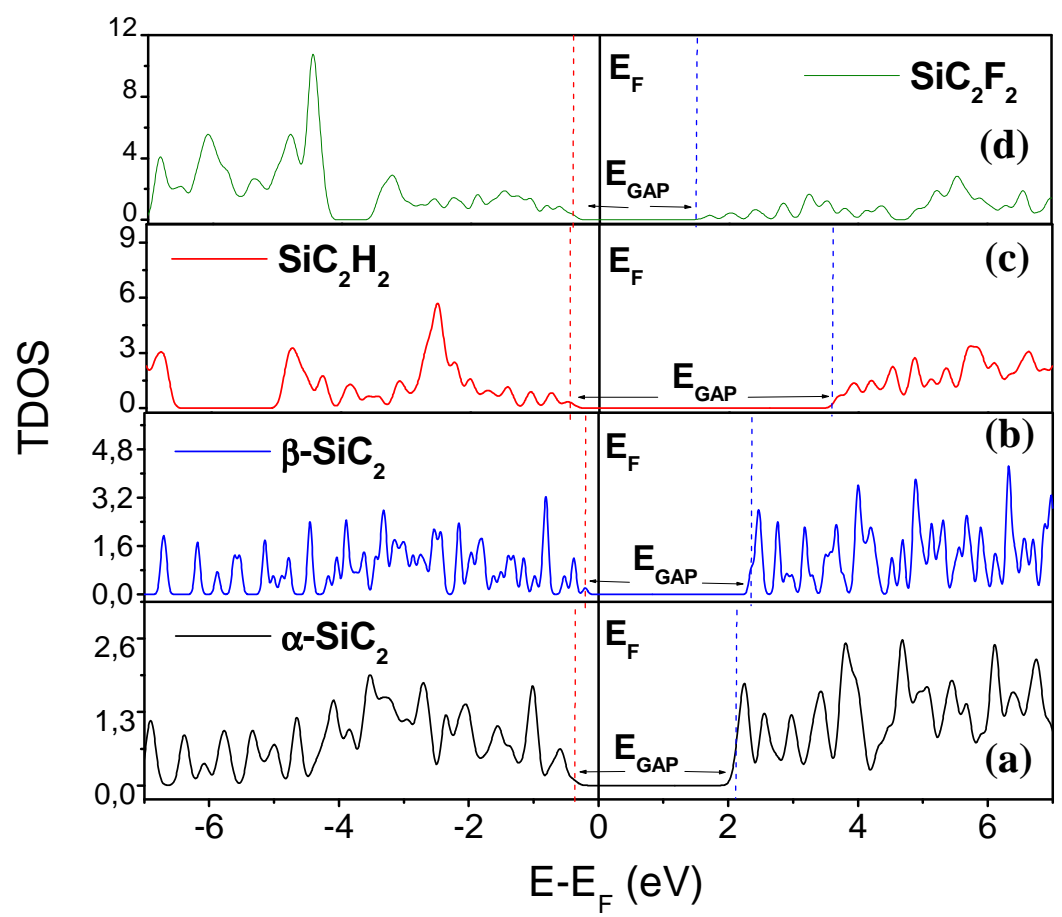

Figura 5.14 - Densidades de Estados (DOS) do Carbeto de Silício para as estruturas: (a) grafeno de silício plano ( $\alpha$-SiC) ; (b) grafeno de carbeto de silício "buckled" ( $\beta$-SiC); (c) grafano de carbeto de silício $\left(\mathrm{SiCH}_{2}\right)$ e (d) grafano de carbeto de silício fluorinado $\left(\mathrm{SiCF}_{2}\right)$. As linhas pontilhadas em vermelho e azul representam a localização do orbital mais alto ocupado (HOMO) e do orbital desocupado mais baixo (LUMO), respectivamente. 


\section{Capítulo 6}

\section{Propriedades Físicas de Defeitos Estruturais e Dopagem com Boro e Nitrogênio em Grafeno}

\section{1 - Introdução}

Diversas propriedades interessantes do grafeno puro são inerentes ao material, como o movimento eletrônico balístico com a mobilidade de portadores extremamente alta $\left(10^{4} \mathrm{~cm}^{2}\right.$ $\mathrm{V}^{-1} \mathrm{~s}^{-1}$ em temperatura ambiente) ou o efeito Hall quântico em temperatura ambiente, que foram discutidas nos capítulos anteriores. Entretanto, a presença de defeitos no grafeno pode comprometer consideravelmente essas propriedades, ao introduzir centros espalhadores de portadores. Na nanoengenharia de dispositivos, a introdução de defeitos estruturais ou impurezas é usada para permitir, como em semicondutores convencionais, alcançar certas funcionalidades desejadas. Uma vez que a ausência de um bandgap no grafeno perfeito não 
Capítulo 6 - Propriedades Físicas do Grafeno com Defeitos Estruturais e Dopagem com Boro e Nitrogênio.

permite a comutação em transistores baseados em grafeno com uma relação on-off suficientemente alta, por isso, o grafeno tem sido modificado mesmo na fabricação de dispositivos básicos, e muito mais, na fabricação de circuitos sofisticados.

Existem dois tipos de defeitos, os intrínsecos e os extrínsecos. Os intrínsecos são os defeitos estruturais do sistema, entre eles destacam-se as vacâncias, divacâncias e "StoneWales", que são os mais conhecidos, e suas configurações foram discutidas no capítulo 4 . O estudo da influência destes defeitos nas propriedades eletrônicas do grafeno ainda está no seu princípio. Desta forma, os estudos teóricos e experimentais que possam identificar as mudanças nas características eletrônicas e ópticas em função da concentração de defeitos são de grande importância para o avanço na compreensão deste tema.

Por outro lado, os defeitos extrínsecos têm origem externa, ou seja, são geralmente incorporados no grafeno por processos artificiais tais como irradiação ou tratamentos químicos. Um exemplo de defeitos extrínsecos são os átomos dopantes ou impurezas, que são de importância igualmente grande no desenvolvimento de dispositivos baseados em grafeno, uma vez que estes átomos dopantes podem mudar a estrutura eletrônica local ou injetar carga no sistema eletrônico do grafeno.

Os defeitos intrínsecos também causam importantes mudanças nas propriedades eletrônicas, estruturais e óticas do grafeno. Por exemplo, o grafeno, na sua configuração ideal, é não-magnético. Entretanto, foi observado que a presença de uma vacância dá origem a estados semi-localizados próximos ao nível de Fermi que levam a momentos magnéticos locais no grafeno $[158,159]$. Esse magnetismo, por sua vez, também pode surgir no grafeno pela dopagem com átomos substitucionais e adátomos, e pode ser manipulado através do controle do conteúdo dessas impurezas.

Uma investigação recente constatou também que a coalescência de duas vacâncias individuais gera um novo defeito, chamado de divacância 585. Este novo defeito estrutural, por sua vez, pode se reconstruir novamente, resultando na divacância 555777, que é o defeito predominante no grafeno em altas temperaturas (em torno de $3000 \mathrm{~K}$ ) [160].

Entre os defeitos intrínsecos, o "Stone-Wales" (SW) é um dos mais comuns existentes em alótropos do carbono. Ele é criado a partir da rotação de uma ligação C-C por um ângulo de $90^{\circ}$, resultando na formação de dois heptágonos e dois pentágonos em torno dos átomos de carbono rotacionados, conforme descrito no capítulo 4. Observou-se que tanto o "Stone- 
Capítulo 6 - Propriedades Físicas do Grafeno com Defeitos Estruturais e Dopagem com Boro e Nitrogênio.

Wales" como as divacâncias se comportam como centros de quimissorção estáveis a distâncias na faixa de nanômetros, de átomos, tais como o hidrogênio ou de metais. Ou seja, esses defeitos tendem a atrair átomos de hidrogênio ou de metais para a sua periferia [62, 110].

Os defeitos extrínsecos, tais como átomos dopantes em diferentes posições também têm uma forte influência sobre a interação elétron-elétron e, por sua vez, na distribuição de carga e na estrutura de bandas do grafeno. Por exemplo, os átomos de metais de transição com elétrons d e f, incorporados na rede do grafeno, podem dar origem a muitos fenômenos interessantes, incluindo o efeito Kondo [161] e o magnetismo [162]. As dopagens com boro e nitrogênio também tem sido bastante investigadas [157, 163, 164]. A razão da escolha desses elementos é porque além destes serem trivalentes e pentavalentes, respectivamente, eles também apresentam valores de raio atômico aproximado ao do carbono.

Associando os defeitos intrínsecos e extrínsecos, uma recente investigação [165] propôs o uso de faixas regulares unidimensionais de vacâncias para transformar o grafeno em um meta-material magnético com propriedades que podem ser flexivelmente controladas pela dopagem ou funcionalização química. Ao se concretizar a fabricação destas estruturas, será aberta uma ampla gama de possibilidades para a criação de dispositivos para a spintrônica.

Neste capítulo será investigada a formação de defeitos e sua influência sobre as propriedades do grafeno, tendo em vista o alcance de diferentes funcionalidades para aplicações em nanoeletrônica. Na estrutura do grafeno é possível existir um número essencialmente infinito de tipos de defeitos de rede. Entretanto, neste capítulo serão considerados apenas os mais simples. Será focado particularmente sobre os defeitos em monocamada de grafeno, uma vez que defeitos em bi- ou multicamadas também existentes na grafite, já foram bastante investigados antes do grafeno se tornar alvo de interesse da comunidade científica. Sendo assim, este capítulo discutirá as propriedades eletrônicas de defeitos estruturais em grafeno, tais como, a monovacância, divacância, trivacância e StoneWales, bem como defeitos com a adição de átomos substitucionais de boro e nitrogênio em diversas configurações, utilizando a Teoria do Funcional da Densidade (DFT) com spinpolarizado e a aproximação GGA-PBE, implementado no pacote de simulação computacional VASP (Vienna Ab Initio Simulation Package), utilizando o método PAW para descrever os elétrons de valência, conforme descrito no capítulo 3. 


\section{2 - Defeitos Estruturais no Grafeno}

Esta seção descreve os cinco defeitos estruturais em grafeno que serão investigados. O primeiro defeito que será estudado é o "Stone-Wales" (SW), que é caracterizado por apresentar uma distorção na rede produzida pela rotação da ligação química de um par de átomos de carbono em 90 graus, transformando quatro hexágonos em dois heptágonos e dois pentágonos, conforme figura 6.1 (a). Sua estrutura mantém o mesmo número de átomos que o grafeno puro, não apresentando desta forma ligações pendentes (ou “dangling bonds"). Sua estrutura tem sido observada experimentalmente através de imagens de microscopia eletrônica de tunelamento (TEM) apresentadas em [166].

O segundo defeito estrutural que será estudado é a monovacância (MV), que é caracterizada pela a ausência de um único átomo na estrutura do grafeno, o qual se reconstrói formando um pentágono e um eneágono, o que leva a saturação de duas das três ligações pendentes sobrando apenas uma ligação pendente, conforme mostra a figura 6.1 (b). A monovacância tem sido observada experimentalmente através de imagens obtidas via microscopia de tunelamento eletrônico (TEM) e microscopia de tunelamento com varredura (STM) $[115,166,167]$.

O terceiro e o quarto defeitos investigados são a divacância 585 (DV-585) e a divacância 555777 (DV-555777), respectivamente. A divacância 585 é um defeito que pode ser gerado através da coalescência de duas vacâncias ou pela remoção de dois átomos de carbono na estrutura do grafeno, levando ao aparecimento de um octógono e dois pentágonos, conforme mostra a figura 6.1 (c). Por outro lado, a divacância 555777 é um defeito resultante da reconstrução da divacância 585, onde em altas temperaturas um par de átomos de carbono do octógono presente no defeito 585 é rotacionado formando um arranjo de três heptágonos e três pentágonos, conforme mostra a figura 6.1 (d). Como pode ser observado, não existem ligações pendentes para estes defeitos. Estes defeitos também são freqüentemente observados em experimentos de microscopia eletrônica [113, 168]

Por fim, o quinto defeito estrutural estudado nesta seção será a trivacância (TV), que é caracterizado pela a ausência de três átomos na estrutura do grafeno, levando ao aparecimento de dois pentágonos e um decágono, o que leva a saturação de quatro das cinco 
Capítulo 6 - Propriedades Físicas do Grafeno com Defeitos Estruturais e Dopagem com Boro e Nitrogênio.

(a)
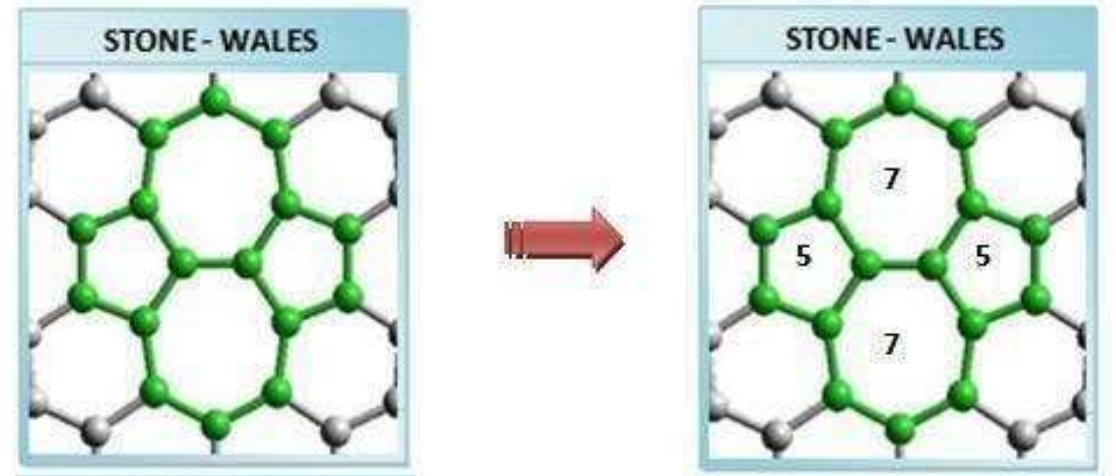

VACÂNCIA

(b)
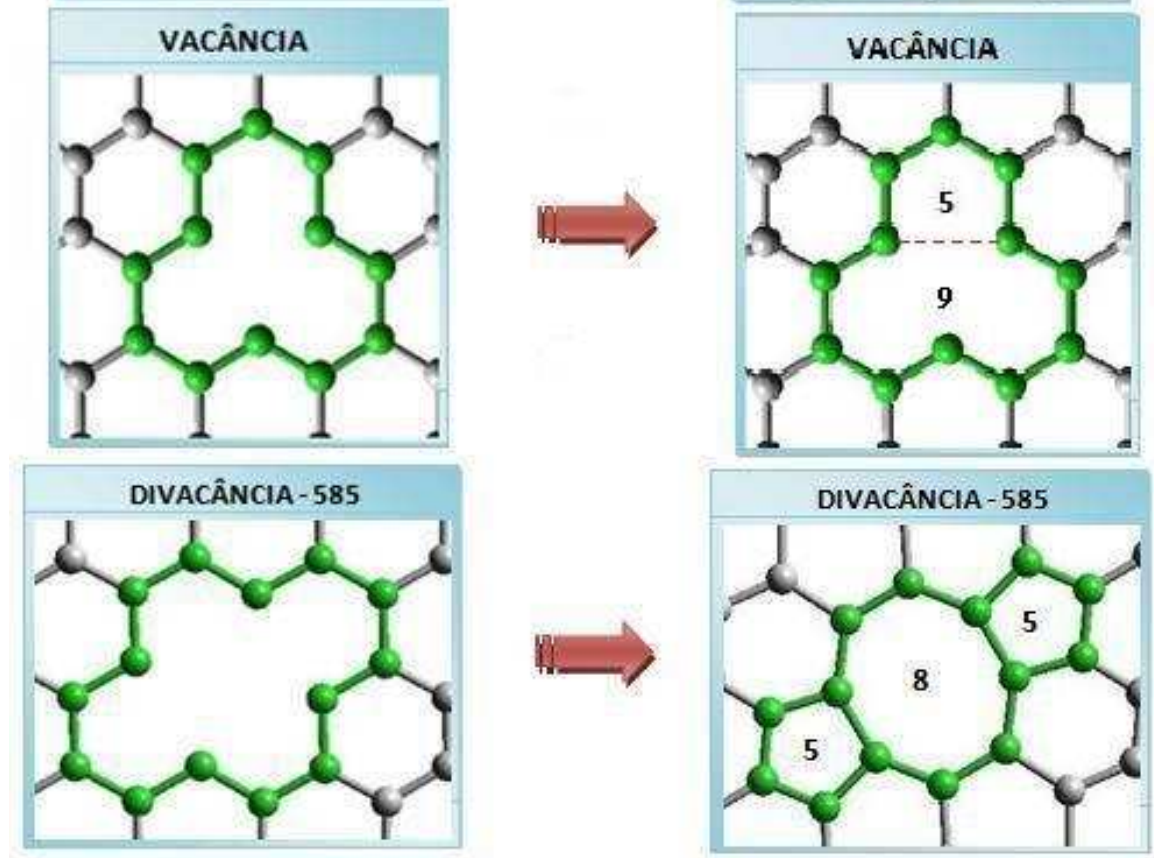

(c)

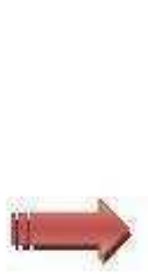

(d)
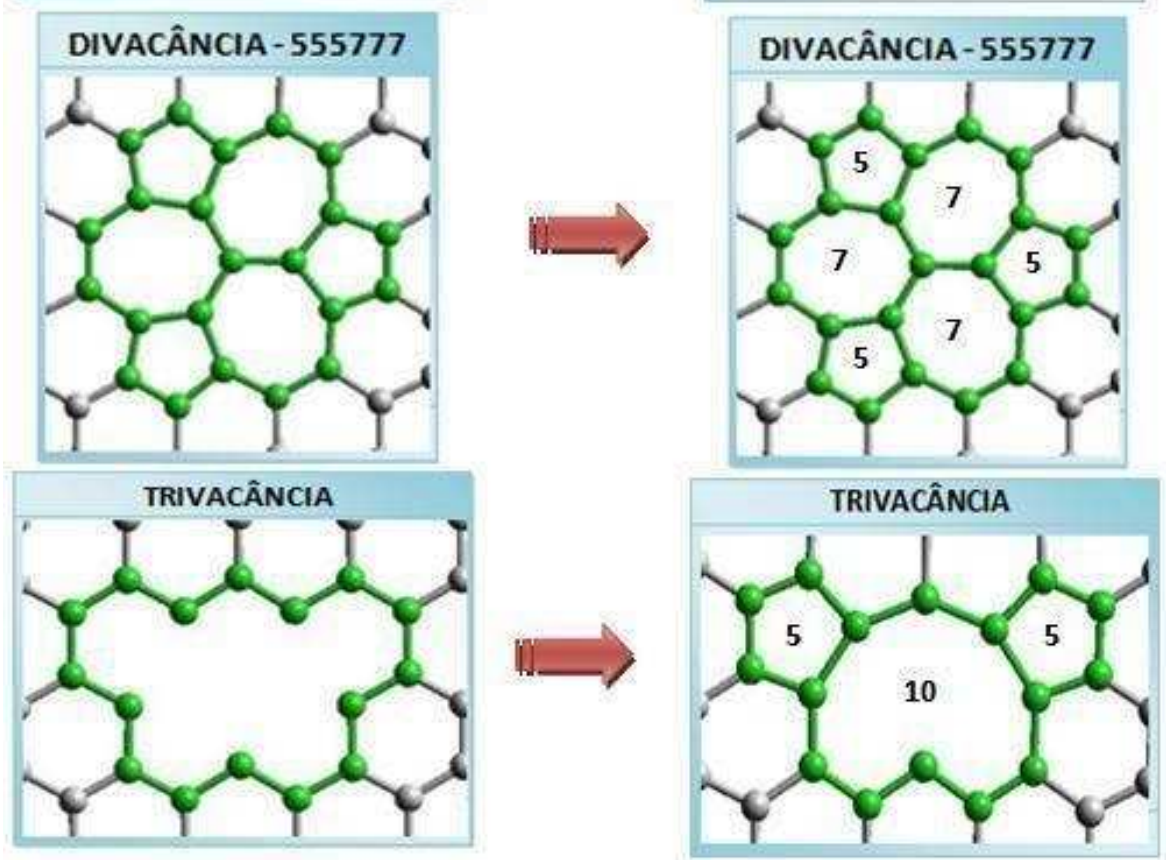

Figura 6.1 - Representação esquemática dos defeitos estruturais em grafeno e suas respectivas reconstruções: (a) "Stone-Wales"; (b) Vacância; (c) Divacância - 585; (d) Divacância - 555777 e (e) Trivacância. 
Capítulo 6 - Propriedades Físicas do Grafeno com Defeitos Estruturais e Dopagem com Boro e Nitrogênio.

ligações pendentes (ou "dangling bonds") sobrando apenas uma ligação pendente, conforme mostra a figura 6.1 (e). Foi observado que quando o número de vacâncias presentes na estrutura do grafeno é par, ocorre a reconstrução total, ou seja, a saturação completa de todas as ligações pendentes. Por outro lado, quando o grafeno apresenta um número ímpar de vacâncias, sempre sobra uma ligação pendente.

Para investigar os defeitos mencionados nos parágrafos anteriores, foi utilizada uma supercélula contendo oito repetições $(8 \times 8)$ da célula primitiva do grafeno perfeito, o que equivale a 128 átomos de carbono, apresentando apenas um defeito por supercélula. A distância entre o plano atômico e sua imagem foi de 10 Á e o tamanho da supercélula foi suficiente para não permitir a interação entre os defeitos de diferentes supercélulas.

$\mathrm{Na}$ próxima seção serão apresentados os resultados das propriedades físicas e eletrônicas dos defeitos estruturais descritos nesta seção.

\section{3 - Propriedades Físicas do Grafeno com Defeitos Estruturais}

\subsection{1 - Estabilidade e Distâncias Interatômicas}

A variável que possibilita medir a estabilidade dos defeitos em grafeno independente do número de átomos do sistema é chamada de energia de formação $E_{F}$, que é definida pela seguinte equação geral:

$$
E_{\text {Formação }}(D)=E_{\text {Total }}(\text { grafeno }+ \text { defeito })-E_{\text {Total }}(\text { grafeno })+n \mu_{C}
$$

onde, $E_{\text {Total }}($ grafeno + defeito $)$ e $E_{\text {Total }}($ grafeno $)$ são as energias totais do sistema do grafeno com e sem defeito, respectivamente. Por outro lado, $n$ é o número de átomos removidos do sistema puro e $\mu_{C}$ é o potencial químico do carbono, que é definido como a energia total do sistema puro dividido pelo número total de átomos do sistema, representado pela equação 6.2:

$$
\mu_{C}=\frac{E_{\text {Total }}(\text { grafeno })}{N}
$$


Capítulo 6 - Propriedades Físicas do Grafeno com Defeitos Estruturais e Dopagem com Boro e Nitrogênio.

Neste caso, o termo $N$ simboliza o número de átomos presentes no sistema do grafeno puro. Uma vez que para o defeito de "Stone-Wales" não há remoção de átomos, o valor de $n$ é igual a zero. Desta forma, o valor da energia de formação para este defeito passa a ser a diferença entre as energias totais do grafeno com "Stone-Wales" e o grafeno puro, que podem ser representados pelos dois primeiros termos da equação 6.1. Para os sistemas onde há remoção de átomos, neste caso, a monovacância, as divacâncias 585 e 555777 e a trivacância, estes números serão 1, 2 e 3, respectivamente. Desta forma, foram calculadas as energias de formação para todos os sistemas com defeitos descritos na seção anterior, apresentados na tabela 6.1.

A partir da análise da tabela 6.1, que apresenta os resultados dos cálculos descrito nos parágrafo anteriores, é possível constatar que o defeito "Stone-Wales" é o que tem a menor energia de formação $\left(E_{F}\right)$. Comparando a energia de formação deste defeito com os outros investigados, pode-se notar que o defeito SW apresenta uma energia de formação menor que a da monovacância e da divacância 585 em mais de $2 \mathrm{eV}$, e menor que a divacância 555777 em mais de $1.5 \mathrm{eV}$.

Comparando entre si os dois defeitos de divacância, é possível notar que a divacância 555777 possui energia de formação menor que a divacância 585, sendo, portanto, mais estável, em conformidade com outros resultados existentes na literatura [160, 162]. Outro ponto importante é que ambos os defeitos de divacância apresentam energia de formação menor que a monovacância, o que significa que as divacâncias são mais estáveis que as monovacâncias. Por fim, entre todos os defeitos investigados, o que apresentou menor estabilidade foi a trivacância, que possui a maior energia de formação dentre os defeitos estudados.

Comparando as energias de formação obtidas neste capítulo com os resultados teóricos das referências citadas na tabela 6.1, é possível observar uma boa conformidade para a energia de formação do defeito "Stone-Wales". Para o grafeno com monovacância houve uma pequena diferença em torno de $0.2 \mathrm{eV}$ entre o resultado da energia de formação calculada comparado com o resultado teórico máximo citados, fato que pode ser explicado uma vez que o funcional de troca-correlação GGA-PBE utilizado nesta investigação normalmente apresenta uma pequena diferença em relação ao funcional GGA-PW91, que foi utilizado nas investigações teóricas citadas. 


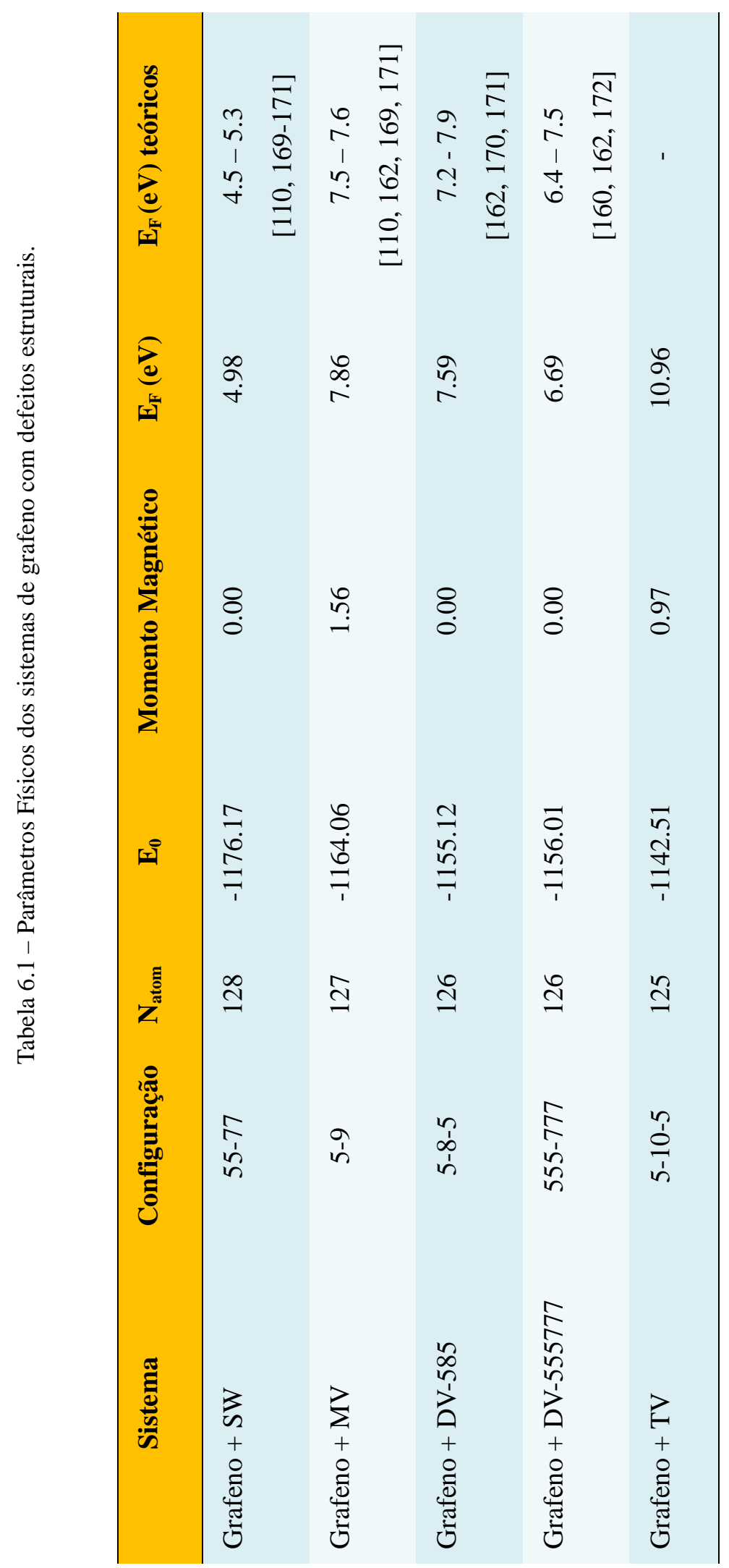


Capítulo 6 - Propriedades Físicas do Grafeno com Defeitos Estruturais e Dopagem com Boro e Nitrogênio.

No caso das divacâncias (585 e 555777), semelhantemente ao defeito de "StoneWales", os valores de energia de formação estão em boa conformidade com os resultados teóricos citados na tabela 6.1. Para a trivacância, não há notícia de outras investigações que forneçam o valor da energia de formação $\left(\mathrm{E}_{\mathrm{F}}\right)$ utilizando metodologia semelhante à dos cálculos realizados nesta seção.

Com relação às distâncias interatômicas, para o defeito de "Stone-Wales", a distância $\mathrm{d}_{\mathrm{AB}}$ apresentada na figura 6.2 (a) foi de $1.32 \AA$, valor aproximado a $1.336 \AA$ apresentado em [169, 173]. A distância $d_{A B}$, foi muito menor que as demais distâncias interatômicas nos pentágonos e heptágonos, que variaram de 1.38 a $1.46 \AA$, e menor que as distâncias interatômicas nos outros defeitos estudados, o que explica o fato deste defeito ser o mais estável entre os investigados nesta seção. Este defeito não apresentou magnetismo, uma vez que houve a reconstrução total, sem aparecimento de ligações pendentes.

Para as vacâncias, as distâncias interatômicas $d_{C E}$ e $d_{D E}$ apresentadas na figura 6.2 (b) foram de $2.46 \AA$ em ambos os casos, enquanto que $\mathrm{d}_{\mathrm{CD}}$ foi de $2.47 \AA$. Como pode ser constatado, essas distâncias foram bem maiores do que as demais no restante do defeito que variou entre 1.37 e $1.43 \AA$, o que sugere a formação de uma fraca ligação covalente entre dois dos três átomos, no caso os átomos C e o D, representada pela linha vermelha pontilhada na figura 6.2 (b) ficando o terceiro não pareado (átomo E), este terceiro átomo com ligação pendente produz magnetismo na vacância, que será explicado em maiores detalhes nas próximas seções.

No caso das divacâncias, houve a reconstrução total, tanto para a divacância 585 como para a divacância 555777. Para as ligações no centro da divacância 555777, as distâncias interatômicas $\mathrm{d}_{\mathrm{FG}}, \mathrm{d}_{\mathrm{FH}}$ e $\mathrm{d}_{\mathrm{FI}}$ foram de 1.49 Å. Por outro lado, para a divacância 585, as distâncias $\mathrm{d}_{\mathrm{JK}}$ e $\mathrm{d}_{\mathrm{LM}}$ foram $1.75 \AA$ concordando com outros resultados apresentados em $[159,160,162]$. Observou-se que houve uma aproximação entre os átomos J e K e os átomos L e M, na divacância 585. A diminuição da distância entre estes pares de átomos sugere o alcance de estabilidade através da formação destas fracas ligações covalentes acompanhado pelo desaparecimento de ligações pendentes, o que explica o fato deste defeito não apresentar magnetismo.

Como foi apresentado na seção anterior, na reconstrução da trivacância surgem dois pentágonos e um decágono, as distâncias interatômicas $\mathrm{d}_{\mathrm{NO}}$ e $\mathrm{d}_{\mathrm{PQ}}$ foram de $1.80 \AA$, valor aproximado a distância de $1.82 \AA$ apresentado em [159], que é $0.67 \AA$ menor que a distância 
Capítulo 6 - Propriedades Físicas do Grafeno com Defeitos Estruturais e Dopagem com Boro e Nitrogênio.

da ligação covalente fraca existente no pentágono da vacância. Como pode ser visto na figura 6.2 (e), houve a formação dos dois pentágonos com a formação de duas ligações covalentes fracas dos dois pares de átomos, $\mathrm{NO}$ e $\mathrm{PQ}$, respectivamente, ficando o quinto (átomo $\mathrm{R}$ ) não pareado, o que explica a existência de magnetismo neste defeito.

Através da análise das distâncias interatômicas e das reconstruções dos defeitos foi possível concluir que existe a tendência para o aparecimento de magnetismo em estruturas com um número ímpar de vacâncias, devido ao surgimento de ligações pendentes, característica que será detalhada na próxima seção. É importante ressaltar que as ligações mais fracas em torno destes defeitos podem afetar a condutividade térmica e reduzir a resistência mecânica do grafeno.

(a)

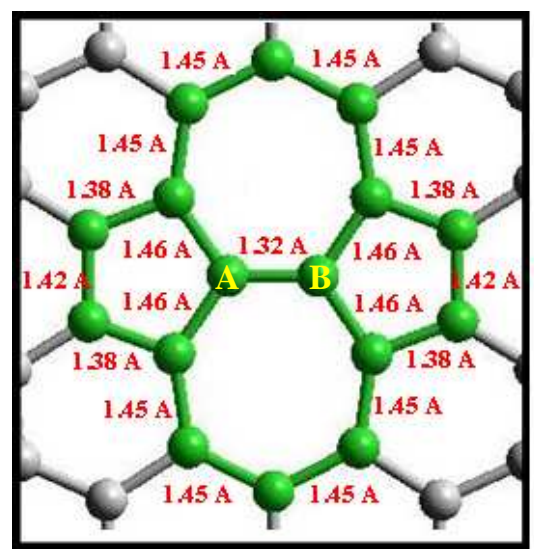

(b)

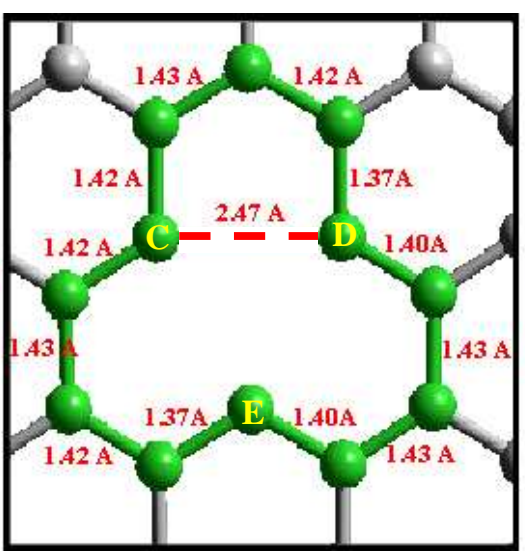

(c)

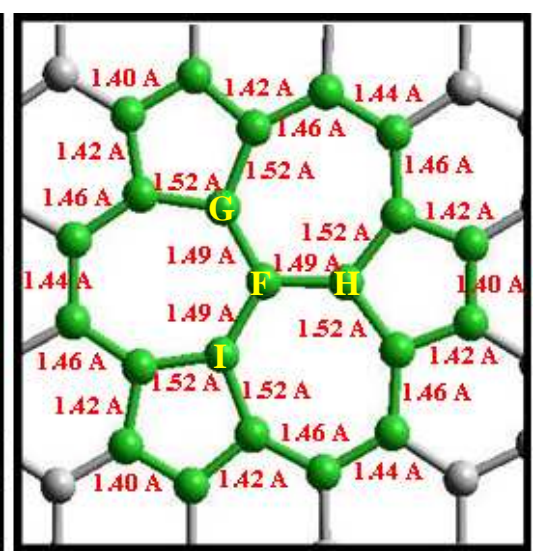

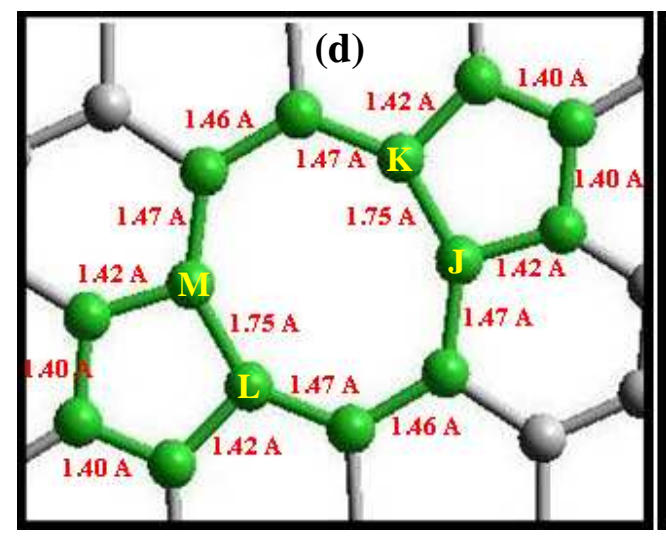

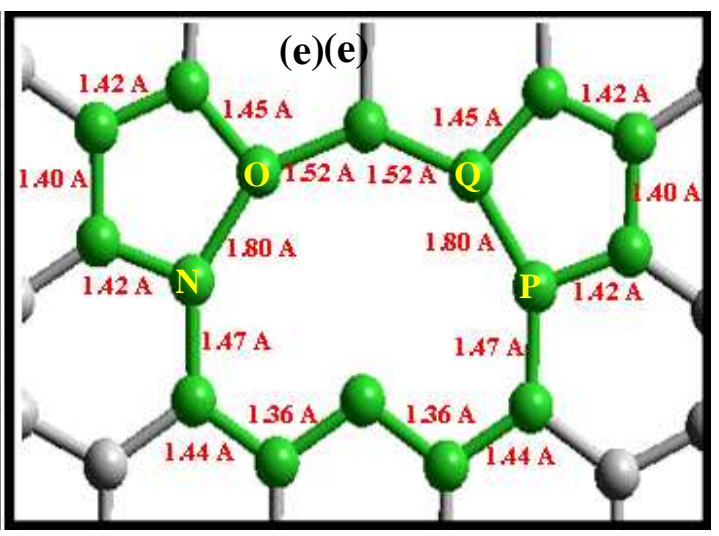

Figura 6.2 - Distâncias interatômicas: (a) "Stone-Wales"; (b) Vacância; (c) Divacância - 555777; (d) Divacância - 585; (e) Trivacância. 


\section{4 - Propriedades Eletrônicas do Grafeno com Defeitos Estruturais}

Nesta seção será feita a análise das estruturas de bandas e suas respectivas densidades de estados (DOS) obtidas através de cálculos DFT para os defeitos da monovacância, divacâncias (585 e 555777), trivacância e Stone-Wales.

\subsection{1 - Estrutura de Bandas e Densidade de Estados (DOS)}

Os defeitos estruturais afetam significativamente as propriedades eletrônicas do grafeno. O que determina as propriedades eletrônicas do grafeno é a sobreposição de orbitais $p_{z}$. Entretanto, uma vez que são introduzidos defeitos na rede do grafeno, esta sobreposição de orbitais sofre alterações na vizinhança destes defeitos.

Um dos motivos é que os comprimentos das ligações nos campos de tensão dos defeitos são diferentes daqueles na rede perfeita do grafeno. Além disso, os defeitos induzem a uma re-hibridização local de orbitais $\pi$ e $\sigma$, os quais novamente modificam a estrutura eletrônica. Outro fator que influencia na re-hibridização é a curvatura local em torno dos defeitos devido ao aparecimento de anéis não-hexagonais. Também é importante ressaltar que todos os defeitos estruturais levam ao espalhamento das ondas dos elétrons e mudam a trajetória dos mesmos.

Nos capítulos anteriores foi discutido que na estrutura de bandas do grafeno puro existem duas bandas lineares atravessando o nível de Fermi. Entretanto, a presença de defeitos quebra a simetria da rede, produzindo importantes mudanças na estrutura de bandas do grafeno. Um defeito criado na sub-rede A, quebra a simetria entre as sub-redes A e B, dando origem a estados magnéticos semi-localizados na sub-rede B e vice versa, além de remover a degeneração das bandas no nível de Fermi [158].

Para os defeitos investigados neste capítulo, através da análise das estruturas de bandas apresentadas nas figuras 6.3 a 6.7, é possível notar que estes defeitos pontuais deram origem a estados localizados próximos ao nível de Fermi. Para todas as estruturas de banda, o nível de Fermi é representado pela linha vermelha, enquanto que o nível mais alto ocupado e o nível mais baixo desocupado estão representados pelas linhas em azul mais espessas. 
Capítulo 6 - Propriedades Físicas do Grafeno com Defeitos Estruturais e Dopagem com Boro e Nitrogênio.

No caso da estrutura de bandas da monovacância com simetria planar $\mathrm{D}_{3 h}$, representada na figura 6.2 (b), houve o aparecimento de uma banda simétrica $(\sigma)$ e uma antisimétrica $(\pi)$, localizadas próximas ao nível de Fermi, como pode ser visto na figura 6.4. As estruturas de bandas obtidas estão de acordo com outros cálculos Ab-initio [117, 165]. Em adição a isso, surgiram bandas planas (flat bands) na faixa de energia de $-0.25 \mathrm{eV}$ na estrutura de bandas, que correspondem aos estados ligantes e anti-ligantes do átomo não-pareado. $\mathrm{O}$ aparecimento destas bandas localizadas também afeta a densidade de estados total (TDOS) do grafeno, induzindo ao aparecimento de estados próximos ao nível de Fermi, os quais não existiam no grafeno puro, cuja distribuição irá determinar o magnetismo do material, que neste caso foi de $1.56 \mu_{B}$, fato que pode ser visualizado pela existência de bandas degeneradas na sua estrutura de bandas, sendo o spin up e down representados pelas bandas em azul e vermelho, respectivamente.

$\mathrm{Na}$ estrutura de bandas correspondente ao defeito de "Stone-Wales", apresentada na figura 6.3, não houve mudanças significativas quando comparada a estrutura de bandas do grafeno puro. Por outro lado, para a estrutura de bandas da divacâncias 585, apresentada na figura 6.5, observou-se que, ao longo da direção $K-\Gamma$ o nível ocupado mais alto, análogo à banda de valência (BV) em semicondutores usuais, toca o nível de Fermi, o que dá origem a novos estados localizados próximo ao nível de Fermi, fato que pode ser confirmado pela densidade de estados total (TDOS) que apresenta um pico um pouco mais saliente em torno de 0.25 eV. Para a estrutura de bandas da divacância 555777, apesar do defeito ter dado origem a novos estados localizados abaixo do nível de Fermi, isto não alterou sua estrutura eletrônica no nível de Fermi.

Por fim, na estrutura de bandas da trivacância, da mesma maneira que ocorreu com a monovacância, surgiram bandas cruzando o nível de Fermi, o que sugere um comportamento metálico para a estrutura, além de gerar novos estados na TDOS. Entretanto, é possível notar que o spin up e spin down representados pelas linhas azul e vermelha, respectivamente, estão praticamente sobrepostas, o que indica que o magnetismo gerado por este defeito é menor que o da monovacância, enquanto a monovacância apresentou um magnetismo de $1.56 \mu_{B}$, a trivacância apresentou magnetismo de $0.97 \mu_{B}$, como pode ser visualizado na tabela 6.1.

$\mathrm{Na}$ próxima seção, será apresentada uma investigação dos defeitos estruturais da monovacância e divacância 585 com os átomos das ligações pendentes substituídos por átomos de boro e nitrogênio. 
Capítulo 6 - Propriedades Físicas do Grafeno com Defeitos Estruturais e Dopagem com Boro e Nitrogênio.

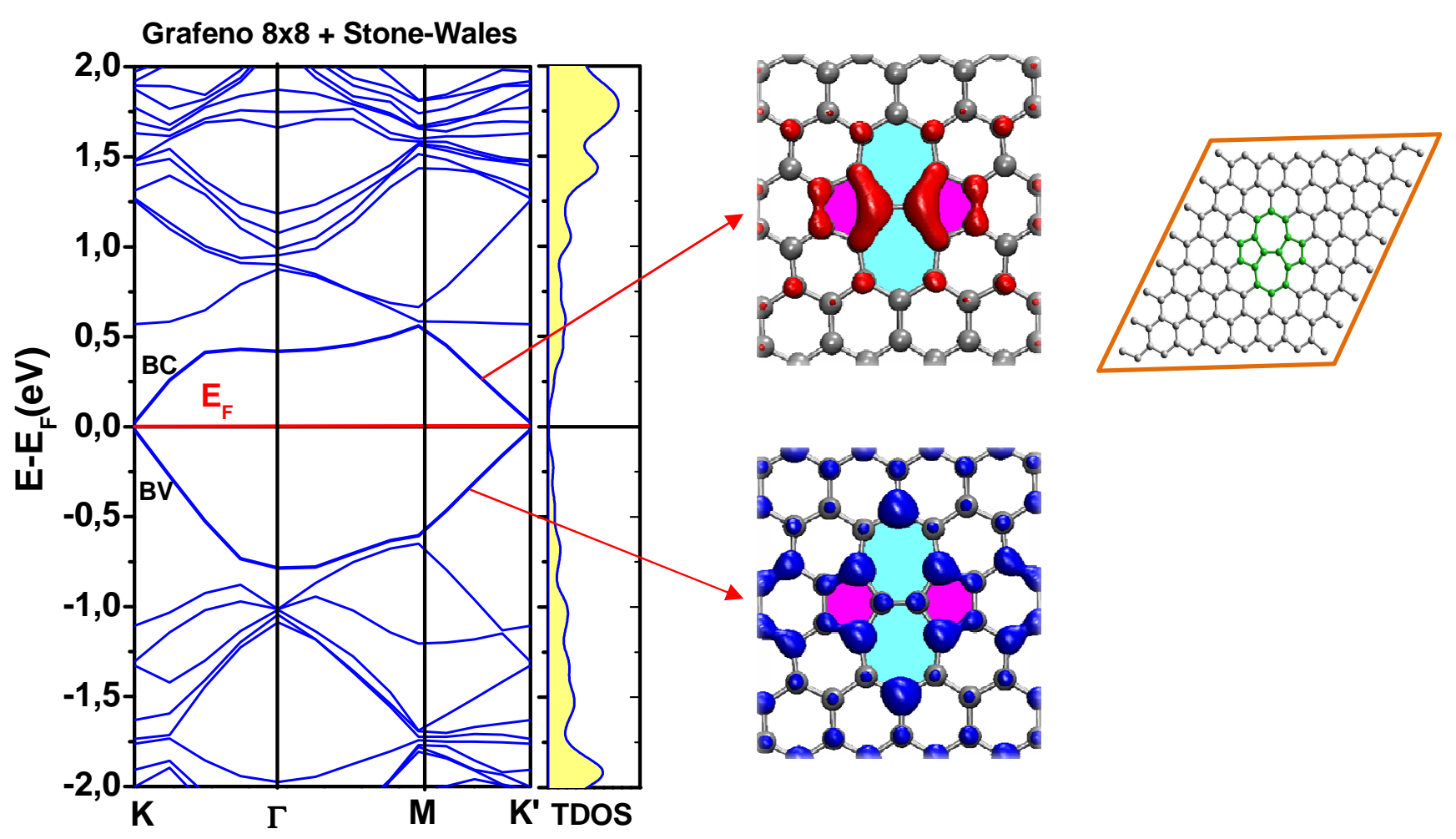

Figura 6.3 - Estrutura de bandas eletrônica e densidade de estados total (TDOS) para o defeito de "Stone-Wales" e a densidade de carga eletrônica para o nível mais alto ocupado e o nível mais baixo desocupado.

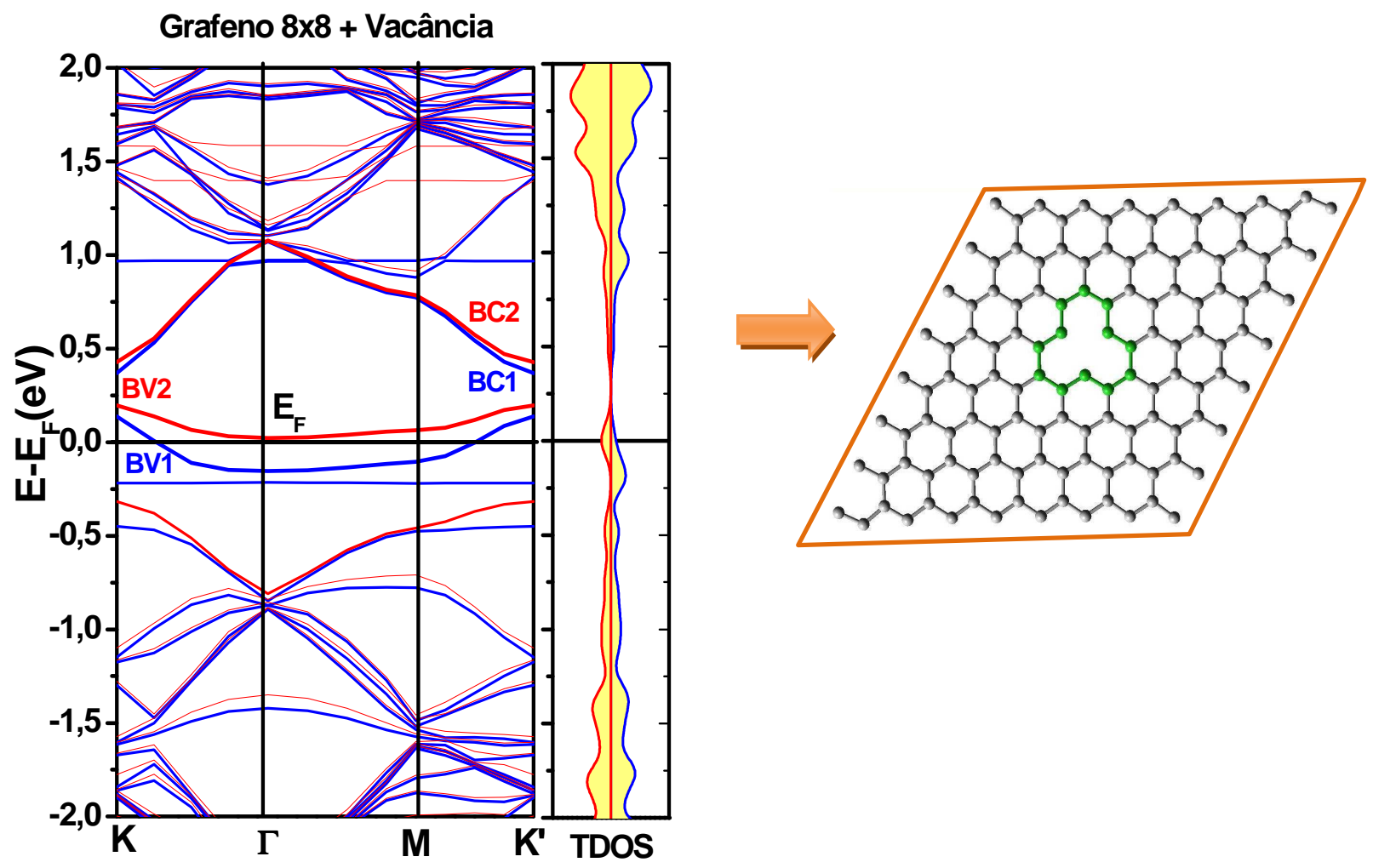

Figura 6.4 - Estrutura de bandas eletrônica e densidade de estados total (TDOS) para o defeito da monovacância. As linhas em azul e vermelho representam o spin-up e spin-down, respectivamente 
Capítulo 6 - Propriedades Físicas do Grafeno com Defeitos Estruturais e Dopagem com Boro e Nitrogênio.

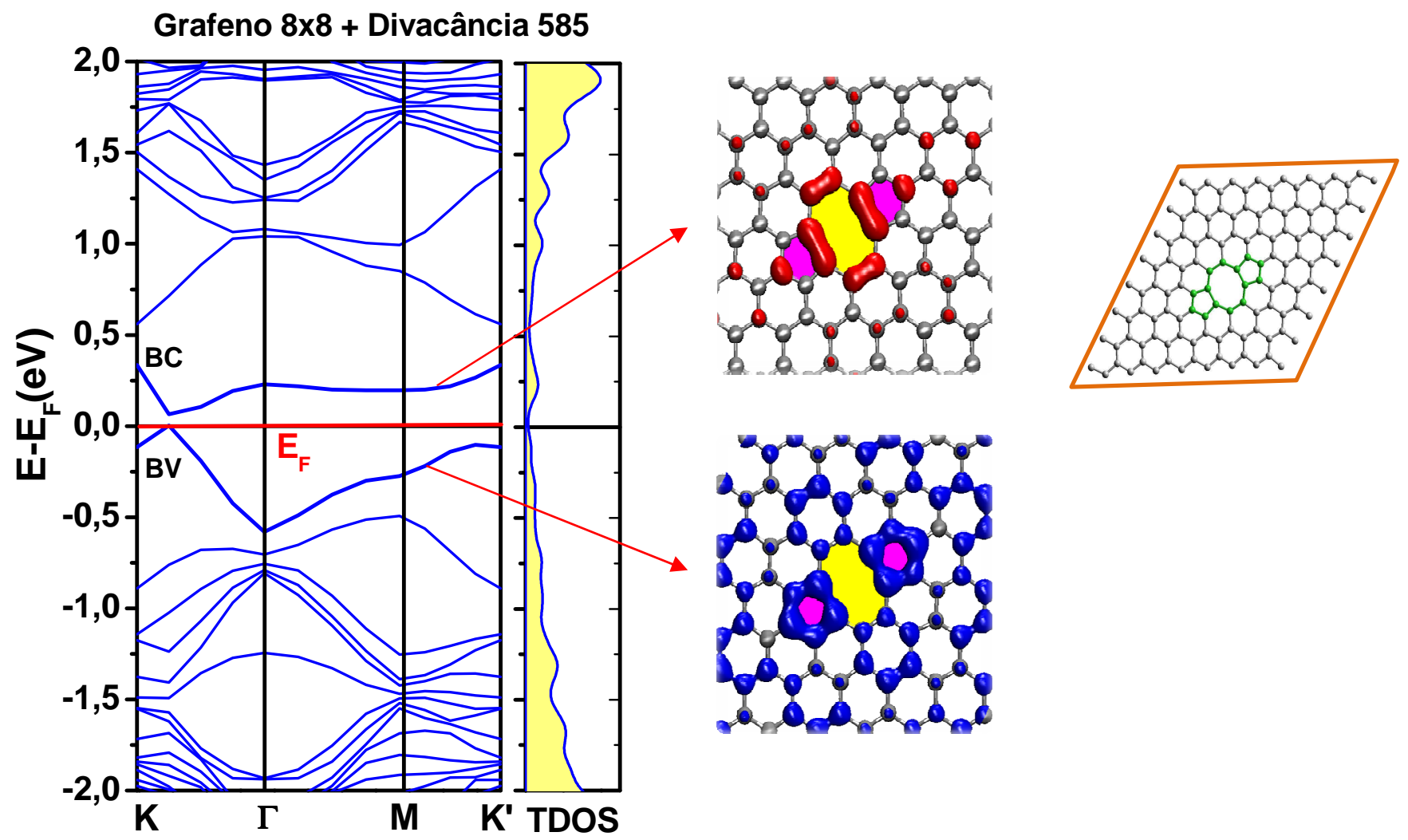

Figura 6.5 - Estrutura de bandas eletrônica e densidade de estados total (TDOS) para o defeito da divacância 585 e a densidade de carga eletrônica para o nível mais alto ocupado e o nível mais baixo desocupado..

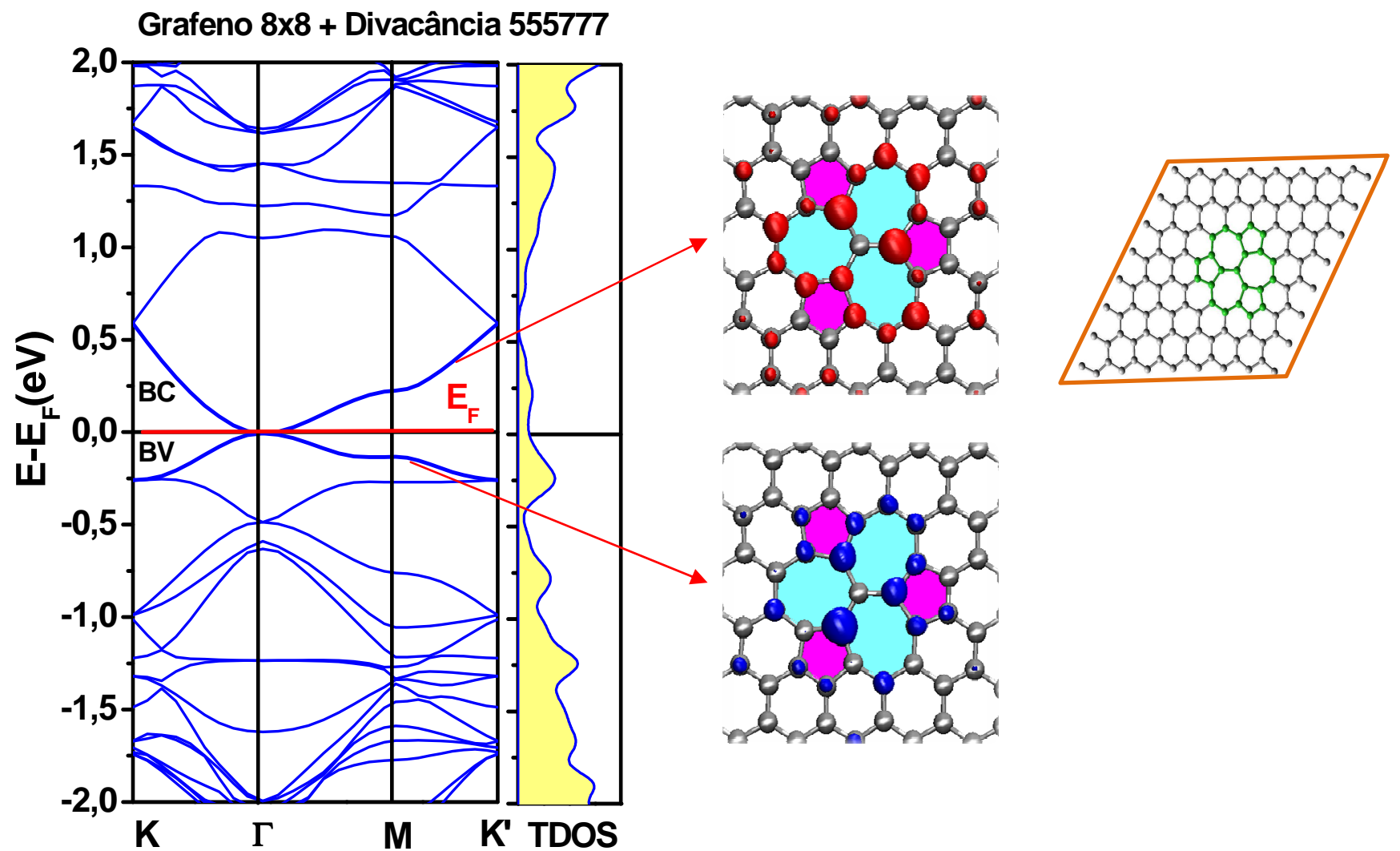

Figura 6.6 - Estrutura de bandas eletrônica e densidade de estados total (TDOS) para o defeito da divacância 555777 e a densidade de carga eletrônica para o nível mais alto ocupado e o nível mais baixo desocupado.

Tese de Doutorado - Denille Brito de Lima

Página 131 


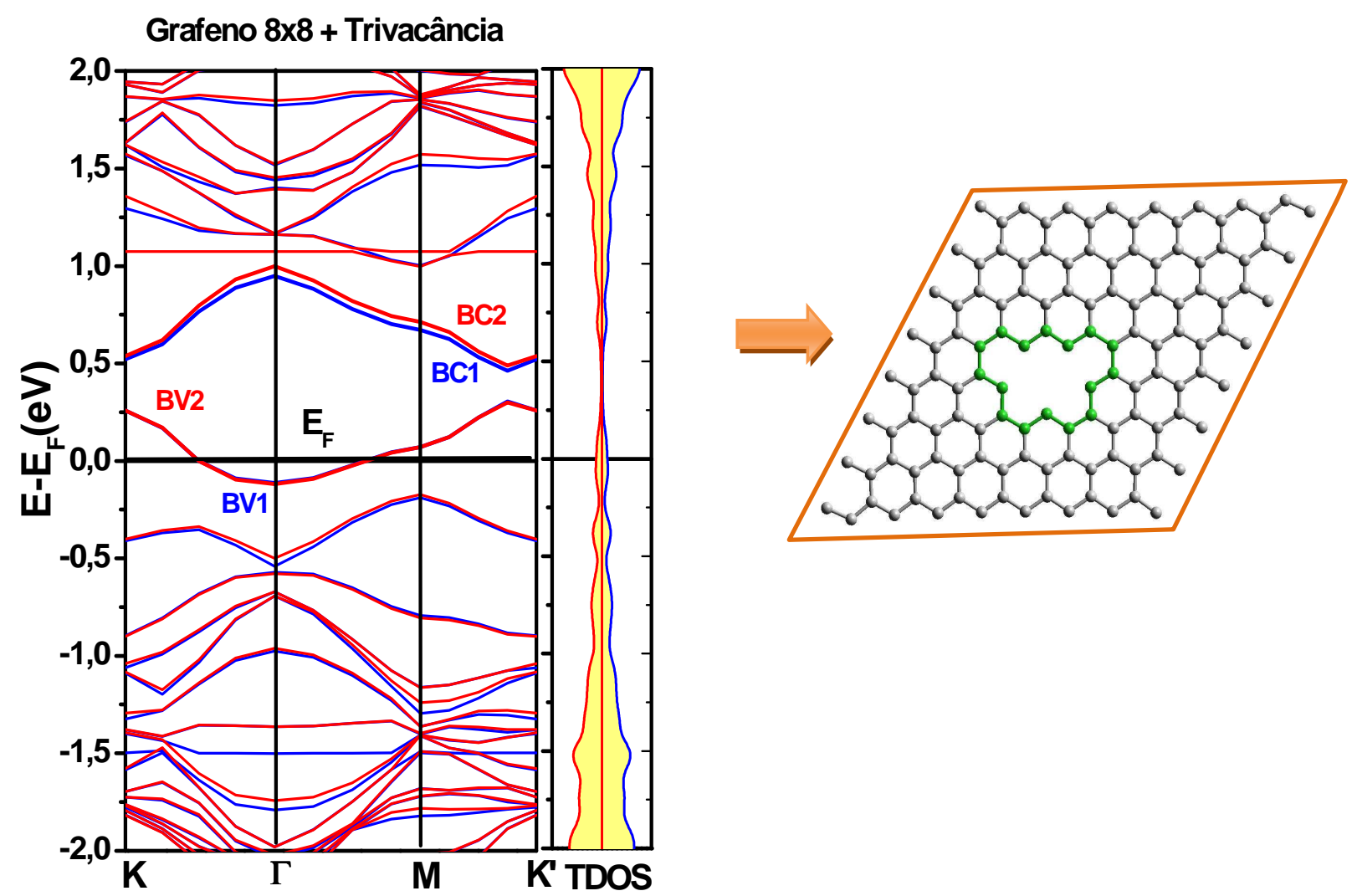

Figura 6.7 - Estrutura de bandas eletrônica e densidade de estados total (TDOS) para o defeito da trivacância. As linhas em azul e vermelho representam o spin-up e spin-down, respectivamente

\section{5 - Propriedades Físicas do Grafeno com monovacância e divacância 585 dopados com Boro e Nitrogênio}

Nesta seção, serão investigados os defeitos estruturais da monovacância e divacância 585 com átomos de carbono substituídos por átomos de boro e nitrogênio nas ligações pendentes (ou "dangling bonds"). Estas estruturas são chamadas de 3BV e 3NV, para o grafeno com monovacâncias dopadas com átomos de boro e nitrogênio, respectivamente, e 4BD e 4ND, para a estrutura do grafeno com a divacância 585 dopada com átomos de boro e nitrogênio, repectivamente. Os números três e quatro fazem referência ao número de ligações pendentes existentes no sistema. As estruturas descritas são representadas na figura 6.8 (a)-(d), onde os átomos de Boro e Nitrogênio são representados pelas esferas laranja e azul, respectivamente. 

e Nitrogênio.

(a)

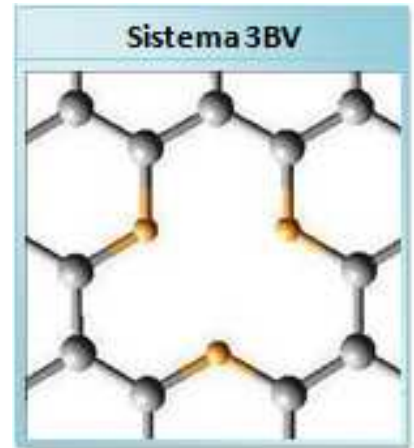

(c)

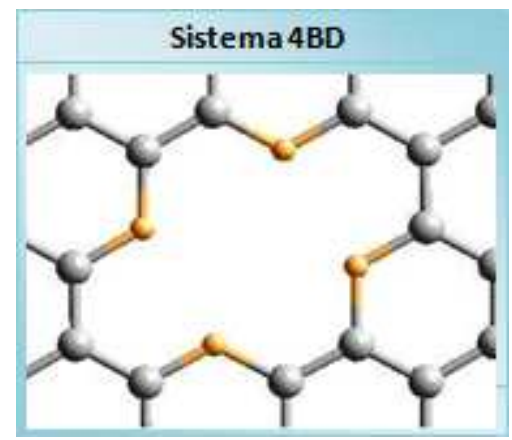

(b)

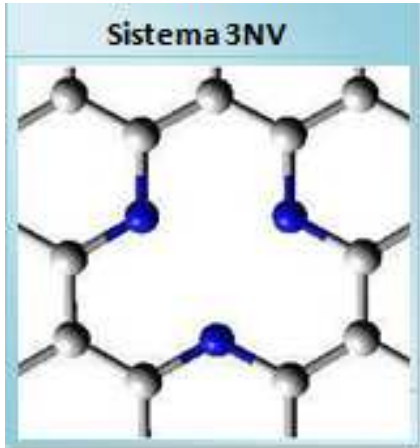

(d)

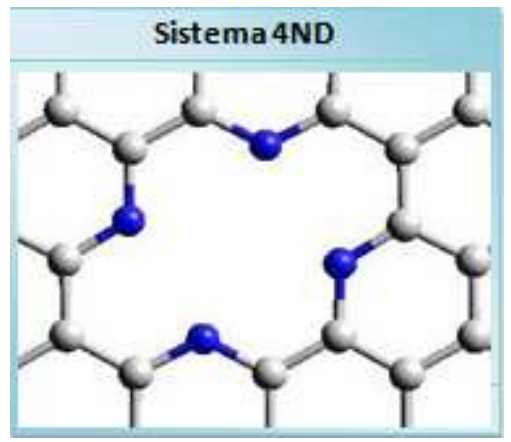

Figura 6.8 - Representação esquemática do grafeno com os defeitos: (a) 3BV; (b) 3NV; (c) 4BD e (d) 4ND.

\subsection{1 - Propriedades Estruturais}

A presença dos átomos de boro nas ligações pendentes da monovacância e divacância 585 resultou na aproximação destes átomos, o que diminuiu as distâncias interatômicas $\mathrm{d}_{\mathrm{AB}}$, $\mathrm{d}_{\mathrm{BC}}$ e $\mathrm{d}_{\mathrm{AC}}$, para o sistema $3 \mathrm{BV}$ e para as distâncias $\mathrm{d}_{\mathrm{GH}}$ e $\mathrm{d}_{\mathrm{IJ}}$ para o sistema $4 \mathrm{BV}$, quando comparados as mesmas estruturas sem dopagem e sem reconstrução, valores que podem ser vistos nas figuras 6.9 (a) e (c), respectivamente.

Por outro lado, os átomos de nitrogênio produziram efeito inverso. Na reconstrução dos sistemas 3NV e 4ND, as distâncias interatômicas aumentaram para 2.61 e 2.63 Á, respectivamente, conforme mostra figura 6.9 (b) e (d).

Outro aspecto importante a ser analisado é o motivo do aparecimento de momentos magnéticos para a monovacância dopada com átomos de nitrogênio, que foi o único sistema que apresentou magnetismo, embora menor do que na monovacância sem dopantes (em torno 
Capítulo 6 - Propriedades Físicas do Grafeno com Defeitos Estruturais e Dopagem com Boro e Nitrogênio.

de $0.17 \mu_{B}$ ), considerando que não acontece o mesmo para a monovacância dopada com átomos de boro. A explicação para este fenômeno é o fato de que os átomos de nitrogênio induzem ao magnetismo no grafeno quando existem ligações pendentes na estrutura [175].

(a)

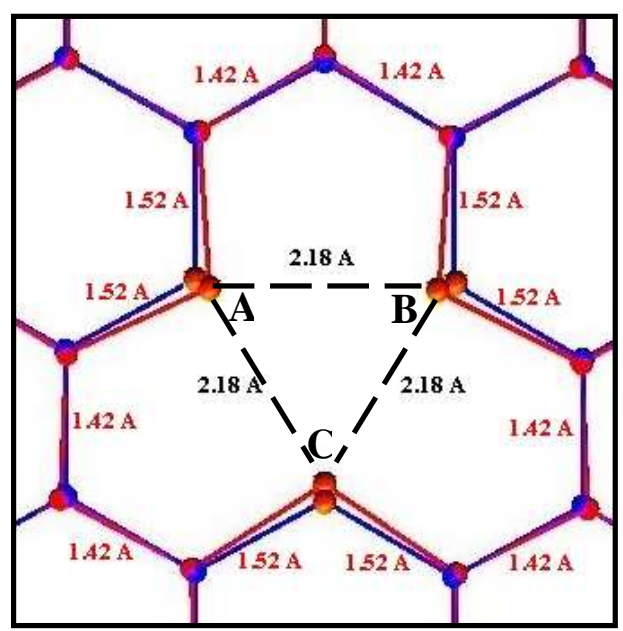

(c)

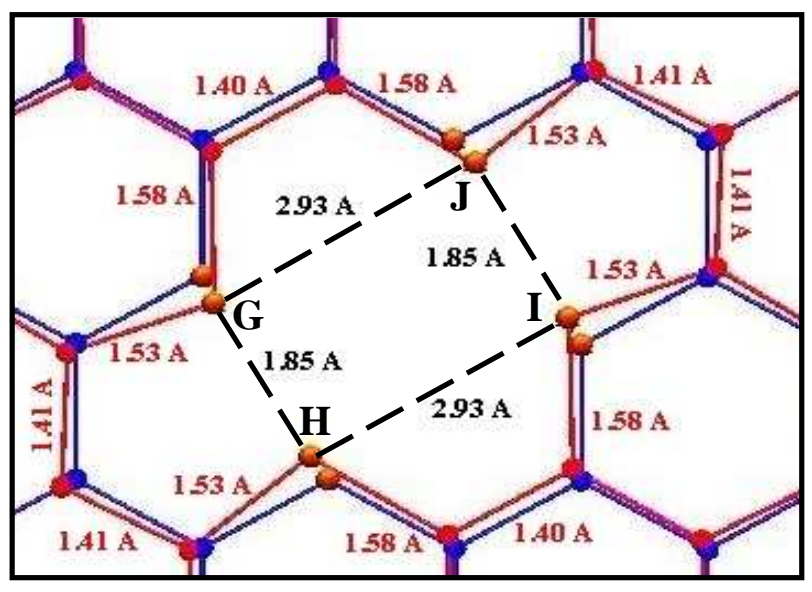

Figura 6.9 - Distâncias interatômicas para o grafeno com os defeitos: (a) 3BV ; (b) 3NV; (c) 4BD e (d) 4ND.

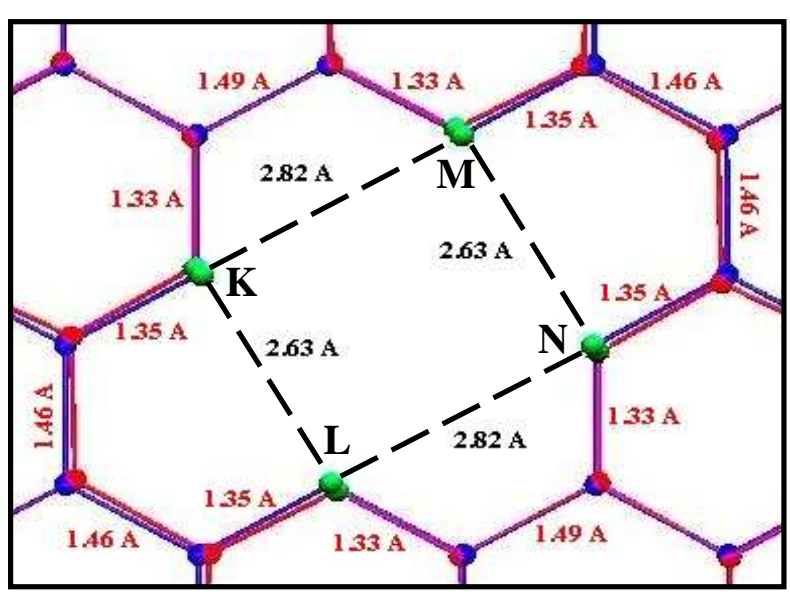

(b)

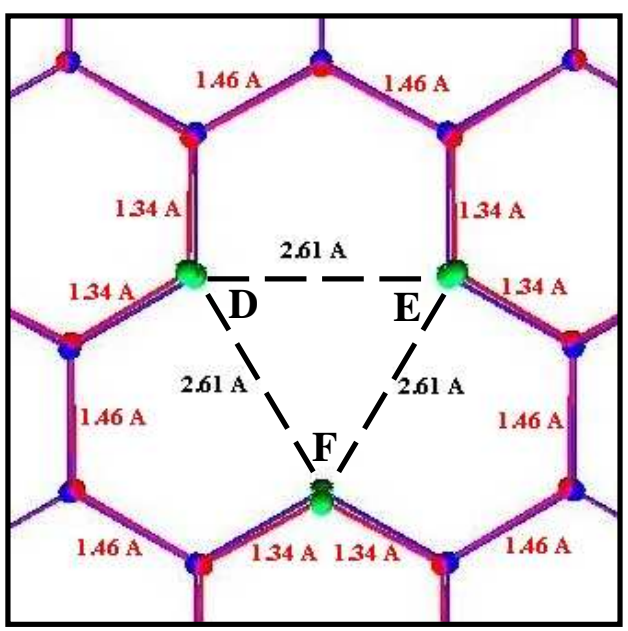

(d) 


\subsection{2 - Estrutura de Bandas e Densidade de Estados (DOS)}

Com relação às mudanças na estrutura de bandas eletrônica. Para os sistemas $3 \mathrm{BV}$ e $3 \mathrm{NV}$, foi possível notar que na estrutura de bandas eletrônicas de ambos os sistemas surgiram bandas cruzando o nível de Fermi, que afeta a densidade de estados (DOS) destes sistemas, gerando um aumento do número de estados no nível de Fermi, como pode ser visto nas figuras 6.10 e 6.11 .

A grande diferença entre as estruturas de bandas dos sistemas em questão foi que para o sistema 3BV apareceu uma banda acima do nível de Fermi, que gerou mais estados na região que corresponde 0.25 e $0.75 \mathrm{eV}$ da sua respectiva DOS. Por outro lado, na estrutura de bandas do sistema $3 \mathrm{NV}$, foram geradas bandas planas (flat bands) que aparecem na faixa de energia entre 0 e $-0.50 \mathrm{eV}$, que correspondem aos estados ligantes e anti-ligantes do elétron não-pareado da mesma forma que acontece com a monovacância não dopada.

Para as estruturas de bandas dos sistemas 4BD e 4ND, apresentadas nas figuras $6.12 \mathrm{e}$ 6.13, respectivamente, em torno do nível de Fermi, também aparecem bandas que geram mais estados localizados próximos ao nível de Fermi. O sistema 4ND apresentou comportamento metálico, uma vez que a banda de mais alta energia ocupada tocou no nível de Fermi.

Com relação aos níveis de energia mais alto ocupado e mais baixo desocupado, análogos aos orbitais HOMO (Highest Occupied Molecular Orbital) e LUMO (Lowest Unoccuppied Molecular Orbital) em sistemas moleculares, é possível visualizar nas figuras 6.10 a 6.13, que para os sistemas G3BV e G4BD, que contém um defeito de monovacância e divacância 585, respectivamente, com os átomos das ligações pendentes substituídos por átomos de boro, que no nível mais alto ocupado a densidade de carga eletrônica está mais localizada nos átomos próximos ao defeito. Por outro lado, para os sistemas G3NV e G4ND, que possui os átomos das ligações pendentes substituídos por átomos de nitrogênio, a densidade de carga eletrônica se localiza mais especificamente sobre os átomos de nitrogênio, fato que pode ser explicado uma vez que os átomos de nitrogênio apresentam cinco elétrons na sua camada de valência, resultando em uma densidade de carga eletrônica maior sobre estes átomos. 
Capítulo 6 - Propriedades Físicas do Grafeno com Defeitos Estruturais e Dopagem com Boro e Nitrogênio.

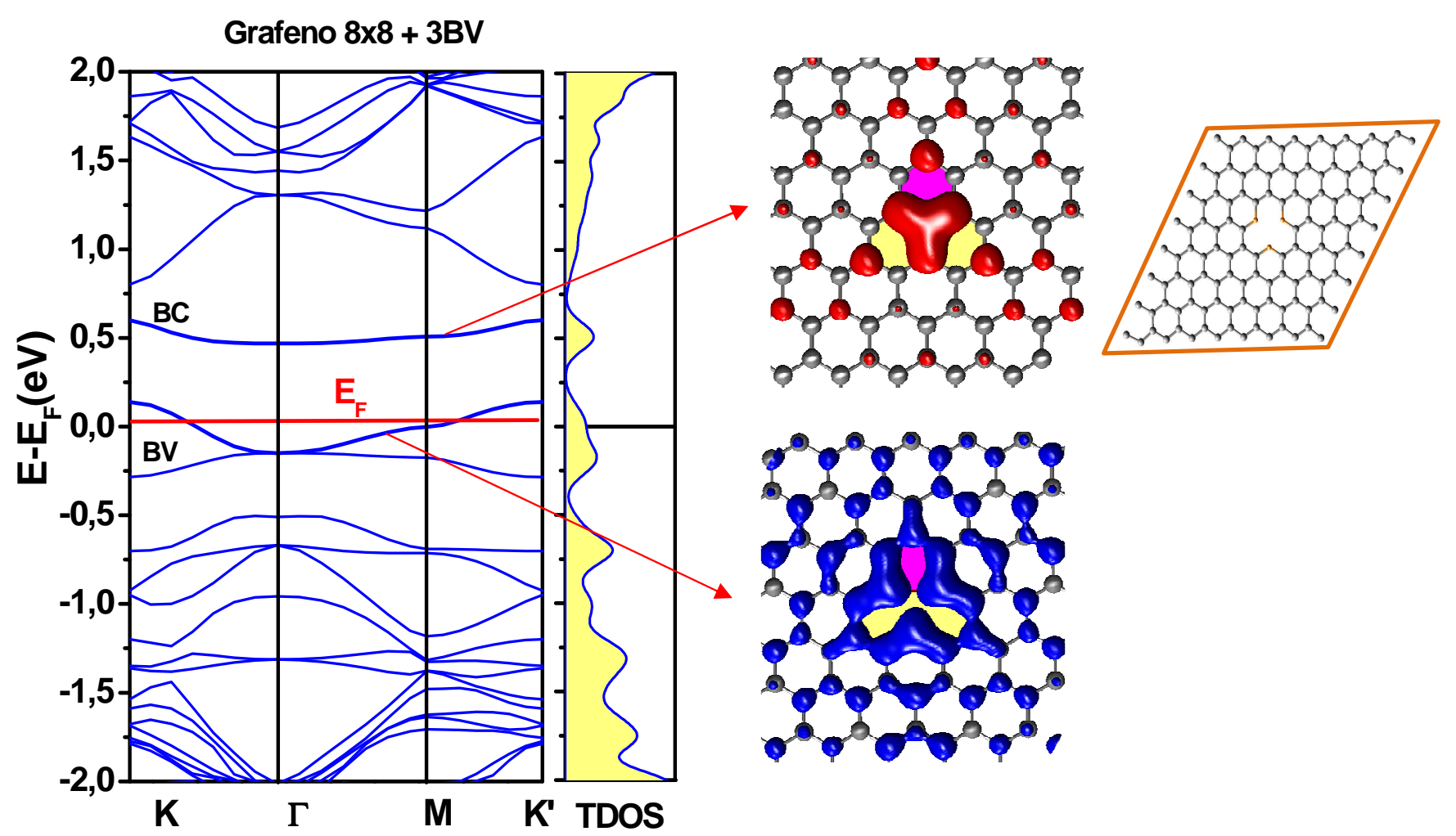

Figura 6.10 - Estrutura de bandas eletrônica e densidade de estados total (TDOS) para o defeito 3BV e a densidade de carga eletrônica para o nível mais alto ocupado e o nível mais baixo desocupado..

\section{Grafeno 8x8 + 3NV}
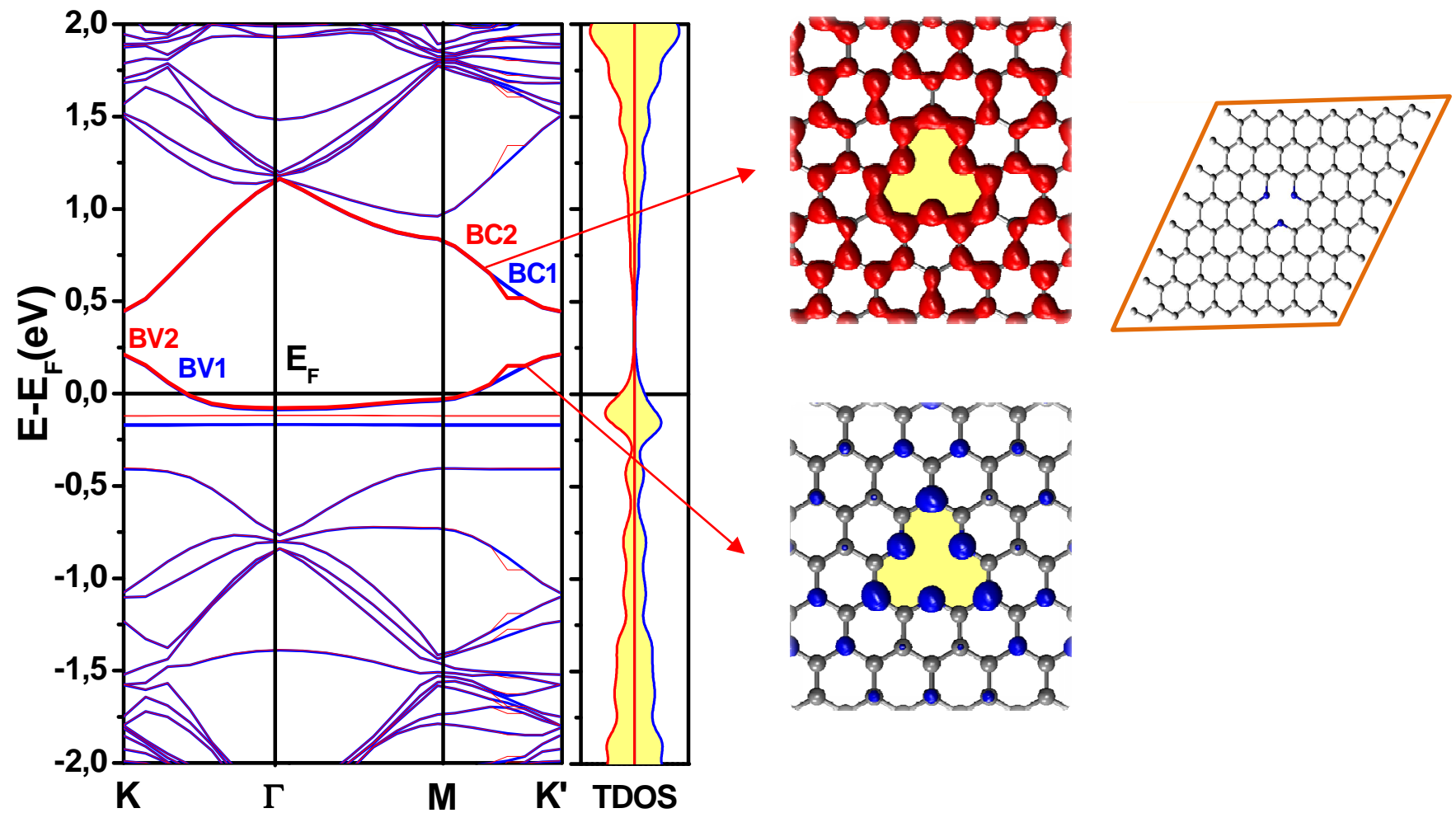

Figura 6.11 - Estrutura de bandas eletrônica e densidade de estados total (TDOS) para o defeito 3NV e a densidade de carga eletrônica para o nível mais alto ocupado e o nível mais baixo desocupado. $\mathrm{Na}$ estrutura de bandas, as linhas em azul e vermelho representam o spin-up e spin-down, respectivamente.

Tese de Doutorado - Denille Brito de Lima

Página 136 
Capítulo 6 - Propriedades Físicas do Grafeno com Defeitos Estruturais e Dopagem com Boro e Nitrogênio.

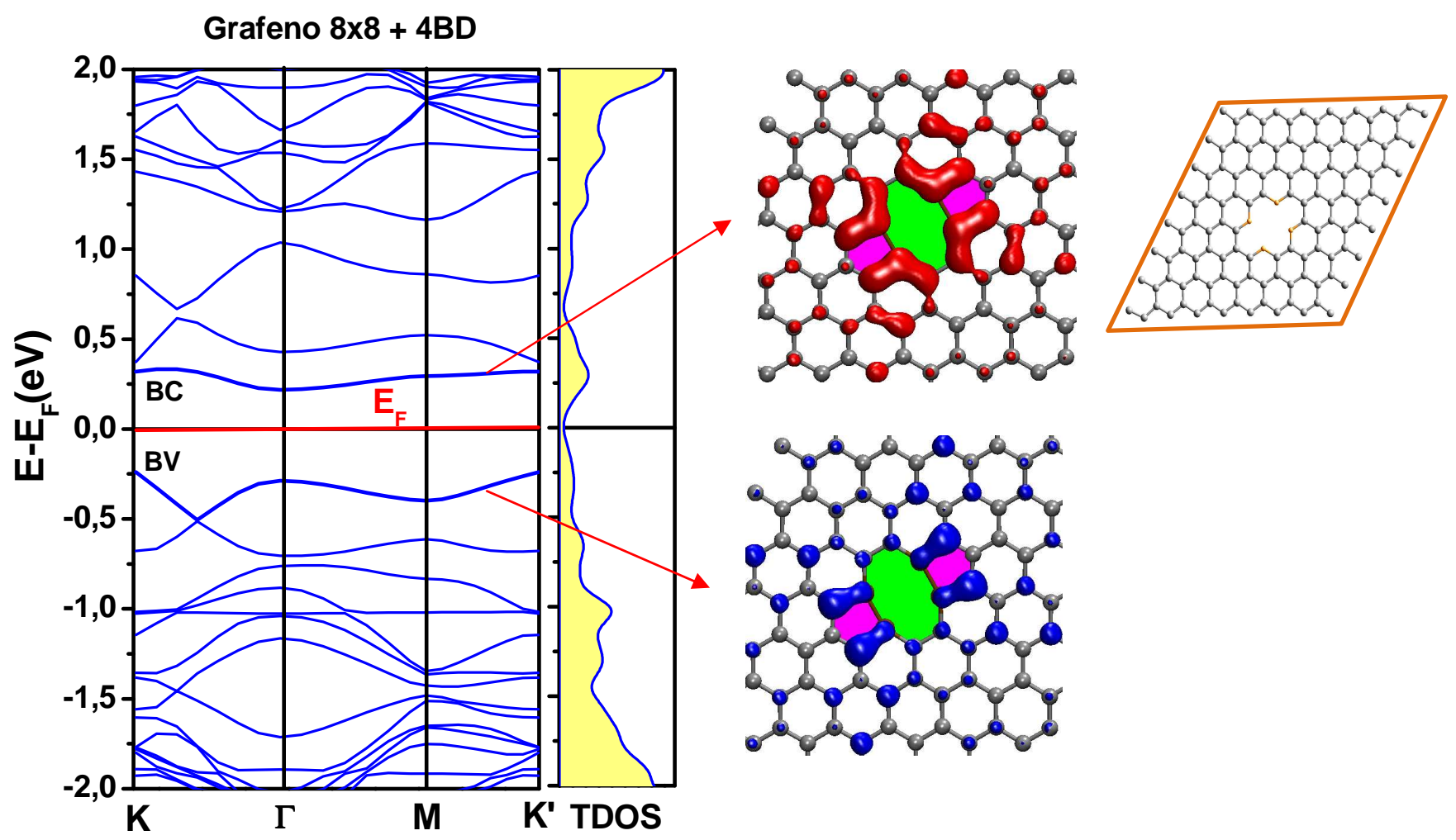

Figura 6.12 - Estrutura de bandas eletrônica e densidade de estados total (TDOS) para o defeito 4BD e a densidade de carga eletrônica para o nível mais alto ocupado e o nível mais baixo desocupado..

Grafeno 8x8 + 4ND

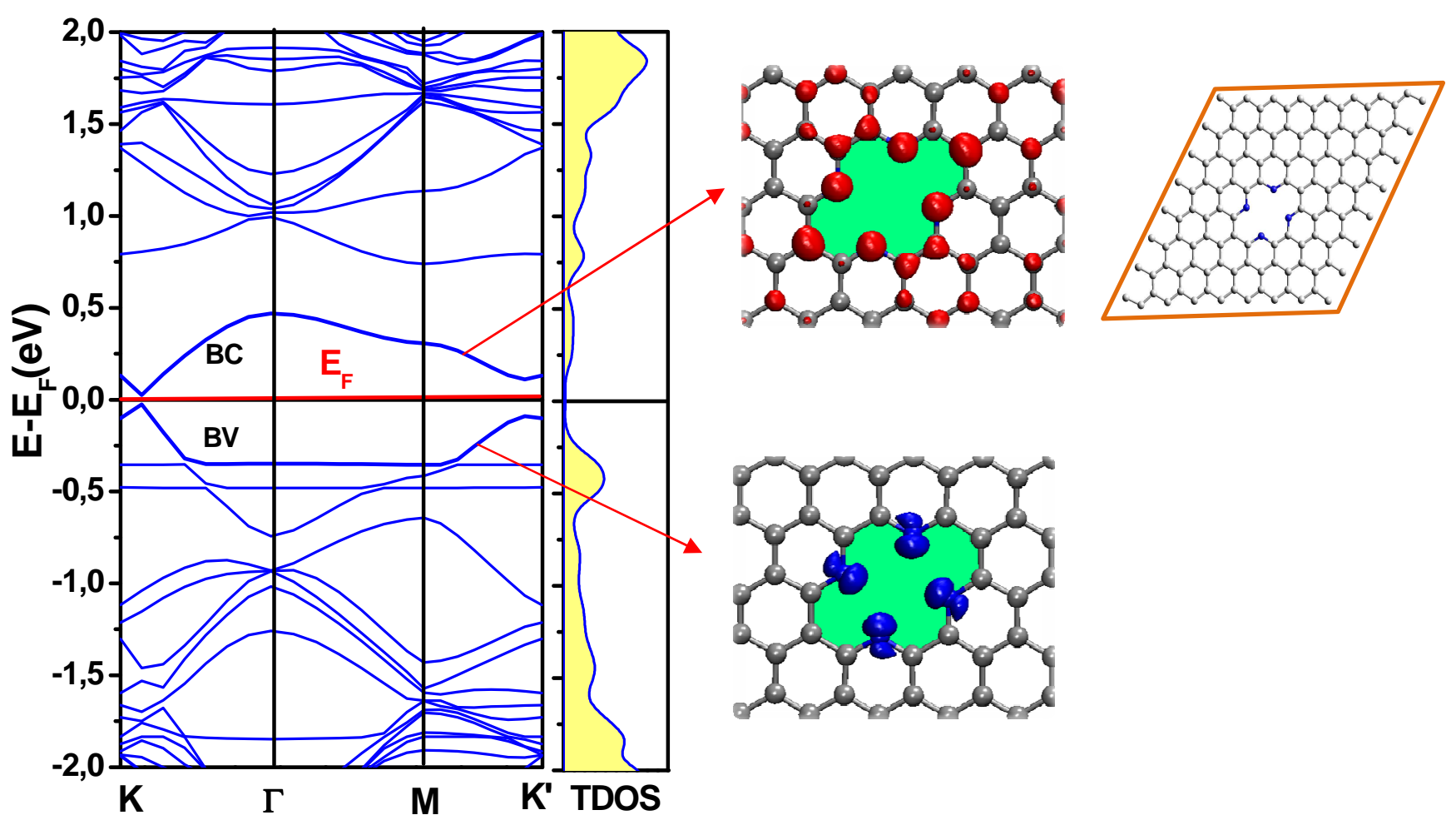

Figura 6.13 - Estrutura de bandas eletrônica e densidade de estados total (TDOS) para o defeito 4ND e a densidade de carga eletrônica para o nível mais alto ocupado e o nível mais baixo desocupado..

Tese de Doutorado - Denille Brito de Lima

Página 137 


\section{Capítulo}

\section{Conclusões Gerais e Perspectivas}

Nesta tese foi investigada a influência dos defeitos estruturais, dopagem e funcionalização nas propriedades eletrônicas e estruturais do grafeno. Todos os cálculos realizados foram baseados na teoria do funcional densidade (DFT), com spin-polarizado e a aproximação GGA no formalismo de Perdew-Burke-Ernzehof (PBE) [48], implementados no pacote de simulação computacional VASP (Vienna Ab Initio Simulation Package), utilizando o método PAW para descrever os elétrons de valência.

No capítulo 5 foi apresentada uma investigação sistemática das tendências das propriedades estruturais e eletrônicas dos sistemas de grafeno e grafano do grupo IV (C, SiC, $\mathrm{Si}, \mathrm{Ge}$ e Sn), nas configurações "buckled” e plana. 
Capítulo 6 - Propriedades Físicas do Grafeno com Defeitos Estruturais e Dopagem com Boro e Nitrogênio.

Os resultados indicaram que enquanto estruturas de grafeno (de $\mathrm{Si}, \mathrm{Ge}, \mathrm{Sn}$ e $\mathrm{SiC}$ ) parecem ter pouca estabilidade, as respectivas estruturas de grafano hidrogenado e fluorinado são muito estáveis, ou seja, são energeticamente muito acessíveis, o que deve facilitar sua síntese em laboratório.

Além disso, verificou-se que as estruturas de grafano hidrogenado e fluorinado apresentaram os átomos do grupo-IV em uma configuração tetracoordenada e em uma configuração aproximadamente tetraédrica. As distâncias interatômicas nessas configurações foram próximas às suas respectivas distâncias nas fases sólidas [149, 157], uma propriedade que poderia facilitar a integração destas estruturas bidimensionais dentro de nanodispositivos tridimensionais.

No capítulo 6 foi apresentada uma investigação teórica sobre as mudanças produzidas nas propriedades estruturais e eletrônicas do grafeno devido à presença de defeitos estruturais e dopagens. Foram investigados defeitos intrínsecos pontuais como o "Stone-Wales", a monovacância, as divacâncias (585 e 555777) e a trivacância. Além dos defeitos da monovacância e divacância 585 dopados com átomos de Boro e Nitrogênio.

Com relação à estabilidade, foi possível constatar que os defeitos mais estáveis para o grafeno foi o "Stone-Wales" e a divacância 555777, que apresentaram as menores energias de formação entre os defeitos estruturais investigados.

De uma forma geral, os resultados indicaram que os defeitos estruturais intrínsecos quebram a simetria da rede do grafeno, produzindo anéis não-hexagonais. Estas mudanças estruturais tiveram grande influência sobre a estrutura eletrônica do grafeno, uma vez que deram origem a estados localizados próximos ao nível de Fermi e também resultaram na mudança da linearidade da relação de dispersão na estrutura de bandas destes sistemas.

Outro ponto muito importante observado, foi a tendência para o aparecimento de magnetismo em estruturas com um número ímpar de vacâncias, devido ao surgimento de ligações pendentes (dangling bonds). As estruturas investigadas com um número ímpar de vacâncias foram a monovacância e a trivacância, ressaltando que a monovacância foi o defeito com maior magnetismo. O aparecimento do magnetismo se deve ao fato destas estruturas não se reconstruíram totalmente, ou seja, elas apresentarem ligações pendentes.

Estas ligações pendentes tornam o defeito da monovacância e trivacância centros de atração para átomos de metais [176], o que pode ser usado na engenharia de estrutura eletrônica e magnética do grafeno através da produção controlada de defeitos. 

e Nitrogênio.

De um modo geral, os resultados obtidos nesta investigação apontaram que tanto os defeitos intrínsecos existentes no grafeno como os extrínsecos, que são produzidos por métodos artificiais, como irradiação de íons ou tratamentos químicos, podem ser utilizados de maneira a produzir mudanças favoráveis na estrutura de bandas eletrônica do grafeno para potenciais aplicações na nanoeletrônica.

As perspectivas futuras para o trabalho englobam a necessidade de investigar quais as alterações produzidas na estrutura de bandas eletrônica por defeitos em diferentes posições e em maiores concentrações. Outro aspecto importante a ser estudado são as mudanças das propriedades eletrônicas produzidas pela presença de dopantes (em especial, o Boro e Nitrogênio) no grafeno em diferentes configurações.

Outro ponto de grande interesse é o estudo das estruturas de grafeno e grafano do grupo IV (C, SiC, Si, Ge e $\mathrm{Sn}$ ) com a presença de defeitos e dopantes, principalmente as estruturas de grafeno e grafano de silício, com o objetivo de obter maior conhecimento sobre as mudanças produzidas em suas propriedades estruturais e eletrônica, com o objetivo de explorar as possíveis aplicações para a construção de nanotransistores baseados em folhas bidimensionais de silício, uma vez que, se essas estruturas de silício se mostrarem robustas, elas poderiam ser facilmente incorporadas em circuitos integrados à base de silício, o que poderia permitir estender a vida útil da tecnologia do silício. 


\section{Referências Bibliográficas}

[1] MESSINA, G.; SANTANGELO, S. Carbon: The Future Material for Advanced Technology Applications. Itália: SpringerLink, 2005, vol. 100, pp. 26-28.

[2] Carbon Nanotechnology: Recent Developments in Chemistry, Physics, Materials Science and Device Applications. Oxford: Elsevier, 2006, vol. 1, pp. 7.

[3] MAITI, A.; BRABEC, C. J.; BERNHOLE, J. Structure and Energetics of Single and Multilayer Fullerene Cages. Physical Review Letters, vol. 70, no 20, pp. 3023-3027, 2006.

[4] GEIN, A. K.; NOVOSELOV, K. S. The rise of graphene. Nature Materials. vol. 6, no 3, pp. 183-191, 2007.

[5] DRESSELHAUS, M. S.; DRESSELHAUS; EKLUND, P. C. Science of Fullerenes and Carbon Nanotubes. USA, Academic Press, 1995, vol. 1, pp. 110-129.

[6] NOVOSELOV, K. S.; GEIN, A.K.; MOROSOV, S. V., et al. Two Dimensional Gas of Massless Dirac Fermions in Graphene. Nature. vol. 438, no 10, pp. 197-200, 2005.

[7] WALLACE, P. R. The Band Theory of Graphite. Physical. Review. vol. 71, no 9, pp. 622634, 1947.

[8] ZHOU, S.Y.; GWEON, G. H.; GRAF, J., et al. First Direct Observation of Dirac Fermions in Graphite. Nature Physics, vol. 2, no 9, pp. 595-599, 2006.

[9] ZHANG, Y.; TAN, Y. W.; STORMER, H. L., et al. Experimental Observation of the Quantum Hall Effect and Berry's Phase in Graphene. Nature. vol. 438, no 10, pp. 201204, 2005.

[10] BALANDIN, A. A.; GHOSH, S.; BAO, W. Z., et al. Superior Thermal Conductivity of Single-Layer Graphene. Nanoletters. vol. 8, no 3, pp. 902-907, 2008.

[11] LEE, C.; WEI, X.; KYSAR, J. W., et al. Measurement of the Elastic Properties and Intrinsic Strength of Monolayer Graphene. Science. vol. 321, no 5887, pp. 385-388, 2008.

[12] CAMPBELL, J. C.; YU, L.C.; CHEUNG, K. P., et al. Large Random Telegraphy Noise in Sub-Threshold Operation of Nano-Scale nMOSFETS. IEEE International Conference on IC Design and Technology Proceedings, pp. 17-20, jul. 2009.

[13] CARDAMONE, D. M.; STAFFORD, C. A.; MAZUMDAR, S. Controlling Quantum Transport Through a Single Molecule. Nano Letters, vol. 6, no 11, pp. 2422-2426, 2006. 
[14] SELLIER, H.; LANSBERGEN, G. P.; CARO, J.; ROGGE, S. Transport Spectroscopy of a Single Dopant in a Gated Silicon Nanowire. Physical Review Letters, vol. 97, no 20, pp. 206805, 2006.

[15] FUJIWARA, A.; INOKAWA, H.; YAMAZAKI, K., et al. Single Electron Tunneling Transistor with Tunable Barriers using Silicon Nanowire Metal-Oxide Semiconductor Field-Effect Transistor. Applied Physics Letters. vol. 88, no 5, pp. 053121, 2006.

[16] ALLEN, B. L.; KICHAMBARE, P. D.; STAR, A. Carbon Nanotube Field-EffectTransistor-Based Biosensor. Advanced Materials. vol. 19, no 11, pp. 1439-1451, 2007.

[17] SUN, H.; ALT, A. R.; BENEDICKTER, H.; BOLOGNESI, et al. 102-GHz AlInN/GaN HEMTs on Silicon with $2.5-\mathrm{W} / \mathrm{mm}$ Output Power at $10 \mathrm{GHz}$. IEEE Electron Device Letters. vol. 30, no 8, pp. 796-798, 2009.

[18] LIN, Y. -M.; DIMITRAKOPOULOS, C.; JENKINS, K. A., et al. 100-GHz Transistors From Wafer-Scale Epitaxial Graphene. Science, vol. 327, no 5966, pp. 662, 2010.

[19] PONOMARENKO, L. A.; SCHEDIN, F.; KATSNELSON, M. I.; YANG, R.; WILL, E. W.; NOVOSELOV, K. S.; GEIN, A. K. Chaotic Dirac Billiard in Graphene Quantum Dots. Science. vol. 320, no 5874, pp. 356-358, 2008.

[20] WANG, H.; NEZICH, D.; KONG, J. I., PALACIOS, T. Graphene Frequency Multipliers. Electron Devices Letters. vol. 30, no 5, pp. 547-549, 2009.

[21] LIANG, X.; FU, Z.; CHOU, S. Graphene Transistors Fabricated via Transfer-Printing In Device Active-Areas on Large Wafer. Nano Letters, vol. 7, no 12, pp. 3840-3844, 2007.

[22] MATYBA, P.; YAMAGUCHI, H.; EDA, G., et al. Graphene and Mobile Ions: The Key to All-Plastic, Solution Processed Light-Emitting Devices. ACS Nano. vol. 4, no 2, pp. 637$642,2010$.

[23] KIM, K. S.; ZHAO, Y.; JANG, H., et al. Large-Scale Pattern Growth of Graphene Films for Stretchable Transparent Electrodes. Nature. vol. 457, pp. 706-710, 2009.

[24] BURRESS, J.; SIMMONS, J.; FORD, J.; YILDIRIM, T. Gas adsorption Properties of Graphene-Oxide-Frameworks and Nanoporous Benzene-Boronic acid Polymers. Proceedings of American Physical Society Conference. vol. 55, no 2, 2010.

[25] NETO, A. H.; GUINEA, F.; PERES, N. M. R.; NOVOSELOV, K. S.; GEIN, A. K. The Electronic Properties of Graphene. Reviews of Modern Physiscs. vol. 81, no 1, pp. 109$162,2009$.

[26] SEMENOFF, G. W. Condensed-Matter Simulation of a Three-Dimensional Anomaly. Physical Review Letters. vol. 53, no 26, pp. 2449-2452, 1984.

[27] AVOURIS, P.; CHEN, Z.; PEREBEINOS, V. Graphene: Carbon-Based Electronics. Nature Nanotechnology. vol. 2, no 10, pp. 605-615, 2007. 
[28] RAO, C. N. R.; SOOD, A. K.; SUBRAHMANYAM, K. S.; GOVINDARAJ. Graphene: The New Two-Dimensional Nanomaterial. Nanomaterials. vol. 48, no 1, pp. 7752-7777, 2009.

[29] ELIAS, D. C. Estudo das Propriedades de Transporte Elétrico de Grafeno e de Grafeno Hidrogenado. Tese de Doutorado. UFMG, 2009.

[30] PARTOENS, B.; PEETERS, F. M. From Graphene to Graphite: Electronic Structure Around the K Point. Physical Review B. vol. 74, no 7, pp. 075404-075414, 2006.

[31] MCCANN, E.; FAL'KO, V. I. Landau-level Degeneracy and Quantum Hall Effect in a Graphite Bilayer. Physical Review Letters. vol. 96, no 8, pp. 086805, 2006.

[32] NOVOSELOV, K. S.; GEIN, A. K.; MOROSOV, D. et al. Electric Field Effect in Atomically Thin Carbon Films. Science. vol. 306, no 5296, pp. 666-669, 2004.

[33] CHEN, J. H.; CULLEN, W. G.; JANG, C. et al. Defect Scattering in Graphene. Physical Review Letters. vol. 102, no 23, pp. 236805, 2009.

[34] NOVOSELOV, K. S.; JIANG, D.; SCHEDIN, F. et al. Two-dimensional atomic crystal. Proceedings of the National Academy of Sciences of USA. vol. 102, no 30, pp. 1045110453, 2005.

[35] CHEN, J. H.; JANG, C.; XIAO, S. D. et al. Intrinsic and Extrinsic Performance Limits of Graphene Devices on $\mathrm{SiO}_{2}$. Nature Nanotechnology. vol. 3, no 4, pp. 206-209, 2008.

[36] SCHEDIN, F.; GEIN, A. K.; MOROSOV, S. V. et al. Detection of Individual Gas Molecules Adsorbed on Graphene. Nature Materials. vol. 6, no 9, pp. 652-655, 2007.

[37] CHEN, J. H.; JANG, C.; ADAM, S. et al. Charged Impurity Scattering in Graphene. Nature Physics. vol. 4, no 5, pp. 377-381, 2008.

[38] KEMPA, H.; ESQUINAZI, P.; KOPELEVICH, Y. Integer Quantum Hall Effect in Graphite. Solid State Communications. vol. 138, pp. 118-122, 2006.

[39] PRANGE, R. E.; GIRVIN, S. M. The Quantum Hall Effect. New York; Berlim: Springer-Verlag. pp. 37-46, 1987.

[40] PAYNE, M. C.; TETER, M. P.; ALLAN, D. C.; ARIAS, T. A.; JOANNOPOULOS, J. D. Iterative Minimization Techniques for $\mathrm{Ab}$ Initio Total-Energy Calculations: Molecular Dynamics and conjugate Gradients. The American Physical Society. vol. 64, no 4, pp. 1045-1097, 1992. 
[41] BRODY, D. E.; BRODY, A. R. As Sete Maiores Descobertas Científicas da História e seus autores. São Paulo: Cia. Das Letras, 1997.

[42] SZABO, A. Modern Quantum Chemistry: Introduction to Advanced Electronic Structure Theory. New York: McGraw-Hill, 1989.

[43] CANUTO, S.; FAZZIO, A.; VIANA, J. D. Teoria Quântica de Moléculas e Sólidos: Simulação Computacional. São Paulo: Editora Livraria da Física, 2004.

[44] KOHN, W.; SHAM, L. J. Quantum Density Oscillations in an Inhomogeneous Electron Gas. Physical Review. vol. 137, no 6A, pp. A1697-A1705, 1965.

[45] KOHANOFF, J. Electronic Structure Calculations for Solids and Molecules: Theory and Computational Methods. Cambridge: Cambridge University Press, 2006.

[46] PERDEW, J. P.; ZUNGER, A. Self-interaction Correction to Density-Functional Approximations for many Electrons Systems. Physical Review B. vol. 23, no 10, pp. 5048-5079, 1981.

[47] GARCIA, J. C. Tese de Doutorado. Propriedades Físicas de Diamantóides. PPGF USP, 2010.

[48] PERDEW, J. P.; BURKE, K.; ERNZERHOF, M. Generalized Gradient Approximation Made Simple. Physical Review Letters. vol. 77, no 18, pp. 3865-3868, 1996.

[49] SINGH, D. J.; NORDSTROM, L. Planewaves, Pseudopotentials, and LAPW Method. Washington: Springer, 2ed., 2006.

[50] KRESSE, G; JOUBERT, D. From Ultrasoft Pseudopotentials to the Projector Augmented-Wave Method. Physical Review B. vol. 59, no 3, pp. 1758-1775, 1999.

[51] BLÖCHL, P.E. Projector Augmented-Wave Method. Physical Review B. vol. 50, no 24, pp. 17953 - 17979, 1994.

[52] COSTA, R. N.; FARIAS, G. A.; PEETERS, F. M. Spin Scaling of the Electron-Gas Correlation Energy in the High-Density Limit. Physical Review B. vol. 43, no 11, pp. 8911-8916, 1991.

[53] SOFO, J. O.; CHAUDHARI, A. S.; BARBER, G. D. Graphane: A Two-Dimensional Hydrocarbon. Physical Review B. vol. 75, no 15, pp. 153401-153404, 2007.

[54] FloreS, M. Z. S.; AUTRETO, P. A. S.; LEGOAS, S. B.; GALVAO, D. S. Graphene to Graphane: A Theoretical Study. Nanotechnology. vol. 20, no. 465704, 2009.

[55] SAHIN, H.; ATACA, C.; CIRACI, S. Graphane Nanoribbons: A Theoretical Study. Physical Review B. vol. 81, no 205417, 2010. 
[56] ROMAN, T.; DIÑO, W. A.; NAKANISHI, H.; KASAI, H.; SUGIMOTO, T.; TANGE, K. Realizing a Carbon-Based Hydrogen Storage Material. Japanese Journal of Applied Physics. vol. 45, pp. 1765-7, 2006.

[57] LEHTINEN, P. O.; FOSTER, A. S.; KRASHENINNIKOV, A. V.; NIEMIEN, R. M. Irradiation-Induced Magnetism in Carbon Nanostructures. Physical Review Letters. vol. 93, no 18, pp. 187202, 2004.

[58] STOJKOVIC, D.; ZHANG, P.; LAMMERT, P. E.; CRESPI, V. H. Collective Stabilization of Hydrogen Chemisorption on Graphenic Surfaces. Physical Review B. vol. 68, no 19, pp. 195406, 2003.

[59] BOUKHALOV, D. W.; KATSNELSON, M. I. Chemical Functionalization of Graphene. Journal of Physics Condensed Matter. vol. 21, no. 344205, pp. 1-12, 2009.

[60] BOUKHVALOV, D. W.; KATSNELSON, M. I.; LICHTENSTEIN, A. I. Hydrogen on Graphene: Electronic Structure, Total Energy, Structural Distortions, and Magnetism from First-Principles Calculations. Physical Review B. vol. 77, no 3, pp. 035427, 2008.

[61] COSTA, R. N.; FARIAS, G. A.; PEETERS, F. M. Graphene Ribbons with a Line of Impurities. Physical Review B. vol. 76, no 19, pp. 193409, 2007.

[62] BOUKHVALOV, D. W.; KATSNELSON, M. I. Chemical Functionalization of Graphene with Defects. Nano Letters. vol. 8, no 12, pp. 4373-4379, 2008.

[63] BOUKHVALOV, D. W.; KATSNELSON, M. I. Modeling of Graphite Oxide. Journal of the American Chemical Society. vol. 130, no 32, pp. 10697-10701, 2008.

[64] KUDIN, K. N.; OZBAS, B.; SCHNIEPP, H. C.; PRUD'HOMME, R. K.; AKSAY, I. A.; CAR, R. Raman Spectra of Graphite Oxide and Functionalized Graphene Sheets. Nano Letters. vol. 8, no 1, pp. 36-41, 2008.

[65] SON, Y-W.; COHEN, M. L.; LOUIE, S. G. Half-Metallic Graphene Nanoribbons. Nature. vol. 446, no 7133, pp. 342, 2007.

[66] WANG, W. L.; MENG, S.; KAXIRAS, E. Graphene Nanoflakes with Large Spin. Nano Letters. vol. 8, no 1, pp. 241 - 245, 2008.

[67] YAZYEV, O. V.; KATSNELSON, M. I. Magnetic Correlations at Graphene Edges: Basis for Novel Spintronic Devices. Physical Review Letters. vol. 100, no. 4, pp. 047209, 2008.

[68] LI, J-L.; KUDIN, K. N.; MACALLISTER, M. J.; PRUD'HOMME, R. K. OxygenDriven Unzipping of Graphitic Materials. Physical Review Letters. vol. 96, no. 17, pp. 176101, 2006. 
[69] DATTA, S. S.; STRACHAN, D. R.; KHAMIS, S. M.; JOHNSON, A. T. C. Crystallographic Etching of Few-Layer Graphene. Nano Letters. vol. 8, no 7, pp. 1912 - 1915, 2008.

[70] MIWA, R. H.; MARTINS, T. B.; FAZZIO, A. Hydrogen Adsorption om Boro Doped Graphene: An Ab Initio Study. Nanotechnology. vol. 19, no. 15, pp. 155708, 2008.

[71] DHARMA-WARDANA, M. W. C.; ZGIERSKI, M. Z. Magnetism and Structure at a Vacancy in Graphene. Physica E-Low-Dimensional Systems \& Nanostructures. vol. 41, no. 1, pp. 80-83, 2008.

[72] JANOTTI, A.; WEI, S. H.; SINGH, D. J. First-Principles Study of the Stability of BN and C. Physical Review B. vol. 64, no 17, pp. 174107, 2001.

[73] RYDBERG, H.; DION, M.; JACOBSON, N.; SCHRODER, E.; HYLDGAARD, P.; SIMAK, S. I.; LANGRETH, D. C.; LUNDQVIST, B. I. Van der Waals Density Functional for Layered Structures. Physical Review Letters. vol. 91, no 12, pp. $126402,2003$.

[74] ENOKI, T.; SUZUKI, M.; ENDO, M. Graphite Intercalation Compounds and Applications. New York: Oxford University Press 2003.

[75] DRESSELHAUS, M. S.; DRESSELHAUS, G. Intercalation Compounds of Graphite. Advances in Physics. vol. 51, no. 1, pp. 1 - 186, 2002.

[76] WELLER, T. E.; ELLERBY, M.; SAXENA, S.; SMITH, R. P.; SKIPPER, N. T. Superconductivity in the Intercalated Graphite Compounds $\mathrm{C6Yb}$ and $\mathrm{C6Ca}$. Nature Physics. vol. 1, no. 1, pp. 39 - 41, 2005.

[77] HENDERSON, C. C.; CAHILL, P. A. Semiempirical Calculations of the Isomeric C $_{60}$ Dihydrides. Chemical Physics Letters. vol. 198, no. 6, pp. 570-6, 1992.

[78] MATSUZAWA, N.; DIXON, D. A.; FUKUNAGA, T. Semiempirical Calculations of Dihydrogenated Buckminsterfullerenes, $\mathrm{C}_{60} \mathrm{H}_{2}$. Journal of Physical Chemistry. vol. 96, no. 19, pp. 7594-7604, 1992.

[79] HENDERSON, C. C.; CAHILL, P. A. $\mathrm{C}_{60} \mathrm{H}_{2}-$ Synthesis of the Simplest $\mathrm{C}_{60}$ Hydrocarbon Derivative. Science. vol. 259, no. 5103, pp. 1885-7, 1993.

[80] DIEDERICH, F. Covalent Fullerene Chemistry. Pure and Applied Chemistry. vol. 69, no 3, pp. 395 - 400, 1997.

[81] PRATO, M. Fullerene Chemistry for Materials Science Applications. Journal of Materials Chemistry. vol. 7, no. 7, pp. 1097 - 1109, 1997. 
[82] SLUITET, F. H. M.; KAWAZOE, Y. Cluster expansion method for adsorption: Application to hydrogen chemisorption on graphene. Physical Review B. vol. 68, no. 8, pp. 085410, 2003.

[83] ATACA, C.; AKTÜRK, E.; CIRACI, S.; USTUNEL, H. High-Capacity Hidrogen Storage by Metallized Graphene. Applied Physics Letters. vol. 93, no. 4, pp. 043123, 2008.

[84] HORNEKAER, L.; XU, W.; SLJIVANCANINI, Z.; OTERO, R; RAULS, E.; STENSGAARD, I, et al. Metastable Structures and Recombination Pathways for Atomic Hydrogen on the Graphite (0001) Surface. Physical Review Letters. vol. 96, no. 15, pp. 156104, 2006.

[85] HORNEKAER, L.; XU, W.; OTERO, R; LAEGSGAARD, E.; BASENBACHER, F. Long Range Orientation of Meta-Stable Atomic Hydrogen Adsorbate Clusters on the Graphite (0001) Surface. Chemical Physics Letters. vol. 446, pp. 237-42,

[86] AllOUCHE, A.; FERRO, Y.; ANGOT, T.; THOMAS, C.; LAYET, JM. Hydrogen Adsorption on Graphite (0001) Surface: A Combined SpectroscopyDensity-Functional-Theory Study. Journal of Chemical Physics. vol. 123, no. 12,

[87] YAZYEV, O. V. Magnetism on Disordered Graphene and Irradiated Graphite. Physical Review Letters. vol. 101, no. , pp. 037203, 2008.

[88] YAZYEV, O. V.; HELM, L. Defect-Induced Magnetism in Grapheme. Physical Review B. vol. 75, no. 12, pp. 125408, 2007.

[89] ROMAN, T.; DIÑO, W. A.; NAKANISHI, H.; KASAI, H.; SUGIMOTO, T.; TANGE, K. Hydrogen Pairing on Graphene. Carbon. vol. 45, no. 1, pp. 218-20, 2007.

[90] FERRO, Y.; TEILLET-BILLY, D.; ROUGEAU, N.; SIDIS, V.; MORISSET, S.; ALLOUCHE, A. Stability and Magnetism of Hydrogen Dimers on Graphene. Physical Review B. vol. 78, no. 8, pp. 085417, 2008.

[91] DU, X.; SKACHKO, I.; BARBER, A.; ANDREI, E. Y. Approaching Ballistic Transport in Suspended Graphene. Nature Nanotechnology. vol. 3, no. 8, pp. 491$5,2008$.

[92] MARCHINI, S.; GÜNTER, S.; WINTTERLIN, J. Scanning Tunneling Microscopy of Graphene on Ru (0001). Physical Review B. vol. 76, no. 075429, 2007.

[93] VAZQUEZ DE PARGA, A. L.; CALlEJA, F.; BORCA, B.; PASSEGI, M. C. G. jr., et al. Periodically Rippled Graphene: Growth and Spatially Resolved Electronic Structure. Physical Review Letters. vol. 100, no. 5, pp. 056807, 2008.

[94] PREOBRAJENSKI, A. B.; NG, M. L.; VINOGRADOV, A. S.; MARTENSSON, N. Controlling Graphene Corrugation on Lattice-Mismatched Substrates. Physical Review B. vol. 78, no. 7, pp. 073401, 2008. 
[95] CORAUX, J. N.; DIAYE, A. T.; BUSSE, C.; MICHELY, T. Structural Coherence of Graphene on Ir (111). Nano Letters. vol. 8, no. 2, pp. 565-70, 2008.

[96] BOUKHVALOV, D. W.; KATSNELSON, M. I. Tunning the Gap on Bilayer Graphene Using Chemical Functionalization: Density Functional Calculations. Physical Review B. vol. 78, no 8, pp. 085413, 2008.

[97] JELOAICA, L.; SIDIS, V. DFT Investigation of the Adsorption of Atomic Hydrogen on a Cluster-Model Graphite Surface. Chemical Physics Letters. vol. 300, no. 1-2, pp. 157-62, 1999.

[98] MEYER, J. C.; GIRIT, C. O.; CROMMIE, M. F.; ZETTL, A. Imaging and Dynamics of Light Atoms and Molecules on Graphene. Nature. vol. 454, no. 7202, pp. 319-22, 2008.

[99] KUDIN, K. N.; SCUSERIA, G. E.; YAKOBSON, B. I. C 2 F, BN, and C Nanoshell Elasticity From Ab Initio Computations. Physical Review B. vol. 64, no. 23, pp. 235406, 2001.

[100] KUDIN, K. N.; BETTINGER, H. F.; SCUSERIA, G. E. Fluorinated single-wall carbon nanotubes. Physical Review B. vol. 63, no. 4, pp. 045413, 2001.

[101] RAMANATHAN, T; ABDALA, AA.; STANCOVICH, S., et al. Functionalized Graphene Sheets for Polymer Nanocomposites. Nature Nanotechnology. vol. 3, no. 6, pp. 327-31, 2008.

[102] YU, S. S.; ZHENG, W. T.; JIANG, Q. Oxidation of Graphene Nanoribbon by Molecular Oxygen. IEEE Transactions on Nanotechnology. vol. 7, no. 5, pp. 62835, 2008.

[103] LIU, L.; RYU, S.; TOMASIK, M. R.; JUNG, N.; HYBERTSEN, M. S.; STEIGERWALD, M. L.; BRUS, L. E.; FLYNN, G. W. Graphene oxidation: Thickness-dependent etching and strong chemical doping. Nano Letters. vol. 8, no. 7 , pp. 1965-70, 2008.

[104] STANKOVICH, S.; DIKIN, D. A.; PINER, R. D.; KOHLHAAS, K. A., et al. Synthesis of Graphene-Based Nanosheets via Chemical Reduction of Exfoliated Graphite Oxide. Carbon. vol. 45, no. 7, pp. 1558-65, 2007.

[105] SON, Y-. W.; COHEN, M. L.; LOUIE, S. G. Energy Gaps in Graphene Nanoribbons. Physical Review Letters. vol. 97, no. 21, pp. 216803, 2006.

[106] PISANI, L.; CHAN, J. A.; MONTANARI, B.; HARRISON, N. M. Electronic Structure and Magnetic Properties of Graphitic Ribbons. Physical Review B. vol. 74, no. 6, pp. 064418, 2007.

[107] SCHEDIN, F.; GEIM, A. K.; MOROZOV, S. V., et al. Eletric Field Effect in Atomically Thin Carbon Films. Science. vol. 306, no. 5696, pp. 666-669, 2004. 
[108] ROBINSON, J. T.; PERKINS, F. K.; SNOW, E. S., et al. Reduced Graphene Oxide Molecular Sensors. Nano Letters. vol. 8, no. 10, pp. 3137-40, 2008.

[109] PALACIOS, J. J.; FERNÁNDEZ-ROSSIER, J.; BREY, L. Vacancy-Induced Magnetism in Graphene and Graphene Ribbons. Physical Review B. vol. 77, no. 19, pp. 195428, 2008.

[110] LUSK, M. T.; CARR, L. D. Nanoengineering Defect Structures on Graphene. Physical Review Letters. vol. 100, no. 17, pp. 175503, 2008.

[111] YAMASHITA, K.; SAITO, M.; ODA, T. Atomic Geometry and Stability of Mono, Di-, and Trivacancies in Graphene. Japanese Journal of Applied Physics. vol. 45, no. 8A, pp. 6534-36, 2006.

[112] APELlHANS, D. J.; LIN, Z.; LUSK, M. T. Two-Dimensional Carbon Semiconductor: Density Functional Theory Calculations. Physical Review B. vol. 82, no. 7, pp. 073410, 2010.

[113] KIM, Y.; IHM, J.; YOON, E.; LEE, GD. Dynamics and Stability of Divacancy Defects in Graphene. Physical Review B. vol. 84, no. 7, pp. 075445, 2011.

[114] HASHIMOTO, A.; SUENAGA, K.; GLOTER, A.; URITA, K.; IJIMA, S. Direct Evidence for Atomic Defects in Graphene Layers. Nature. vol. 430, no. 7002, pp. 870-73, 2004.

[115] MEYER, J. C.; KISIELOWSKI, C.; ERNI, R.; ROSSEL, M. D.; CROMIE, M. F.; ZETTL, A. Direct Imaging of Lattice Atoms and Topological Defects in Graphene Membranes. Nano Letters. vol. 8, no. 11, pp. 3582-86, 2008.

[116] KRASHENINNIKOV, A. V.; NORDLUND, K.; SIRVIÖ, M.; SALONEN, E.; KEINONEN, J. Formation of Ion-Irradiation-Induced Atomic-Scale Defects on Walls of Carbon Nanotubes. Physical Review B. vol. 63, pp. 245405, 2001.

[117] AMARA, H.; LATIL, S.; MEUNIER, V.; LAMBIN, P.; CHARLIER, J. -C. Scanning Tunneling Microscopy Fingerprints of Point Defects in Graphene: A Theoretical Prediction. Physical Review B. vol. 76, no. 11, pp. 115423, 2007.

[118] LEE, G. -D.; WANG, C. Z.; YOON, E.; HWANG, N. -M.; KIM, D. -Y.; HO, K. M. Diffusion, Coalescence and Reconstruction of Vacancy Defects in Graphene Layers. Physical Review Letters. vol. 95, no. 20, pp. 205501, 2005.

[119] LEE, G. -D.; WANG, C. Z.; YOON, E.; HWANG, N. -M.; HO, K. M. Vacancy Defects and Formation of Local Haeckelite Structures in Graphene from TightBinding Molecular Dynamics. Physical Review B. vol. 74, no. 245411, 2006.

[120] DUPLOCK, E. J.; SCHEFFLER, M.; LINDAN, P. J. D. Hallmark of Perfect Graphene. Physical Review Letters. vol. 92, pp. 225502, 2004. 
[121] CERVANTES-SODI, F.; CSÁNYI, G.; PISCANEC, S.; FERRARI, A. C. EdgeFunctionalized and Substitutionally Doped Graphene Nanoribbons: Electronic and Spin Properties. Physical Review B. vol. 77, no. 16, pp. 165427, 2008.

[122] VEIGA, R. G. A.; MIWA, R. H.; SRIVASTAVA, G. P. Quenching of Local Magnetic Moment in Oxygen Adsorbed Graphene Nanoribbons. Journal of Chemical Physics. vol. 128, no. 20, pp. 201101, 2008.

[123] WASSMANN, T.; SEITSONEN, A. P.; SAITA, A. M.; LAZZERI, M.; MAURI, F. Structure, Stability, Edge States, and Aromaticity of Graphene Ribbons. Physical Review Letters. vol. 101, no. 9, pp. 096402, 2008.

[124] KOSKINEN, P.; MALOLA, S.; HÄKKINEN, H. Self-Passivating Edge Reconstructions of Graphene. Physical Review Letters. vol. 101, no. 11, pp. 115502, 2008.

[125] HOD, O.; BARONE, V.; SCUSERIA, G. E. Half-Metallic Graphene Nanodots: A Comprehensive First-Principles Theoretical Study. Physical Review B. vol. 77, no. 3, pp. 035411, 2008.

[126] HOD, O.; PERALTA, J.; SCSERIA, G. E. Edge effects in Finite Elongated Graphene Nanoribbons. Physical Review B. vol. 76, no. 23, pp. 233401, 2007.

[127] LEI, Y.; SHEVLIN, S. A.; ZHU, W.; GUO, Z. X. Hydrogen-Induced Magnetization and Tunable Hydrogen Storage in Graphitic Structures . Physical Review B. vol. 78, no. 13, pp. 134114, 2008.

[128] SHEMELLA, P.; ZHANG, Y.; MAILMAN, M.; AJAYAN, P. M.; NAYAK, S. K. Energy Gaps in Zero-Dimensional Graphene Nanoribbons. Applied Physics Letters. vol. 91, no. 4, pp. 042101, 2007.

[129] FERNANDEZ-ROSSIER, J.; PALACIOS, J. J. Magnetism in Graphene Nanoislands . Physical Review Letters. vol. 99, no. 17, pp. 177204, 2007.

[130] JIANG, D.; SUMPTER, B. G.; DAI, S. First-Principles Study of Magnetism in Nanographenes. Journal of Chemical Physics. vol. 127, no. 124703, 2007.

[131] EZAWA, M. Metallic Graphene Nanodisks: Electronic and Magnetic Properties. Physical Review B. vol. 76, no. 24, pp. 245415, 2007.

[132] EZAWA, M. Graphene Nanoribbon and Graphene Nanodisk. Physica E-Low Dimensional Systems and Nanostructures. vol. 40, no. 5, pp. 1421-23, 2008.

[133] RADOVIC, L. R.; BOKRATH, B. On the Chemical Nature of Graphene Edges: Origin of Stability and Potential for Magnetism in Carbon Materials. Journal of the American Chemical Society. vol. 127, pp. 5917-27, 2005.

[134] KUSAKABE, K.; MARUYAMA, M. Magnetic Nanographite. Physical Review B. vol. 67, no. 9, pp. 092406, 2003. 
[135] GUNLYCKE, D.; LI, J.; MINTMIRE, J. W.; WHITE, C. T. Altering Low-Bias Transport in ZigZag-Edge Graphene Nanostrips with Edge Chemistry. Applied Physics Letters. vol. 91, no. 112108, 2007.

[136] TAKAI, K.; SATO, H.; ENOKI, T.; YOSHIDA, N.; OKINO, F.; TOUHARA, H.; ENDO, M. Effect of Fluorination on Nano-Sized pi-electron Systems. Journal of the Physical Society of Japan. vol. 70, no. 1, pp. 175-185, 2001.

[137] GIESBERS, A. J. M.; ZEITLER, U.; NEUBECK, S. FREITAG, F.; NOVOSELOV, K. S.; MAAN, J. C. Nanolithography and Manipulation of Graphene Using an Atomic Force Microscope. Solid State Communications. vol. 147, no. 9-10, pp. 366-369, 2008.

[138] MASUBUCHI, S.; ONO, M.; YOSHIDA, K.; HIRAKWA, K.; MACHDA, T. Fabrication of Graphene Nanoribbon by Local Anodic Oxidation Lithography using Atomic Force Microscope. Applied Physics Letters. vol. 94, no. 8, pp. 082107, 2009.

[139] CAMPOS-DELGADO, J.; ROMO-HERRERA, JM.; JIA, X. T., et al. Bulk Production of a New Form of $\mathrm{sp}(2)$ Carbon: Crystalline Graphene Nanoribbons. Nano Letters. vol. 8, no. 9, pp. 2773-78, 2008.

[140] HOD, O.; BARONE, V.; PERALTA, J. E.; SCUSERIA, G. E. Enhanced HalfMetallicity in Edge-Oxidized ZigZag Graphene Nanoribbons. Nano Letters. vol. 7, no. 8, pp. 2295-99, 2007.

[141] BARONE, V.; HOD, O.; SCUSERIA, G. E. Electronic Structure and Stability of Semiconducting Graphene Nanoribbons. Nano Letters. vol. 6, no. 12, pp. 2748-54, 2006.

[142] OKAMOTO, H.; SUGIYAMA, Y.; NAKANO, H. Synthesis and Modification of Silicon Nanosheets and Other Silicon. Chemistry: An European Journal. vol. 17, no 36, pp. 9864-9887, 2011.

[143] VOON, L. C. L. Y.; SANDBERG, E.; AGA, R. S.; FARAJIAN, A. A. Hydrogen Compounds of Group-IV Nanosheets. Applied Physics Letters. vol. 97, no. 16, pp. 163114-163117, 2010.

[144] CAHANGIROV, S.; TOPSAKAL, M.; AKTURK, E.; SAHIN, H.; CIRACI, S. Twoand One-Dimensional Honeycomb Structures of Silicon and Germanium. Physical Review Letters. vol. 102, no. 23, pp. 236804-236807, 2009.

[145] HUDA, M. N.; YAN, Y. F.; AL-JASSIM, M. M. On the Existence of Si-C Double Bonded Graphene-like Layers. Chemical Physics Letters. vol. 479, no. 4-6, pp. 255258, 2009.

[146] LEENAERTS, O.; PEELAERS, H.; HERNANDEZ-NIEVES, A. D.; PARTOENS, B.; PEETERS, F. M. First-Principles Investigation of Graphene Fluoride and Graphane. Physical Review B. vol. 82, no. 19, pp. 195436-195442, 2010. 
[147] CHARliER, J. C.; GONZE, X.; MICHENAUD, J. P. First-Principles Study of Graphite Monofluoride (CF) $)_{n}$ Physical Review B. vol. 47, no. 24, pp. 16162-16168, 1993.

[148] TANG, S. B.; CAO, Z. X. Structural and Electronic Properties of the Fully Hydrogenated Boron Nitride Sheets and Nanoribbons: Insight From First-Principles Calculations. Chemical Physics Letters. vol. 488, no. 1-3, pp. 67-72, 2010.

[149] HOUSSA, M.; POURTOIS, G.; AFANAS'EV, V. V.; STESMANS, A. Electronic Properties of Two-Dimensional Hexagonal Germanium. Applied Physics Letters. vol. 96, no. 8, pp. 082111-3, 2010.

[150] BEHERA, H; MUKHOPADHYAY, G. First-Principles Study of Structural and Electronic Properties of Germanene. Solid State Physics - Proceedings of the 55th Dae Solid State Physics Symposium. vol. 1349, pp. 823-824, 2011.

[151] HOUSSA, M.; SCALISE, E.; SANKARAN, K.; POURTOIS, G.; AFANAS'EV, V. V.; STESMANS, A. Electronic Properties of Hydrogenated Silicene and Germanene. Applied Physics Letters. vol. 98, pp. 223107, 2011.

[152] BEKAROGLU, E.; TOPSAKAL, M.; CAHANGIROV, S.; CIRACI, S. FirstPrinciples Study of Defects and Adatoms in Silicon Carbide Honeycomb Structures. Physical Review B. vol. 81, no. 7, pp. 075433, 2010.

[153] AUFRAY, B; KARA, A.; VIZZINI, S.; OUGHADDOU, H; LÉANDRI, C.; EALET, B; LE LAY, G. Graphene-like silicon nanoribbons on $\operatorname{Ag}(110)$ : A possible formation of silicene. Applied Physics Letters. vol. 96, no. 18, pp. 183102, 2010.

[154] DE PADIOVA, P.; QUARESIMA, C.; OTTAVIANI, C. et. al. Evidence of Graphene-Like Electronic Signature in Silicene Nanoribbons. Applied Physics Letters. vol. 96, no. 26, pp. 261905, 2010.

[155] ELIAS, D. C.; NAIR, R. R.; MOHIUDDIN, et al. Control of Graphene's Properties by Reversible Hydrogenation: Evidence for Graphane. Science. vol. 323, no. 5914, pp. 610-613, 2009.

[156] SHRIVER, D. F.; ATKINS, P.W.; LANGFORTT, C.H. Inorganic Chemistry, Oxford University Press: Oxford, 1994.

[157] MONKHORST, H. J.; PACK, J. D. Special Points for Brillouin-Zone Integrations. Physical Review B. vol. 13, no. 12, pp. 5188-5192, 1976.

[158] SINGH, R.; KROLL, P. Magnetism in Graphene due to Single-Atom Defects: Dependence on the Concentration and Packing Geometry of Defects. Journal of Physics:Condensed Matter. vol. 21, no. 19, pp. 1-7, 2009. 
[159] DAI, X. Q.; ZHAO, J. H.; XIE, M. H.; TANG, Y. N.; LI, Y. H.; ZHAO, B. FirstPrinciple Study of Magnetism Induced by Vacancies in Graphene. The European Physical Journal B. vol. 80, no. 3, pp. 343-349, 2011.

[160] LEE, G-D.; WANG, C. Z.; YOON, E.; HWANG, N-M.; KIM, D-Y.; HO, K. M. Diffusion, Coalescence, and Reconstruction of Vacancy Defects in Graphene Layers. Physical Review Letters. vol. 95, no. 20, pp. 205501, 2005.

[161] WEHLING, T. O.; BALATSKY, A. V.; KATSNELSON, M, I.; LICHTENSTEIN, A. I.; ROSCH, A. Orbitally Controlled Kondo Effect of Co Adatoms on Graphene. Physical Review B. vol. 81, no. 11, pp. 115427, 2010.

[162] BANHART, F.; KOTAKOSKI, J.; KRASHENINNIKOV, A. V. Structural Defects in Graphene. ACS Nano. vol. 5, no. 1, pp. 26-41, 2011.

[163] FACCIO, R.; FERNÁNDEZ-WERNER, L.; PARDO, H.; GOYENOLA, C.; VENTURA, O. N.; MOMBRÚ, A. W. Electronic and Structural Distortions in Graphene Induced by Carbon Vacancies and Boron Doping. Journal of Physical Chemistry C. vol. 114, no. 44, pp. 18961-18971, 2010.

[164] WU, M.; JIANG, J. Z. Light Non-Metallic Atom (B, N, O and F)-doped Graphene: A First-Principles Study. Nanotechnology. vol. 21, no. 50, pp. 505202, 2010.

[165] ARTYUKHOV, V. I.; CHERNOZATONSKII, L. A. Vacancy-Patterned Graphene: A Meta-Material for Spintronics. Physica Status Solid B. vol. 246, no. 11-12, pp. 2534$2539,2009$.

[166] GASS, M. H.; BANGERT, U.; BLELOCH, A. L.; WANG, P.; NAIR, R. R.; GEIM, A. K. Free-Standing Graphene at Atomic Resolution. Nature Nanotechnology. vol. 3, pp. 676-681, 2008.

[167] UGEDA, M. M.; BRIHUEGA, I.; GUINEA, F.; GO’MEZ-RODRÍGUEZ, J. M. Missing Atom as a Source of Carbon Magnetism. Physical Review Letters. vol. 104, no. 9, pp. 096804, 2010.

[168] CRETU, O.; KRASHENINNIKOV, V. A.; RODRÍGUEZ-MANZO, J. A.; SUN, L.; NIEMINEM, R. M.; BANHART, F. Migration and Localization of Metal Atoms on Strained Graphene. Physical Review Letters. vol. 105, no. 19, pp. 196102, 2010.

[169] LI, L.; REICH, S.; ROBERTSON, J. Defect energies of graphite: Density-functional calculations. Physical Review B. vol. 72, no. 18, pp. 184109, 2005.

[170] MA, J.; ALFÈ, D.; MICHAELIDES, A.; WANG, E. Stone-Wales Defects in Graphene and Other Planar $s p^{2}$-bonded Materials. Physics Review B. vol. 80, no. 3, pp. 033407, 2009.

[171] El-BARBARY, A. A.; TElling, R. H.; EWEELS， C. P.; HEGGIE， M. I.; BRIDDON, P. R. Structure and Energetics of the Vacancy in Graphite. Physica. Review B. vol. 68, no. 14, pp. 144107, 2003. 
[172] CRETU, O.; KRASHENINNIKOV, A. V.; RODRÍGUEZ-MANZO, J. A.; SUN, L.; NIEMINEM, R.; BANHART, F. Migration and Localization of Metal Atoms on Graphene. Physical Review Letters. vol. 105, no. 19 , pp. 196102, 2010.

[173] FAN, B. B.; YANG, X. B.; ZHANG, R. Anisotropic Mechanical Properties and Stone-Wales Defects in Graphene Monolayer: A Theoretical Study. Physics Letters A. vol. 374, no. 27, pp. 2781-2784, 2010.

[174] SANTOS, E. J. G..; SÁNCHEZ-PORTAL, D.; AYUELA, A. Magnetism of substitutional Co impurities in graphene: Realization of Single $\pi$ Vacancies. Physics Review B. vol. 81, no. 12, pp. 2781-2784, 2010.

[175] CHO, J. Y.; KIM, H. S.; BAIK, S. Y.; MYUNG, Y.; JUNG, C. S.; KIM, C. H.; PARK, J.; KANG, H.S. Selective Nitrogen-Doping Structures of Nanosize Graphitic Layers. The Journal of Physical Chemistry C. vol. 115, no. 9, pp. 3737-3744, 2011.

[176] KRASHENINNIKOV, A. V.; NIEMINEM, R. M. Attractive Interaction Between Transition-Metal Atom Impurities and Vacancies in Graphene: A First-Principle Study. The Journal of Physical Chemistry C. vol. 115, no. 9, pp. 3737-3744, 2011.

[177] CERPELEY, D. M.; ALDER, B. J. Ground State of the Electron Gas by a Stochastic Method. Physical Review Letters. vol. 45, no. 7 pp. 566-569, 1980. 


\section{APÊNDICE A}

\section{PRODUÇÕES CIENTÍFICAS DURANTE O DOUTORADO}

\section{Artigos Completos Publicados em Periódicos}

[A1] GARCIA, J. C.; LIMA, D. B.; ASSALI, L. V. C.; JUSTO, J. F. Group IV Grapheneand Graphane-Like Nanosheets. Journal of physical chemistry. C. vol. 115, n. 27, pp. 13242-13246, 2011.

Trabalho Apresentado em Congresso Internacional:

[A2] GARCIA, J. C. ; LIMA, D. B. ; ASSALI, L. V. C. ; JUSTO, J. F. An Ab-Initio Investigation on the Properties of Group-IV Graphene- and Graphane-like Nanolayers. Anais do Diamond 2011. 2011. 


\section{APÊNDICE B: Artigo A1}

“Group IV Graphene- and Graphane-Like Nanosheets" 


\title{
Group IV Graphene- and Graphane-Like Nanosheets
}

\author{
Joelson C. Garcia, ${ }^{\dagger}$ Denille B. de Lima, ${ }^{\dagger}$ Lucy V. C. Assali, ${ }^{\ddagger}$ and João F. Justo ${ }^{* \dagger}$ \\ ${ }^{\dagger}$ Escola Politécnica, Universidade de São Paulo, CP 61548, CEP 05424-970, São Paulo, SP, Brazil \\ ${ }^{\ddagger}$ Instituto de Física, Universidade de São Paulo, CP 66318, CEP 05315-970, São Paulo, SP, Brazil
}

\begin{abstract}
We performed a first-principles investigation on the structural and electronic properties of group IV (C, SiC, Si, Ge, and $\mathrm{Sn}$ ) graphene-like sheets in flat and buckled configurations and the respective hydrogenated or fluorinated graphane-like ones. The analysis on the energetics, associated with the formation of those structures, showed that fluorinated graphane-like sheets are very stable and should be easily synthesized in the laboratory. We also studied the changes of the properties of the graphene-like sheets as a result of hydrogenation or fluorination. The interatomic distances in those graphanelike sheets are consistent with the respective crystalline ones, a property that may facilitate integration of those sheets within three-dimensional nanodevices.
\end{abstract}

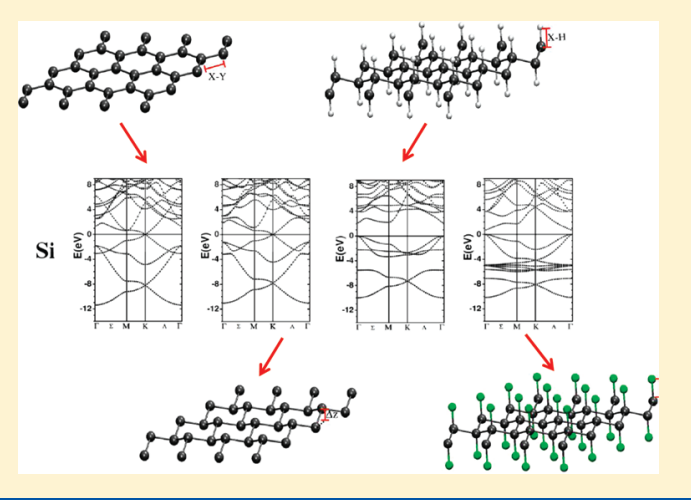

\section{INTRODUCTION}

The properties of graphene, the one-atom-thick sheet with carbon atoms with the $\mathrm{sp}^{2}$ hybridization, were first discussed in the literature more than 60 years ago. ${ }^{1}$ It has been long considered only a theoretical curiosity of impossible experimental realization. This perception changed radically a few years ago, after the separation of graphene sheets with single and multiple layers. ${ }^{2-4}$ Since then, graphene has been intensively investigated, with focus on its physical and chemical properties. ${ }^{5}$ This material carries unique properties that allow one to envision a number of potential applications, such as chemical sensors, ${ }^{6,7}$ nanoelectronic devices, ${ }^{8}$ or hydrogen storage systems. ${ }^{9}$

Graphene could be considered as a prototypical material to study the properties of other two-dimensional nanosystems. Recently, several two-dimensional structures have been explored in the literature. For example, graphane, a fully hydrogenated graphene sheet with all carbon atoms in the $\mathrm{sp}^{3}$ hybridization, has been proposed by theoretical investigations ${ }^{10}$ and was later synthesized. ${ }^{11}$ Graphene-like sheets, made of silicon carbide, ${ }^{12,13}$ silicon, ${ }^{14,15}$ germanium, ${ }^{16,17}$ boron nitride, ${ }^{18,19}$ and zinc oxide, ${ }^{20}$ have also been discussed in the literature.

Here, we performed a systematic investigation on the trends in the properties of group IV (C, SiC, $\mathrm{Si}, \mathrm{Ge}$, and $\mathrm{Sn}$ ) graphene-like structures, in flat and buckled configurations, using first-principles total energy calculations. We then observed the modifications on those properties as a result of full coverage of hydrogen and fluorine atoms, to form $\mathrm{sp}^{3}$ graphane-like structures. We found that hydrogenation and fluorination processes provide structures that were energetically very accessible for all compounds and should be easily synthesized in the laboratory. We also found that all group IV graphene-like structures present null gaps in both flat or buckled configurations, which opened up with hydrogenation or fluorination in most materials. The only exception was the fluorinated graphane-like tin, which, although tin atoms were 4-fold coordinated, the material presented a null gap. This paper is organized as follows: We first discuss the methodology, then the properties of group IV graphene-like sheets. Finally, we discuss the energetics and resulting physical properties of hydrogenated and fluorinated graphane-like sheets.

\section{METHODOLOGY}

The calculations were performed using the Vienna Ab-initio Simulation Package (VASP). ${ }^{21}$ The electronic exchange-correlation potential was described within the density functional theory and the generalized gradient approximation (DFT-GGA). ${ }^{22}$ The electronic wave functions were described by a projector augmented wave (PAW) method, ${ }^{23}$ taking a plane-wave basis set with an energy cutoff of $550 \mathrm{eV}$. For all calculations, convergence in total energy was set to $0.1 \mathrm{meV} /$ atom between two self-consistent iterations. Configurational optimization was performed by considering relaxation in all atoms, without symmetry constrains, until forces were lower than $3 \mathrm{meV} / \AA ̊$ in any atom. The Brillouin zone was sampled by a $15 \times 15 \times 1$ Monkhorst-Pack $k$-point grid. ${ }^{24}$ The planar structures were built using periodic boundary conditions with a hexagonal simulation cell. In the direction perpendicular to the sheets $(z)$, we used a lattice parameter of 20 $\AA$, which was large enough to prevent image interactions. Such theoretical framework and convergence criteria have been shown to provide a reliable description of carbon-based nanosystems. ${ }^{25,26}$

Binding and formation energies for all systems were computed following the same procedure presented elsewhere. ${ }^{10}$ The binding energy $\left(E_{\mathrm{B}}\right)$ of a certain structure was computed as the difference between the total energy of that stable structure and the total energies of the respective isolated atoms in their neutral

Received: April 19, 2011

Revised: June 8, 2011 
Table 1. Structural and Electronic Properties of Graphene-Like Sheets ( $\alpha$-XY and $\beta$-XY, Respectively, for Flat and Buckled Sheets) and Hydrogenated $\left(\mathrm{XYH}_{2}\right)$ or Fluorinated $\left(\mathrm{XYF}_{2}\right)$ Graphane-Like Sheets with $\mathrm{X}=\mathrm{Y}=\mathrm{C}, \mathrm{Si}, \mathrm{Ge}$, or $\mathrm{Sn}($ or $\mathrm{X}=\mathrm{C}$ and $\mathrm{Y}=\mathrm{Si}$ for $\mathrm{SiC})^{a}$

\begin{tabular}{|c|c|c|c|c|c|c|c|c|c|c|}
\hline & $a$ & $d(\mathrm{X}-\mathrm{Y})$ & $d(\mathrm{X}-\mathrm{H})$ & $d(\mathrm{X}-\mathrm{F})$ & $d(\mathrm{Y}-\mathrm{H})$ & $d(\mathrm{Y}-\mathrm{F})$ & $\Delta z$ & $E_{\mathrm{B}}$ & $E_{\mathrm{F}}$ & $E_{\mathrm{g}}$ \\
\hline$\alpha-C_{2}$ & 2.468 & 1.425 & & & & & 0 & -7.848 & & 0.0 \\
\hline $\mathrm{C}_{2} \mathrm{H}_{2}$ & 2.539 & 1.536 & 1.110 & & & & 0.459 & -5.161 & -0.111 & 3.47 \\
\hline $\mathrm{C}_{2} \mathrm{~F}_{2}$ & 2.609 & 1.583 & & 1.382 & & & 0.488 & -5.403 & -0.802 & 3.10 \\
\hline$\alpha-\mathrm{Si}_{2}$ & 3.897 & 2.250 & & & & & 0 & -3.894 & & 0.0 \\
\hline$\beta-\mathrm{Si}_{2}$ & 3.867 & 2.279 & & & & & 0.459 & -3.914 & & 0.0 \\
\hline $\mathrm{Si}_{2} \mathrm{H}_{2}$ & 3.968 & 2.392 & 1.502 & & & & 0.687 & -3.379 & -0.297 & 2.11 \\
\hline $\mathrm{Si}_{2} \mathrm{~F}_{2}$ & 3.968 & 2.395 & & 1.634 & & & 0.697 & -4.656 & -2.019 & 0.70 \\
\hline$\alpha-\mathrm{Ge}_{2}$ & 4.127 & 2.383 & & & & & 0 & -3.114 & & 0.0 \\
\hline$\beta-\mathrm{Ge}_{2}$ & 4.061 & 2.444 & & & & & 0.690 & -3.243 & & 0.0 \\
\hline $\mathrm{Ge}_{2} \mathrm{H}_{2}$ & 4.091 & 2.473 & 1.563 & & & & 0.730 & -2.882 & 0.107 & 0.95 \\
\hline $\mathrm{Ge}_{2} \mathrm{~F}_{2}$ & 4.182 & 2.492 & & 1.790 & & & 0.617 & -3.892 & -1.349 & 0.19 \\
\hline$\alpha-\mathrm{Sn}_{2}$ & 4.798 & 2.770 & & & & & 0 & -2.581 & & 0.0 \\
\hline$\beta-\mathrm{Sn}_{2}$ & 4.639 & 2.841 & & & & & 0.947 & -2.728 & & 0.0 \\
\hline $\mathrm{Sn}_{2} \mathrm{H}_{2}$ & 4.719 & 2.846 & 1.738 & & & & 0.824 & -2.517 & -0.030 & 0.45 \\
\hline $\mathrm{Sn}_{2} \mathrm{~F}_{2}$ & 5.028 & 2.951 & & 1.970 & & & 0.531 & -3.625 & -1.581 & 0.0 \\
\hline$\alpha-\mathrm{SiC}$ & 3.100 & 1.790 & & & & & 0 & -5.905 & & 2.54 \\
\hline$\beta$-SiC & 3.098 & 1.788 & & & & & 0.001 & -5.906 & & 2.54 \\
\hline $\mathrm{SiCH}_{2}$ & 3.124 & 1.892 & 1.108 & & 1.497 & & 0.573 & -4.366 & -0.288 & 4.04 \\
\hline $\mathrm{SiCF}_{2}$ & 3.168 & 1.914 & & 1.445 & & 1.609 & 0.563 & -5.096 & -1.463 & 1.94 \\
\hline
\end{tabular}

${ }^{a}$ The table presents the lattice parameter $(a)$; interatomic distances $(d)$; buckling distances $(\Delta z)$; and binding $\left(E_{\mathrm{B}}\right)$, formation $\left(E_{\mathrm{F}}\right)$, and electronic band-gap $\left(E_{\mathrm{g}}\right)$ energies. Interatomic distances, binding and formation energies, and electronic band-gap energies are given, respectively, in $\AA$, eV/atom, and $\mathrm{eV}$.

charge states. The formation energy $\left(E_{\mathrm{F}}\right)$ of a certain hydrogenated (or fluorinated) sheet was computed as the difference between the binding energy of the graphane-like structure and the binding energies of the respective (stable) graphene-like structure and those energies of the diatomic molecules $\mathrm{H}_{2}$ ( or $\mathrm{F}_{2}$ ). In group IV materials, we found that the stable graphenelike structure was the buckled configuration (lower in energy), except for carbon.

The total energies of the isolated atoms and diatomic molecules were obtained considering a large simulation cell and the same methodological approximations of all the other calculations described in the previous paragraphs.

To check the validity of all approximations used in this investigation, we compared the properties of graphene with available data from experiments and other theoretical investigations. The computed that the binding energy of graphene was $-7.848 \mathrm{eV} /$ atom, being $0.136 \mathrm{eV} /$ atom lower than the respective energy of the diamond cubic structure. Those two values are in excellent agreement with other investigations. ${ }^{27,28}$ In terms of the structural properties of graphene, the carboncarbon interatomic distance was $1.425 \AA$, which is in excellent agreement with the respective experimental values $(1.42 \AA),{ }^{1}$ but a little larger than the one (1.414 $\AA$ ) of a recent theoretical investigation. $^{15}$ It should be pointed out that, whereas our investigation used a generalized gradient approximation, the other investigation used the local density approximation, which is known to underestimate interatomic distances. ${ }^{15}$

\section{RESULTS}

Figure 1 presents a schematic representation of graphene-like structures in flat (labeled $\alpha$ ) and buckled (labeled $\beta$ ) configurations and their hydrogenated and fluorinated graphane-like forms. Table 1 presents the structural properties of group IV graphene-like sheets and their respective binding energies. According to the table, graphene-like structures of $\mathrm{Si}, \mathrm{Ge}$, and $\mathrm{Sn}$ in flat $(\alpha)$ configurations are metastable, with the respective buckled ones $(\beta)$ being energetically more favorable, consistent with other investigations for $\mathrm{Si}^{15,16}$

Figure 2 presents the theoretical interatomic distances and binding energies of all group IV graphene-like and graphane-like structures as a function of the respective properties in the (diamond cubic or zinc-blende) crystalline solid phases, in which all group IV atoms are in the $\mathrm{sp}^{3}$ hybridization. ${ }^{29}$ According to Figure 2a, interatomic distances between group IV atoms in flat graphene-like structures are, on average, 5\% shorter than those distances in the respective solid phases. These results show that the group IV atoms, in an $\mathrm{sp}^{2}$ environment, behave essentially the same way as carbon atoms do. For the buckled configurations, those distances are always larger than the respective ones in the flat configurations. Buckling distances $(\Delta z)$ are consistent with recent theoretical results for buckled sheets of silicon and germanium. $^{16}$

Figure $2 \mathrm{~b}$ shows that the binding energies of most group IV graphene-like structures in either flat or buckled configurations, except for carbon, are higher than the respective energies in the solid stable phases. This indicates that graphene-like structures, with atoms in the $\mathrm{sp}^{2}$ hybridization, are not very stable when compared to the respective solid phases, in which atoms are in the $\mathrm{sp}^{3}$ hybridization. These results are consistent with the generally large energy difference between those two hybridizations in most covalent materials, being small only for carbon. Additionally, the binding energy of the buckled configurations is larger than the one of the flat configurations, except for carbon. In 
(a)

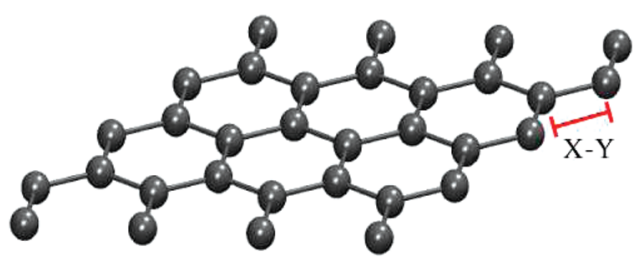

(c)

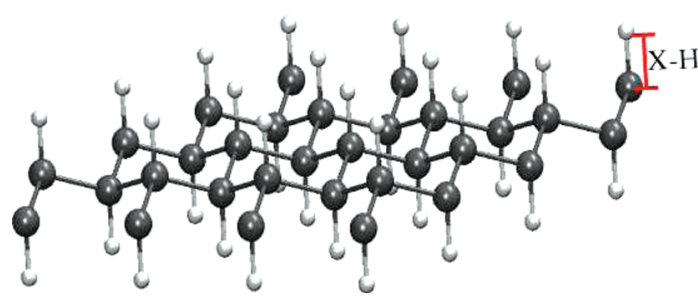

(b)

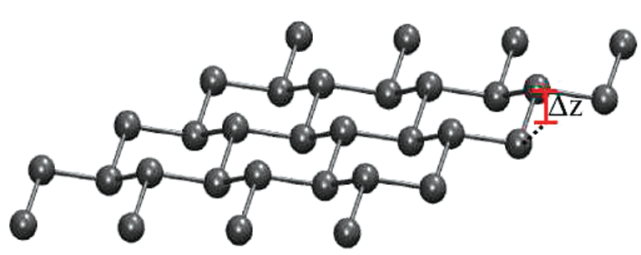

(d)

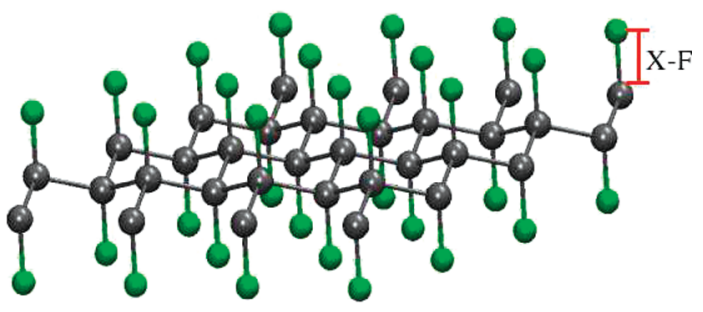

Figure 1. Schematic representation of group IV two-dimensional materials: (a) flat graphene-like ( $\alpha$ ), (b) buckled graphene-like $(\beta)$, (c) hydrogenated graphane-like, and (d) fluorinated graphane-like structures. The figure also indicates the interatomic distance labels, consistent with the ones in Table 1. Black, gray, and green spheres represent group IV, hydrogen, and fluorine atoms, respectively.
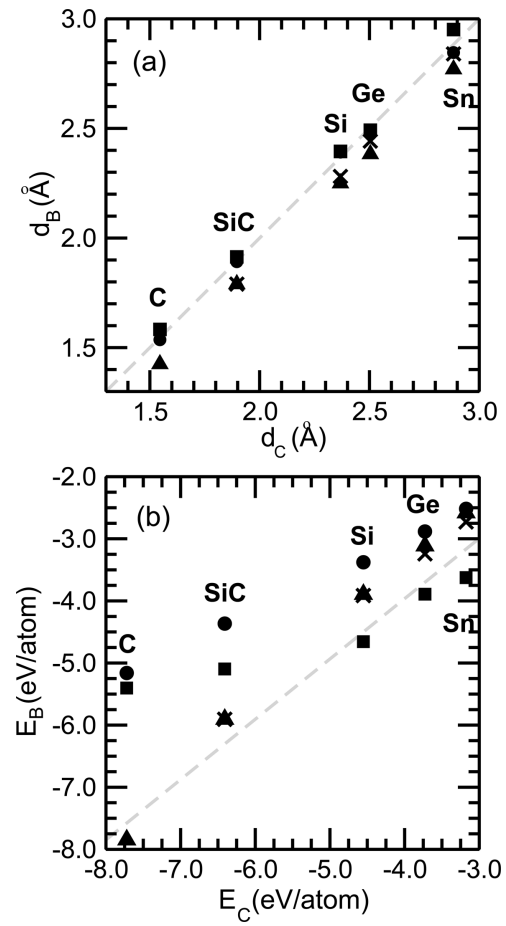

Figure 2. Properties of group IV (C, SiC, $\mathrm{Si}, \mathrm{Ge}$, and $\mathrm{Sn}$ ) graphene-like (in flat and buckled sheets) and graphane-like structures (with full coverage of $\mathrm{H}$ or $\mathrm{F}$ atoms). The figure shows the (a) interatomic distances $\left(d_{\mathrm{B}}\right)$ and $(\mathrm{b})$ binding energies $\left(E_{\mathrm{B}}\right)$ of those structures as a function of the respective distances $\left(d_{\mathrm{C}}\right)$ and binding energies $\left(E_{C}\right)$ in the diamond cubic (or zinc-blende) crystalline structures. The $\mathbf{\Delta}, \times, \bullet$, and $\mathbf{\square}$ symbols represent, respectively, the flat graphene-like $(\alpha)$, buckled graphene-like $(\beta)$, hydrogenated graphane-like, and fluorinated graphane-like structures. The dashed lines are only a guide to the eye, representing the properties $d_{\mathrm{B}}=d_{\mathrm{C}}$ in (a) and $E_{\mathrm{B}}=E_{\mathrm{C}}$ in (b).

the case of carbon, the calculations indicated that the buckled configuration is unstable, relaxing toward the flat one. An interesting case is $\mathrm{SiC}$, in which the binding energy difference between flat and buckled configurations is only $1 \mathrm{meV} /$ atom and the buckling is also very small. All those graphene-like structures, in either flat or buckled configurations, presented a null electronic gap, except for $\mathrm{SiC}$, which presented a large gap of $2.54 \mathrm{eV}$. This value is in excellent agreement with a recent theoretical investigation using similar approximations. ${ }^{12,13}$

Figure 3 presents the electronic band structure of all graphenelike structures in flat and buckled configurations. All group IV graphene-like structures (of $\mathrm{C}, \mathrm{Si}, \mathrm{Ge}$, and $\mathrm{Sn}$ ) in a flat configuration (Figure 3a) present a similar electronic band structure, with a band crossing in the Dirac $(\mathrm{K})$ points at the Fermi level. For all of those materials, there is linear dispersion around those Dirac points, a property that results from the honeycomb structure. In buckled configurations (Figure 3b), the linear dispersion around those Dirac points is maintained.

The electronic band structures of the flat graphene-like configurations differ among themselves only by the fact that, in structures of $\mathrm{C}$ and $\mathrm{Si}$, the system is semimetallic, being metallic in $\mathrm{Ge}$ and $\mathrm{Sn}$ ones. Such a difference in the band structure could be understood by the following explanation. For graphene-like flat structures of $\mathrm{C}$ and $\mathrm{Si}$, there is a specific energy band that stays over the Fermi level in all the Brillouin zone. However, for graphene-like flat structures of $\mathrm{Ge}$ and $\mathrm{Sn}$, the same band crosses the Fermi level in the $\Gamma \rightarrow$ M symmetry direction, and the system is metallic. The electronic band structures of the flat and buckled configurations differ by the fact that the later ones do not present the band crossing described in this paragraph.

Because the electronic band structure of group IV graphenelike materials, in flat configurations, are equivalent to the one of carbon, we computed the carrier velocities around their respective Dirac points. From the results of Figure 3, the computed carrier velocities in those points are $0.91,0.58,0.59$, and $0.52 \times 10^{6} \mathrm{~m} / \mathrm{s}$ for flat graphene-like of $\mathrm{C}, \mathrm{Si}, \mathrm{Ge}$, and $\mathrm{Sn}$, respectively. The computed carrier velocities in those points are $0.46,0.69$, and $0.95 \times 10^{6} \mathrm{~m} / \mathrm{s}$ for buckled graphene-like of $\mathrm{Si}, \mathrm{Ge}$, and $\mathrm{Sn}$, respectively. Those results 
(a)

C

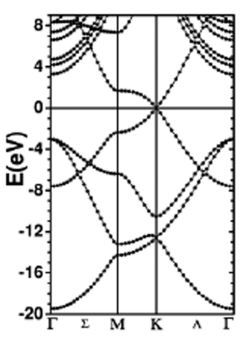

Si
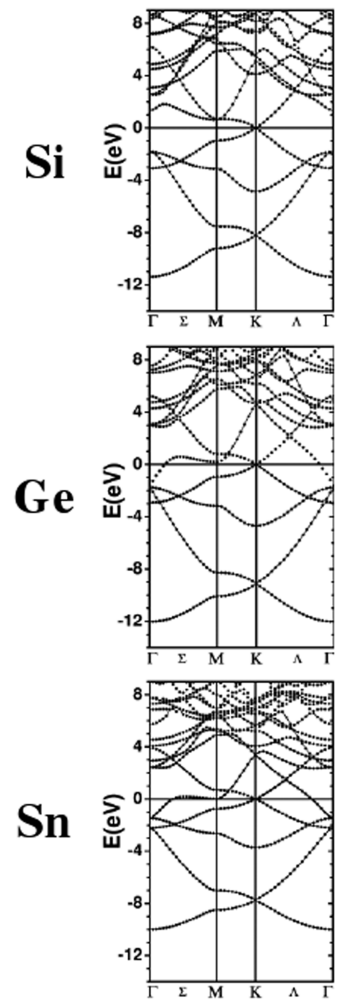

SiC

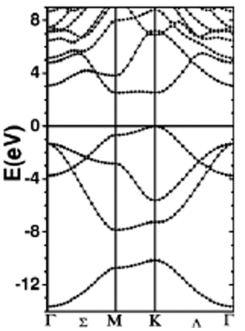

(b)
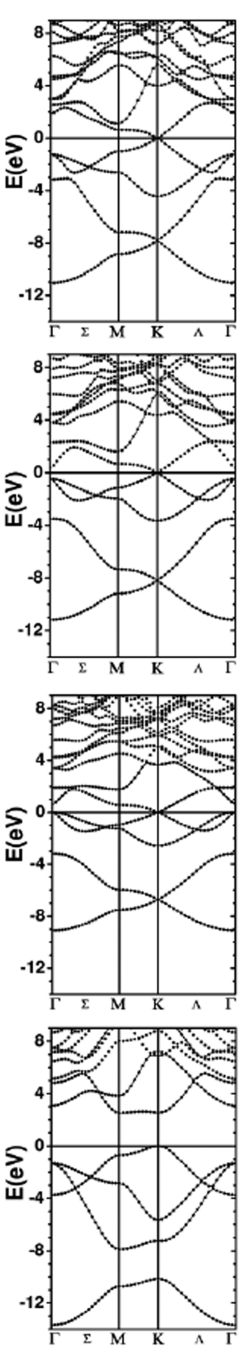

(c)
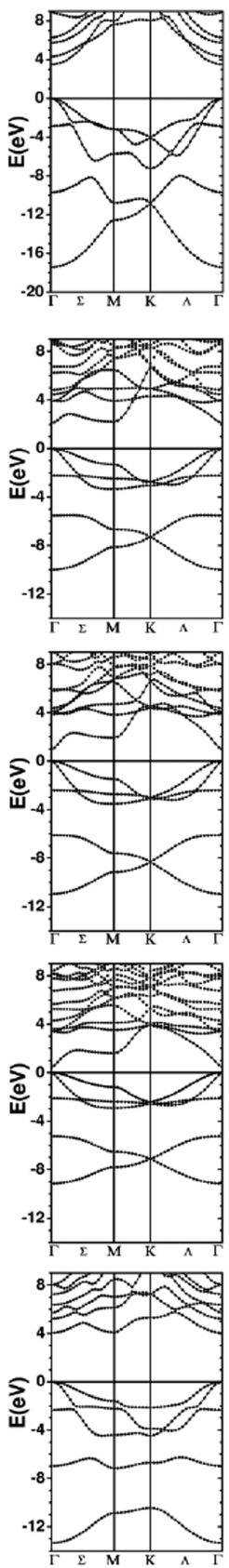

(d)
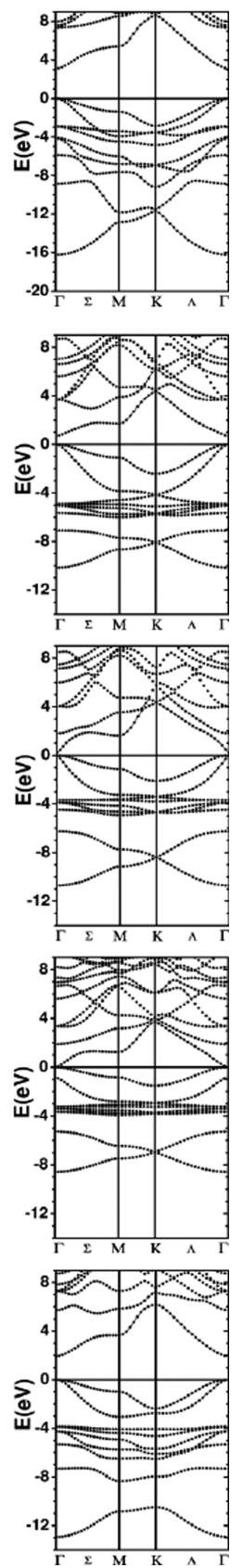

Figure 3. Electronic band structure of group IV in (a) flat graphene-like $(\alpha),(b)$ buckled graphene-like $(\beta)$, (c) hydrogenated graphane-like, and (d) fluorinated graphane-like structures.

indicate that carrier velocities around the Dirac points could be very large in the buckled configurations. Our result for graphene is in good agreement with the experimental value of $1.1 \times 10^{6} \mathrm{~m} / \mathrm{s}$ (refs 2 and $30)$ and with the theoretical one of $0.63 \times 10^{6} \mathrm{~m} / \mathrm{s}($ ref 15$)$.

Table 1 presents the structural parameters for hydrogenated and fluorinated graphane-like structures and their respective binding and formation energies. Here, we considered only systems associated with the chairlike configurations and neglected the boatlike isomeric ones. This is justified by recent theoretical investigations for graphane ${ }^{10,31}$ and fluorinated graphane, ${ }^{32}$ indicating that the chairlike configuration is energetically more favorable than the boatlike one. As described in Figure 1c (or Figure 1d), the chairlike configuration has hydrogen (or fluorine) atoms alternating over and below the plane containing the group IV atoms. Incorporation of either hydrogen or fluorine atoms leads to very stable structures, with binding energies (per atom) for graphane-like structures larger than the ones for graphene-like, as shown in Figure $2 \mathrm{~b}$. Additionally, the graphane-like structures have large formation energies in most cases, consistent with other theoretical investigations for hydrogen incorporation in graphene $^{10}$ and in boron nitride graphene-like structures. ${ }^{18}$

Figure $2 \mathrm{~b}$ shows the trends in the binding energies (per atom) for hydrogenated and fluorinated graphane-like structures. The fluorinated structures are energetically more stable than the 
hydrogenated ones and become considerably favorable for $\mathrm{Si}, \mathrm{Ge}$, and Sn materials. These results are consistent with available experimental results for graphane and fluorinated graphane structures. ${ }^{11,31}$ Therefore, it is expected that those fluorinated graphane-like forms should be easily synthesized in the laboratory.

In terms of the structural properties of hydrogenated and fluorinated forms, Table 1 presents the interatomic and buckling distances. The interatomic distances between the group IV atoms and hydrogen (or fluorine) atoms are in excellent agreement with the respective distances in typical organic molecules. For example, in graphane $\left(\mathrm{C}_{2} \mathrm{H}_{2}\right)$, the $\mathrm{C}-\mathrm{C}, \mathrm{C}-\mathrm{H}$, and buckling $(\Delta z)$ distances are $1.536,1.110$, and $0.459 \AA$ and agree very well with recent theoretical results ${ }^{15}$ of $1.520,1.084$, and $0.45 \AA$, respectively. For the fluorinated graphane-like structure $\left(\mathrm{C}_{2} \mathrm{~F}_{2}\right)$, the $\mathrm{C}-\mathrm{C}$ and $\mathrm{C}-\mathrm{F}$ distances are 1.583 and $1.382 \AA$, which agree well with recent theoretical results ${ }^{31}$ of 1.579 and $1.371 \AA$, respectively. According to Figure $2 \mathrm{a}$, along the series, interatomic distances between group IV atoms, in either hydrogenated or fluorinated forms, are all very close to the interatomic distances in their respective crystalline forms.

The results indicate that group IV atoms, in hydrogenated and fluorinated graphane-like structures, are 4-fold coordinated and have a near tetrahedral configuration, and their interatomic distances and binding are close to the ones in a crystalline environment. The structures deviated from a tetrahedral configuration, evidenced by the buckling distance $(\Delta z)$, due to some ionic character in the binding between the group IV atoms and the hydrogen (or fluorine) neighboring atoms. The results suggest that hydrogenation or fluorination may generate two-dimensional structures that could be easily incorporated in the surface of the respective three-dimensional crystalline counterparts. Therefore, although integration of graphene-like structures in three-dimensional devices is still difficult, due to large lattice mismatch, it may be easier for hydrogenated and fluorinated graphane-like structures.

According to Figure 3c,d, hydrogenation and fluorination open the electronic gap of the graphene-like structures. In all cases, the electronic gap is larger in the hydrogenated configurations than in the fluorinated ones. An interesting case is the fluorinated graphane-like tin $\left(\mathrm{Sn}_{2} \mathrm{~F}_{2}\right)$, in which, although tin atoms have a 4-fold coordination, the material has a null gap. This result indicates that carrier velocities should be very large in this system, even with tin atoms with all valence electrons paired with neighboring atoms.

\section{SUMMARY}

In summary, we have investigated the trends of the structural and electronic properties of graphene-like structures made of group IV atoms, in terms of their energetics and electronic band structure. The results indicated that, whereas the graphene-like structures (of $\mathrm{Si}, \mathrm{Ge}, \mathrm{Sn}$, and $\mathrm{SiC}$ ) appear to have low stability, the respective hydrogenated and fluorinated graphane-like ones are very stable and should be easily synthesized in the laboratory.

The hydrogenated and fluorinated graphane-like structures presented the group IV atoms in a 4-fold configuration and in a near tetrahedral configuration. Interatomic distances in those configurations were close to the respective ones in the solid phase counterparts, a property that could facilitate integration of those twodimensional structures within three-dimensional nanodevices.

\section{AUTHOR INFORMATION}

\section{Corresponding Author}

*E-mail: jjusto@lme.usp.br.

\section{ACKNOWLEDGMENT}

The authors acknowledge support from Brazilian agencies CNPq and FAPESP.

\section{REFERENCES}

(1) Castro Neto, A. H.; Guinea, F.; Peres, N. M. R.; Novoselov, K. S.; Geim, A. K. Rev. Mod. Phys. 2009, 81, 109-162.

(2) Novoselov, K. S.; Geim, A. K.; Morozov, S. V.; Jiang, D.; Katsnelson, M. I.; Grigorieva, I. V.; Dubonos, S. V.; Firsov, A. A. Nature (London) 2005, 438, 197-200.

(3) Geim, A. K.; Novoselov, K. S. Nat. Mater. 2007, 6, 183-191.

(4) Wang, G. X.; Yang, J.; Park, J.; Gou, X. L.; Wang, B.; Liu, H.; Yao, J. J. Phys. Chem. C 2008, 112, 8192-8195.

(5) Geim, A. K. Science 2009, 324, 1530-1534.

(6) Pumera, M. Chem. Rec. 2009, 9, 211-223.

(7) Casolo, S.; Martinazzo, R.; Tantardini, G. F. J. Phys. Chem. C 2011, 115, 3250-3256.

(8) Schwierz, F. Nat. Nanotechnol. 2010, 5, 487-496.

(9) Boukhvalov, D. W.; Katsnelson, M. I.; Lichtenstein, A. I. Phys. Rev. B 2008, 77, 035427.

(10) Sofo, J. O.; Chaudhari, A. S.; Barber, G. D. Phys. Rev. B 2007, $75,153401$.

(11) Elias, D. C.; Nair, R. R.; Mohiuddin, T. M. G.; Morozov, S. V.; Blake, P.; Halsall, M. P.; Ferrari, A. C.; Boukhvalov, D. W.; Katsnelson, M. I.; Geim, A. K.; Novoselov, K. S. Science 2009, 323, 610-613.

(12) Huda, M. N.; Yan, Y. F.; Al-Jassim, M. M. Chem. Phys. Lett. 2009, 479, 255-258.

(13) Bekaroglu, E.; Topsakal, M.; Cahangirov, S.; Ciraci, S. Phys. Rev. B 2010, 81, 075433.

(14) Nakano, H.; Mitsuoka, T.; Harada, M.; Horibuchi, K.; Nozaki, H.; Takahashi, N.; Nonaka, T.; Seno, Y.; Nakamura, H. Angew. Chem. 2006, 45, 6303-6306.

(15) Voon, L. C. L. Y.; Sandberg, E.; Aga, R. S.; Farajian, A. A. Appl. Phys. Lett. 2010, 97, 163114.

(16) Cahangirov, S.; Topsakal, M.; Akturk, E.; Sahin, H.; Ciraci, S. Phys. Rev. Lett. 2009, 102, 236804.

(17) Houssa, M.; Pourtois, G.; Afanasév, V. V.; Stesmans, A. Appl. Phys. Lett. 2010, 96, 082111.

(18) Tang, S. B.; Cao, Z. X. Chem. Phys. Lett. 2010, 488, 67-72.

(19) Topsakal, M.; Aktürk, E.; Ciraci, S. Phys. Rev. B 2009, 79, 115442.

(20) Zhang, Y.; Wu, S. Q.; Wen, Y. H.; Zhu, Z. Z. Appl. Phys. Lett. 2010, 96, 223113.

(21) Kresse, G.; Furthmüller, J. Phys. Rev. B 1996, 54, 11169-11186.

(22) Perdew, J. P.; Burke, K.; Ernzerhof, M. Phys. Rev. Lett. 1996, 77, 3865-3868.

(23) Kresse, G.; Joubert, D. Phys. Rev. B 1999, 59, 1758-1775.

(24) Monkhorst, H. J.; Pack, J. D. Phys. Rev. B 1976, 13, 5188-5192.

(25) Garcia, J. C.; Justo, J. F.; Machado, W. V. M.; Assali, L. V. C. Phys. Rev. B 2009, 80, 125421.

(26) Garcia, J. C.; Assali, L. V. C.; Machado, W. V. M.; Justo, J. F. J. Phys.: Condens. Matter 2010, 22, 315303.

(27) Yin, M. T.; Cohen, M. L. Phys. Rev. B 1984, 29, 6996-6998.

(28) Popok, V. N.; Vuckovic, S.; Samela, J.; Jarvi, T. T.; Nordlund, K.; Campbell, E. E. B. Phys. Rev. B 2009, 80, 205419.

(29) The properties of group IV solids were computed considering the diamond cubic (or zinc-blende) stable structures within the same approximations used in all the other calculations performed here.

(30) Zhang, Y. B.; Tan, Y. W.; Stormer, H. L.; Kim, P. Nature (London) 2005, 438, 201-204.

(31) Leenaerts, O.; Peelaers, H.; Hernández-Nieves, A. D.; Partoens, B.; Peeters, F. M. Phys. Rev. B 2010, 82, 195436.

(32) Charlier, J. C.; Gonze, X.; Michenaud, J. P. Phys. Rev. B 1993, $47,16162-16168$. 